Supporting Information

\title{
Facile Synthesis of Uniform Metal Carbide Nanoparticles from MOFs by Laser
}

\section{Metallurgy}

Yushan Wu, ${ }^{\dagger}, \perp$ Zhen Huang, ${ }^{\dagger}, \perp$ Haoqing Jiang, ${ }^{*}{ }^{\dagger}$ Chao Wang, ${ }^{\dagger}$ Yi Zhou, ${ }^{\dagger}$ Wei Shen, ${ }^{\ddagger}$ Hualong Xu, ${ }^{*}+$ Hexiang Deng ${ }^{*} \dagger, \#$

$\dagger$ Key Laboratory of Biomedical Polymers-Ministry of Education, College of Chemistry and Molecular Sciences, Wuhan University, Wuhan 430072, China

\#The Institute for Advanced Studies, Wuhan University, Wuhan 430072, China.

*Department of Chemistry, Shanghai Key Laboratory of Molecular Catalysis and Innovative Materials, Collaborative Inno vation Center of Chemistry for Energy Materials, Fudan University, Shanghai 200433, PR China.

Supporting Information Placeholder

*Corresponding authors: jianghaoqing@whu.edu.cn (H.J.); shuhl@fudan.edu.cn (H.X.); hdeng@ whu.edu.cn (H.D.) 


\section{Table of contents}

Section S1. Material synthetic route and experimental setup

Section S2. Characterization of MOFs

Section S3. Characterization of the synthesized TMC nanoparticles

Section S4. Catalytic performance test of TMC nanoparticles in FTS

Section S5. Performance comparison with other FTS catalysts

\section{References.}




\section{Section S1. Material synthetic route and experiment set up}

\section{Synthetic route of MOFs:}

MOLs: MOLs was synthesized on the basis of conditions reported previously [32]. Briefly, a mixture of $\mathrm{H}_{3} \mathrm{BTB}$ (44 $\mathrm{mg}, 0.1 \mathrm{mmol}$ ) and $\mathrm{HfCl}_{4}(34 \mathrm{mg}, 0.16 \mathrm{mmol}$ ) were dissolved in a $10 \mathrm{~mL}$ solvent (water and acetic acid in a volumetric ratio of 3:2) in a $20 \mathrm{~mL}$ vial. The vial was sealed and heated in convection oven at $120{ }^{\circ} \mathrm{C}$ for $20 \mathrm{~h}$ to yield white products. The as synthesized MOLs was washed with fresh DMF for three times and then with methanol for 5 times. The MOF crystals were dried under dynamic vacuum at $120{ }^{\circ} \mathrm{C}$ for $24 \mathrm{~h}$ to obtain activated MOF powder.

UMCM-309a: UMCM-309a was synthesized on the basis of conditions reported previously [33]. Briefly, a mixture of $\mathrm{H}_{3} \mathrm{BTB}$ (44 mg, $0.1 \mathrm{mmol}$ ) and $\mathrm{ZrCl}_{4}(24 \mathrm{mg}, 0.16$ $\mathrm{mmol}$ ) were dissolved in a $10 \mathrm{~mL}$ solvent (water and acetic acid in a volumetric ratio of $3: 2)$ in a $20 \mathrm{~mL}$ vial. The vial was sealed and heated in convection oven at $120^{\circ} \mathrm{C}$ for $20 \mathrm{~h}$ to yield white products. The as synthesized UMCM-309a was washed with fresh DMF for three times and then with methanol for 5 times. The MOF crystals were dried under vacuum at $120{ }^{\circ} \mathrm{C}$ for $24 \mathrm{~h}$ to obtain activated MOF powder.

NH 2 -MIL-125: $\mathrm{NH}_{2}$-MIL-125 was synthesized on the basis of conditions reported previously [34]. Briefly, $3 \mathrm{mmol}$ of titanium isopropoxide and $6 \mathrm{mmol}$ of 2-amino benzene dicarboxylic acid ( $\mathrm{NH}_{2}$ - $\mathrm{BDC}$ ) were mixed in $50 \mathrm{~mL}$ mixed solvent of DMF and methanol with volumetric ratio of 1:1. The mother solution was then sealed in a $150 \mathrm{~mL}$ autoclave and heated at $150{ }^{\circ} \mathrm{C}$ for $16 \mathrm{~h}$ to yield yellow precipitation. The as synthesized $\mathrm{NH}_{2}$-MIL125 was activated by solvent exchange with fresh DMF for three times and then with methanol for 5 times. The MOF crystals were dried under dynamic vacuum at $150{ }^{\circ} \mathrm{C}$ for $12 \mathrm{~h}$ to obtain activated MOF powder.

MIL-47: MIL-47 was synthesized on the basis of conditions reported previously [35]. Briefly, a mixture of $\mathrm{VCl}_{3}$, 1,4-benzene dicarboxylic acid $\left(\mathrm{H}_{2} \mathrm{BDC}\right)$, and ultrapure water (molar ratio 1:0.25:100) was stirred and transferred into autoclave and heated in convection oven at $200{ }^{\circ} \mathrm{C}$ for 4 days to yield light yellow products. The obtained MIL-47 (V) was washed with fresh DMF for 3 times and then with acetone for 5 times. The MOF crystals were calcined in furnace at $300{ }^{\circ} \mathrm{C}$ for $24 \mathrm{~h}$ and then activated under dynamic vacuum at $200{ }^{\circ} \mathrm{C}$ for $24 \mathrm{~h}$. 
TUDMOF-1: TUDMOF-1 was synthesized on the basis of conditions reported previously [36]. Briefly, a mixture of $\mathrm{Mo}(\mathrm{CO})_{6}(1.13 \mathrm{~g}, 4.3 \mathrm{mmol})$ and $\mathrm{H}_{3} \mathrm{BTC}(0.75 \mathrm{~g}, 3.05 \mathrm{mmol})$ was dissolved in $50 \mathrm{~mL}$ of DMF, and then heated under argon atmosphere at $135^{\circ} \mathrm{C}$ for 5 days. After filtration and washing with DMF for 5 times, the obtained precipitate was activated under dynamic vacuum at $135^{\circ} \mathrm{C}$ for $24 \mathrm{~h}$.

MIL-53: MIL-53 was synthesized on the basis of conditions reported previously [37]. Briefly, a mixture of $\mathrm{Cr}\left(\mathrm{NO}_{3}\right)_{3} \cdot 9 \mathrm{H}_{2} \mathrm{O}, 1$,4-benzene dicarboxylic acid, and ultrapure water (molar ratio 1:1:280) was stirred and transferred into autoclave and heated in convection oven at $200{ }^{\circ} \mathrm{C}$ for 4 days to yield light yellow precipitate. The as synthesized MIL-53 (Cr) was washed with fresh DMF for 3 times and then with acetone for 5 times. The MOF powder was calcined in furnace at $300{ }^{\circ} \mathrm{C}$ for $24 \mathrm{~h}$ and then activated under dynamic vacuum at $200{ }^{\circ} \mathrm{C}$ for $24 \mathrm{~h}$.

MIL-101: MIL-101 was synthesized on the basis of conditions reported previously [38]. Briefly, a mixture of $\mathrm{H}_{2} \mathrm{BDC}(216 \mathrm{mg}, 1.3 \mathrm{mmol})$ and $\mathrm{FeCl}_{3} \cdot 6 \mathrm{H}_{2} \mathrm{O}(675 \mathrm{mg}, 2.5 \mathrm{mmol})$ were dissolved in $15 \mathrm{~mL}$ DMF by sonication. The solution was sealed in autoclave and heated at $110^{\circ} \mathrm{C}$ for $24 \mathrm{~h}$ to yield the yellow precipitate. The as synthesized MIL-101 (Fe) was washed with fresh DMF by reflux for $16 \mathrm{~h}$ and then wash with EtOH for $24 \mathrm{~h}$ in a Soxhlet extractor. The final MIL-101(Fe) product was activated under dynamic vacuum at $60{ }^{\circ} \mathrm{C}$ for $8 \mathrm{~h}$.

MIL-101-NH2: MIL-101-NH $\mathrm{NH}_{2}$ was synthesized on the basis of conditions reported previously [38]. Briefly, a mixture of $\mathrm{NH}_{2}-\mathrm{BDC}(224 \mathrm{mg}, 1.3 \mathrm{mmol})$ and $\mathrm{FeCl}_{3} \cdot 6 \mathrm{H}_{2} \mathrm{O}(675$ $\mathrm{mg}, 2.5 \mathrm{mmol}$ ) were dissolved in $15 \mathrm{~mL}$ DMF by sonication. Then the solution was transferred to autoclave and heated at $110{ }^{\circ} \mathrm{C}$ for $24 \mathrm{~h}$ to yield the brown precipitate. The as synthesized MIL-101 $(\mathrm{Fe})-\mathrm{NH}_{2}$ was washed with fresh DMF for $16 \mathrm{~h}$ by reflux and then washed with EtOH for $24 \mathrm{~h}$ in a Soxhlet extractor. The final MIL-101- $\mathrm{NH}_{2}$ product was activated under dynamic vacuum at $60{ }^{\circ} \mathrm{C}$ for $8 \mathrm{~h}$.

MTV-MIL-101: MTV-MIL-101 was synthesized similar to MIL-101 and MIL-101-NH just by tuning the feeding ratio of $\mathrm{BDC}$ and $\mathrm{NH}_{2}-\mathrm{BDC}$ linkers. Briefly, $1.3 \mathrm{mmol}$ mixed linkers (molar ratio, $\left.\mathrm{NH}_{2}-\mathrm{BDC} / \mathrm{BDC}=x: 1-x\right)$ and $\mathrm{FeCl}_{3} \cdot 6 \mathrm{H}_{2} \mathrm{O}(675 \mathrm{mg}, 2.5 \mathrm{mmol}$ ) were dissolved in $15 \mathrm{~mL}$ DMF by sonication. The solution was transferred to autoclave and heated at $110{ }^{\circ} \mathrm{C}$ for $24 \mathrm{~h}$ to yield the brown precipitate. The as synthesized MIL-101- 
$\left(\mathrm{NH}_{2}\right)_{x}$ was washed with fresh DMF for $16 \mathrm{~h}$ by reflux and then washed with EtOH for 24 $\mathrm{h}$ in a Soxhlet extractor. The final product was activated under dynamic vacuum at $60{ }^{\circ} \mathrm{C}$ for $8 \mathrm{~h}$.

Heating and cooling rate: The laser irradiation spot line width $(\mathrm{d}=200 \mu \mathrm{m})$ is equal to spot size of the laser on sample, laser scanning speed $(\mathrm{v})$ is controlled at $50 \mathrm{~mm} / \mathrm{s}$, the heating time $\mathrm{t}$ is obtained by $\mathrm{d} / \mathrm{v}$. And the temperature during the process is calculated by fitting light intensity spectrum with the Plank's blackbody radiation equation, the fitted temperature was close to $2600{ }^{\circ} \mathrm{C}$. So, the heating rate is calculated to be $10^{6} \mathrm{~K} \mathrm{~s}^{-1}$, while the cooling rate is about $10^{5} \mathrm{~K} \mathrm{~s}^{-1}$ according to previous literature [S1].

The productivity calculation: In a typical trial, $14 \mathrm{mg}$ MOF precursor could be converted to $\sim 5 \mathrm{mg}$ pure TMC nanoparticles when laser with power of $6 \mathrm{w}$, beam size of $200 \mu \mathrm{m}$, and scribing speed of $75 \mathrm{~mm} \mathrm{~s}^{-1}$ were applied. Taking that laser could be feasibly scaled up to $1 \mathrm{kw}$ to produce a beam size of $33 \mathrm{~mm}$, the productivity of pure TMC nanoparticles could be as high as $160 \mathrm{~g} \mathrm{kw}^{-1} \mathrm{~h}^{-1}$. If the wavelength of the laser beam was tuned to $355 \mathrm{~nm}$ to provide more efficient laser absorption, the productivity could be further doubled.

The operation temperature for the synthesis of TMCs requires much higher temperature due to the high melting point of metal or metal oxide precursor and the TMC product (up to $3890{ }^{\circ} \mathrm{C}$, Figure S1). The high energy efficiency and even distribution of heat on the illuminated area by laser guarantees the purity and uniformity of TMC nanoparticles in this work. In addition, the metal utilization was usually low in the production of metal carbides, while by laser metallurgy the conversion of metals from MOFs to TMC nanoparticles was quantitative (Table S1) compared with laser spray pyrolysis.

The temperature measurement was based on a "black-body irradiation model", which was widely used to estimate the high temperature objects including the laser induced high temperature plasma. The temperature of the local area was obtained by a spectrometer (AavSpec-UL2048XL-EVO, AVANTES, Netherland) with wavelength detection range from 350 to $900 \mathrm{~nm}$. The light signal was conducted by a Uv-Vis-NIR quartz optical fiber with diameter of $200 \mu \mathrm{m}$ and a cosine corrector was equipped at the head of the fiber to provide a higher light flux. The absolute irradiation intensity of the spectrometer system 
was calibrated by a standard halogen lamp (AvaLight-DHc, AVANTES) at wavelength band from 200 to $1100 \mathrm{~nm}$. For a typical measurement, the light detection head was placed at the same level and close to the MOF tablet with a distance of $10 \mathrm{~cm}$ to the laser source. The acquisition time was $600 \mathrm{~ms}$ for each measurement to ensure higher resolution. By fitting the light intensity spectrum with the Plank's blackbody radiation equation (1), the temperature $(\mathrm{T})$ can be approximated.

$I(\lambda, T)=\frac{2 h c^{2}}{\lambda^{5}} \frac{1}{e \frac{h C}{\lambda k T-1}} ;(1)$

In equation (f), $I(\lambda, T)$ is the measured light intensity, $h, c, K, \lambda$ and $T$ are the Planck constant, light speed, Boltzmann constant, wavelength, and the absolute temperature, respectively. By plugging the constant into equation (1),

This equation could be simplified as the follow equation:

$\boldsymbol{I}(\lambda, \boldsymbol{T})=\frac{c_{1} \lambda^{-5}}{\boldsymbol{e}^{c_{2} /(\lambda T)}-1} \quad ;(2)$

$\mathrm{C}_{1}\left(3.7419 \times 10^{-16} \mathrm{~W} \cdot \mathrm{m}^{2}\right)$ and $\mathrm{C}_{2}\left(1.4388 \times 10^{-2} \mathrm{~m} \cdot \mathrm{K}\right)$ are the first and second irradiation constant, respectively. We measured the spectrums under $7.0 \mathrm{w}$ and fitted these spectrums with Planck's equation to estimate the temperature during laser process. The temperature range obtained by fitting the spectrums were 2520 to $2820 \mathrm{~K}$. 


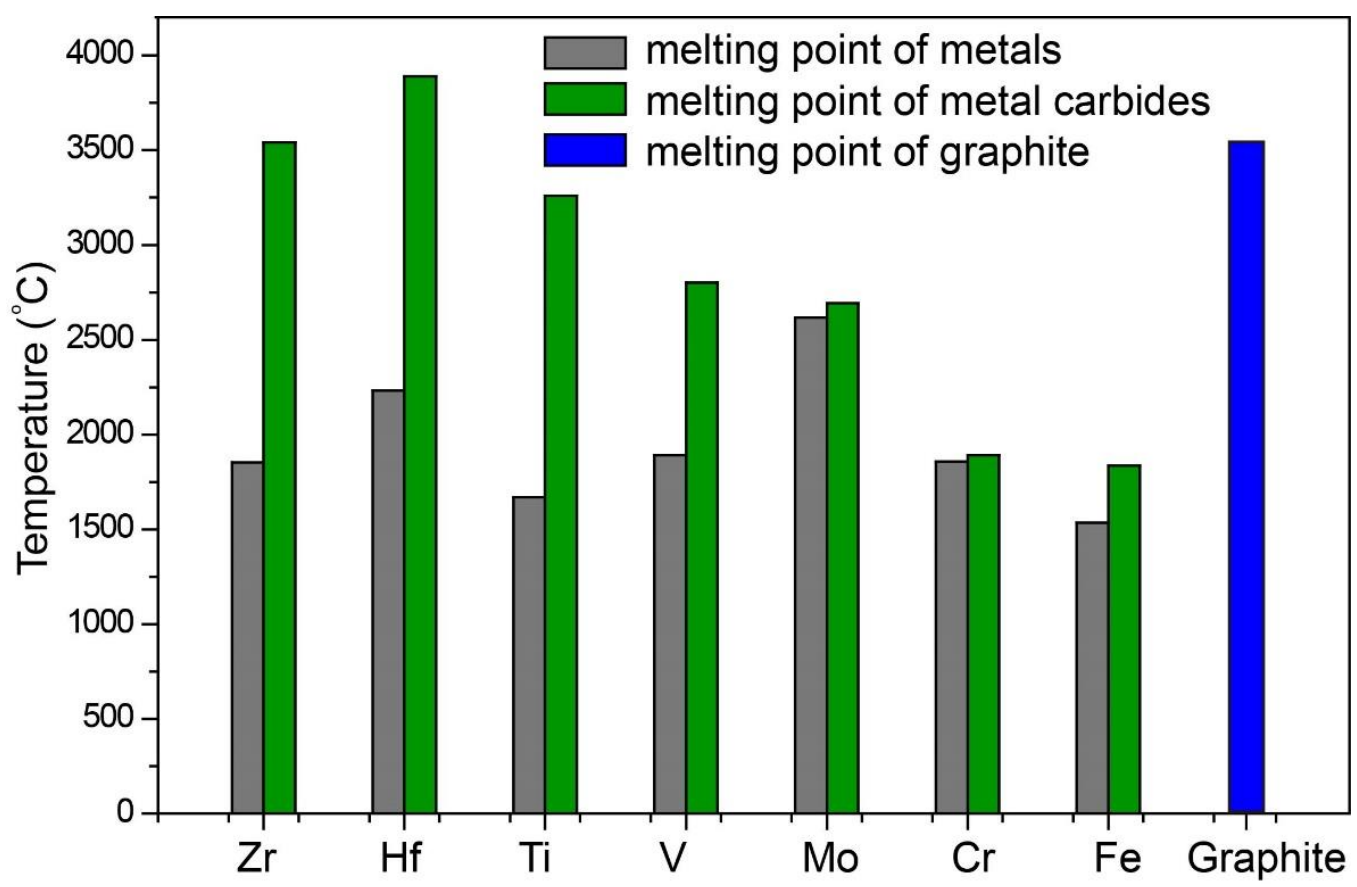

Figure S1. The melting point of metals and their corresponding metal carbides. 

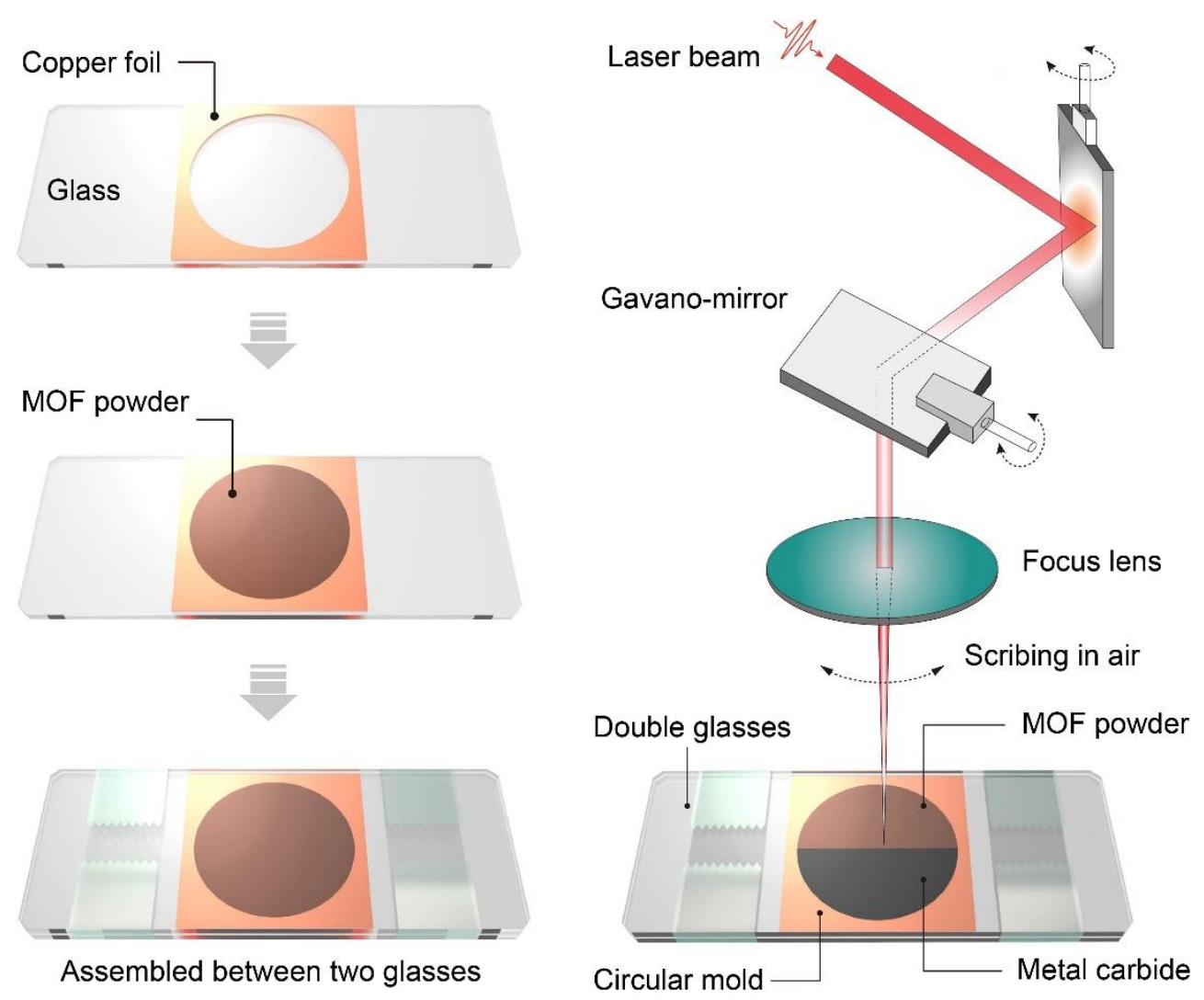

Figure S2. The illustration of sample preparation processes for laser metallurgy. The overall production processes were carried out in ambient condition.

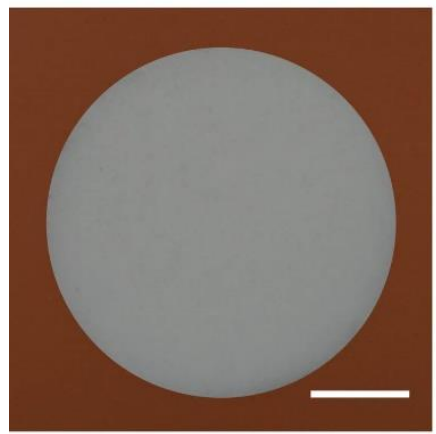

MOF powder

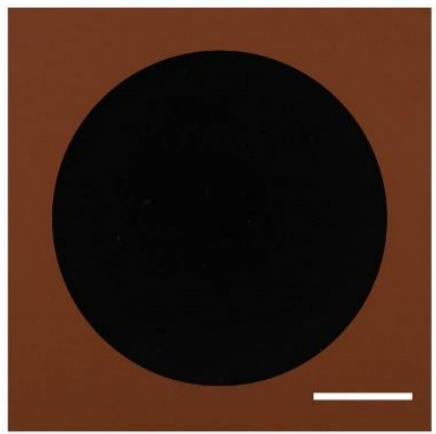

Metal carbide

Figure S3. The MOF powder before and after laser irradiation. The white MOLs instantly turn black once laser irradiates the MOF crystals. Scale bar is $5 \mathrm{~mm}$. 

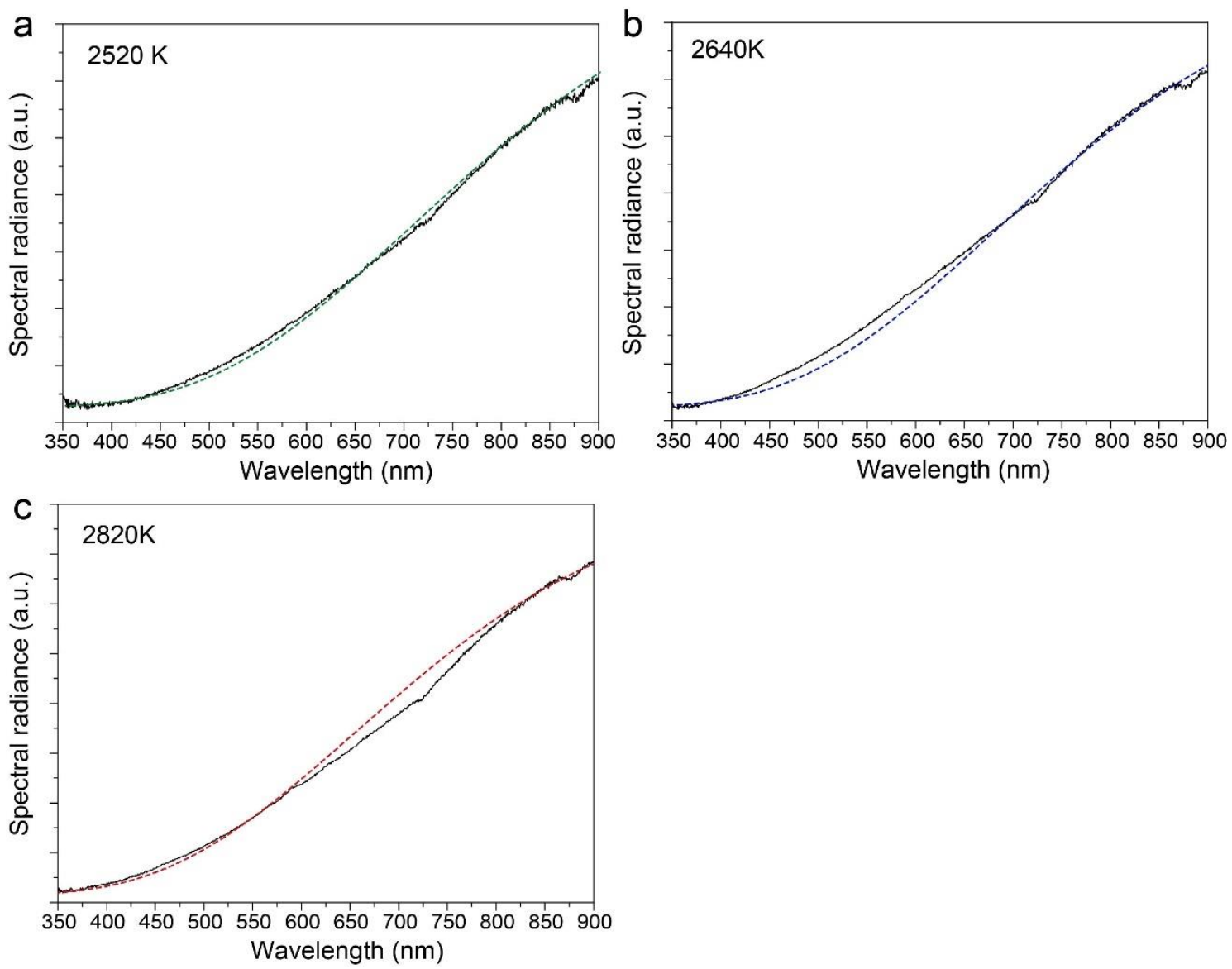

Figure S4. The real temperature of (a) MIL-101, (b) MIL-101-(NH2) 0.5 and (c) MIL-101$\mathrm{NH}_{2}$ during laser metallurgy at $7 \mathrm{~W}$ by fitting the plot with black-body irradiation spectrums. 


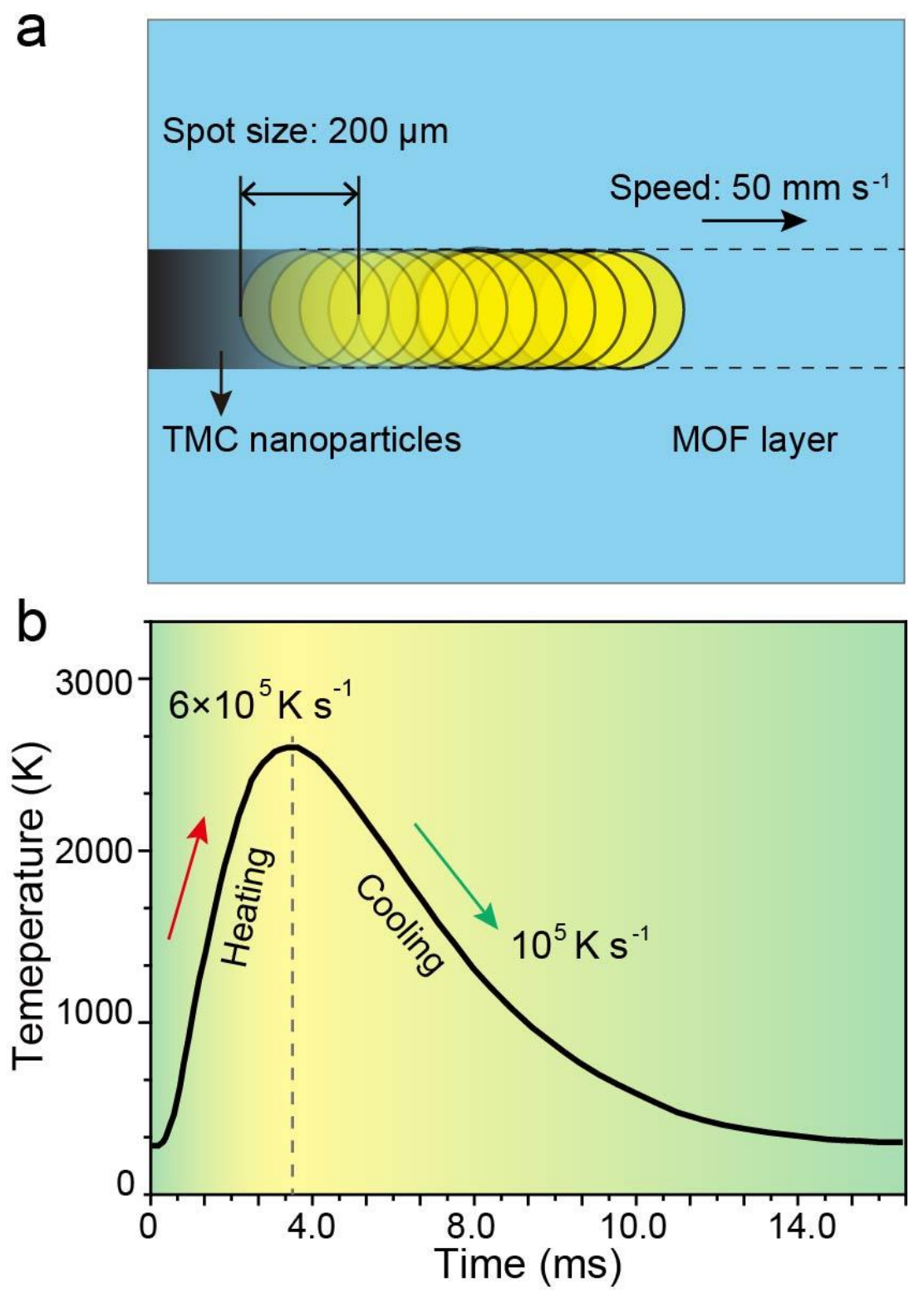

Figure S5. (a) Illustration of the laser scribing process and (b) the heating and cooling rate during the process of laser metallurgy. 
Table S1. Metal conversion rate by laser metallurgy method for the production of TMC nanoparticles.

\begin{tabular}{|c|c|c|c|c|c|c|c|}
\hline MOFs & UMCM-309a & MOLs & $\mathrm{NH}_{2}-\mathrm{MIL}-125$ & MIL-47 & TUDMOF-1 & MIL-53 & MIL-101 \\
\hline Molecular formula of MOF & $\mathrm{Zr}_{6} \mathrm{C}_{27} \mathrm{H}_{28} \mathrm{O}_{26}$ & $\mathrm{Hf}_{6} \mathrm{C}_{27} \mathrm{H}_{28} \mathrm{O}_{26}$ & $\mathrm{Ti}_{8} \mathrm{C}_{48} \mathrm{H}_{40} \mathrm{O}_{36} \mathrm{~N}_{6}$ & $\mathrm{VC}_{8} \mathrm{H}_{9} \mathrm{O}_{5}$ & $\mathrm{Mo}_{3} \mathrm{C}_{18} \mathrm{H}_{12} \mathrm{O}_{12}$ & $\mathrm{CrC}_{8} \mathrm{H}_{9} \mathrm{O}_{5}$ & $\mathrm{Fe}_{3} \mathrm{C}_{24} \mathrm{H}_{12} \mathrm{O}_{13}$ \\
\hline $\begin{array}{l}\text { Metal content from formula of MOF } \\
(w t \%)\end{array}$ & 29.97 & 45.58 & 23.36 & 21.59 & 40.67 & 21.94 & 24.80 \\
\hline $\begin{array}{l}\text { Metal content in MOF from TGA } \\
(\mathrm{wt} \%)\end{array}$ & 27.87 & 44.86 & 21.09 & 21.52 & 38.96 & 21.23 & 22.32 \\
\hline $\begin{array}{l}\text { Metal content inTMC from TGA } \\
(w t \%)\end{array}$ & 56.54 & 59.51 & 45.56 & 46.21 & 53.96 & 54.83 & 43.72 \\
\hline $\begin{array}{l}\text { Metal content in MOF calculated } \\
\text { from TGA of TMC }(w t \%)\end{array}$ & 27.84 & 44.72 & 21.38 & 21.42 & 38.79 & 21.04 & 22.34 \\
\hline Metal conversion rate $(\%)^{[\mathrm{a}]}$ & 99.91 & 99.68 & 101.36 & 99.52 & 99.57 & 99.12 & 100.11 \\
\hline
\end{tabular}

${ }^{[a]}$ metal utilization= Metal content in MOF calculated from TGA of TMC / Metal content in MOF from TGA of MOF. 


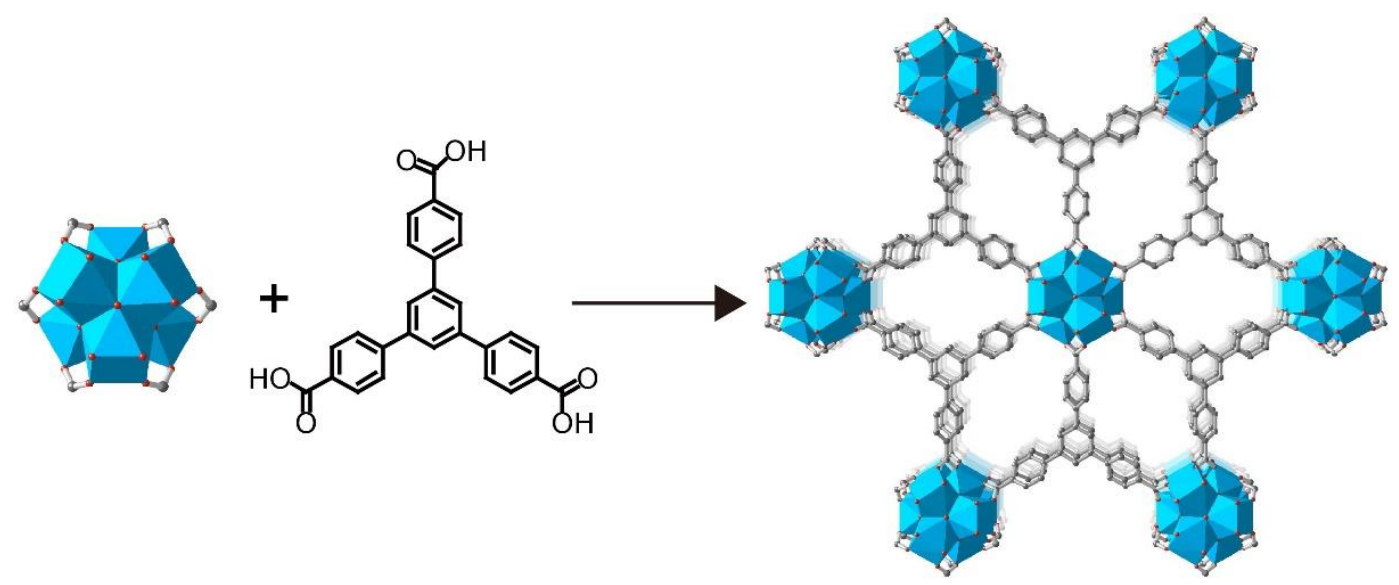

Figure S6. The components of MOLs and the corresponding crystal structure.

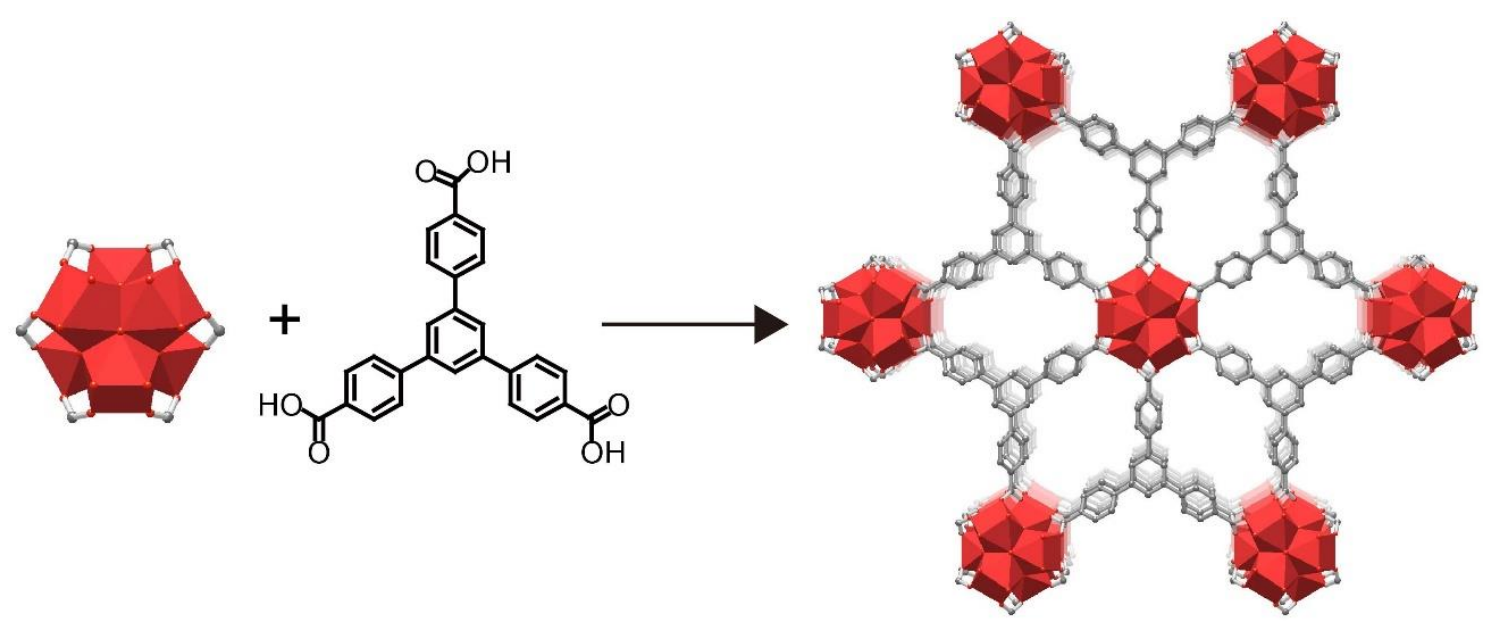

Figure S7. The components of UMCM-309a and the corresponding crystal structure.

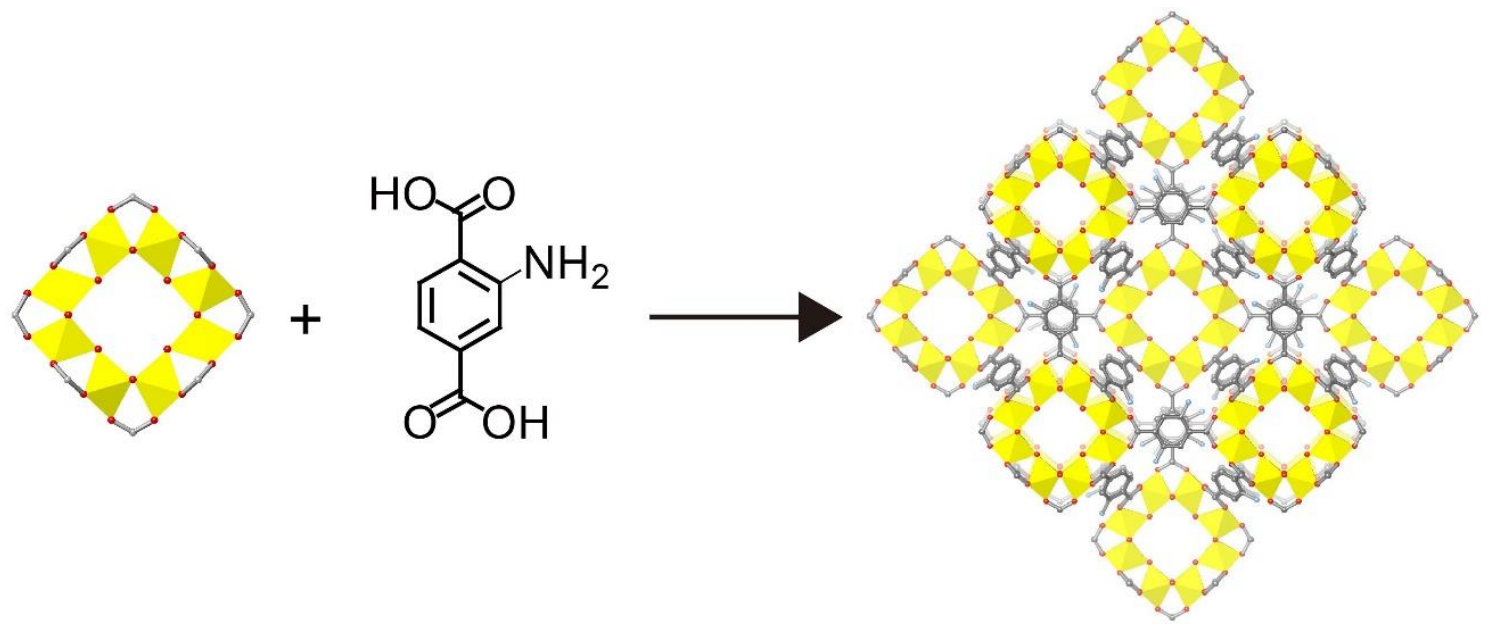

Figure S8. The components of $\mathrm{NH}_{2}-\mathrm{MIL}-125$ and the corresponding crystal structure. 

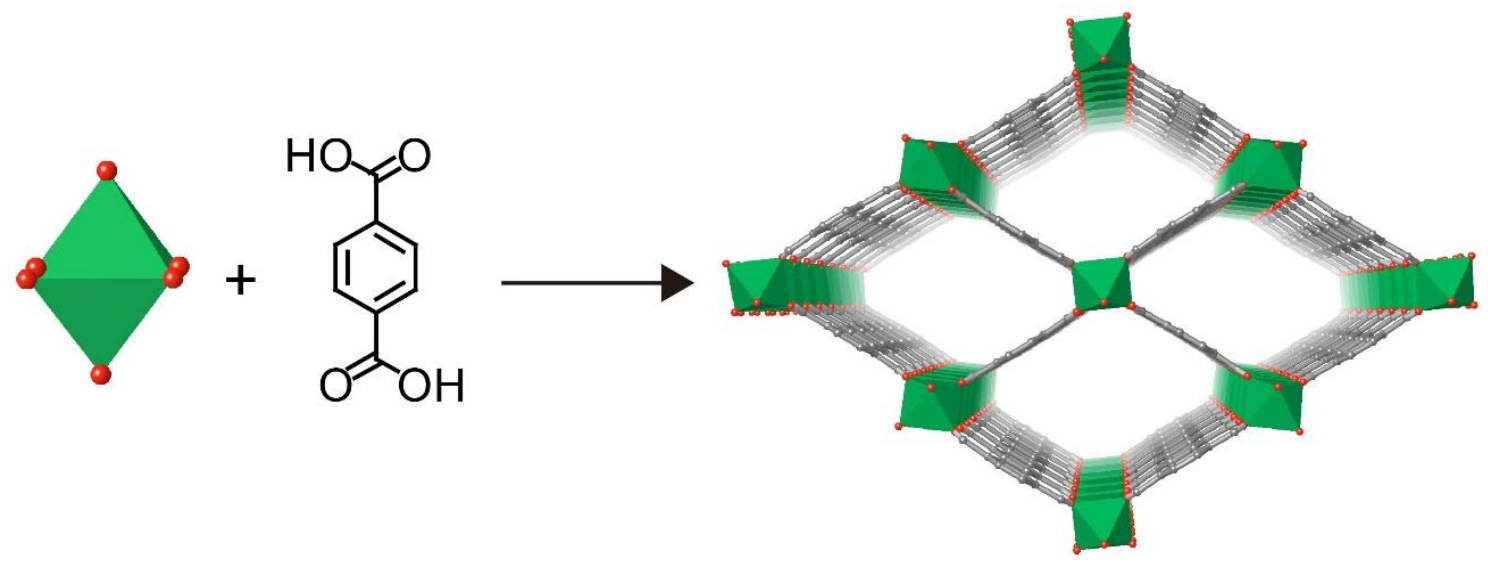

Figure S9. The components of MIL-47 and the corresponding crystal structure.

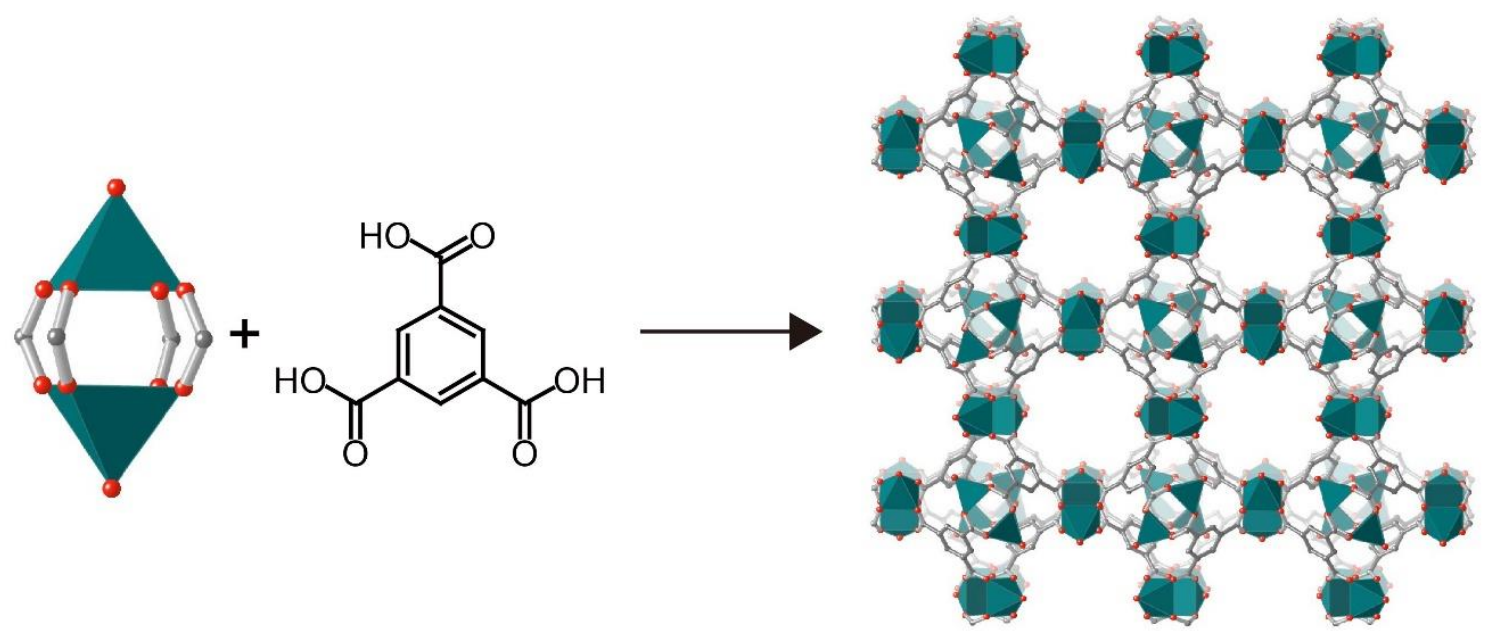

Figure S10. The components of TUDMOF-1 and the corresponding crystal structure.

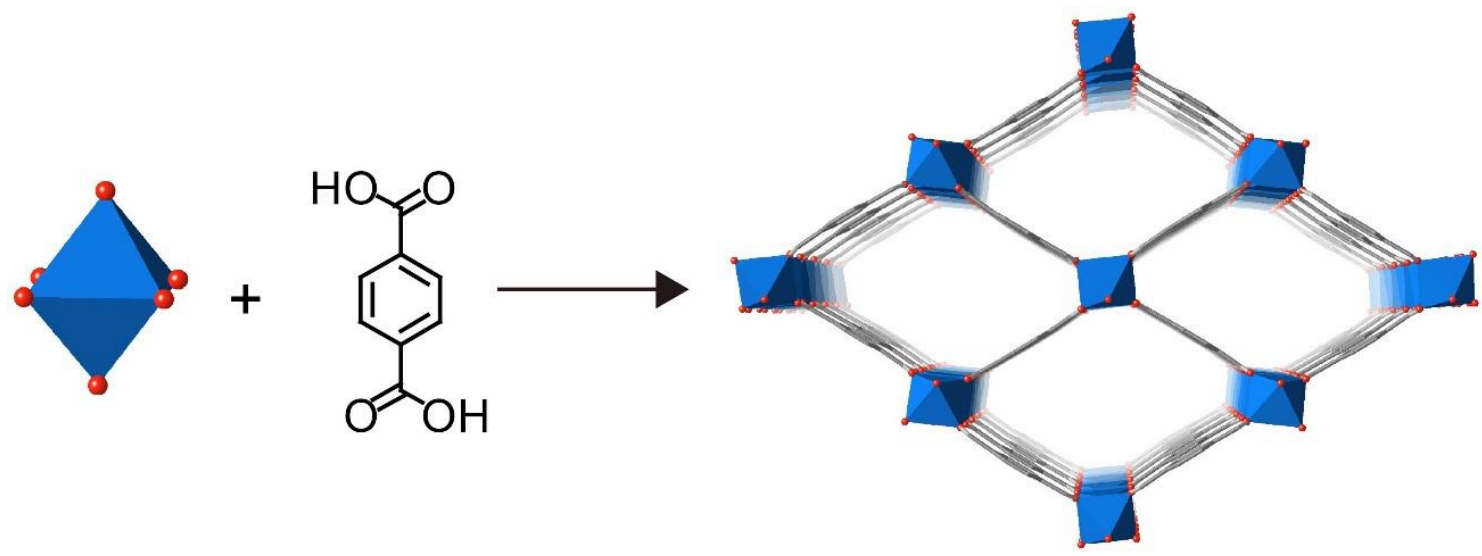

Figure S11. The components of MIL-53 and the corresponding crystal structure. 


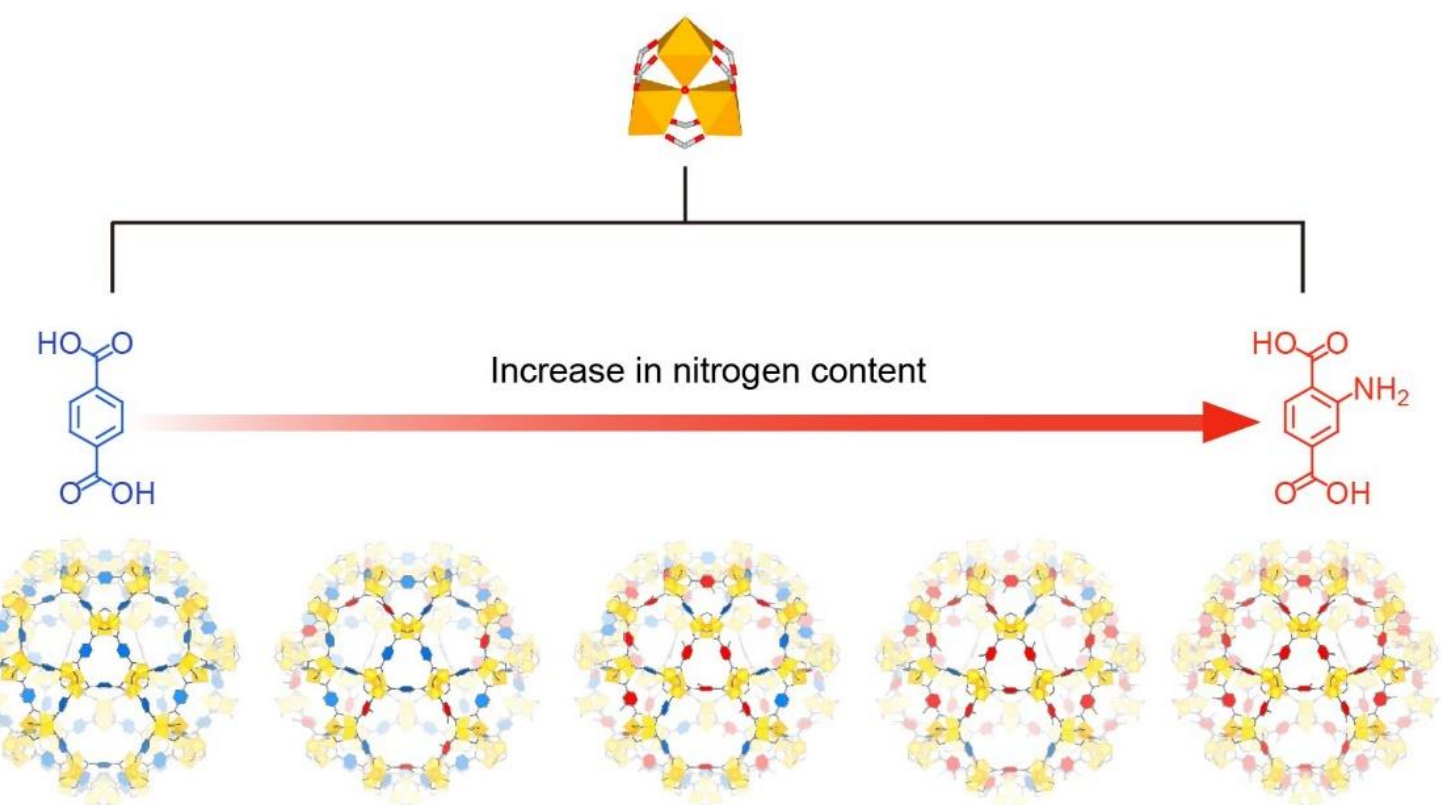

Figure S12. The continuous tuning of amino group containing linkers in MIL-101 for the synthesis of MIL-101-( $\left.\mathrm{NH}_{2}\right)_{x}$. 


\section{Section S2. Characterization of MOFs}

Different methods were used to characterize the synthesized MOF crystals. First, PXRD was used to confirm the phase purity of these MOF precursors. All of the synthesized MOF crystals show identical patterns with the ones simulated from their single crystal structures and no peaks from impurity were observed (Fig. S13-S19). SEM images were collected from a field emitting scanning microscope (Verious460, FEI) without spurting conductive agent on the surface of the MOF crystals. SEM images showed that MOLs and UMCM309a existed as layered structure, and $\mathrm{NH}_{2}$-MIL-125 showed disk-like morphology. MIL47, TUDMOF-1 and MIL-53 were irregular polyhedron, and MIL-101, MIL-101-( $\left.\mathrm{NH}_{2}\right)_{x}$ and MIL-101- $\mathrm{NH}_{2}$ were octahedron (Fig. S20 and S21). $\mathrm{N}_{2}$ adsorption isotherms conducted at $77 \mathrm{~K}$ were used to reveal the permanent porosity of the synthesized MOFs, and they displayed high specific surface areas ranging from 335 to $3259 \mathrm{~m}^{2} \mathrm{~g}^{-1}$ (Fig. S22-S29). Thermal gravimetric analysis (TGA) indicated that the decomposition temperature of these MOFs was above $300{ }^{\circ} \mathrm{C}$, and no obvious weight loss was found before their decompositions, suggesting the successful activation of the MOF samples. The as prepared MOF particles show different color (Fig. S32), manifesting their different light absorption properties. The UV-vis-NIR absorption spectroscopy was used to test the laser absorptivity of MOF crystals at wavelength of $1064 \mathrm{~nm}$. The results showed that their absorptivity varied from $25.3 \%$ to $58.3 \%$ (Fig. S33, S34 and S36), insuring their efficient photothermal conversion. Specifically, MOLs, UMCM-309a and $\mathrm{NH}_{2}-\mathrm{MIL}-125$ showed relatively lower laser absorptivity of $25 \sim 30 \%$, thus relatively higher laser power is applied for their conversions. In contrast, MIL-47 and TUDMOF-1 show higher light absorptivity from 52 to $58 \%$, thus lower laser power was used for laser metallurgy. We found that the laser absorptivity is proportional to the amino group content in the MOF structure, 30\% in MIL101 and $44 \%$ in MIL-101- $\mathrm{NH}_{2}$, indicating that amino functional group is an effective laser absorber in this study. 


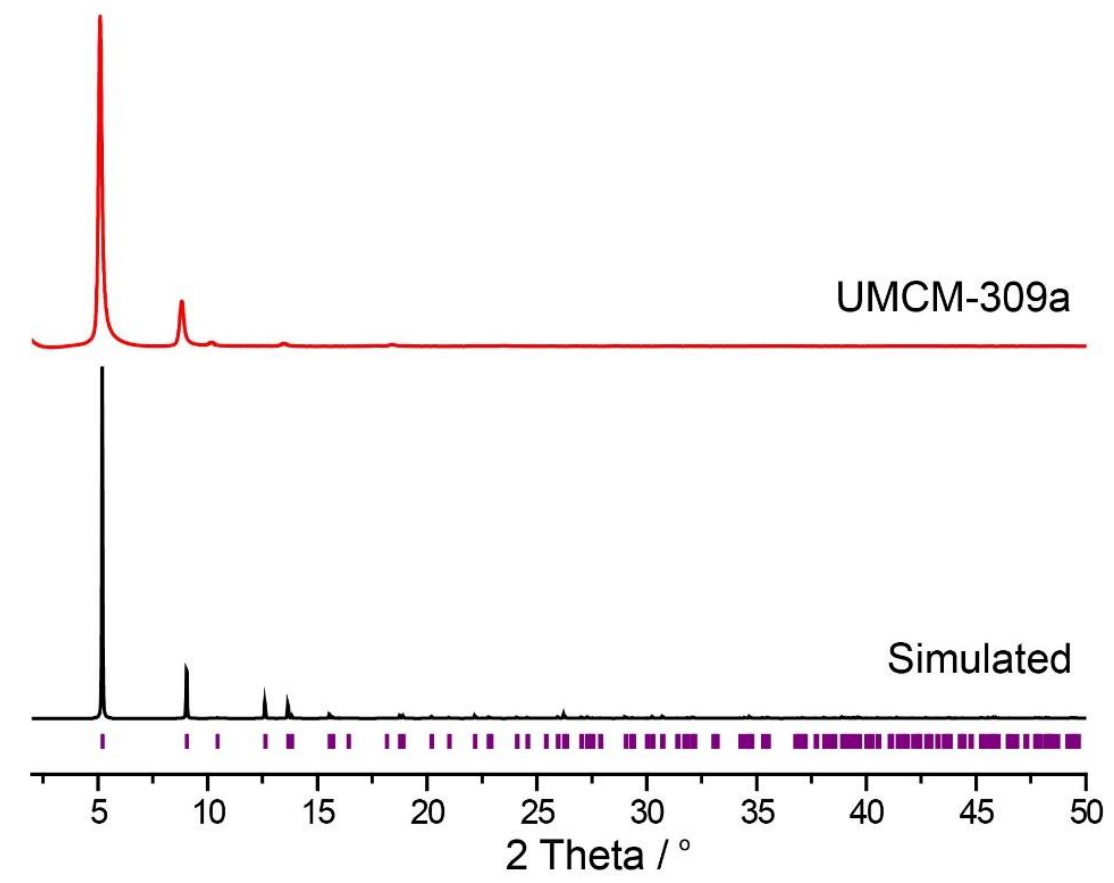

Figure S13. PXRD pattern of activated UMCM-309a compared with the simulated one. The well-matched PXRD pattern confirms the phase purity of MOF.

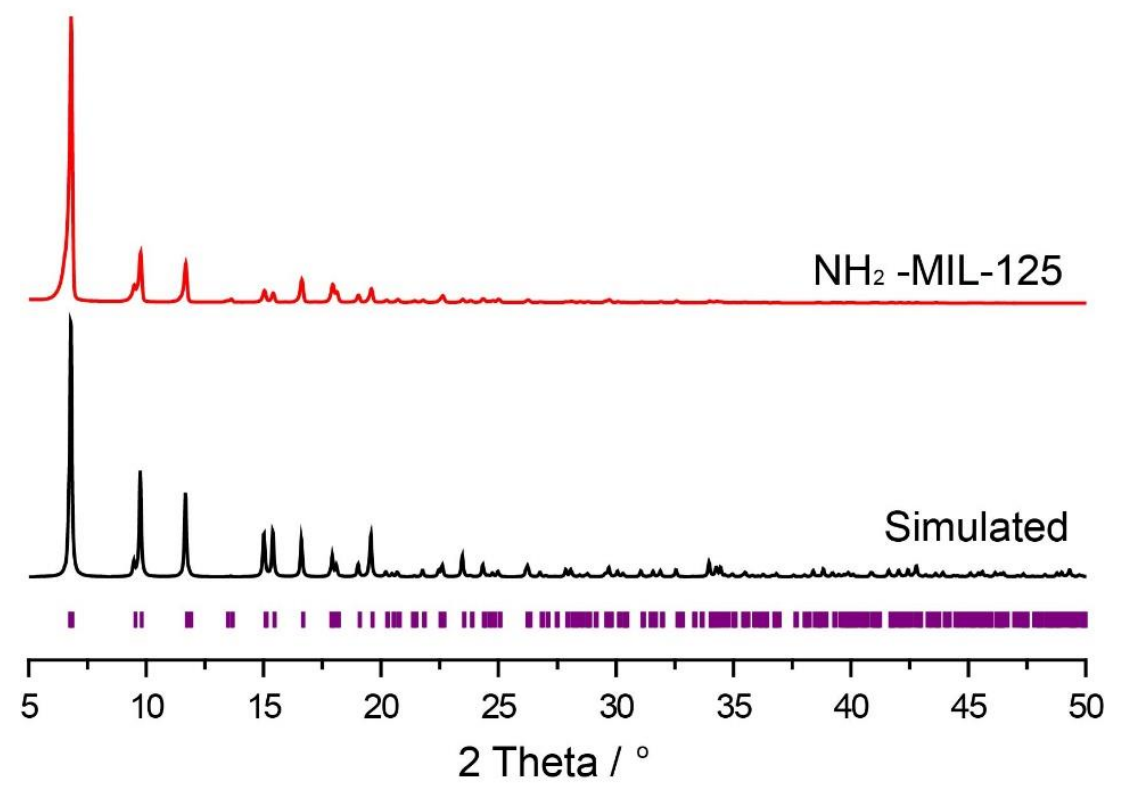

Figure S14. PXRD pattern of activated $\mathrm{NH}_{2}-\mathrm{MIL}-125$ compared with the simulated one. The well-matched PXRD pattern confirms the phase purity of MOF. 


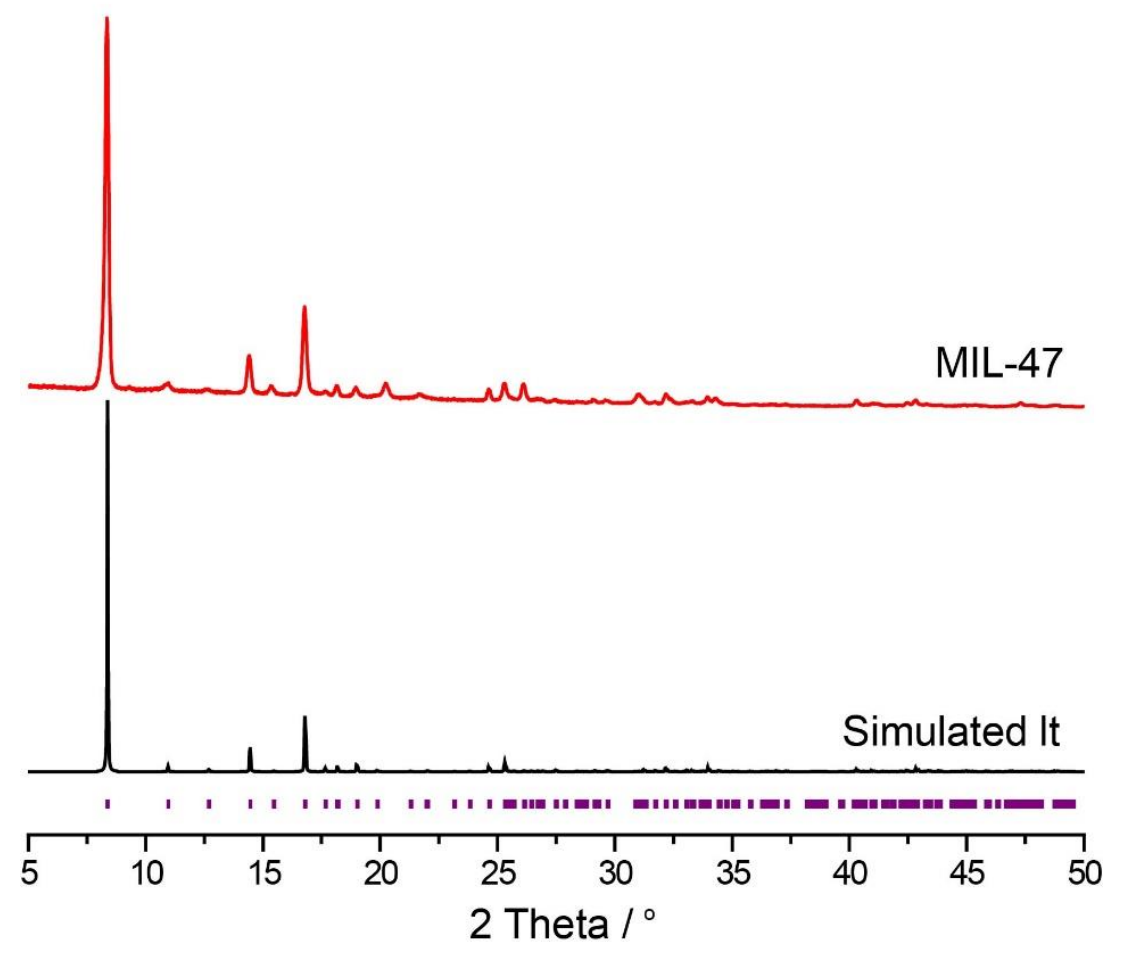

Figure S15. PXRD pattern of MIL-47 compared with the simulated one (as synthesized phase). The well-matched PXRD pattern confirmed the phase purity of MOF.

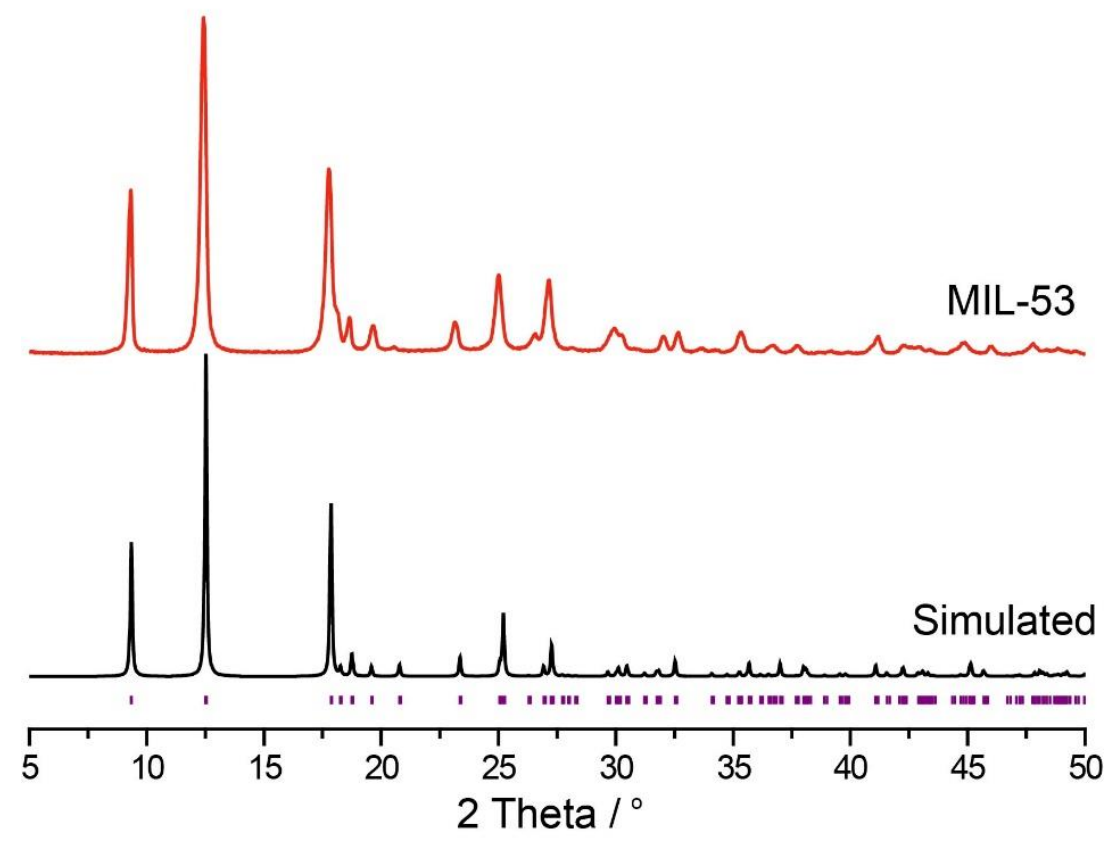

Figure S16. PXRD pattern of activated MIL-53 compared with the simulated one. The well-matched PXRD pattern confirms the phase purity of MOF. 


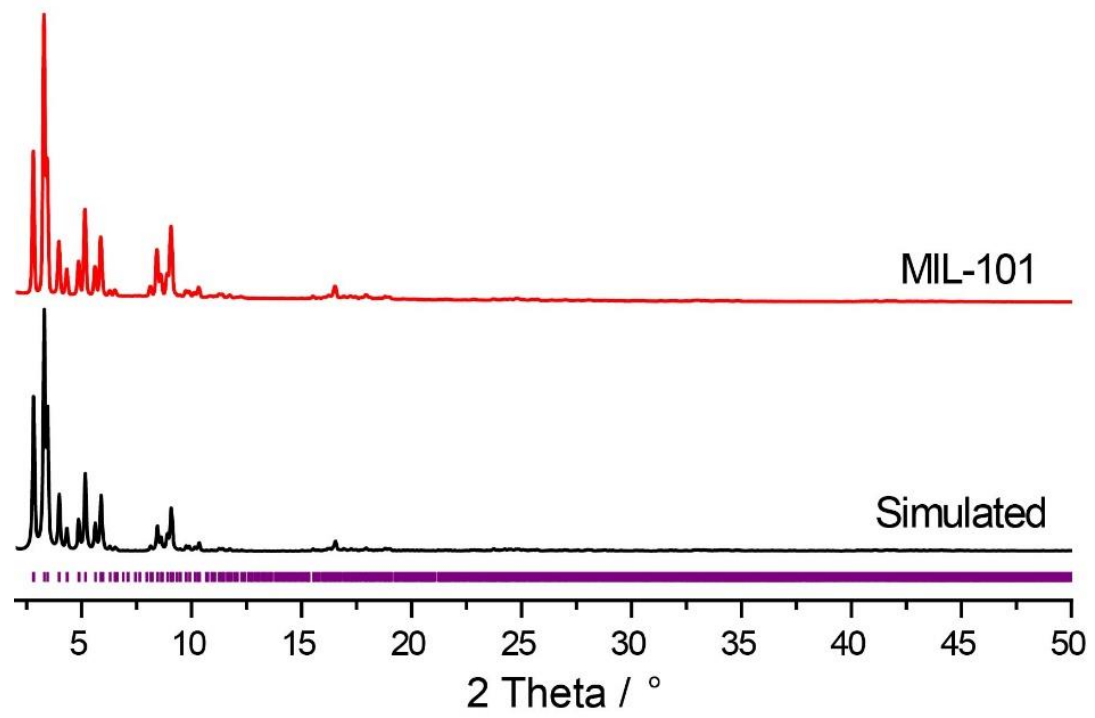

Figure S17. PXRD pattern of activated MIL-101 compared with the simulated one. The well-matched PXRD pattern confirms the phase purity of MOF.

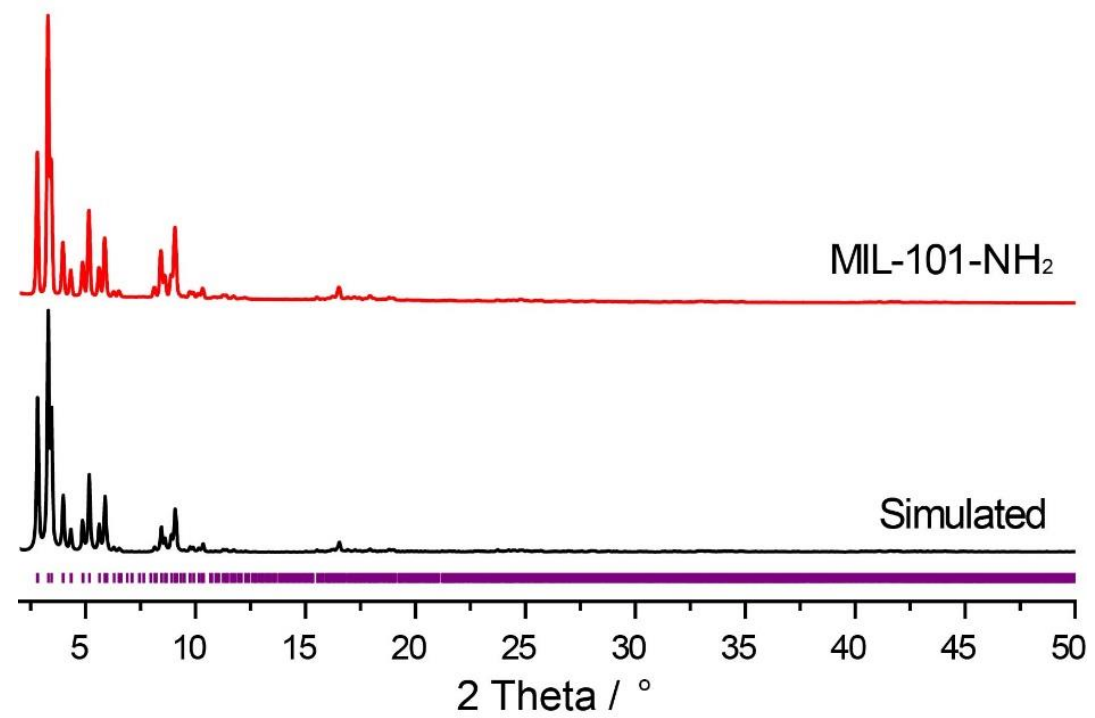

Figure S18. PXRD pattern of activated MIL-101- $\mathrm{NH}_{2}$ compared with the simulated one. The well-matched PXRD pattern confirms the phase purity of MOF. 


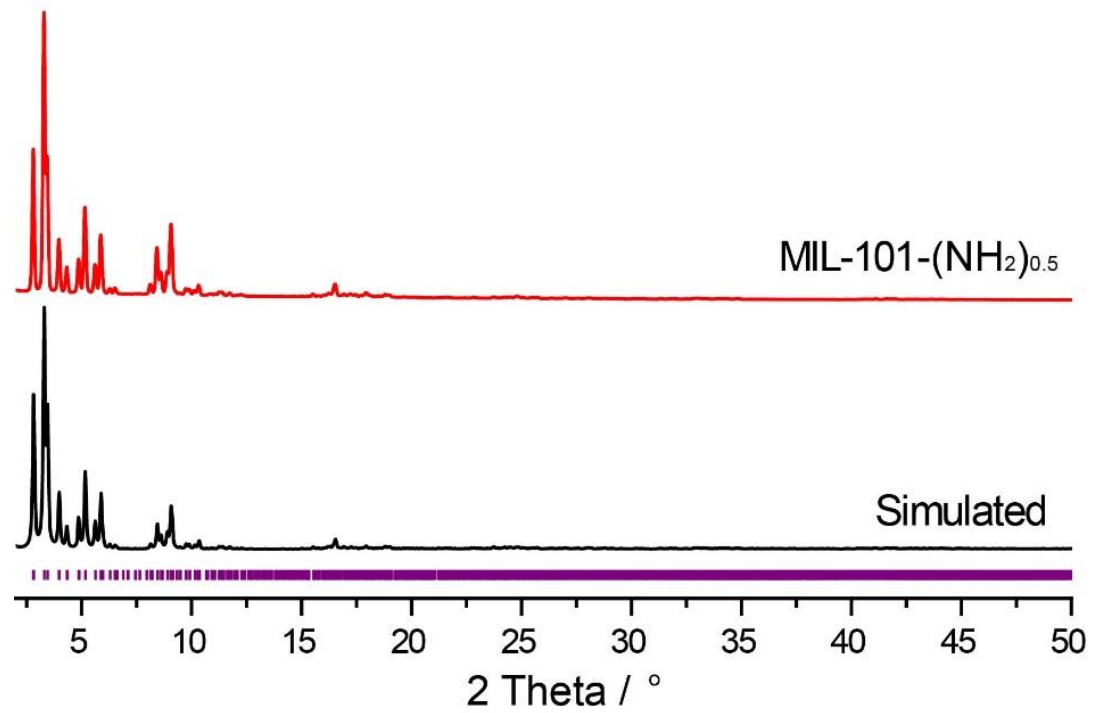

Figure S19. PXRD pattern of activated MIL-101- $\left(\mathrm{NH}_{2}\right)_{0.5}$ compared with the one. The well-matched PXRD pattern confirms the phase purity of MOF. 

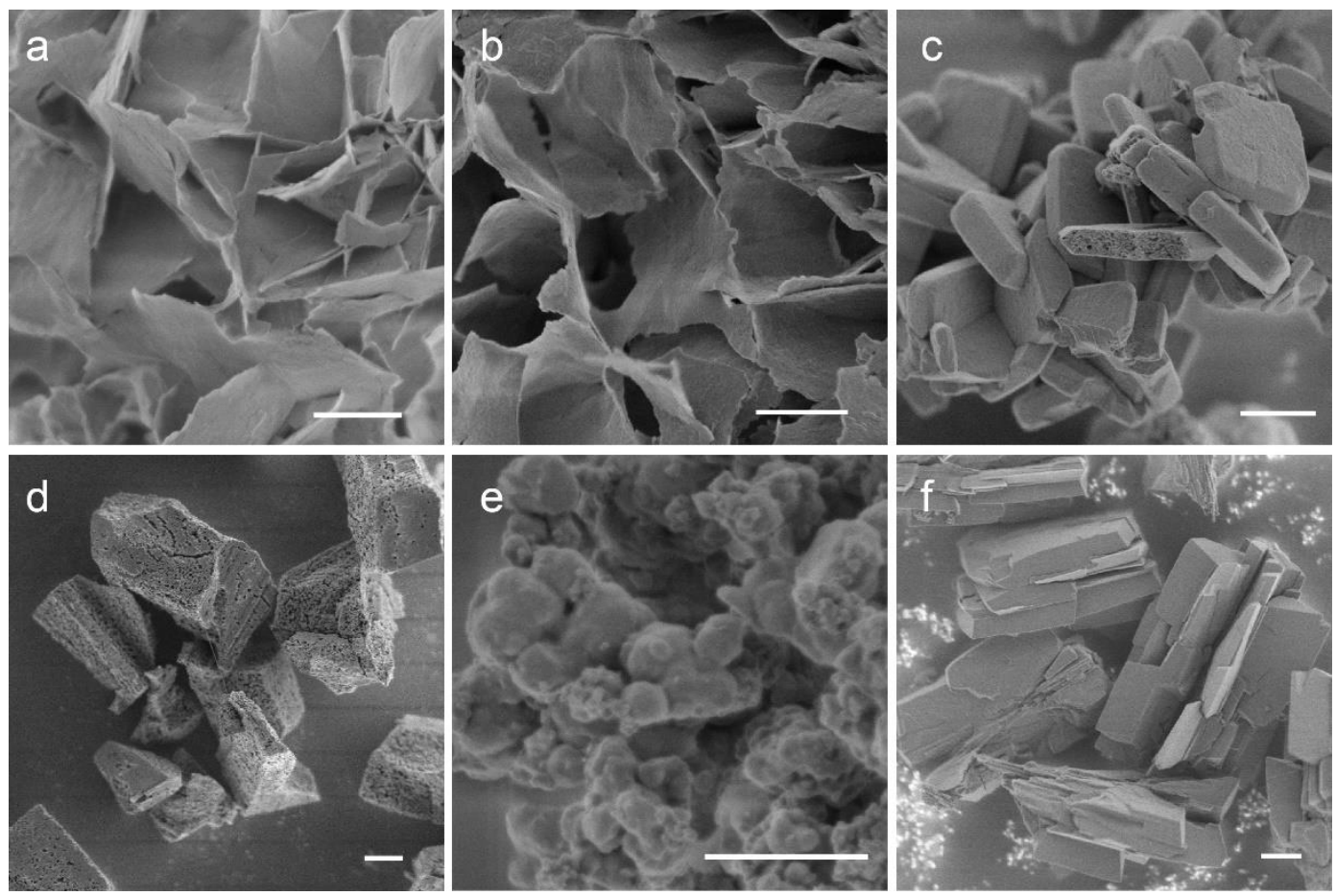

Figure S20. SEM images of MOF precursors for laser metallurgy. (a) MOLs, (b) UMCM309a, (c) NH2-MIL-125, (d) MIL-47, (e) TUDMOF-1, (f) MIL-53. Scale bar is $500 \mathrm{~nm}$ in (a-f).
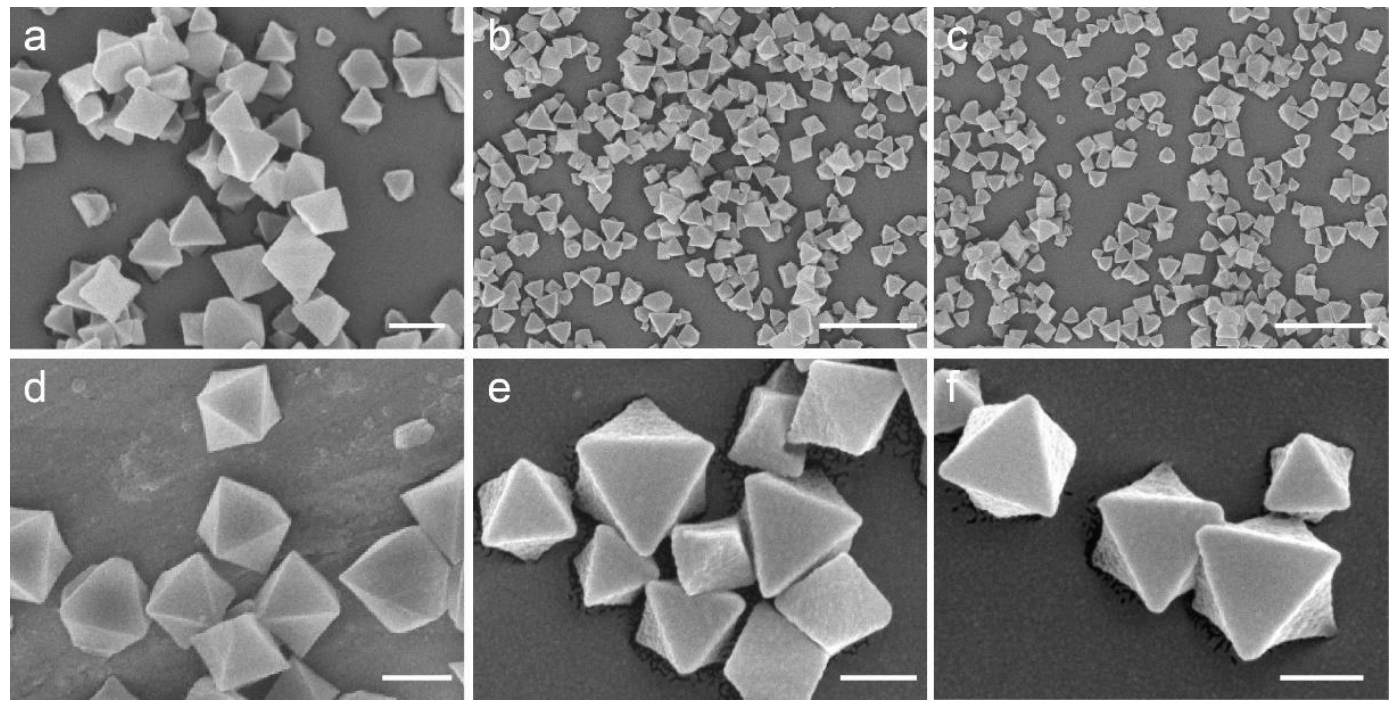

Figure S21. SEM images of (a, d) MIL-101, (b, e) MIL-101-NH2 and (c, f) MIL-101$\left(\mathrm{NH}_{2}\right)_{0.5}$. Scale bar is $1 \mu \mathrm{m}$ in (a-d) and $200 \mathrm{~nm}$ in (e, $\mathrm{f}$. 

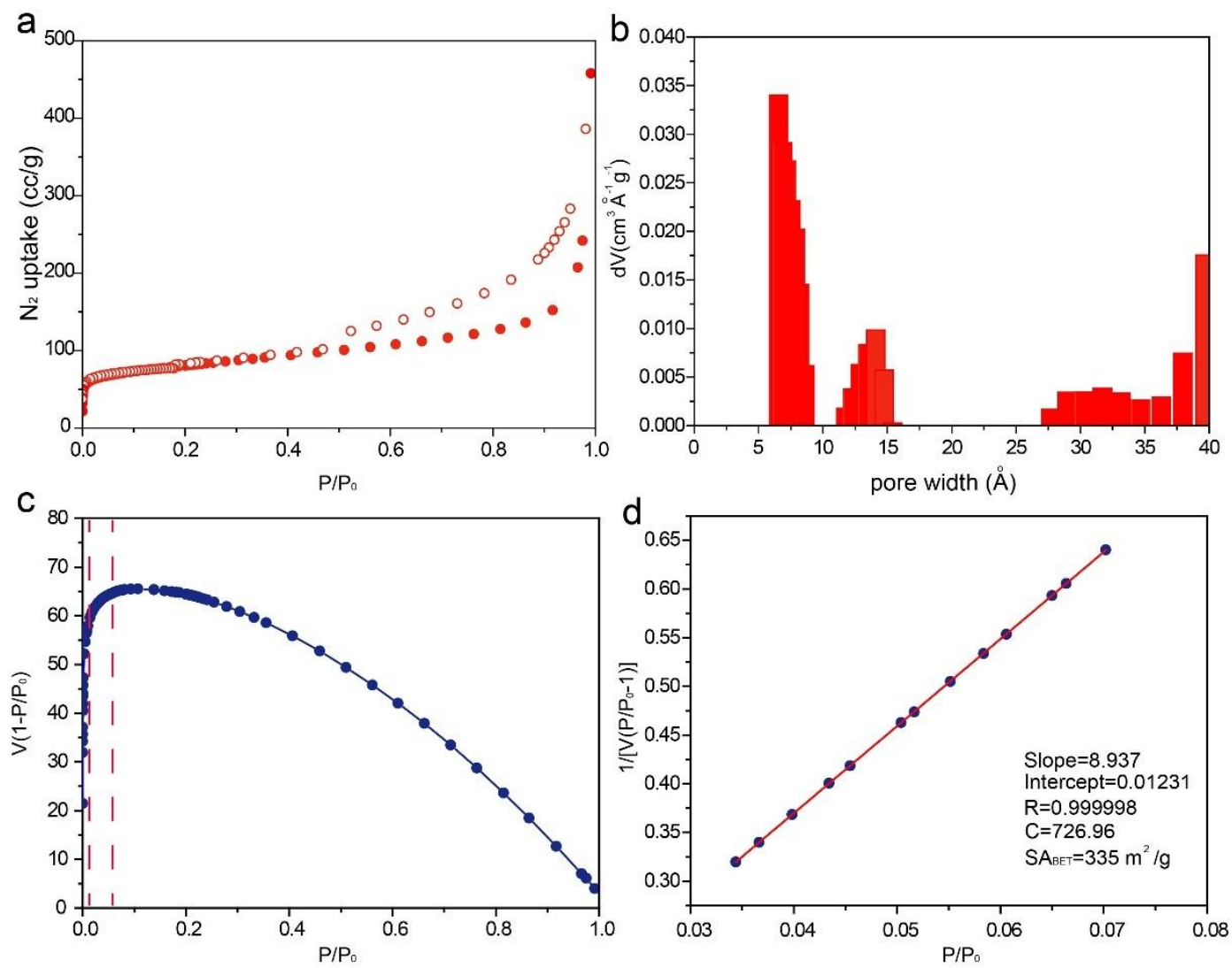

Figure S22. (a) Nitrogen absorption isotherm of MOLs. Filled and open symbols represent the adsorption and desorption curves, respectively. (b) Pore size distribution of MOLs. (c) Points between the dashed lines are selected based on the first consistency criterion, (d) plot of selected linear $\mathrm{P} / \mathrm{P}_{0}$ range. 

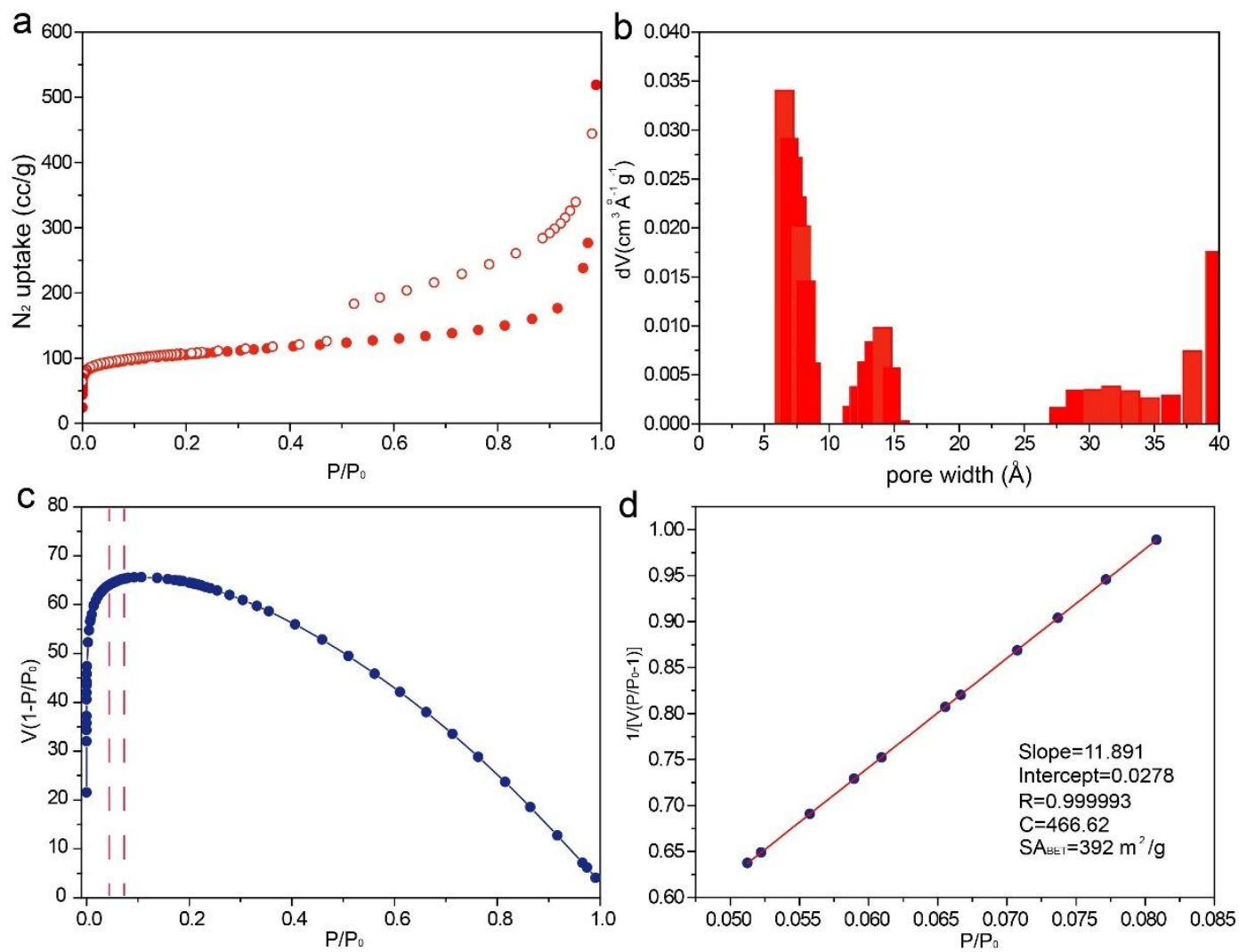

Figure S23. (a) Nitrogen absorption isotherm of UMCM-309a. Filled and open symbols represent the adsorption and desorption curves, respectively. (b) Pore size distribution of UMCM-309a. (c) Points between the dashed lines are selected based on the first consistency criterion, (d) plot of selected linear $\mathrm{P} / \mathrm{P}_{0}$ range. 

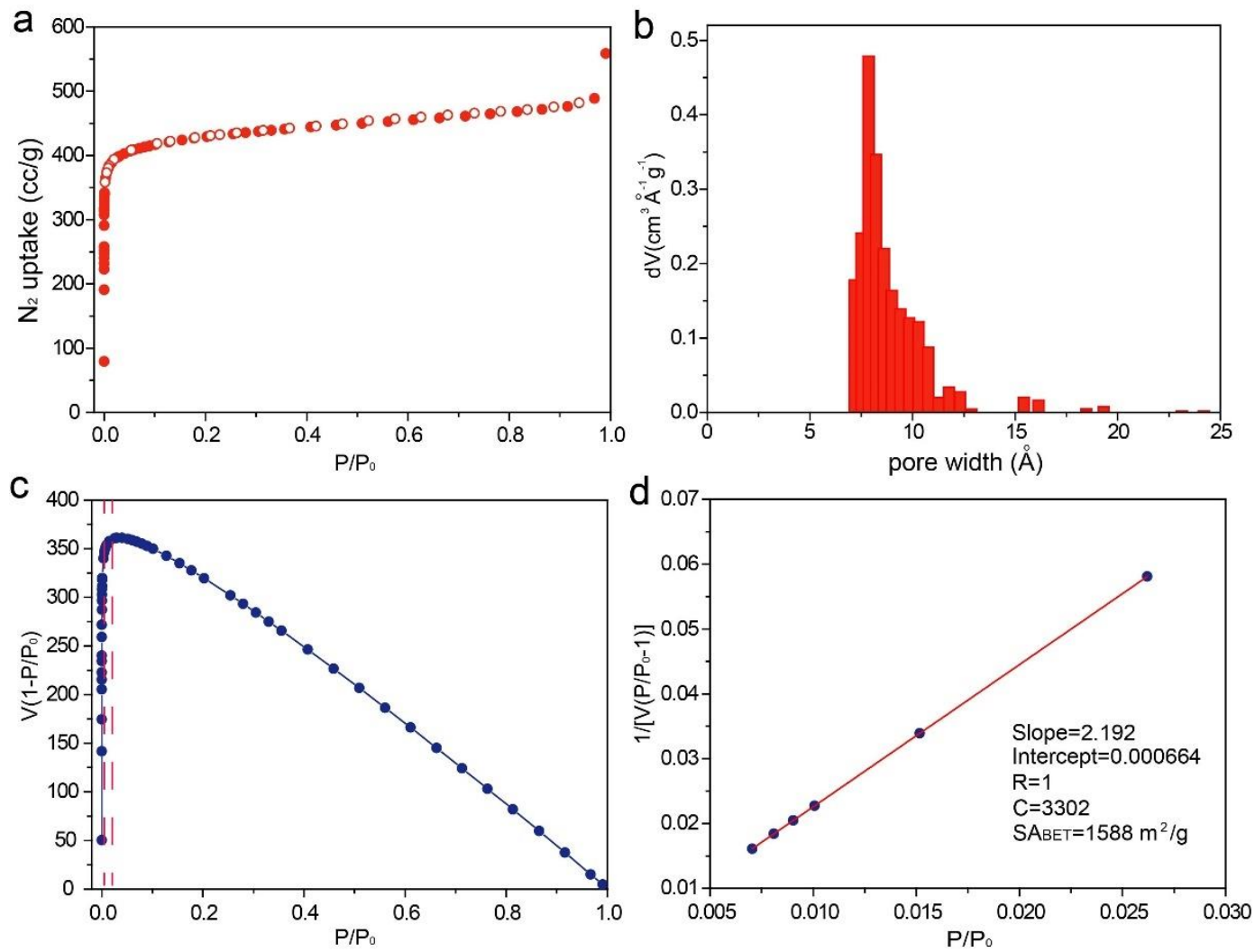

Figure S24. (a) Nitrogen adsorption isotherm of activated $\mathrm{NH}_{2}-\mathrm{MIL}-125$. Filled and open symbols represent the adsorption and desorption curves, respectively. (b) Pore size distribution of $\mathrm{NH}_{2}-\mathrm{MIL}-125$. (c) Points between the dashed lines are selected based on the first consistency criterion, (d) plot of selected linear $\mathrm{P} / \mathrm{P}_{0}$ range. 

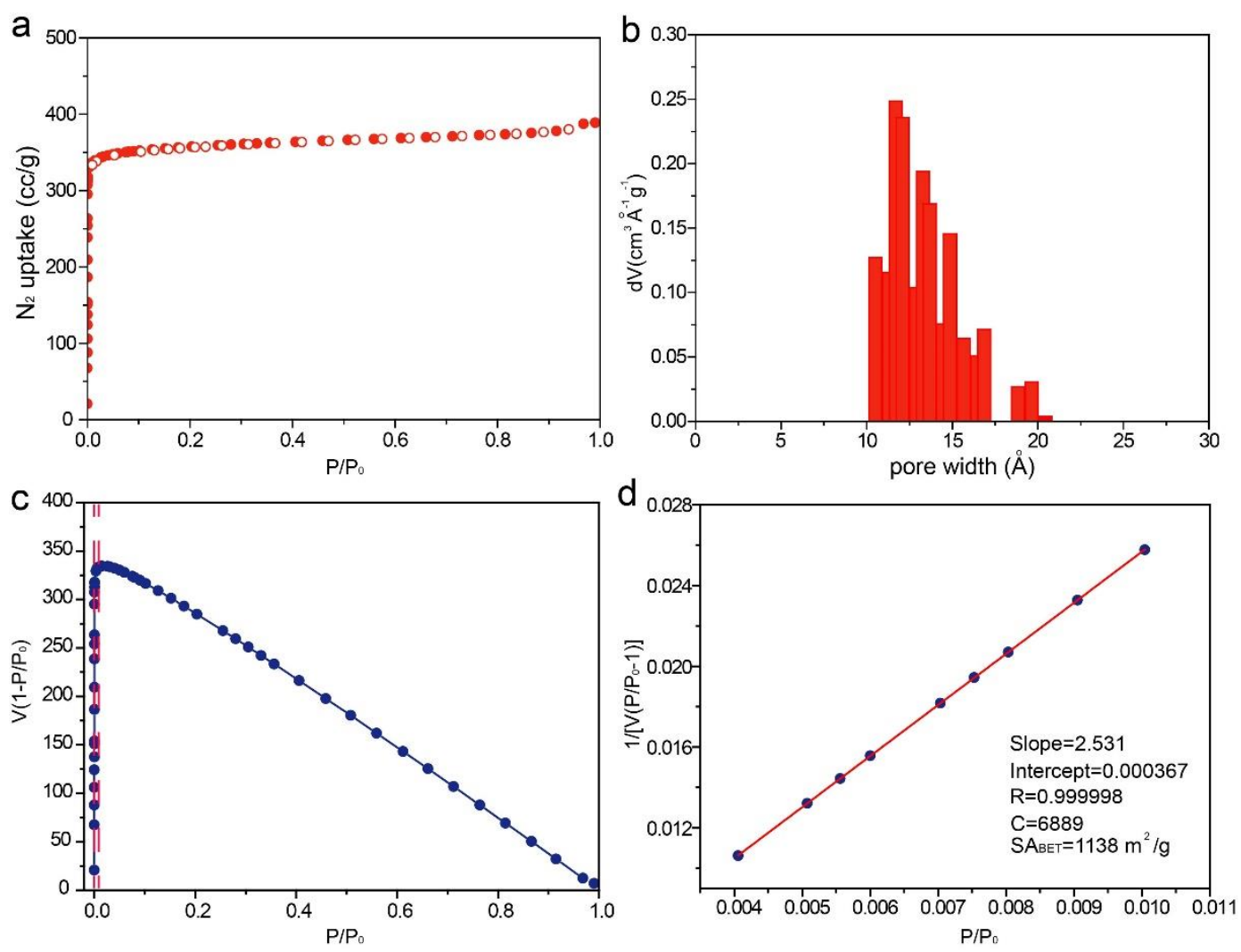

Figure S25. (a) Nitrogen adsorption isotherm of activated MIL-47. Filled and open symbols represent the adsorption and desorption curves, respectively. (b) Pore size distribution of MIL-47. (c) Points between the dashed lines are selected based on the first consistency criterion, (d) plot of selected linear $\mathrm{P} / \mathrm{P}_{0}$ range. 

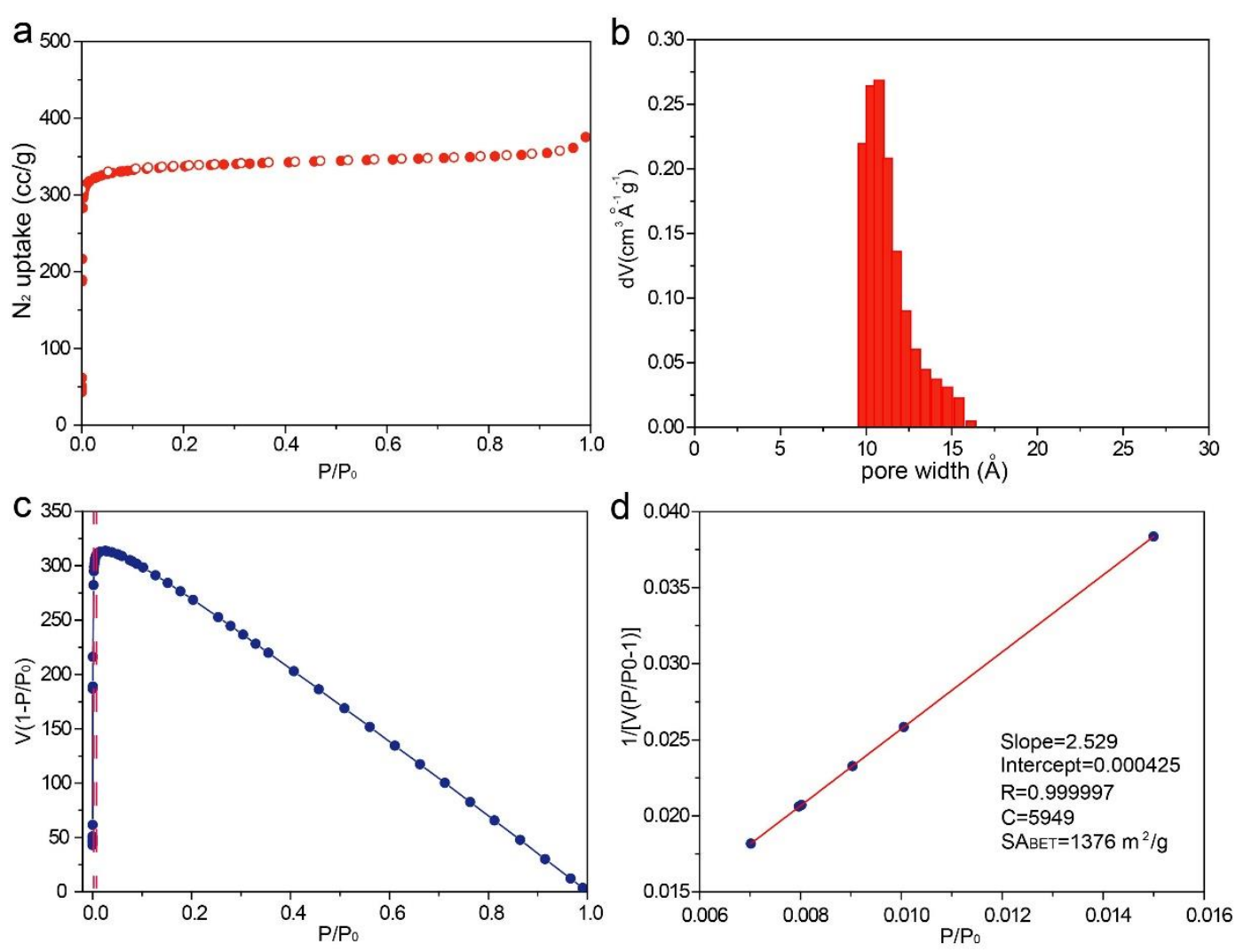

Figure S26. (a) Nitrogen adsorption isotherm of activated MIL-53. Filled and open symbols represent the adsorption and desorption curves, respectively. (b) Pore size distribution of MIL-53. (c) Points between the dashed lines are selected based on the first consistency criterion, (d) plot of selected linear $\mathrm{P} / \mathrm{P}_{0}$ range. 

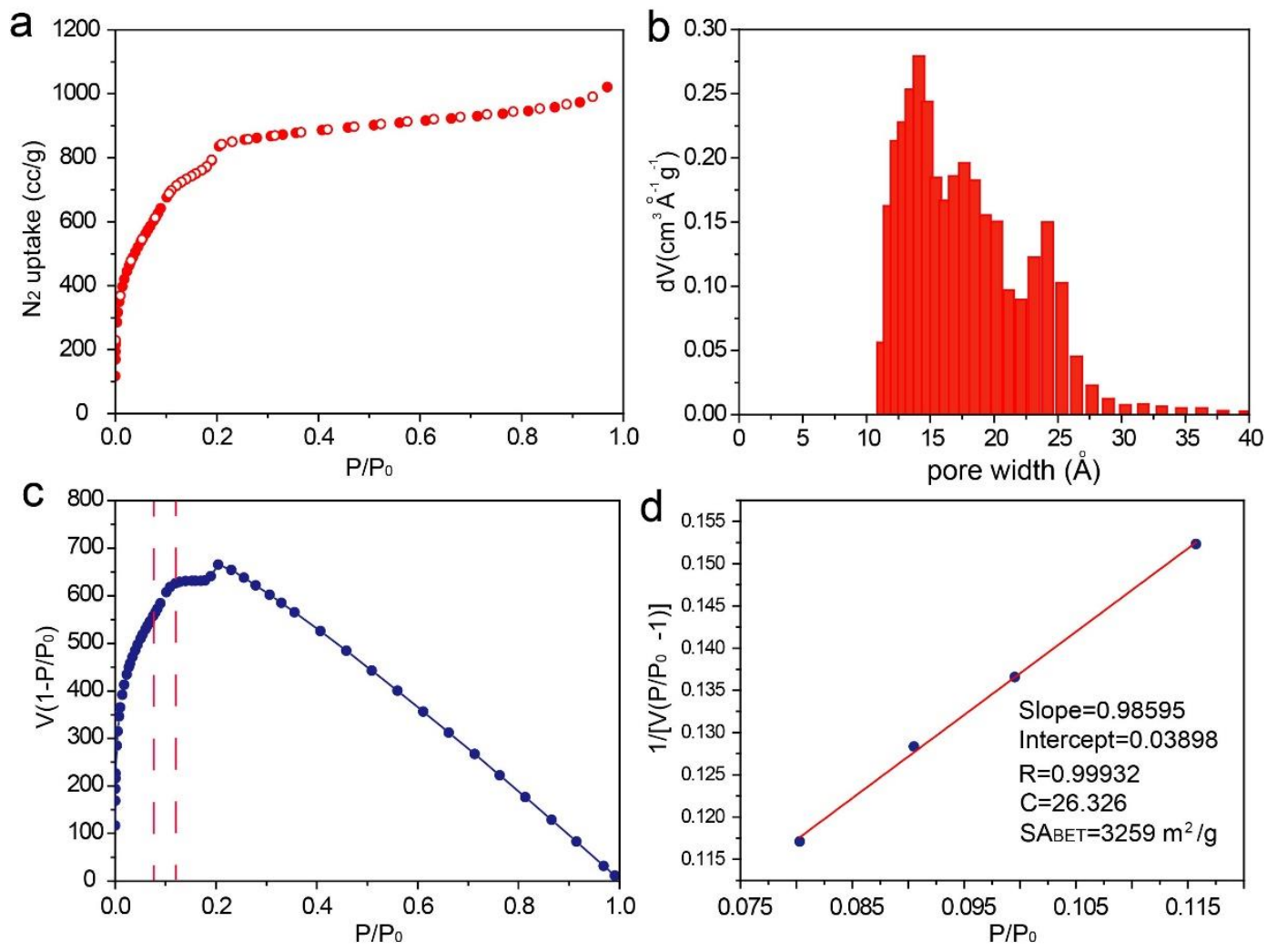

Figure S27. (a) Nitrogen adsorption isotherm of activated MIL-101. Filled and open symbols represent the adsorption and desorption curves, respectively. (b) Pore size distribution of MIL-101. (c) Points between the dashed lines are selected based on the first consistency criterion, (d) plot of selected linear $\mathrm{P} / \mathrm{P}_{0}$ range. 

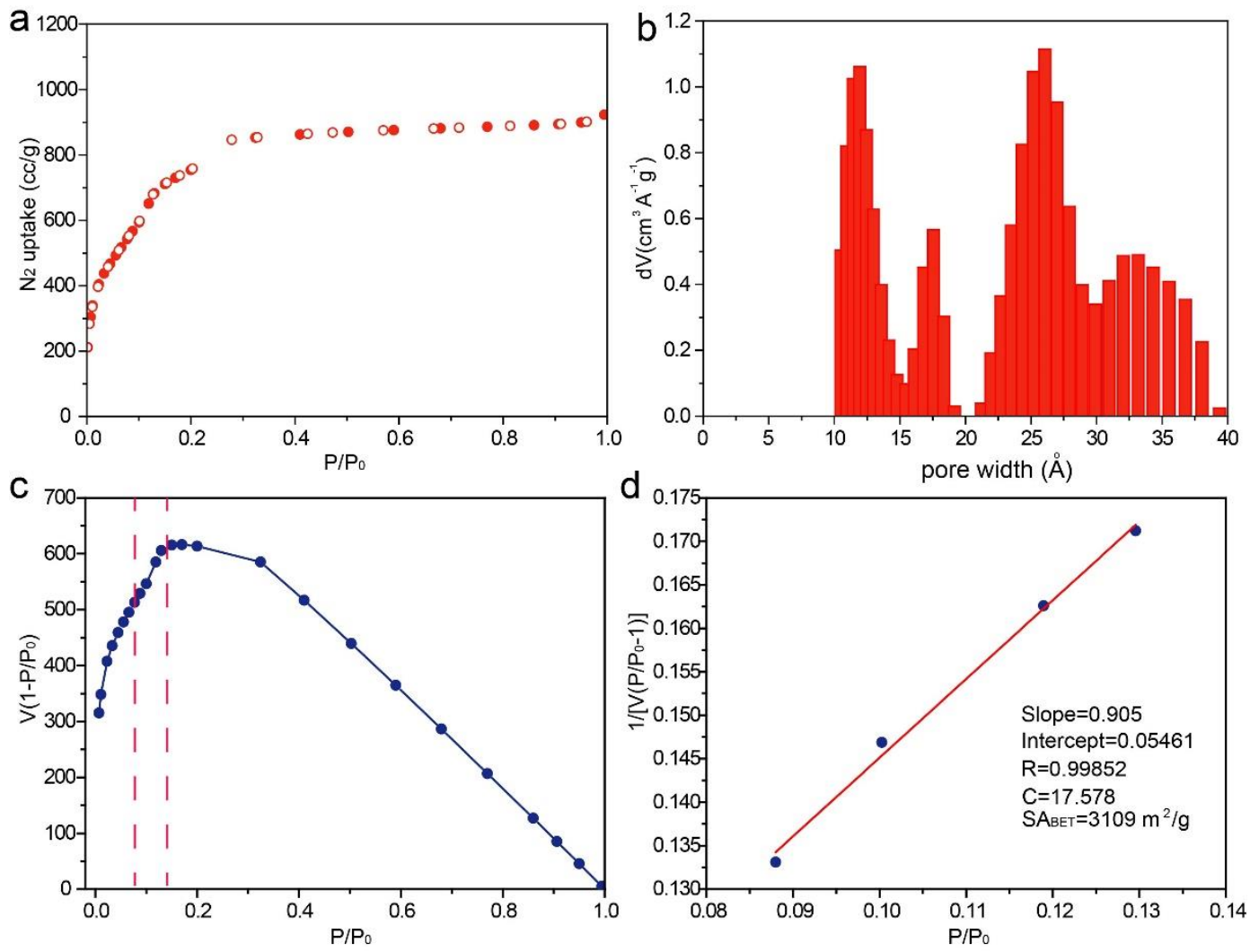

Figure S28. (a) Nitrogen adsorption isotherm of activated MIL-101-( $\left.\mathrm{NH}_{2}\right)_{0.5}$. Filled and open symbols represent the adsorption and desorption curves, respectively. (b) Pore size distribution of MIL-101-( $\left(\mathrm{NH}_{2}\right)_{0.5}$. (c) Points between the dashed lines are selected based on the first consistency criterion, (d) plot of selected linear $\mathrm{P} / \mathrm{P}_{0}$ range. 

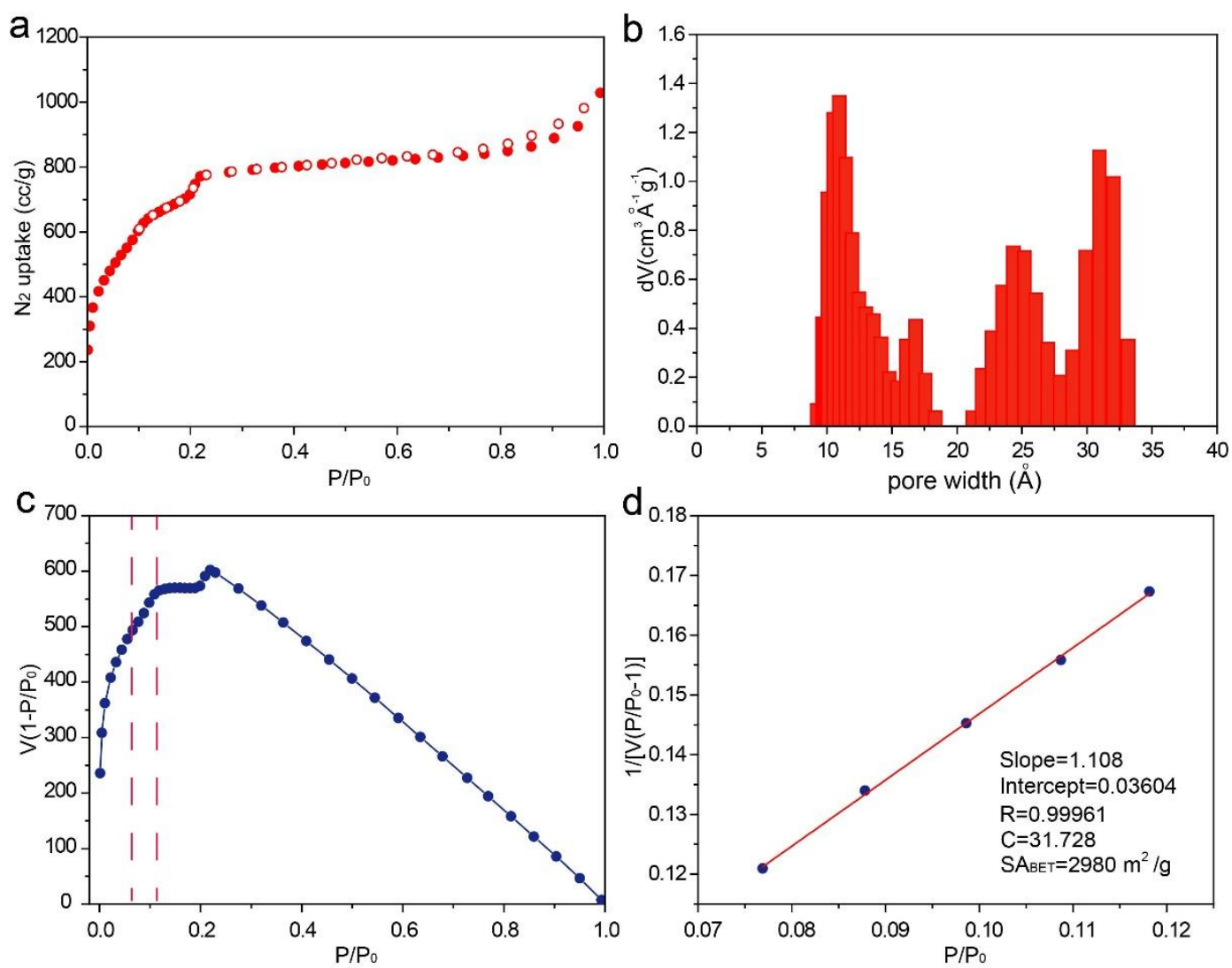

Figure S29. (a) Nitrogen adsorption isotherm of activated MIL-101- $\mathrm{NH}_{2}$. Filled and open symbols represent the adsorption and desorption curves, respectively. (b) Pore size distribution of MIL-101- $\mathrm{NH}_{2}$. (c) Points between the dashed lines are selected based on the first consistency criterion, (d) plot of selected linear $\mathrm{P} / \mathrm{P}_{0}$ range. 

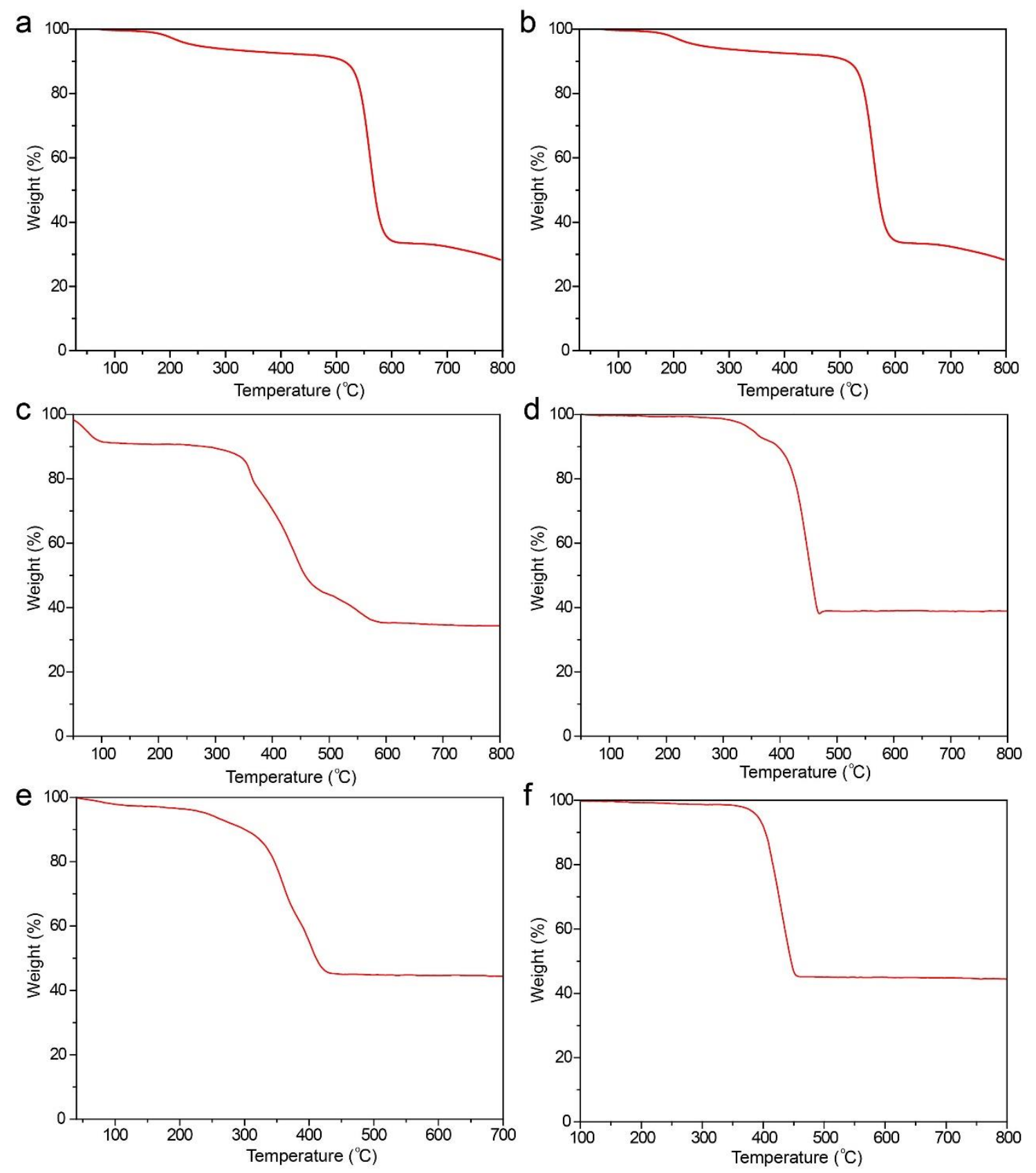

Figure S30. TGA plots of (a) MOLs, (b) UMCM-309a, (c) $\mathrm{NH}_{2}-\mathrm{MIL}-125$, (d) MIL-47, (e) TUDMOF-1 and (f) MIL-53. 

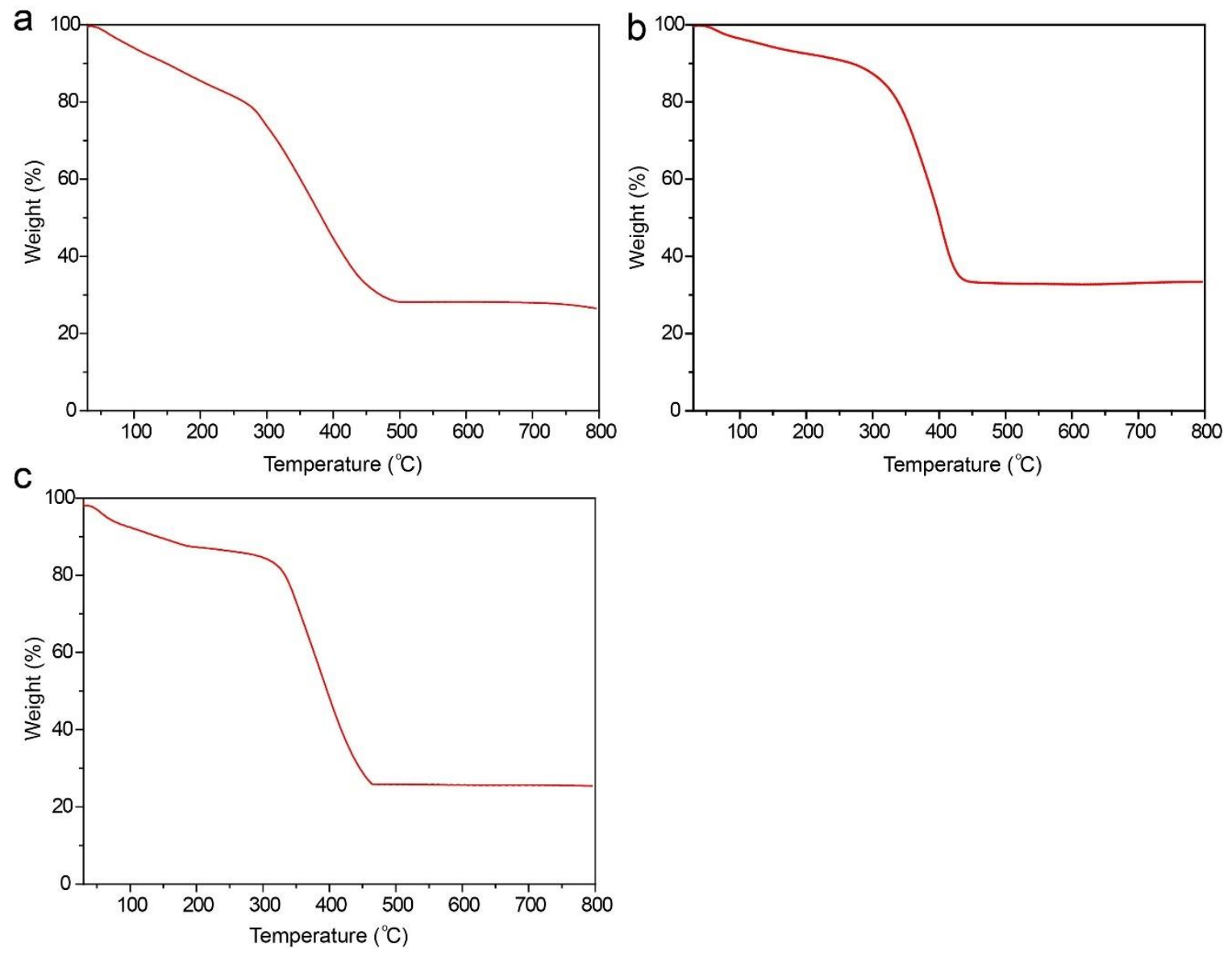

Figure S31. TGA plot of (a) MIL-101, (b) MIL-101-( $\left.\mathrm{NH}_{2}\right)_{0.5}$ and (c) MIL-101-NH 2 . 


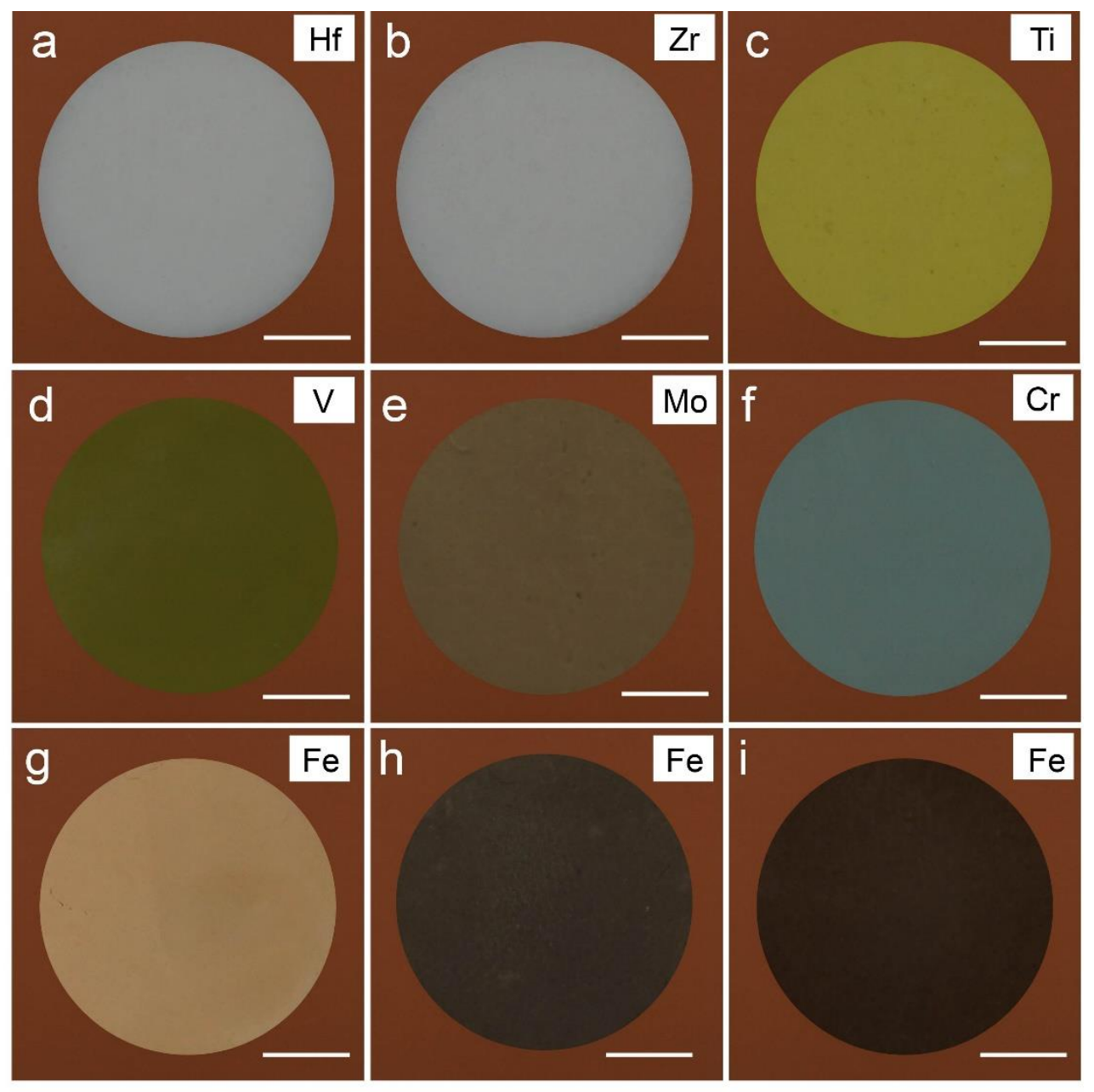

Figure S32. Optic images of MOFs. (a) MOLs containing Hf ions, (b) UMCM-309a containing $\mathrm{Zr}$ ions, (c) $\mathrm{NH}_{2}$-MIL-125 containing Ti ions, (d) MIL-47 containing V ions, (e) TUDMOF-1 containing Mo ions, (f) MIL-53 containing Cr ions, (g) MIL-101 containing Fe ions, (h) MIL-101-( $\left.\mathrm{NH}_{2}\right)_{0.5}$ containing Fe ions and (i) MIL-101- $\mathrm{NH}_{2}$ containing Fe ions. Scale bar is $5 \mathrm{~mm}$ in (a-i). 

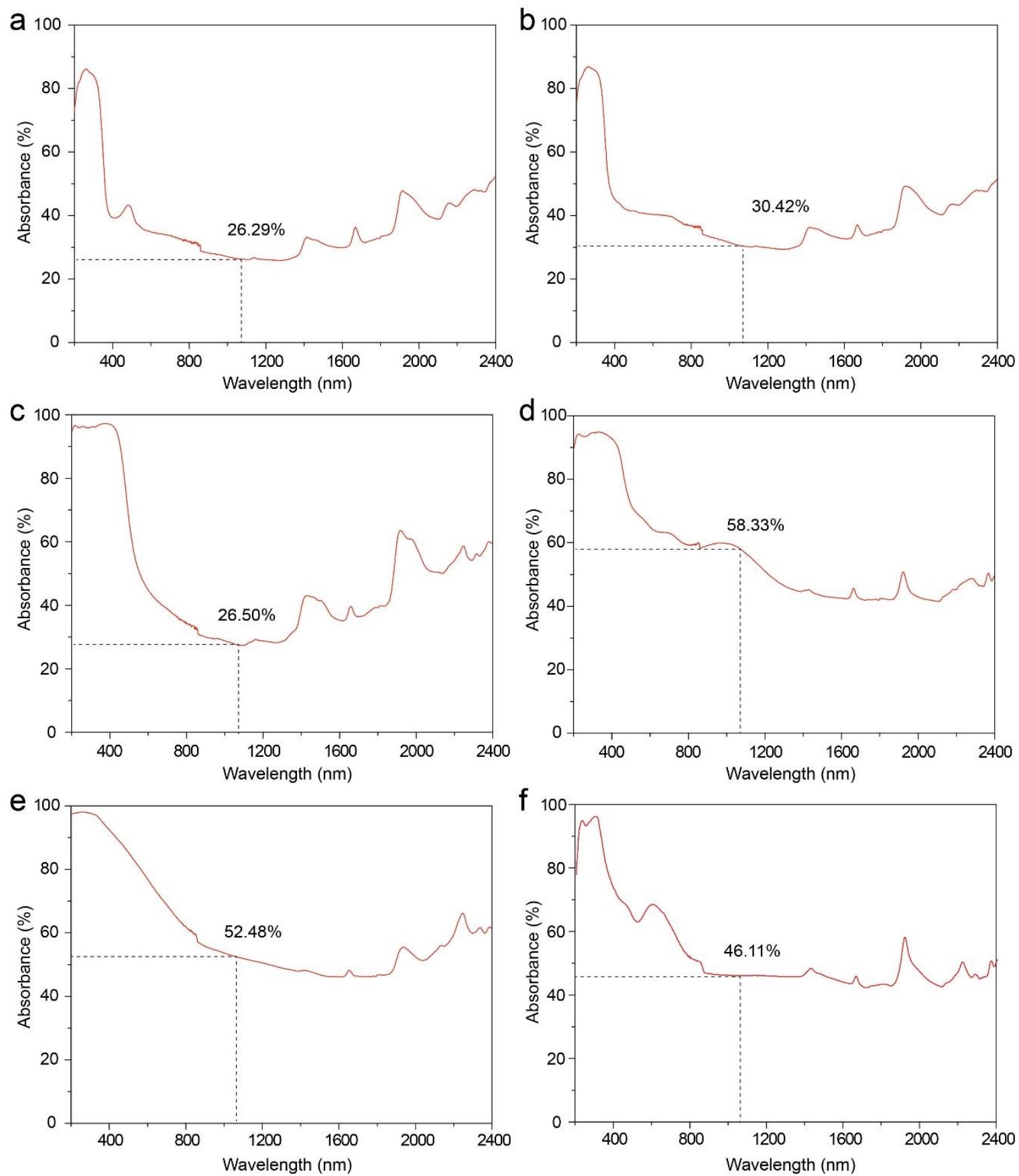

Figure S33. UV-Vis-NIR absorption spectrums of (a) MOLs, (b) UMCM-309a, (c) $\mathrm{NH}_{2}$ MIL-125, (d) MIL-47, (e) TUDMOF-1 and (f) MIL-53. 

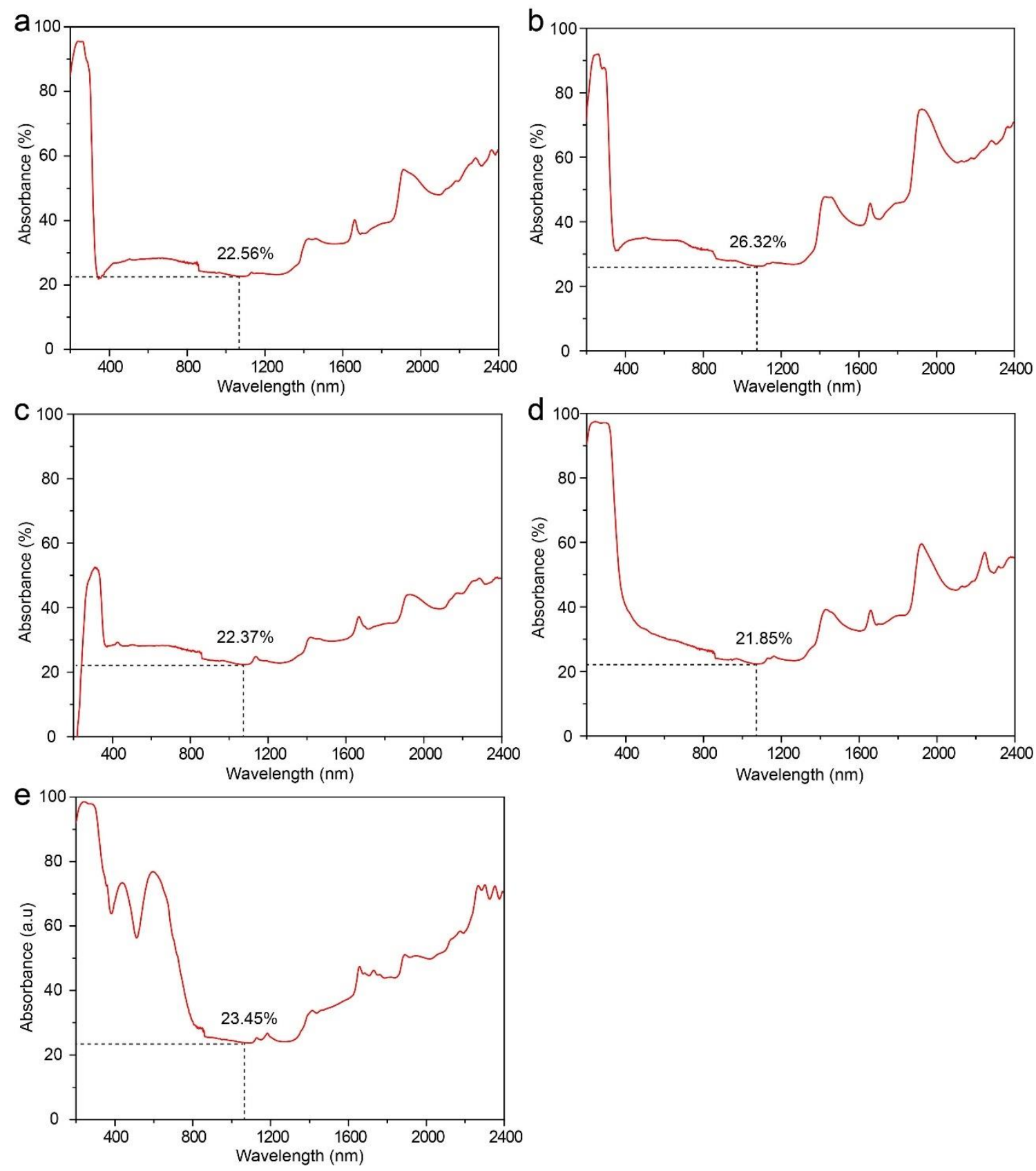

Figure S34. UV-Vis-NIR absorption spectrums of (a) UiO-66 containing Zr ions, (b) UiO66 containing Hf ions, (c) UiO-67 containing Zr ions, (d) MIL-125 containing Ti ions and (e) MIL-101 containing Cr ions. 

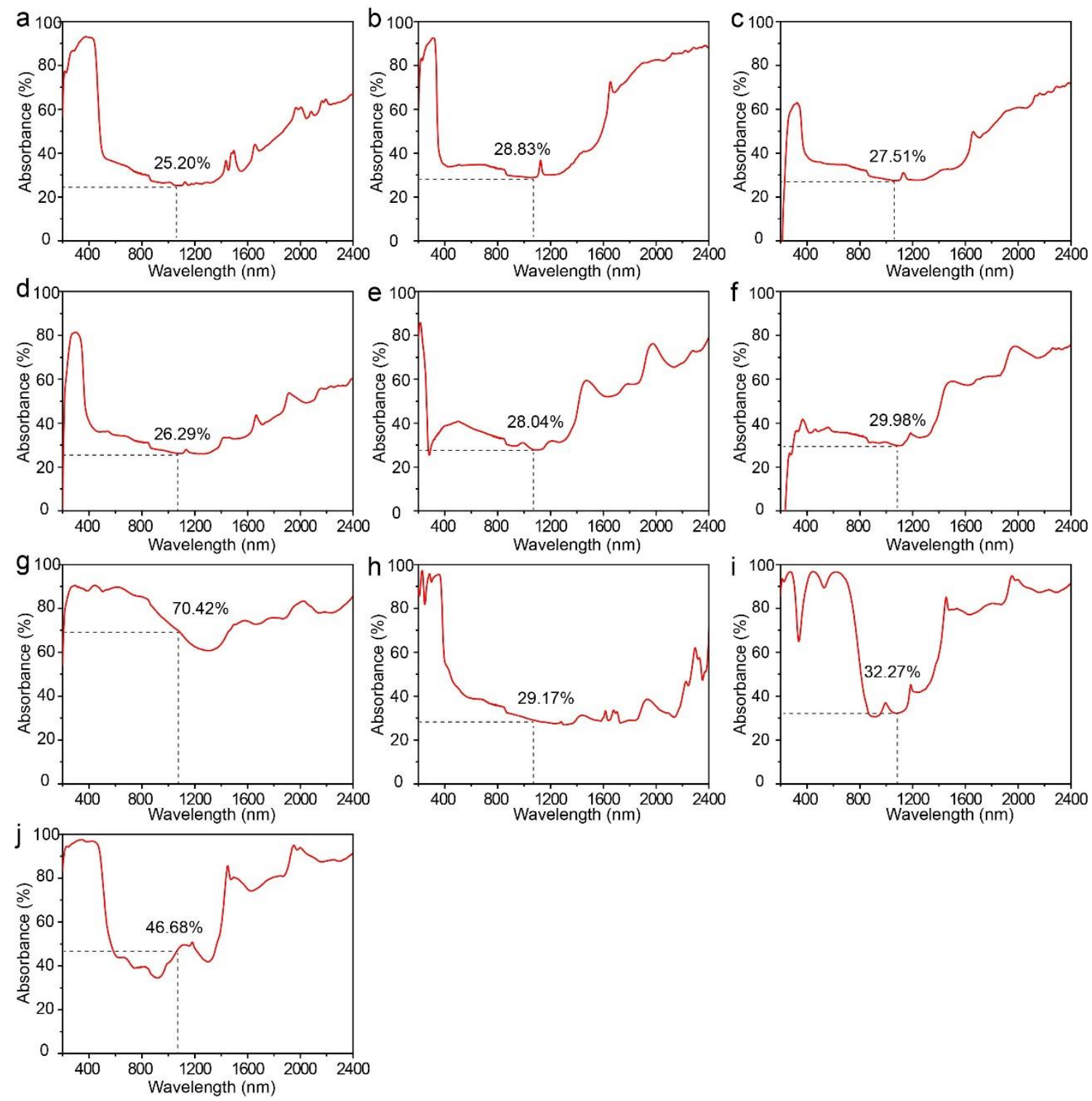

Figure S35. UV-Vis-NIR absorption spectrums of organic linkers and metal salts. (a) BDC, (b) $\mathrm{NH}_{2}-\mathrm{BDC}$, (c) $\mathrm{BPDC}$, (d) $\mathrm{BTB}$, (e) $\mathrm{ZrCl}_{4}$, (f) $\mathrm{HfCl}_{4}$, (g) $\mathrm{VCl}_{3}$, (h) $\mathrm{Mo}(\mathrm{CO})_{6}$, (i) $\mathrm{CrCl}_{3} \cdot 6 \mathrm{H}_{2} \mathrm{O}$ and (j) $\mathrm{FeCl}_{3} \cdot 6 \mathrm{H}_{2} \mathrm{O}$. 

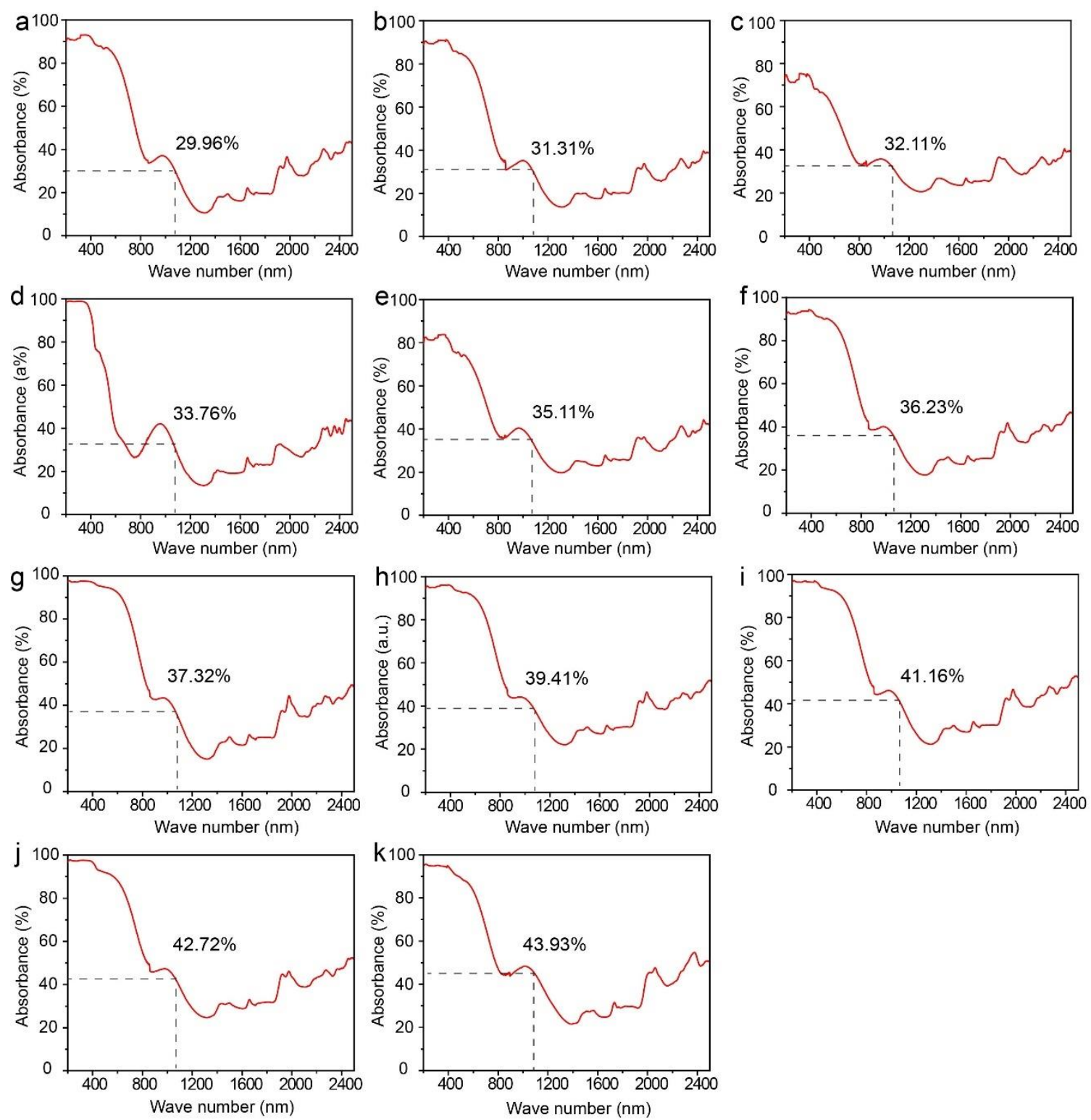

Figure S36. UV-Vis-NIR absorption spectrums of MIL-101-( $\left.\mathrm{NH}_{2}\right)_{x}$. $x$ represent the molar ratio of organic linker $\mathrm{NH}_{2}-\mathrm{BDC} / \mathrm{BDC}$, and $x$ value from a to $\mathrm{k}$ is $0,0.1,0.2,0.3,0.4,0.5$, $0.6,0.7,0.8,0.9$ and 1.0 , respectively. 


\section{Section S3. Characterization of the synthesized TMC nanoparticles}

In order to identify the significance of MOF precursors, a series of control experiments were performed by using different samples as precursor. $\mathrm{HfCl}_{4}$ displayed higher laser absorption, but no change was observed after laser. While organic linker BTB turned little black after laser treatment. Laser scribing of physical mixture of $\mathrm{HfCl}_{4}$ and BTB resulted in carbonization, and white mixture turned to black (Fig. S37), however, the product was $\mathrm{HfO}_{2}$ instead of $\mathrm{HfC}$ which was confirmed by PXRD (Fig. S49). The atomically dispersed metal ions and carbon in MOF backbone makes it an ideal candidate for the synthesis of TMC nanoparticles by laser metallurgy.

In fact, we have tried many other MOFs for the synthesis of TMCs. The light absorptivity has significant impact on the conversion of MOF to TMC. $\mathrm{Zr}$ containing MOFs, UiO-66(Zr) and UiO-67(Zr) displayed low light absorptivity of $22.56 \%$ and $22.37 \%$, respectively, at wavelength of $1064 \mathrm{~nm}$. UiO-66(Zr) and UiO-67(Zr) could not converted to TMC completely even at high laser power of $9 \mathrm{w}$, this phenomenon could also be observed in Hf containing MOFs, UiO-66(Hf). In contrast, MOLs and UMCM309a could converted to TMC at low laser power of $6 \mathrm{w}$ (Fig. S38). As for Ti containing MOFs, MIL-125 showed low light absorptivity compared with $\mathrm{NH}_{2}$-MIL-125, so much higher laser power was required for the fully conversion to TMC for MIL-125 (Fig. S39). At the same time, MIL-53 displayed high light absorptivity of $46.11 \%$, which is twice of that for MIL-101, so it was difficult for MIL-101 to converted to TMC even at laser power of 10 w (Fig. S40).

Different methods were used for the characterization of the synthesized TMC nanoparticles. Firstly, PXRD was used to confirm the phase purity of laser induced TMC nanoparticles from MOF. All of the synthesized TMCs show identical patterns with the reported indexes and no peaks of impurity were observed (Fig. S41-S48), suggesting the phase purity of the obtained TMCs. SEM images, EDS mappings and BSE images were

collected from a field emitting scanning microscope (Verious460, FEI) without spurting conductive agent on the surface of the TMCs. Low magnification SEM images showed that $\mathrm{HfC}$ and $\mathrm{ZrC}$ products maintained the original outline of $\mathrm{MOF}$ precursors after laser irradiation, while ultra-small $\mathrm{HfC}$ and $\mathrm{ZrC}$ nanoparticles were observed homogeneously 
dispersed on the surface of the structures (Fig. S52a, S54a). TiC, $\mathrm{V}_{8} \mathrm{C}_{7}, \alpha-\mathrm{MoC}$ and $\mathrm{Cr}_{3} \mathrm{C}_{2}$ nanoparticles were found uniformly distributed on the porous spheres (Fig. S57a, S59a, S61a and S63a). BSE images clearly featured the signals from HfC nanoparticles from the atomic number difference between Hf and C (Fig. S51). The overlay of BSE and SE images reveal thin graphene layers on the surface of TMC nanoparticles. The EDS mappings of the corresponding meals and carbon indicated that the TMC nanoparticles were homogeneously dispersed. TEM images further reveals that uniform and small TMC nanoparticles were formed across the carbon support. The successful formation of TMC nanoparticles was confirmed by the well-matched the lattice fringe distance with the characteristic facets of TMC. In addition, few-layered graphene was observed on the surface of these TMC nanoparticles (Fig. S52c, S54c, S57c, S59c, S61c and S63c). The formation of few-layered graphene was also confirmed by the appearance of peak at wavelength number of $2700 \mathrm{~cm}^{-1}$ in Raman spectrums, assigning to 2D band of graphene (Fig. S78, S79). After laser irradiation, we used XPS to confirm the reduction of metal ions in MOF. The corresponding spectra of metals matched well with the reported value of metals in zero-valent state. We also found that the peak assigning to $\mathrm{C}=\mathrm{O}$ bond were disappeared after laser irradiation, revealing that oxygen was consumed during laser metallurgy. For $\mathrm{FeC}_{x}$ nanoparticles, we found that the laser power played an important role for the metal reduction. At relatively low laser power, the two peaks at $720.7 \mathrm{eV}$ and 707.5 $\mathrm{eV}$ found, assigning to $\mathrm{Fe}^{0}$. In addition, two peaks at $724.9 \mathrm{eV}$ and $711.5 \mathrm{eV}$ in $\mathrm{Fe} 2 \mathrm{p}$ spectrum assigning to iron oxide were also observed, suggesting that oxygen was not completely consumed at this low laser power (Fig. S75f, S76f). When increased the laser power to $7 \mathrm{w}$, no peaks assigning to iron oxides could be observed, indicating that all metal ions were reduced during laser metallurgy. $\mathrm{N}_{2}$ adsorption isotherms was used to reveal the permanent porosity of the obtained TMCs. High BET surface areas ranging from 50 to 235 $\mathrm{m}^{2} \mathrm{~g}^{-1}$ were observed, indicating their porous nature. TGA was used to identify the TMC content in the product. The TGA curves were tested in air, so the residuals were metal oxides. Specifically, $\mathrm{HfO}_{2}, \mathrm{ZrO}_{2}, \mathrm{TiO}_{2}, \mathrm{~V}_{2} \mathrm{O}_{5}, \mathrm{MoO}_{3}$, and $\mathrm{Cr}_{2} \mathrm{O}_{3}$ were occupying weight percentages of $70.2 \%, 76.4 \%, 76.0 \%, 82.5 \%$, and 79.6\%, respectively (Fig. S80). Based on this, the weight percent of TMC nanoparticles were calculated to be $63.50 \%$ for $\mathrm{HfC}$, $64.0 \%$ for $\mathrm{ZrC}, 57.0 \%$ for $\mathrm{TiC}, 55.7 \%$ for $\mathrm{V}_{8} \mathrm{C}_{7}, 60.7 \%$ for $\alpha-\mathrm{MoC}$ and $62.9 \%$ for $\mathrm{Cr}_{3} \mathrm{C}_{2}$. 

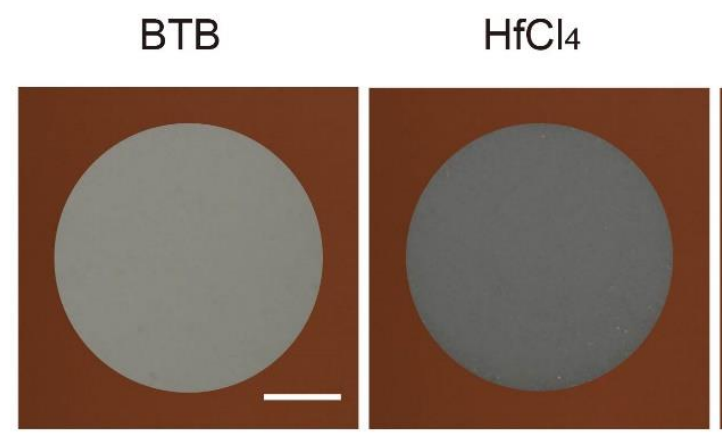

$\mathrm{HfCl}_{4}+\mathrm{BTB}$

MOLs
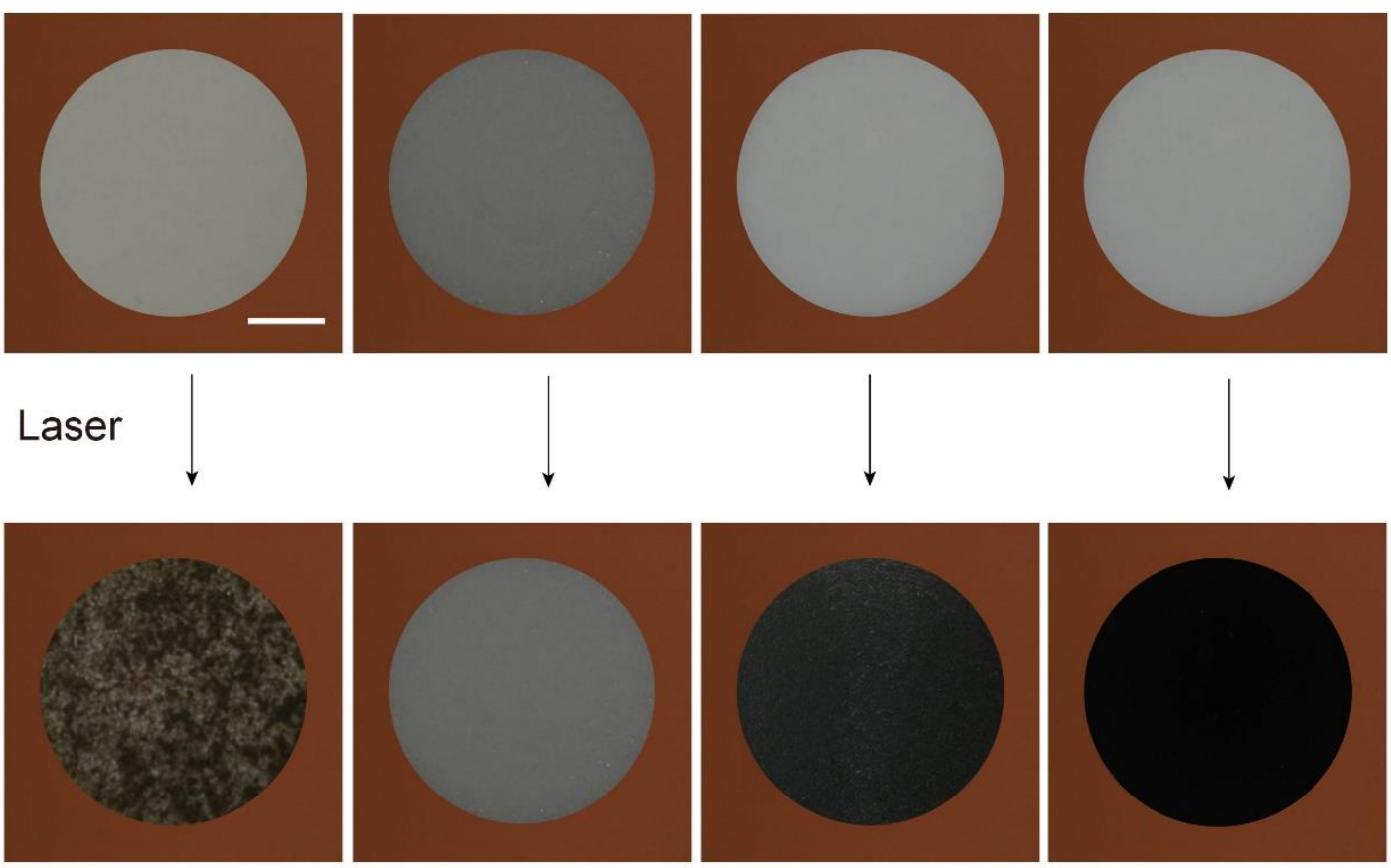

Figure S37. Optical images of BTB, $\mathrm{HfCl}_{4}$, physical mixture of $\mathrm{HfCl}_{4}$ and $\mathrm{BTB}$, and MOLs powder samples scribed by laser at power of $6 \mathrm{w}$. Scale bar is $5 \mathrm{~mm}$. 


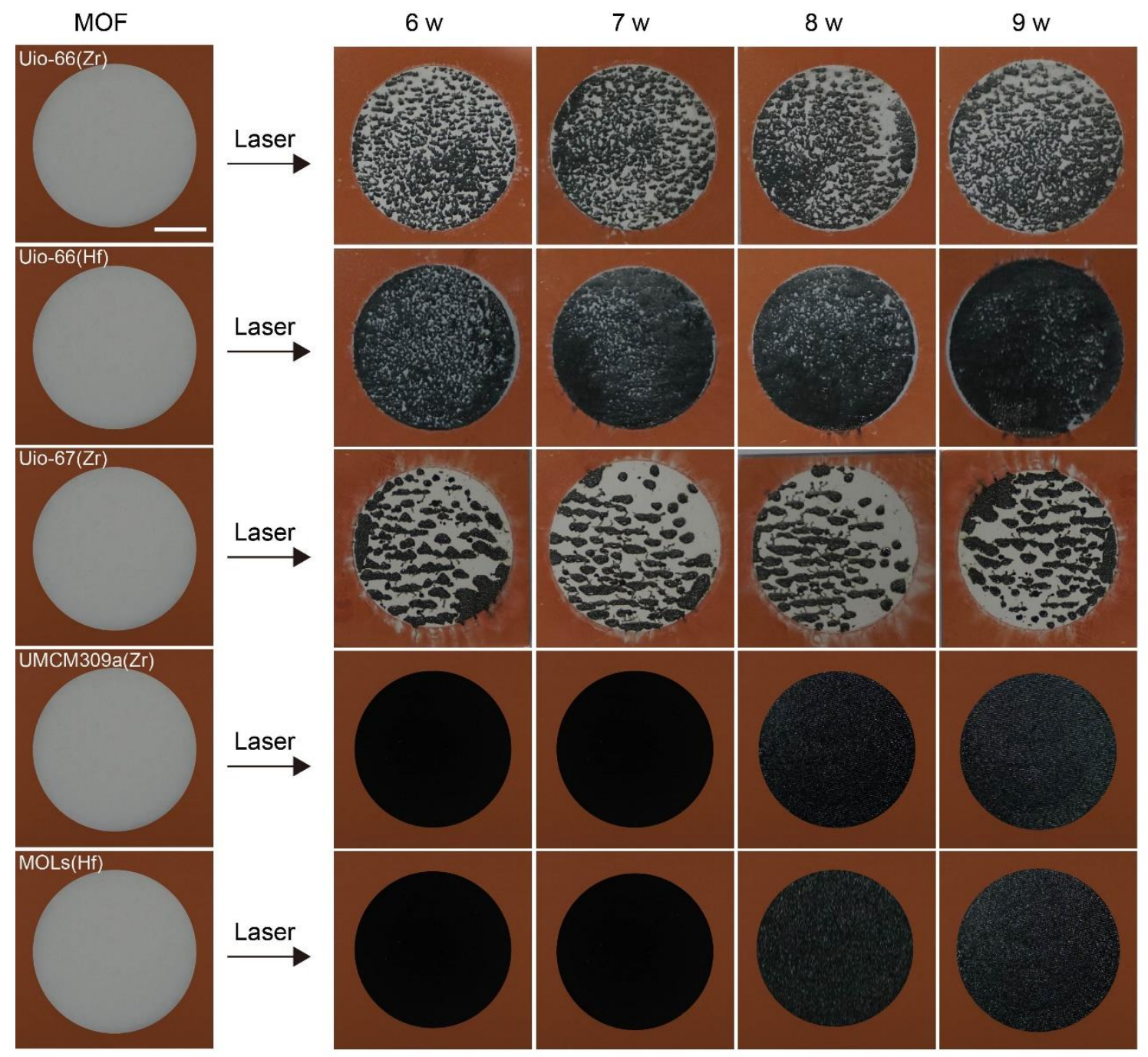

Figure S38. Optical images of UiO-66(Zr), UiO-66(Hf), UiO-67(Zr), UMCM-309a and MOLs powder samples scribed by different laser power. Scale bar is $5 \mathrm{~mm}$. 

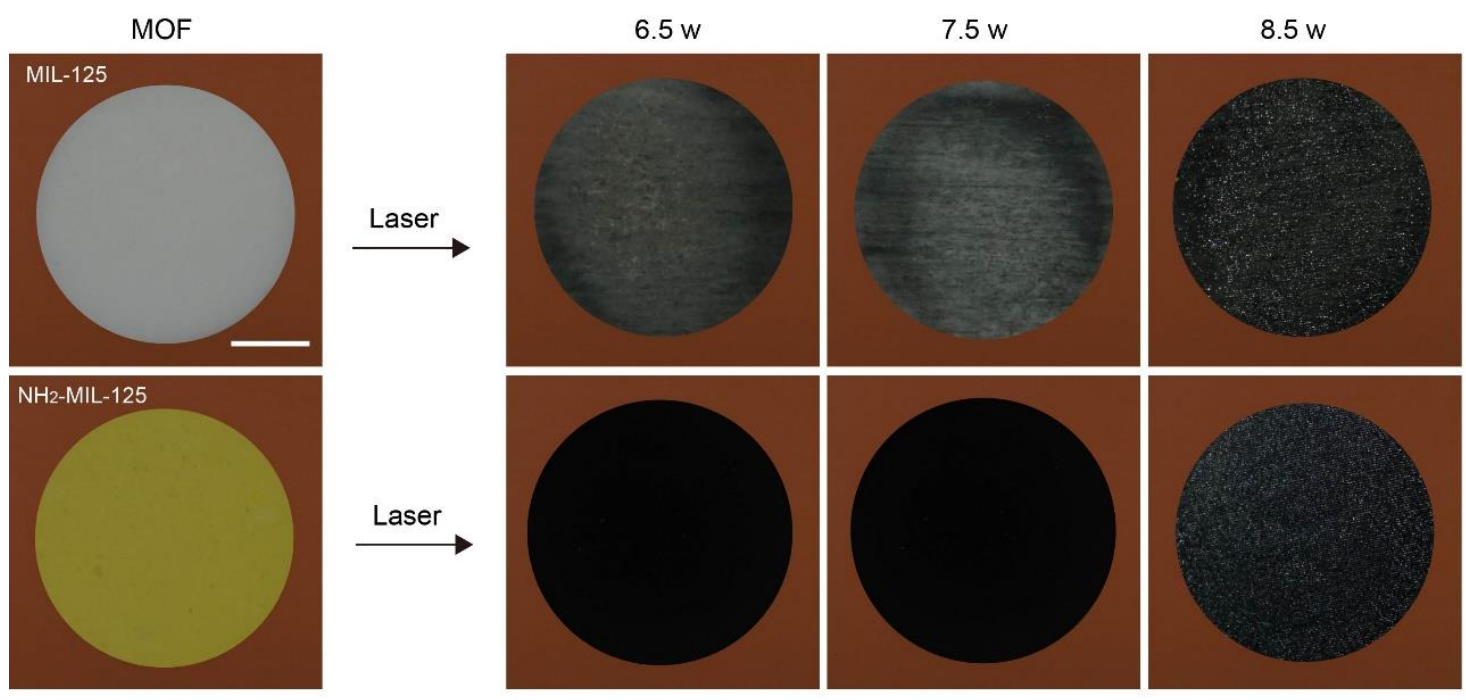

Figure S39. Optical images of Ti containing MOFs, MIL-125 and $\mathrm{NH}_{2}-\mathrm{MIL}-125$ powder samples scribed by different laser power. Scale bar is $5 \mathrm{~mm}$.

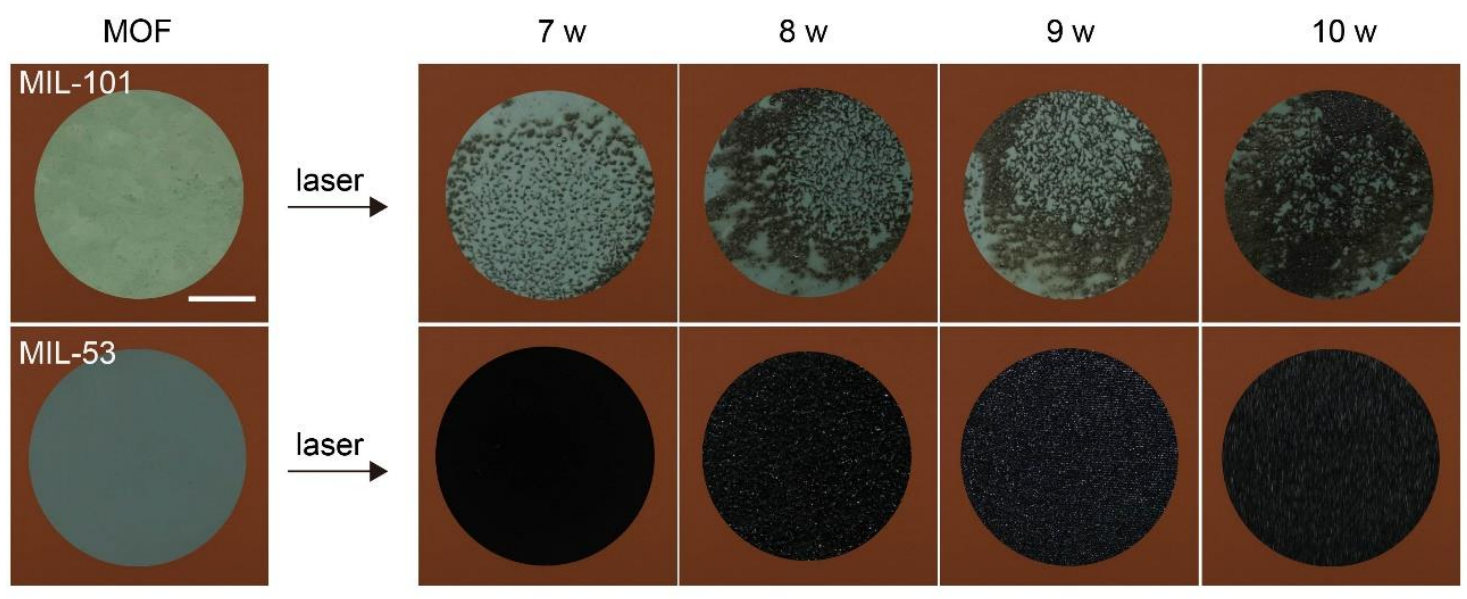

Figure S40. Optical images of Cr containing MOFs, MIL-101 and MIL-53 powder samples scribed by different laser power. Scale bar is $5 \mathrm{~mm}$. 


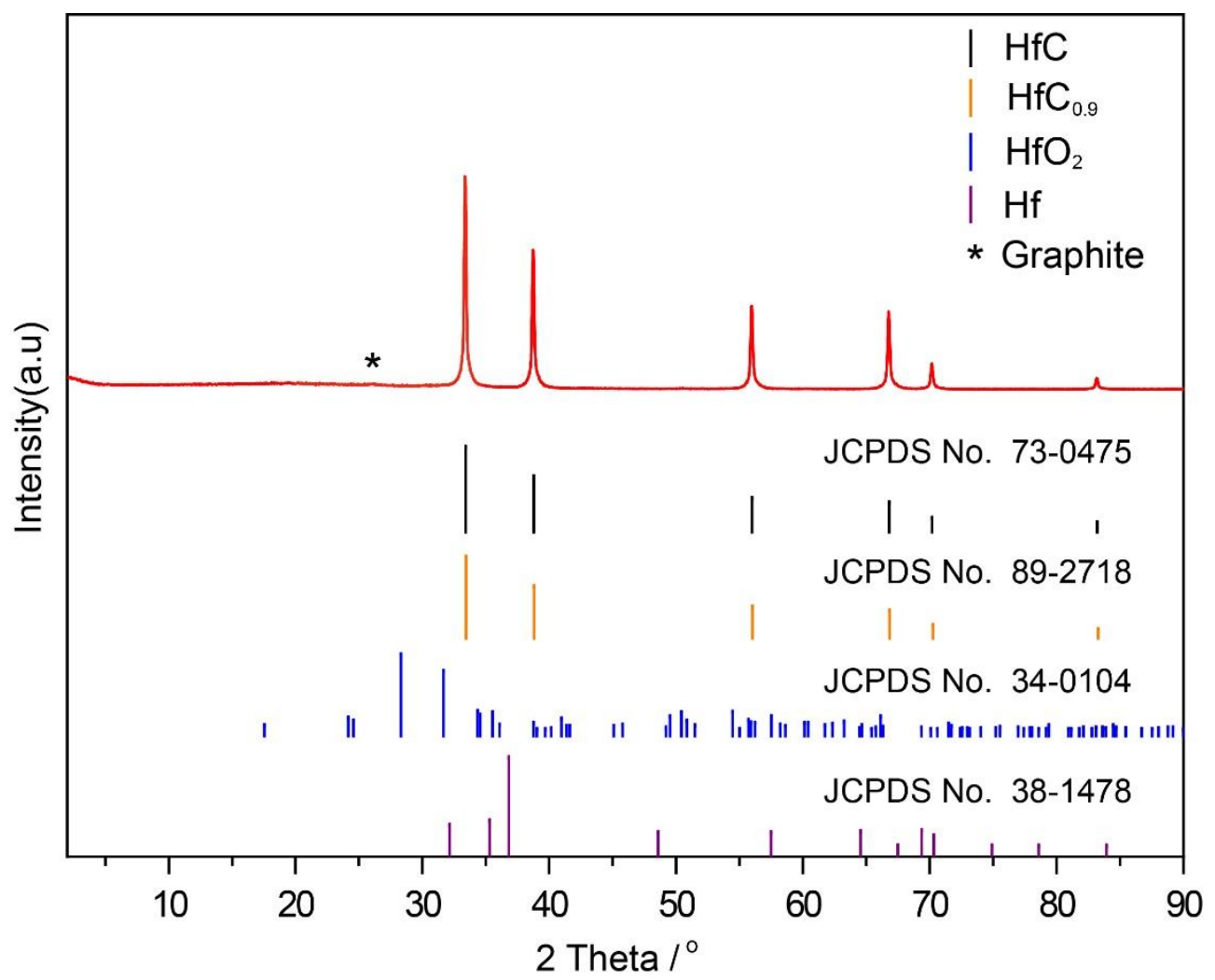

Figure S41. The PXRD patterns of synthesized HfC from corresponding MOLs by laser metallurgy. The obtained HfC nanoparticles show identical PXRD pattern with HfC from JCPDS No. 73-0475. 


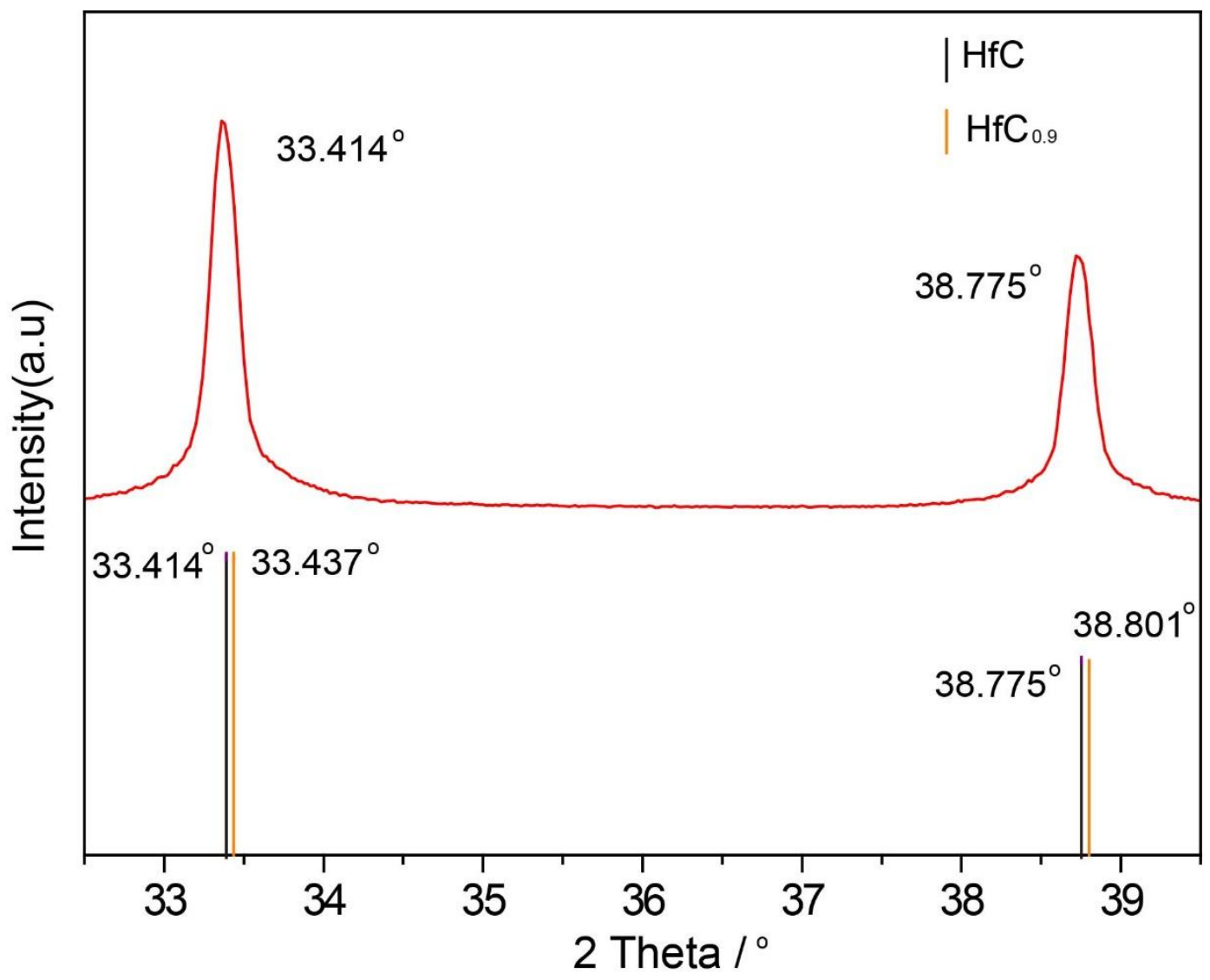

Figure S42. The magnified PXRD patterns of HfC from corresponding MOLs by laser metallurgy from $32.5^{\circ}$ to $39.5^{\circ}$ in Figure S41. 


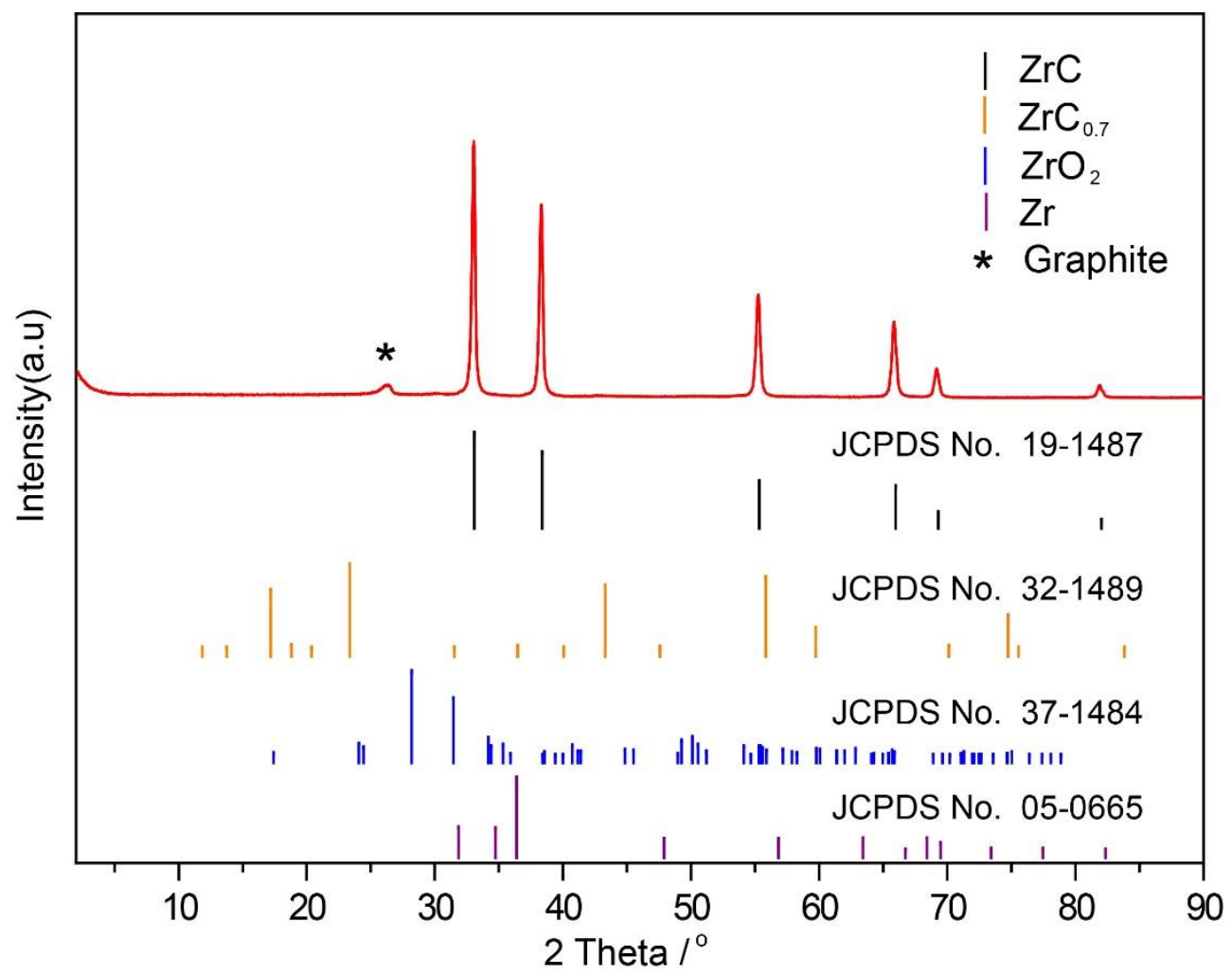

Figure S43. The PXRD patterns of synthesized $\mathrm{ZrC}$ from corresponding UMCM-309a by laser metallurgy. The obtained $\mathrm{ZrC}$ nanoparticles show identical PXRD pattern with the ZrC from JCPDS No. 19-1487. 


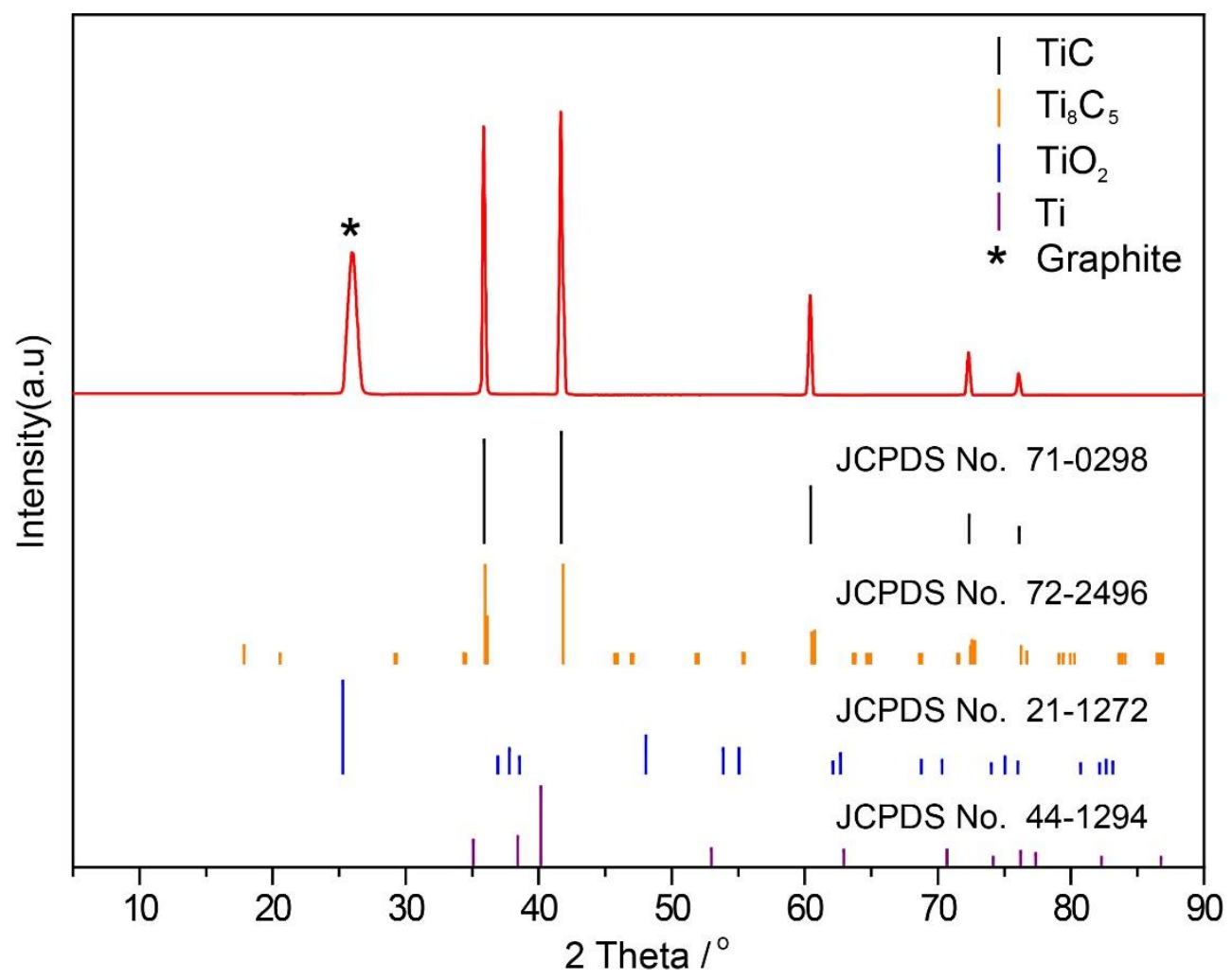

Figure S44. The PXRD patterns of synthesized TiC from corresponding $\mathrm{NH}_{2}-\mathrm{MIL}-125$ by laser metallurgy. The obtained TiC nanoparticles show identical PXRD pattern with TiC from JCPDS No. 71-0298. 


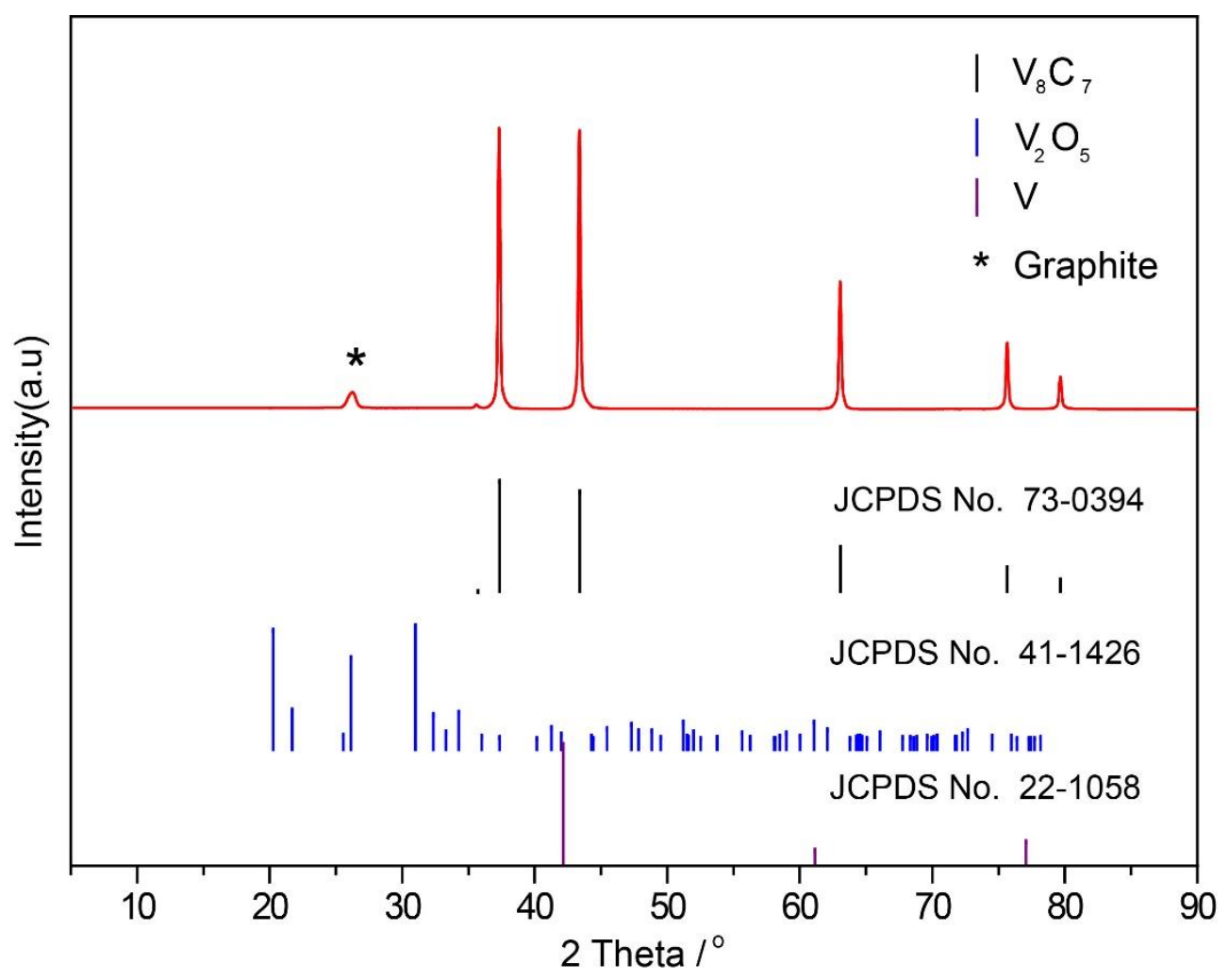

Figure S45. The PXRD patterns of synthesized $\mathrm{V}_{8} \mathrm{C}_{7}$ from corresponding MIL-47 by laser metallurgy. The obtained $\mathrm{V}_{8} \mathrm{C}_{7}$ nanoparticles show identical PXRD pattern with the index $\mathrm{V}_{8} \mathrm{C}_{7}$ from JCPDS No.73-0394. 


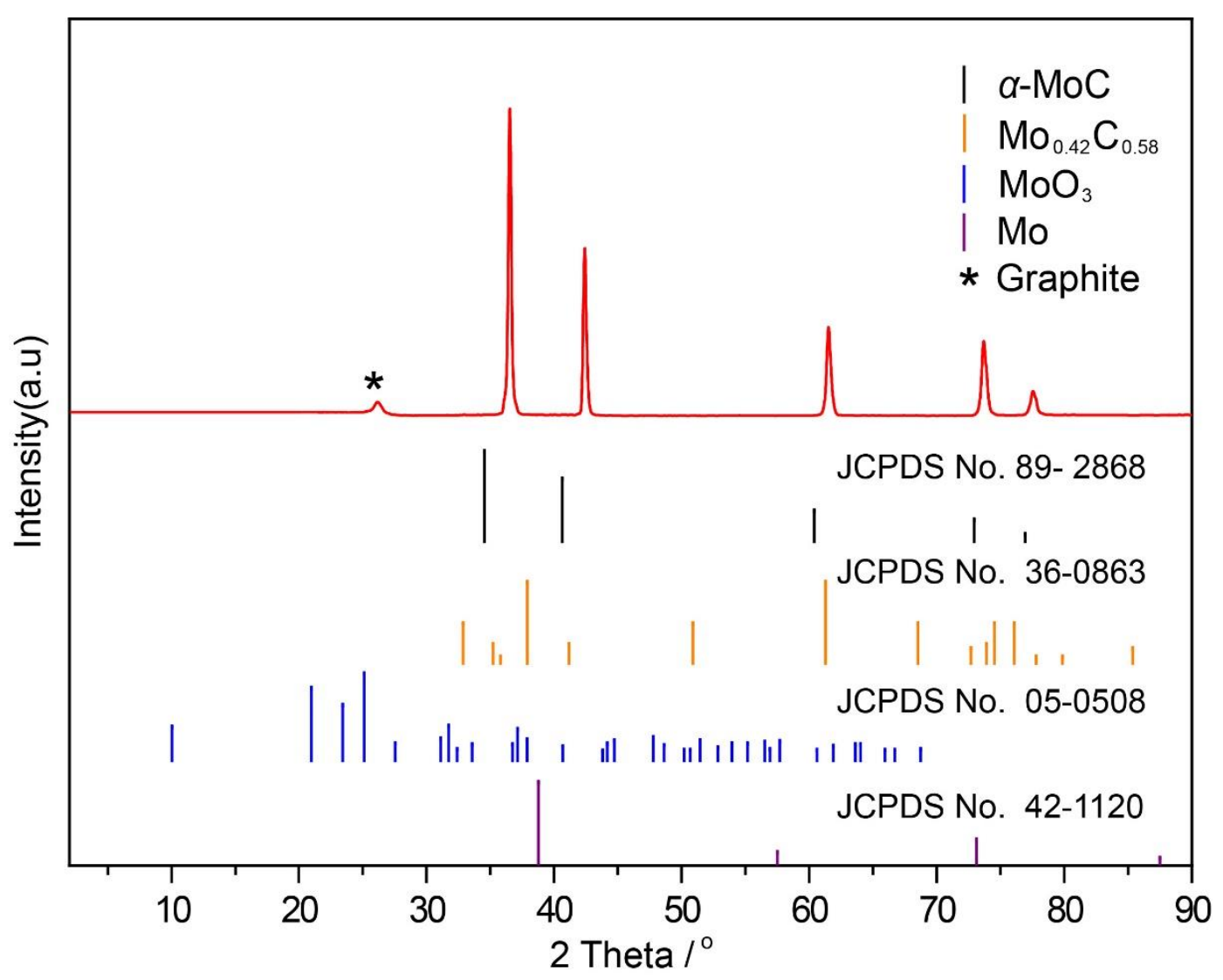

Figure S46. The PXRD patterns of synthesized $\alpha$-MoC from corresponding TUDMOF-1 by laser metallurgy. The obtained $\alpha$-MoC nanoparticles show identical PXRD pattern with $\alpha$-MoC from JCPDS No. 89-2868. 


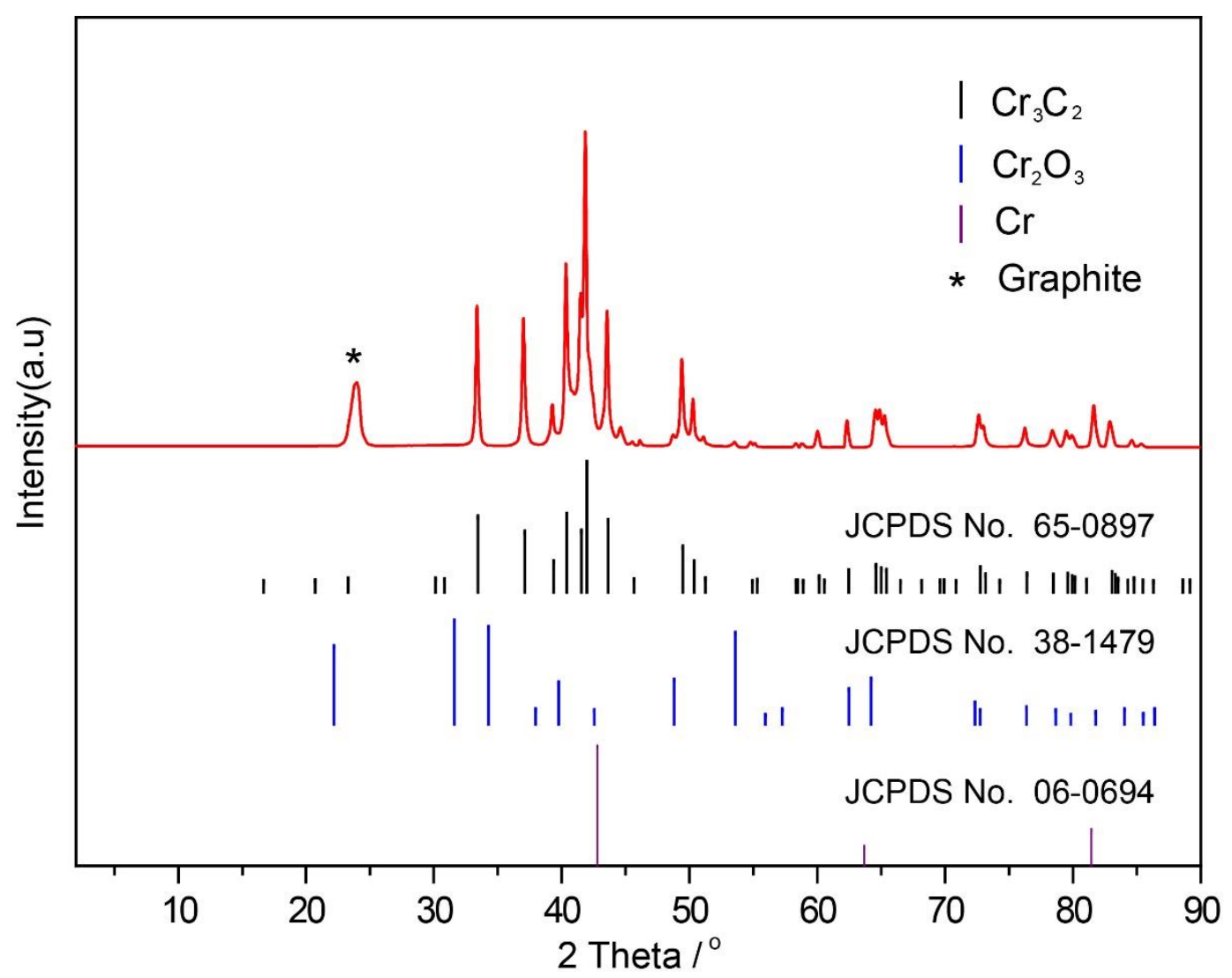

Figure S47. The PXRD patterns of synthesized $\mathrm{Cr}_{3} \mathrm{C}_{2}$ from corresponding MIL-53 by laser metallurgy. The obtained $\mathrm{Cr}_{3} \mathrm{C}_{2}$ nanoparticles show identical PXRD pattern with $\mathrm{Cr}_{3} \mathrm{C}_{2}$ from JCPDS No. 65-0897. 


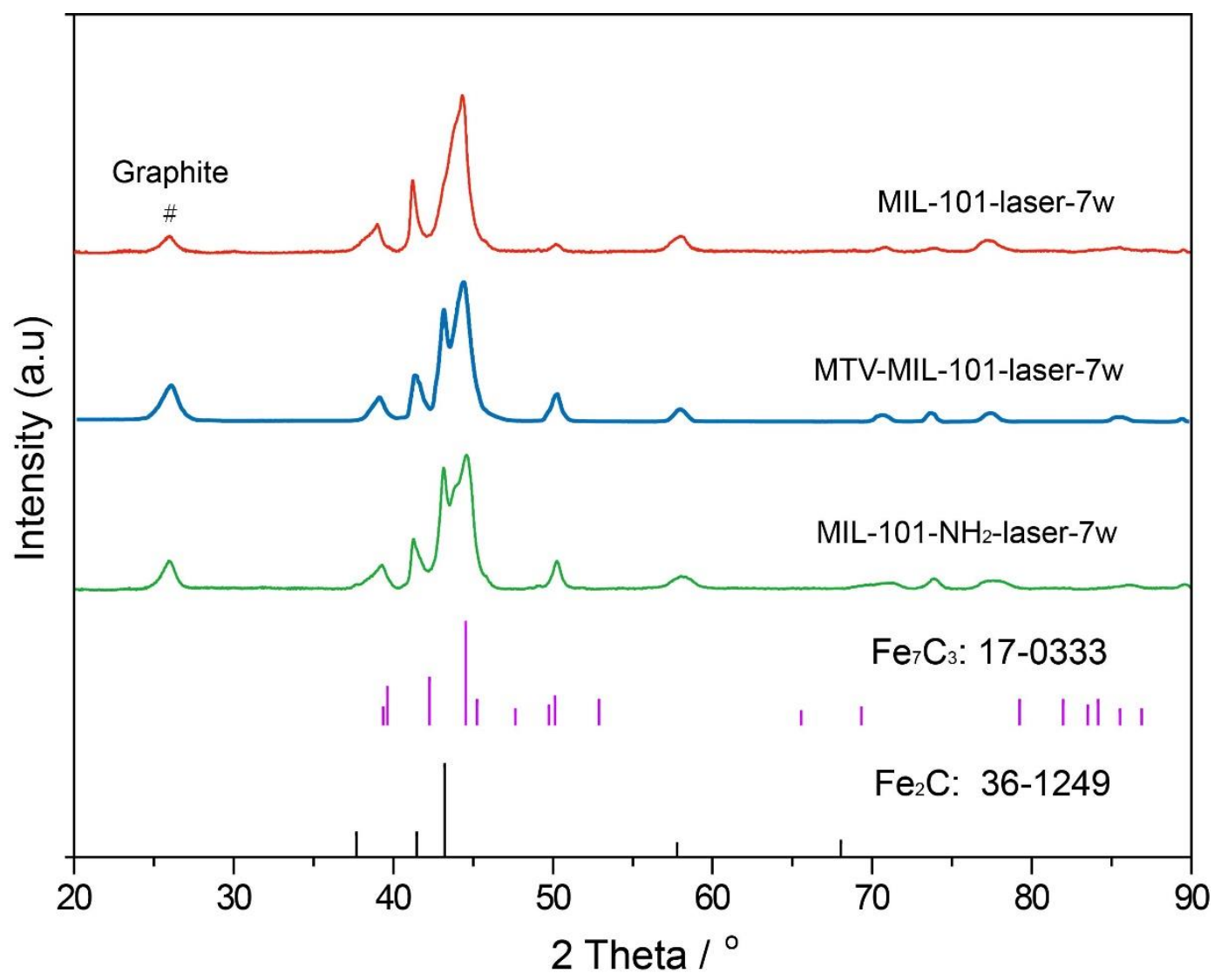

Figure S48. The PXRD patterns of iron carbides from MIL-101, MIL-101-( $\left.\mathrm{NH}_{2}\right)_{0.5}$ and MIL-101- $\mathrm{NH}_{2}$ at laser power of $7 \mathrm{~W}$. 

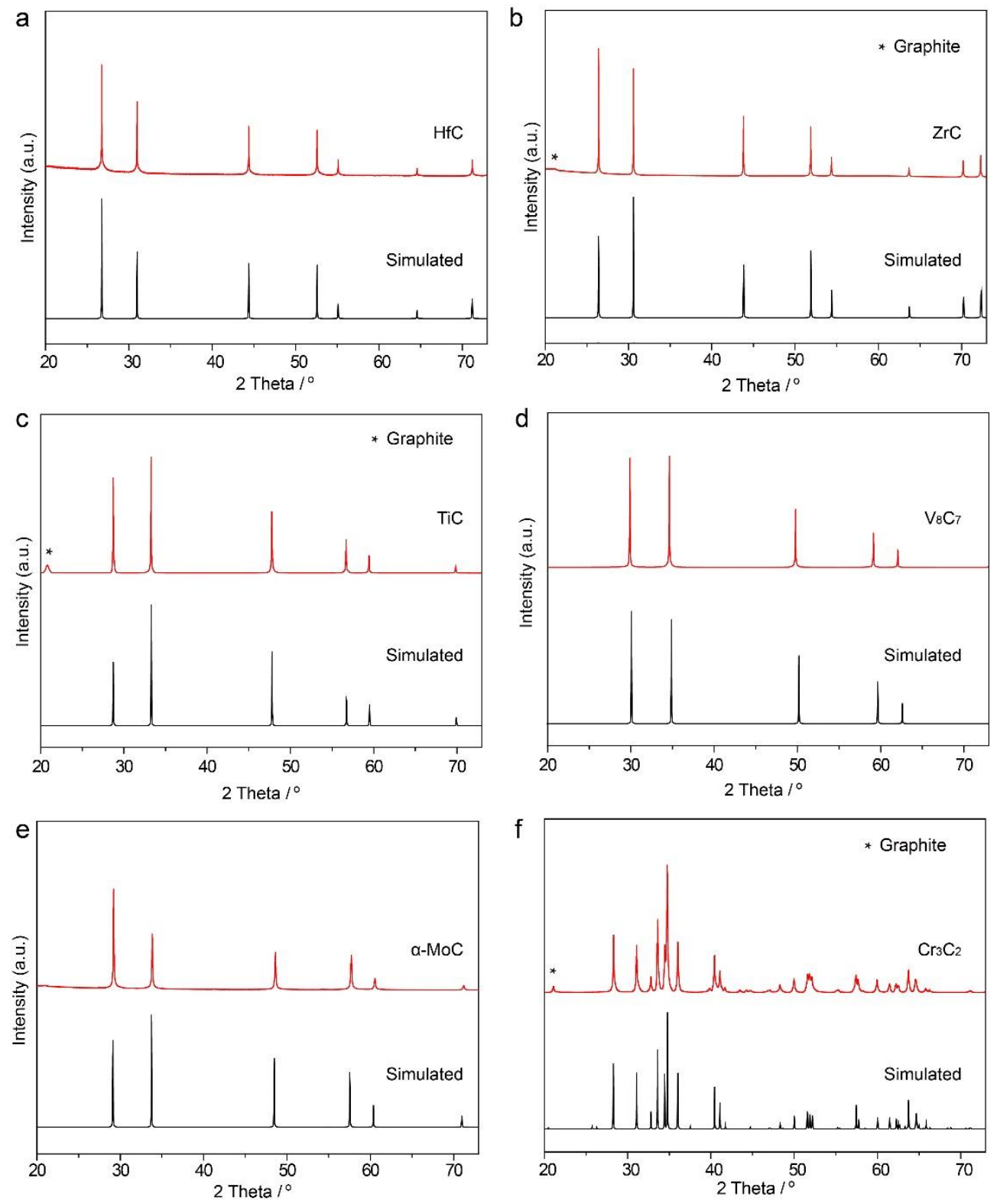

Figure S49. The synchrotron data obtained from Spring- 8 in Japan. $\lambda=1.2398 \AA$. (a) HfC, (b) $\mathrm{ZrC}$, (c) $\mathrm{TiC}$, (d) $\mathrm{V}_{8} \mathrm{C}_{7}$, (e) $\alpha-\mathrm{MoC}$ and (f) $\mathrm{Cr}_{3} \mathrm{C}_{2}$ synthesized by laser metallurgy. 


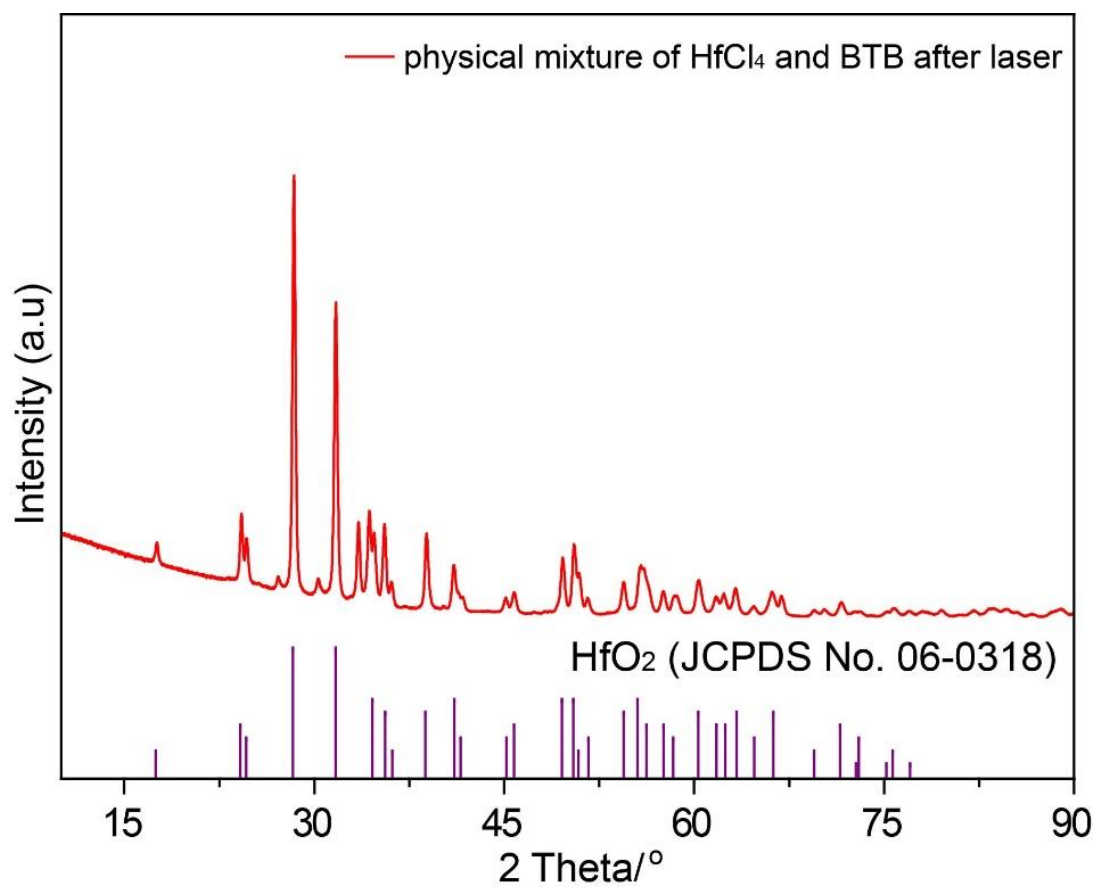

Figure S50. The PXRD pattern of physical mixture of $\mathrm{HfCl}_{4}$ and $\mathrm{BTB}$ after laser irradiation at $6 \mathrm{~W}$. The obtained product was $\mathrm{HfO}_{2}$. 

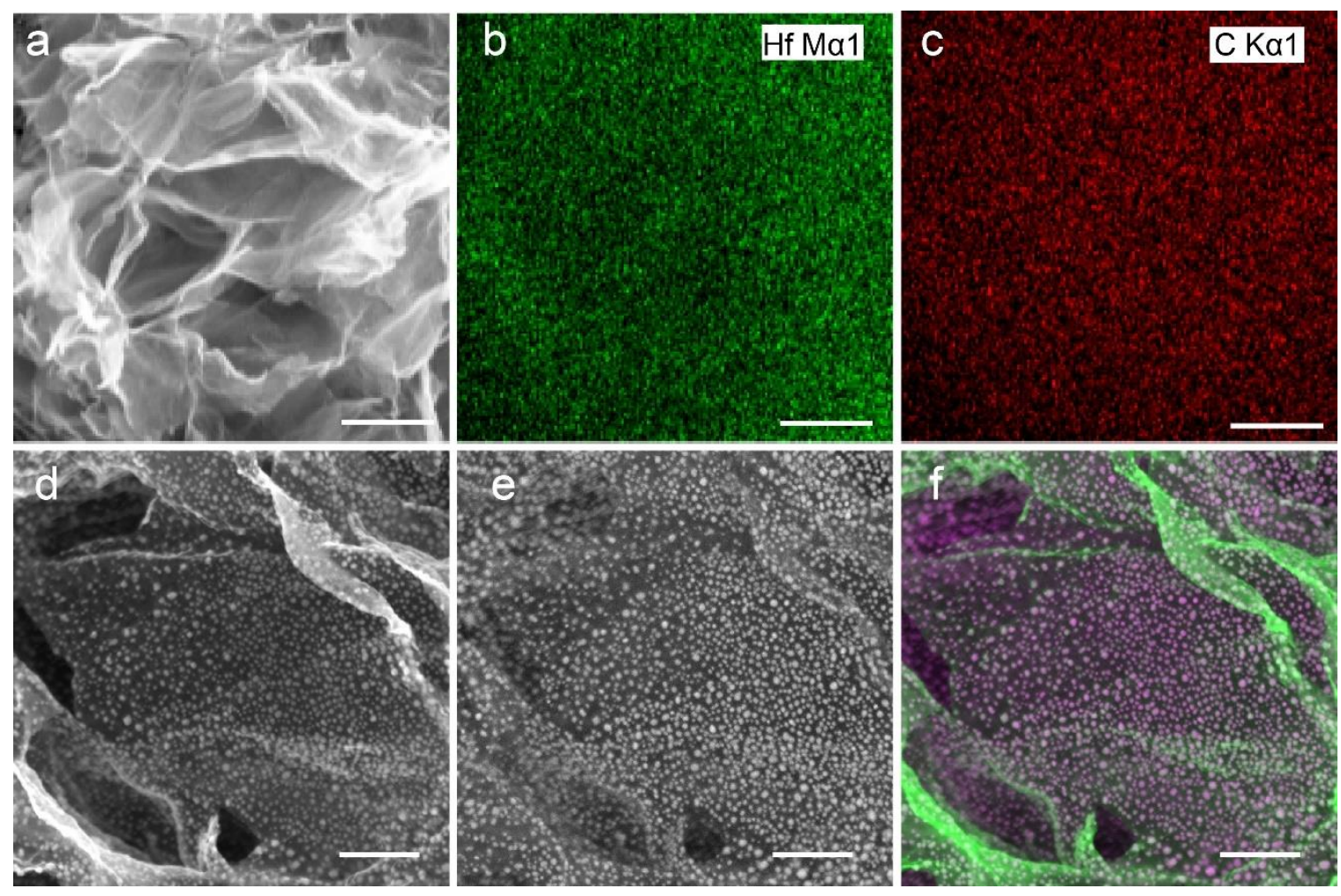

Figure S51. (a) SEM image of HfC and EDS mappings of (b) Hf and (c) C. (d) Secondary electron image, (e) backscatter electron image and (f) mixture of second and backscatter electron signal. Scale bar is $2 \mu \mathrm{m}$ in (a-c) and $100 \mathrm{~nm}$ in (d-f). 

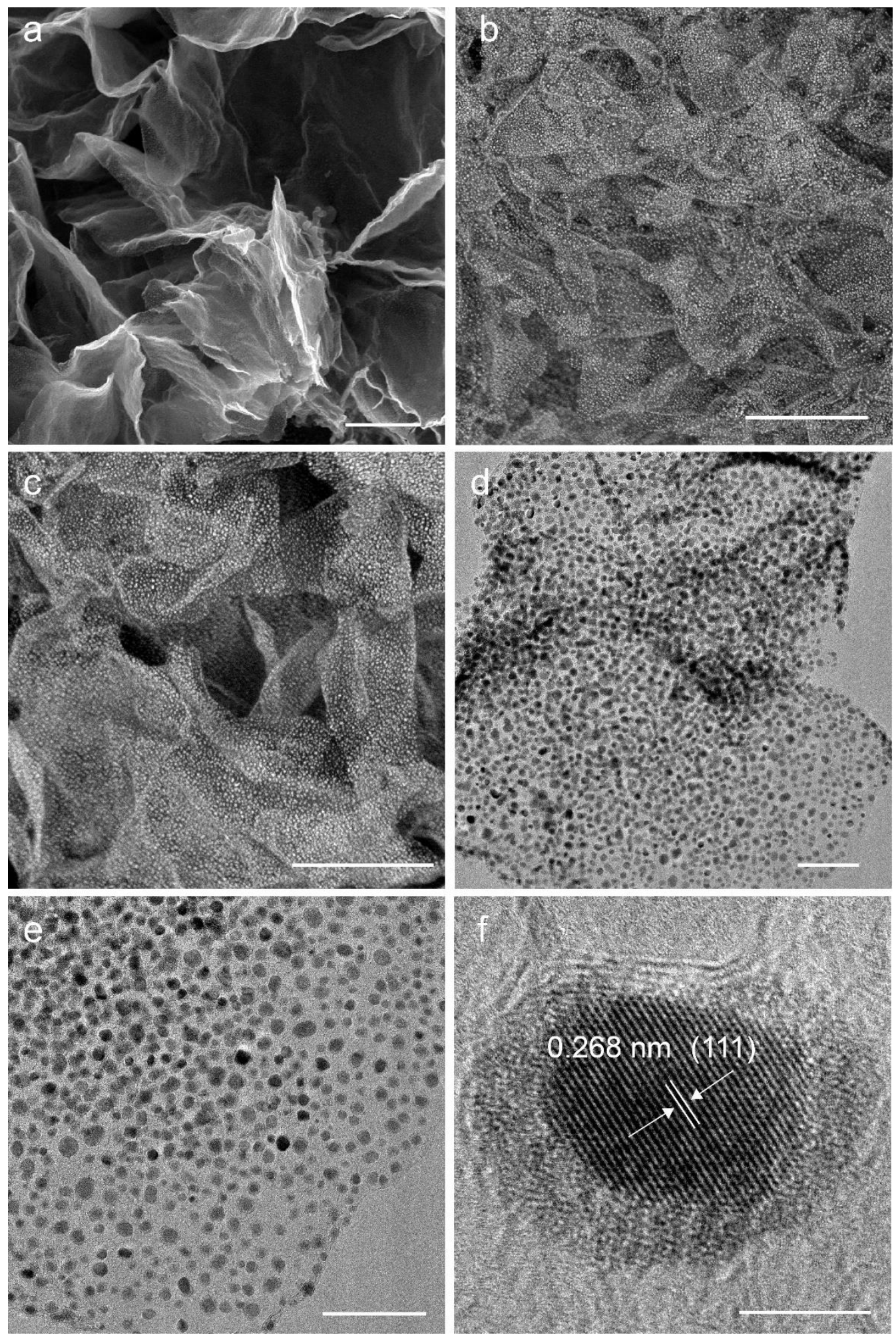

Figure S52. (a-c) SEM images, (d, e) TEM and (f) HRTEM images of HfC nanoparticles.

Scale bar is $500 \mathrm{~nm}$ in (a), $300 \mathrm{~nm}$ in (b, c), $200 \mathrm{~nm}$ in (d, e) and $5 \mathrm{~nm}$ in (f). 


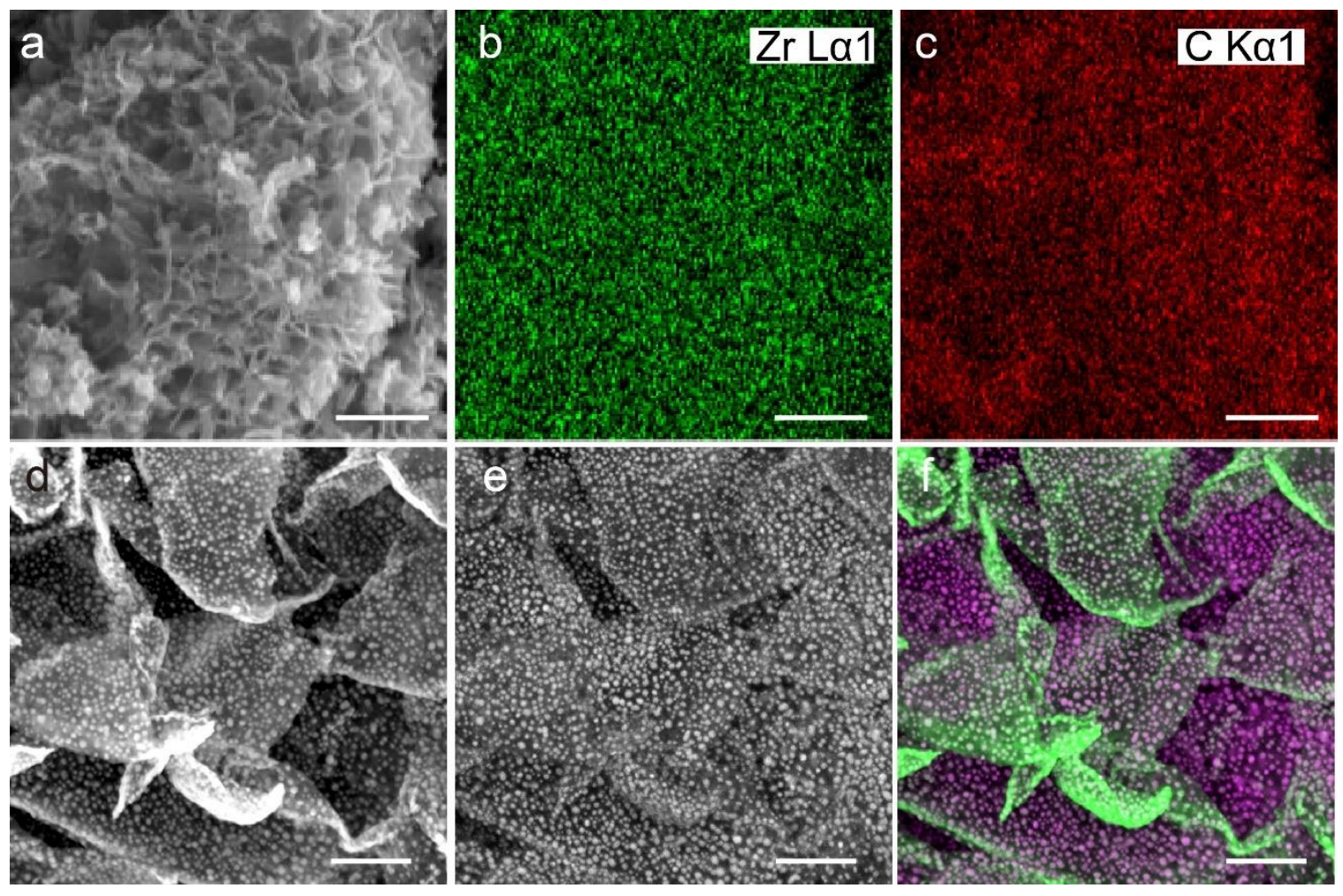

Figure S53. (a) SEM image of $\mathrm{ZrC}$ and EDS mappings of (b) Zr and (c) C. (d) Secondary electron image, (e) backscatter electron image and (f) mixture of second and backscatter electron signal. Scale bar is $5 \mu \mathrm{m}$ in (a-c) and $100 \mathrm{~nm}$ in (d-f). 

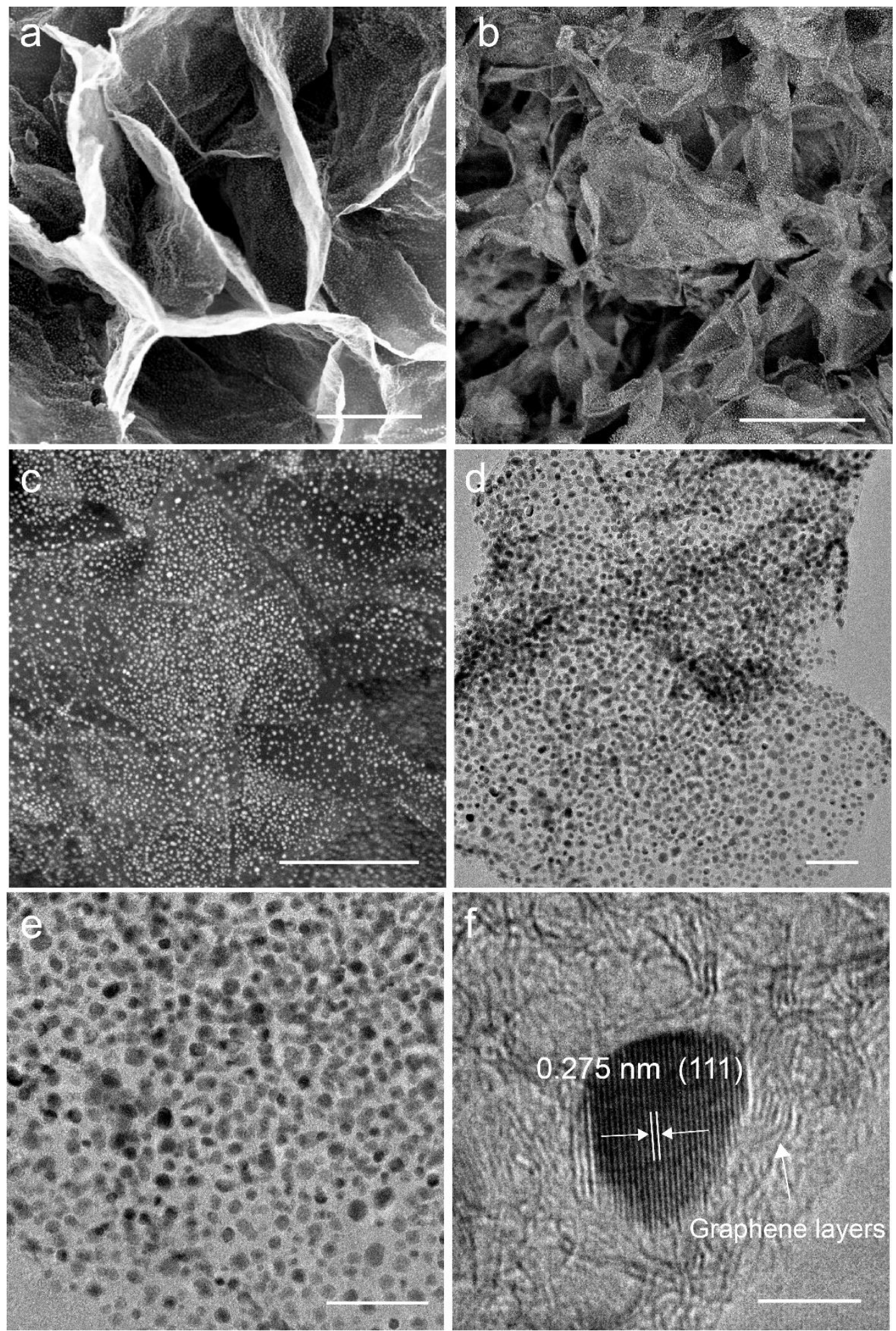

Figure S54. (a-c) SEM images, (d, e) TEM and (f) HRTEM images of ZrC nanoparticles.

Scale bar is $500 \mathrm{~nm}$ in (a, b), $200 \mathrm{~nm}$ in (c), $50 \mathrm{~nm}$ in (d, e), and $5 \mathrm{~nm}$ in (f). 

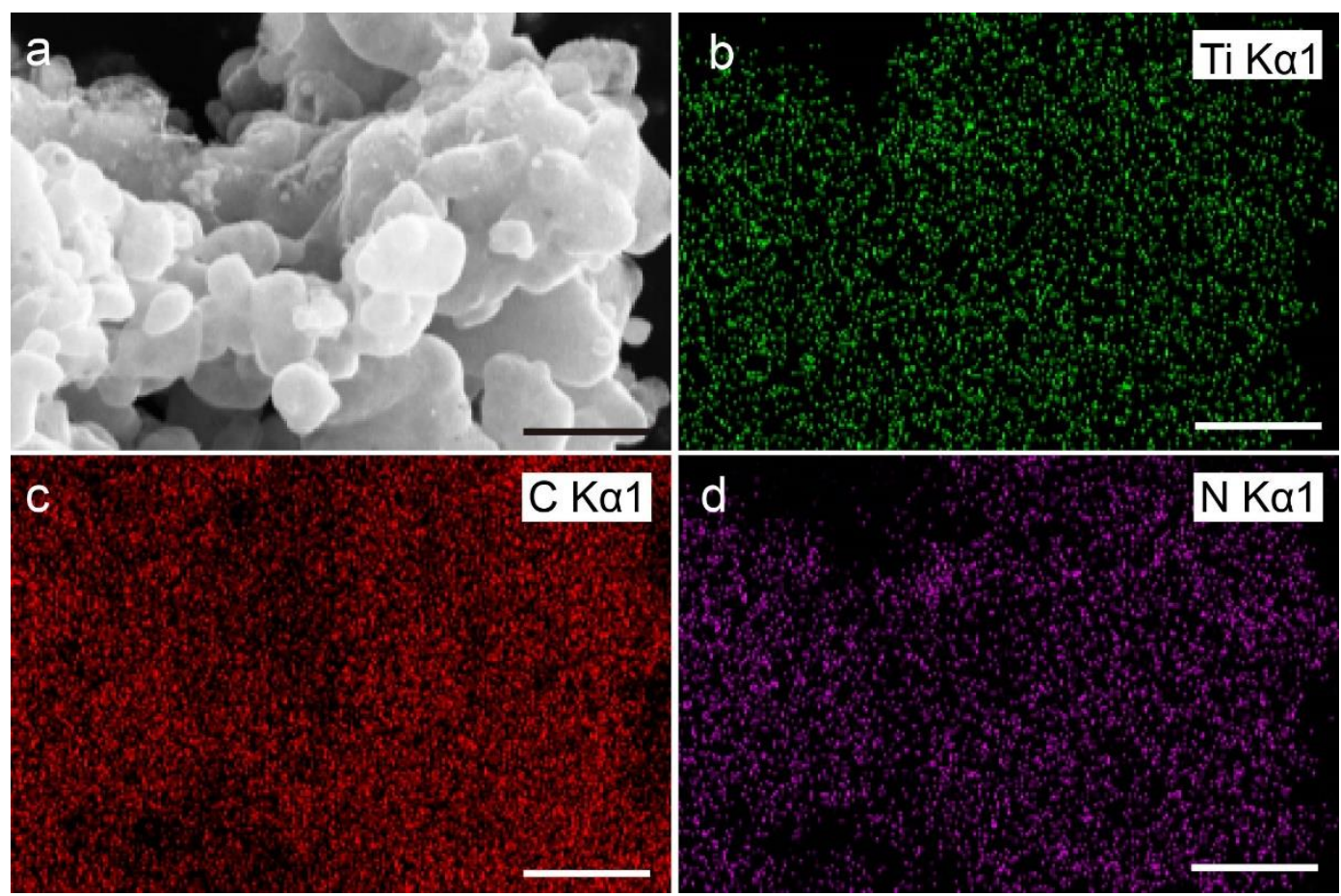

Figure S55. (a) SEM image of TiC and EDS mappings of (b) Ti, (c) C and (c) N. Scale bar is $2 \mu \mathrm{m}$ in (a-d).

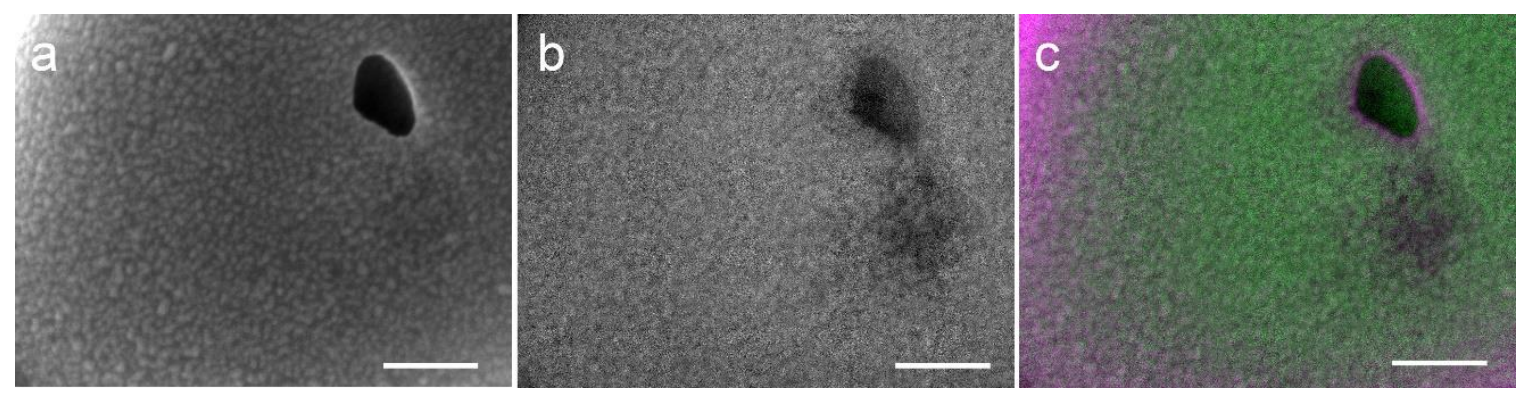

Figure S56. (a) Secondary electron image, (b) backscatter electron image and (c) mixture of second and backscatter electron signal. Scale bar is $100 \mathrm{~nm}$ in (a-c). 

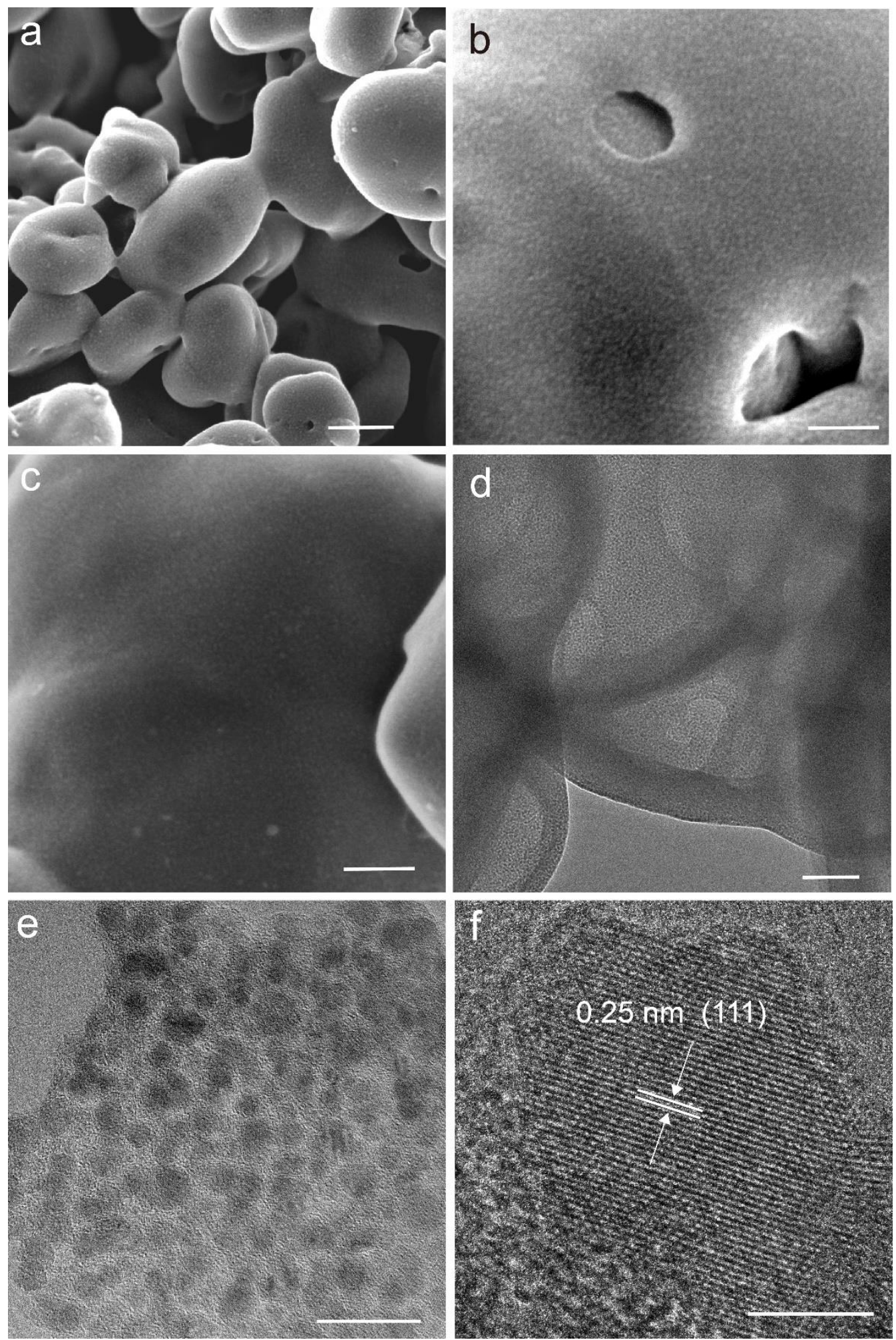

Figure S57. (a-c) SEM images, (d, e) TEM and (f) HRTEM images of TiC nanoparticles. Scale bar is $200 \mathrm{~nm}$ in (a), $100 \mathrm{~nm}$ in (b, c), $150 \mathrm{~nm}$ in (d), $20 \mathrm{~nm}$ in (e) and $5 \mathrm{~nm}$ in (f). 

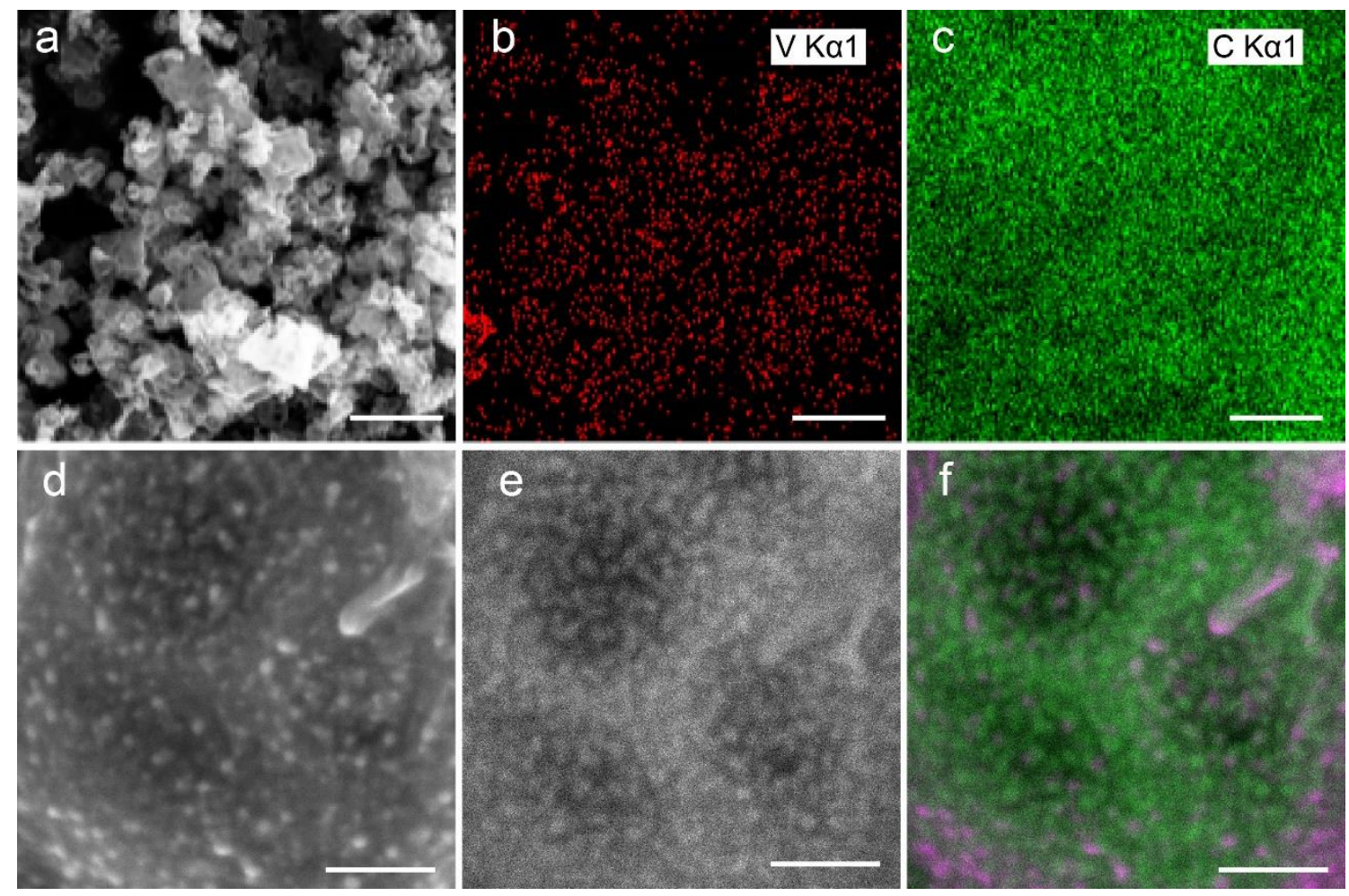

Figure S58. (a) SEM image and EDS mappings of (b) V and (c) C. (d) Secondary electron image, (e) backscatter electron image and (f) mixture of second and backscatter electron signal. Scale bar is $2 \mu \mathrm{m}$ in (a-c) and $100 \mathrm{~nm}$ in (d-f). 

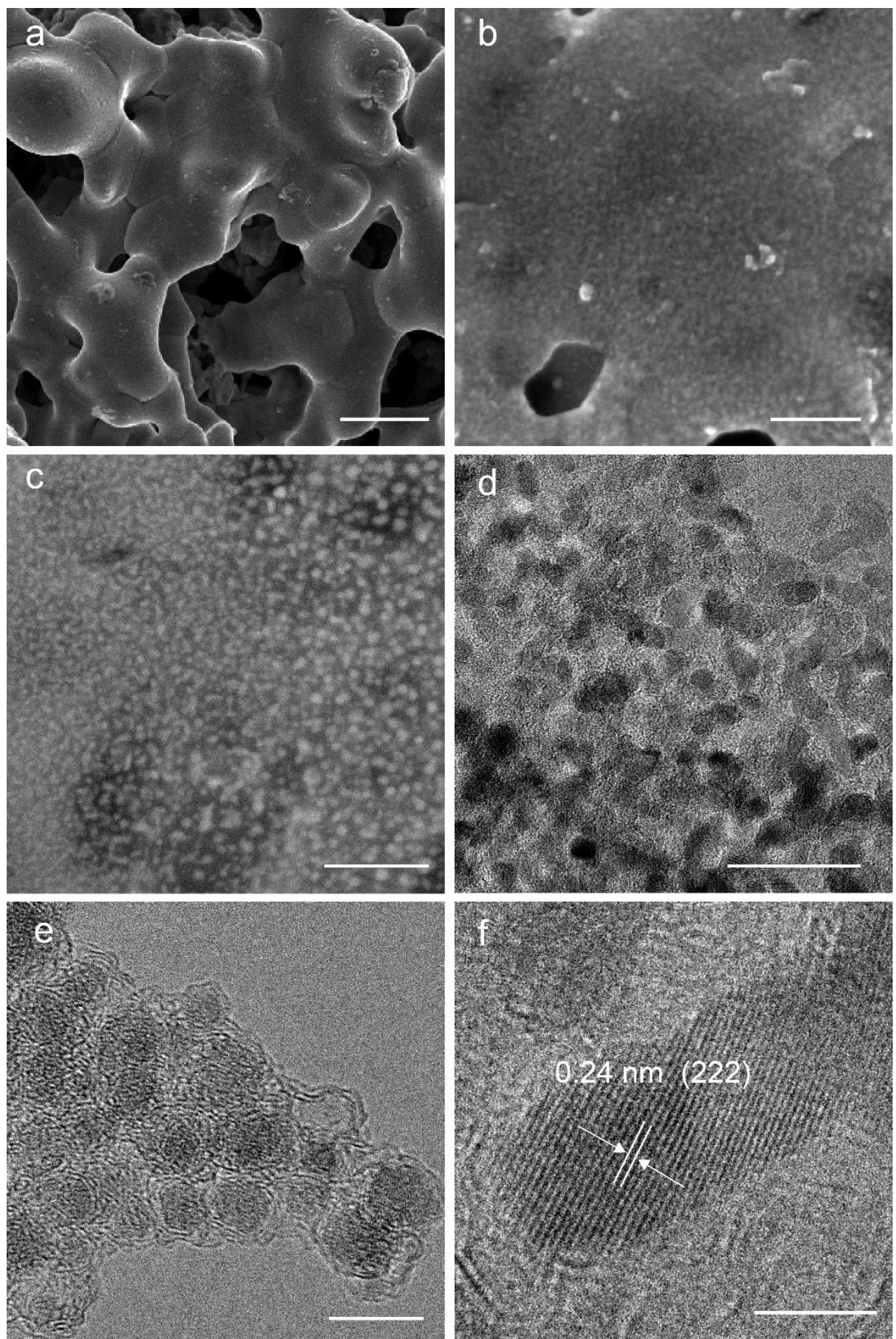

Figure S59. (a-c) SEM images, (d, e) TEM and (f) HRTEM images of $\mathrm{V}_{8} \mathrm{C}_{7}$ nanoparticles.

Scale bar is $1 \mu \mathrm{m}$ in (a), $100 \mathrm{~nm}$ in (b, c), $50 \mathrm{~nm}$ in (d), $10 \mathrm{~nm}$ in (e), and $5 \mathrm{~nm}$ in (c). 

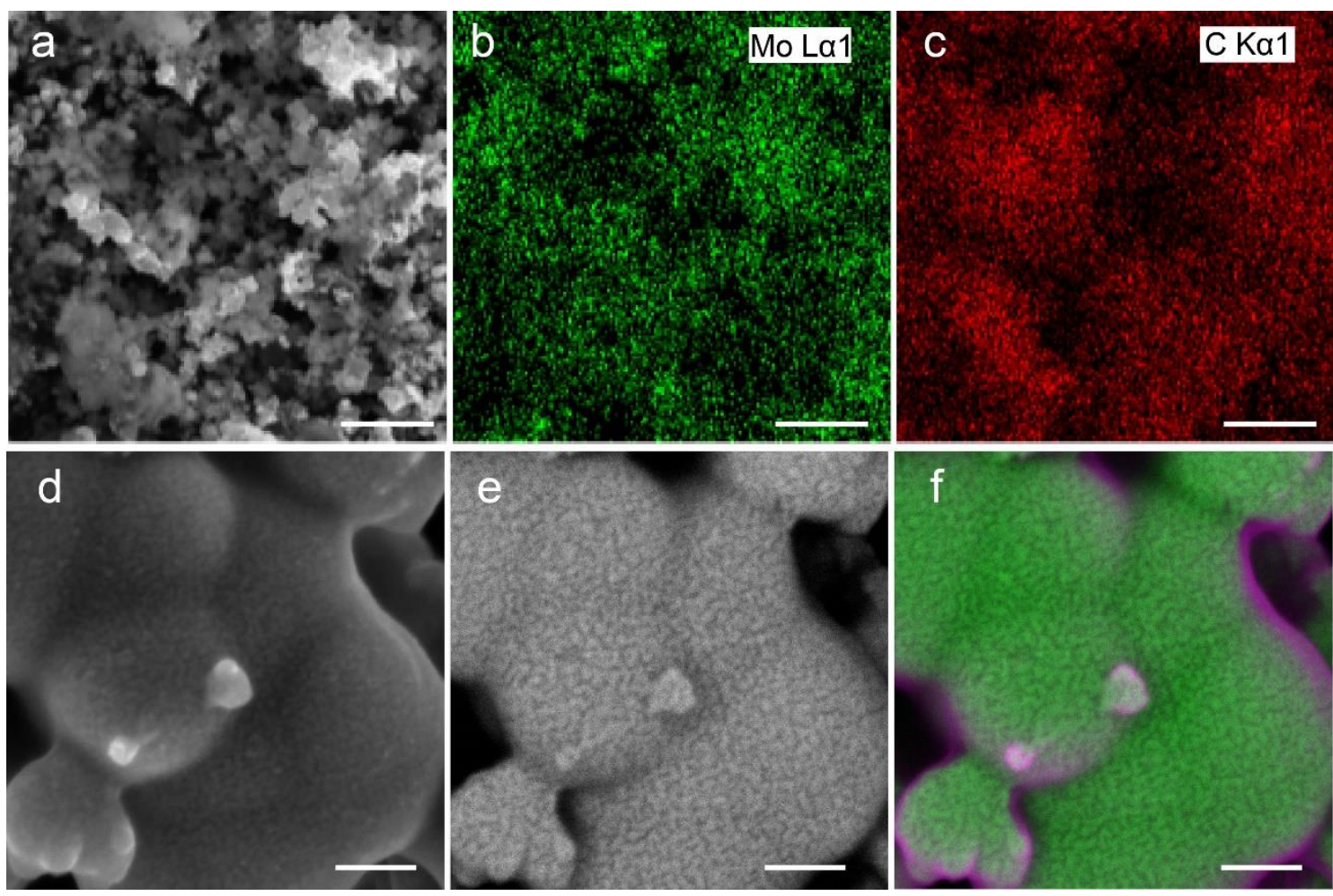

Figure S60. (a) SEM image of $\alpha-M o C$ and EDS mappings of (b) Mo and (c) C. (d) Secondary electron image, (e) backscatter electron image and (f) mixture of second and backscatter electron signal. Scale bar is $2 \mu \mathrm{m}$ in (a-c) and $100 \mathrm{~nm}$ in (d-f). 

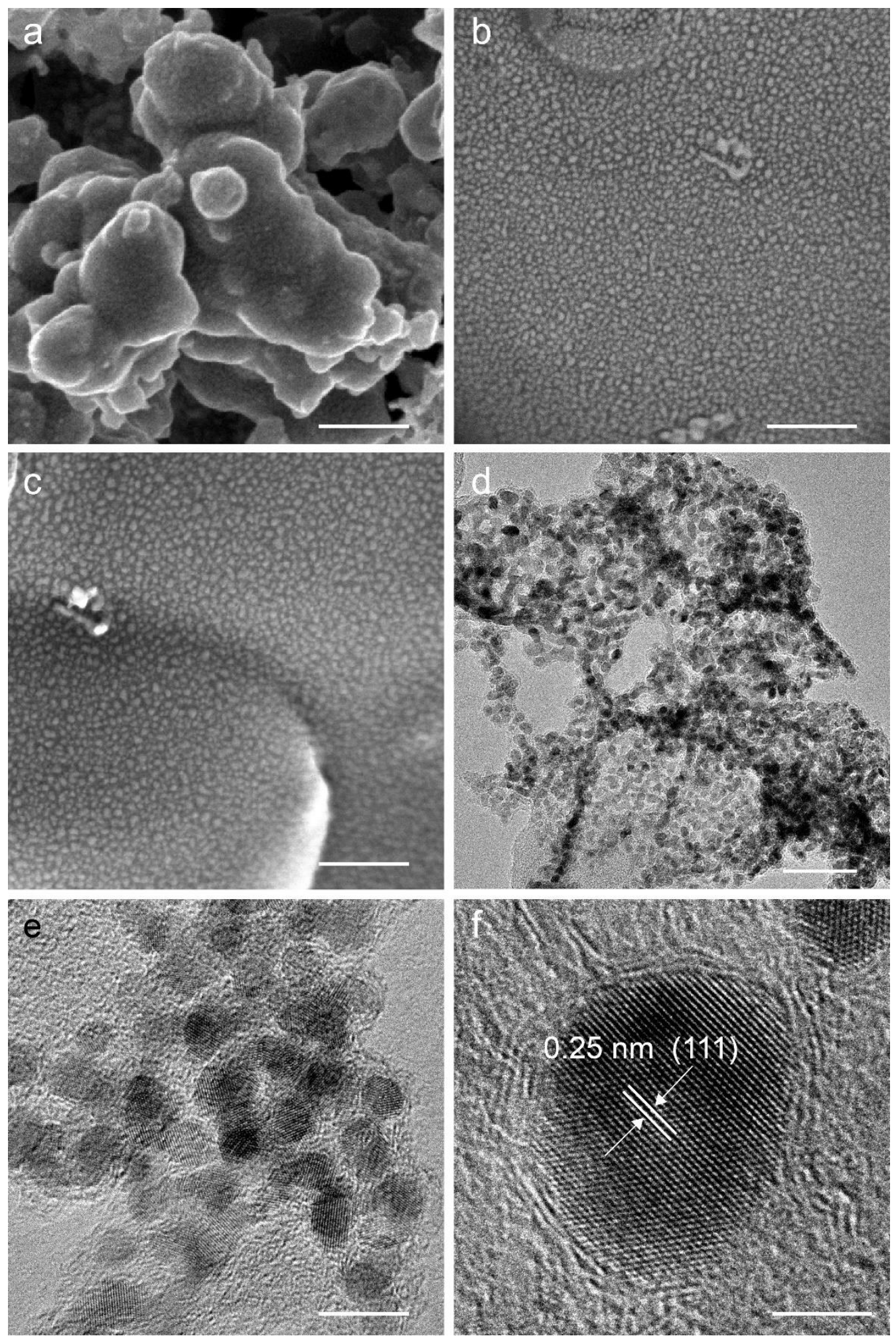

Figure S61. (a-c) SEM images, (d, e) TEM and (f) HRTEM images of $\alpha$-MoC nanoparticles. Scale bar is $100 \mathrm{~nm}$ in (a-c), $50 \mathrm{~nm}$ in (b), $10 \mathrm{~nm}$ in (e), and $5 \mathrm{~nm}$ in (c). 


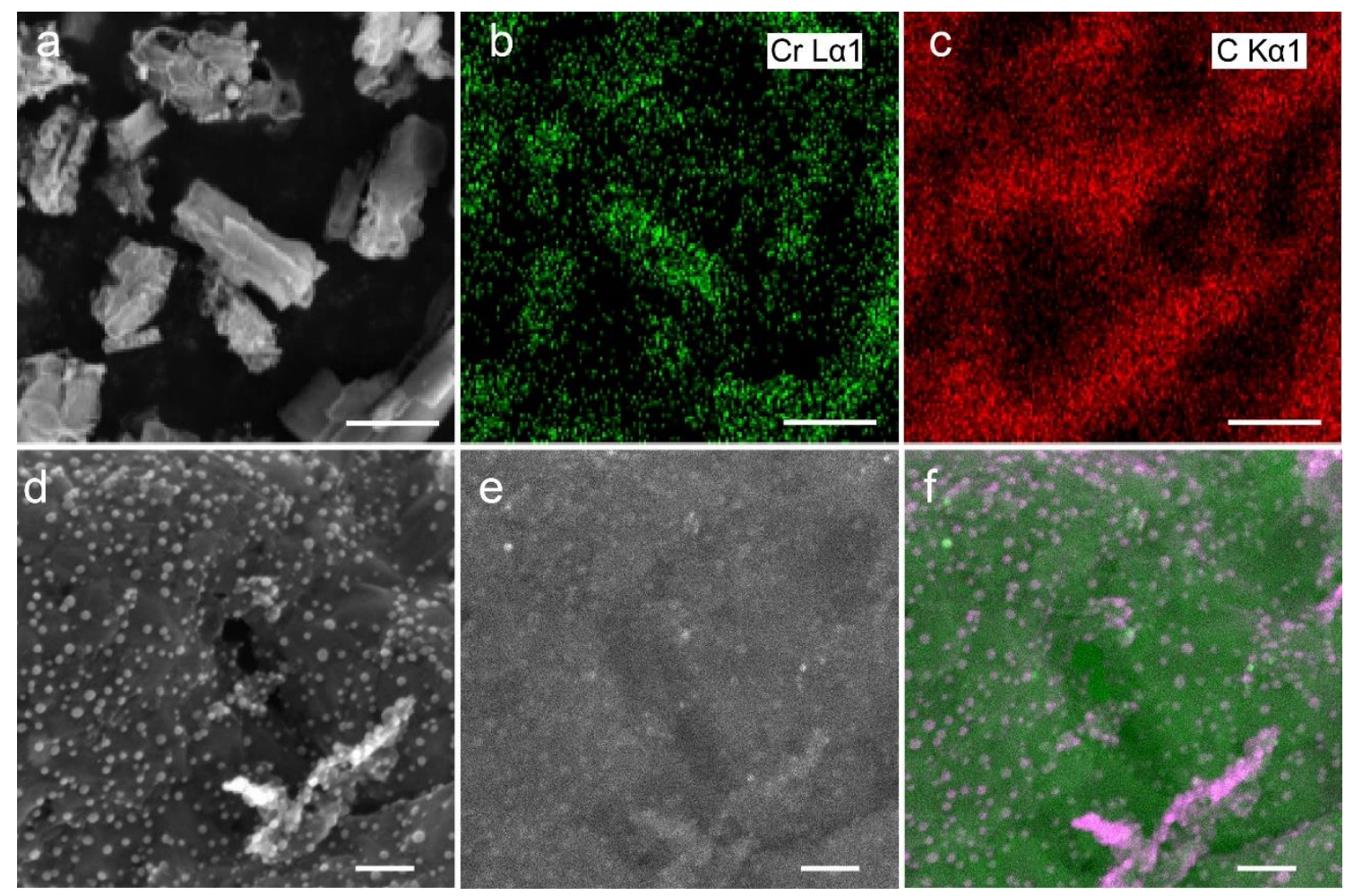

Figure S62. (a) SEM image of $\mathrm{Cr}_{3} \mathrm{C}_{2}$ and (b, c) EDS mappings of $\mathrm{Cr}$ and C. (d) Secondary electron image, (e) backscatter electron image and (f) mixture of second and backscatter electron signal. Scale bar is $5 \mu \mathrm{m}$ in (a-c) and $100 \mathrm{~nm}$ in (d-f). 

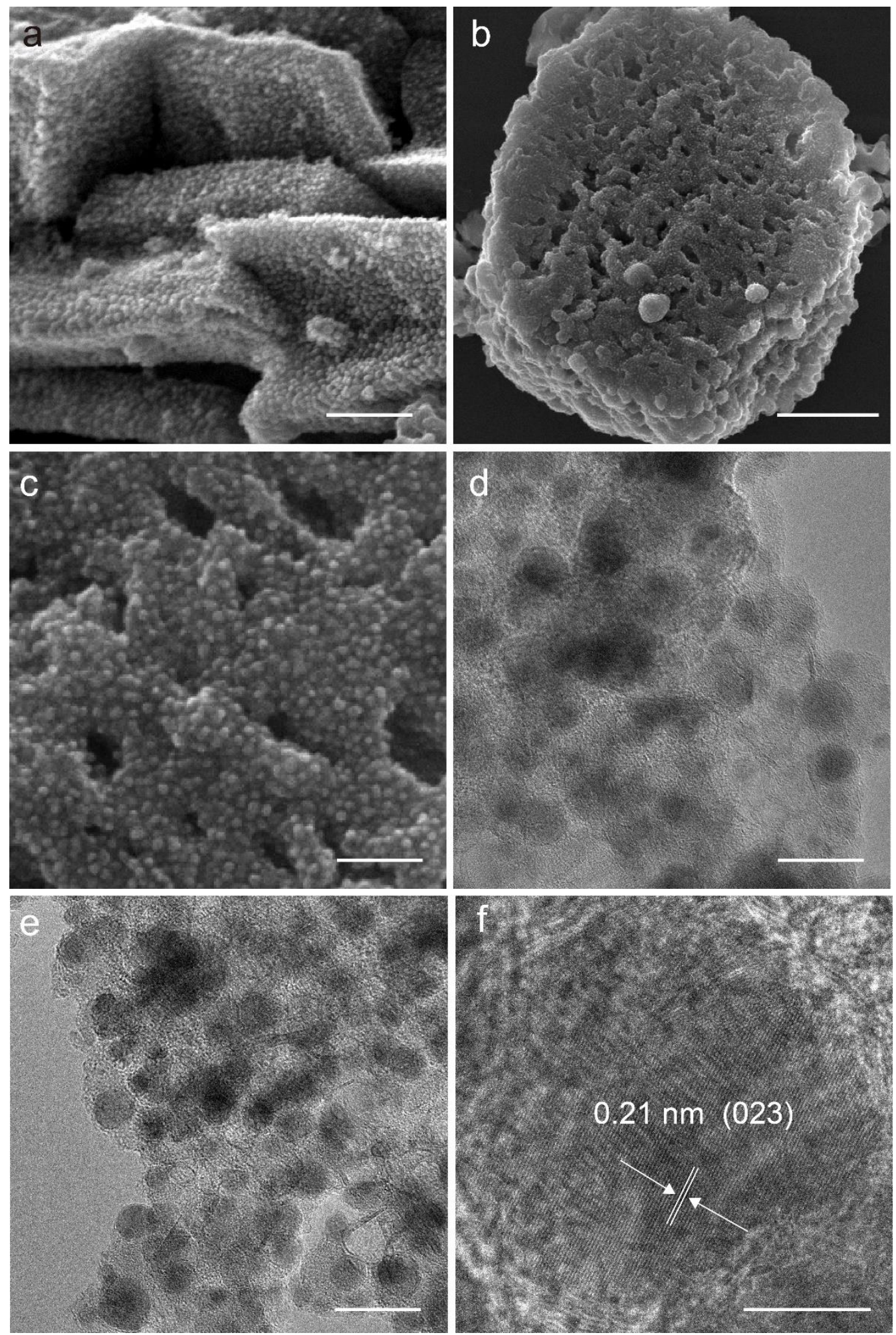

Figure S63. (a-c) SEM images, (d, e) TEM and (f) HRTEM images of $\mathrm{Cr}_{3} \mathrm{C}_{2}$ nanoparticles.

Scale bar is $200 \mathrm{~nm}$ in (a, c), $300 \mathrm{~nm}$ in (b), $20 \mathrm{~nm}$ in (d, e) and $5 \mathrm{~nm}$ in (f). 

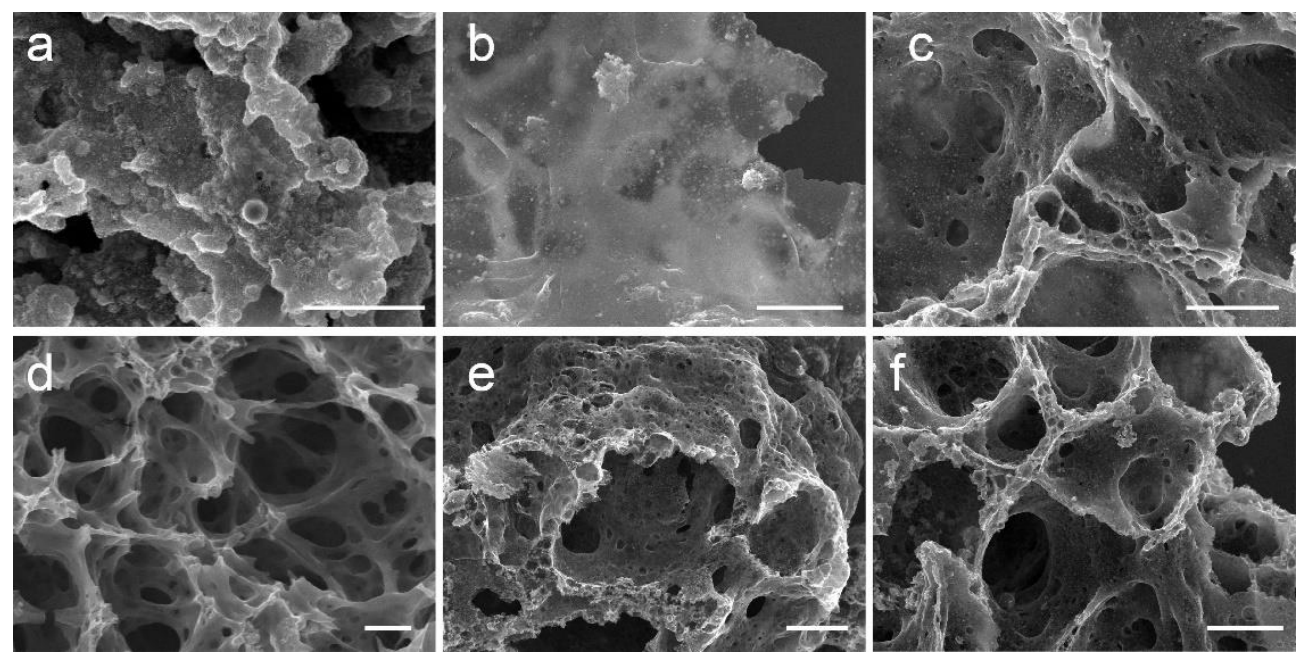

Figure S64. Low-magnification SEM images of $\mathrm{FeC}_{\mathrm{x}}$ samples from (a) MIL-101 at laser power of $7 \mathrm{~W}$, (b) MIL-101-( $\left.\mathrm{NH}_{2}\right)_{0.5}$ at laser power of $5 \mathrm{~W}$, (c) MIL-101-( $\left.\mathrm{NH}_{2}\right)_{0.5}$ at laser power of $7 \mathrm{~W}$, (d) MIL-101-( $\left.\mathrm{NH}_{2}\right)_{1}$ at laser power of $3.5 \mathrm{~W}$, (e) MIL-101-( $\left.\mathrm{NH}_{2}\right)_{1}$ at laser power of $5 \mathrm{~W}$, (f) MIL-101-( $\left.\mathrm{NH}_{2}\right)_{1}$ at laser power of $7 \mathrm{~W}$. Scale bar is $1 \mu \mathrm{m}$ in $(\mathrm{a}, \mathrm{b}, \mathrm{d})$, and $500 \mathrm{~nm}$ in $(\mathrm{c}, \mathrm{e}, \mathrm{f})$.
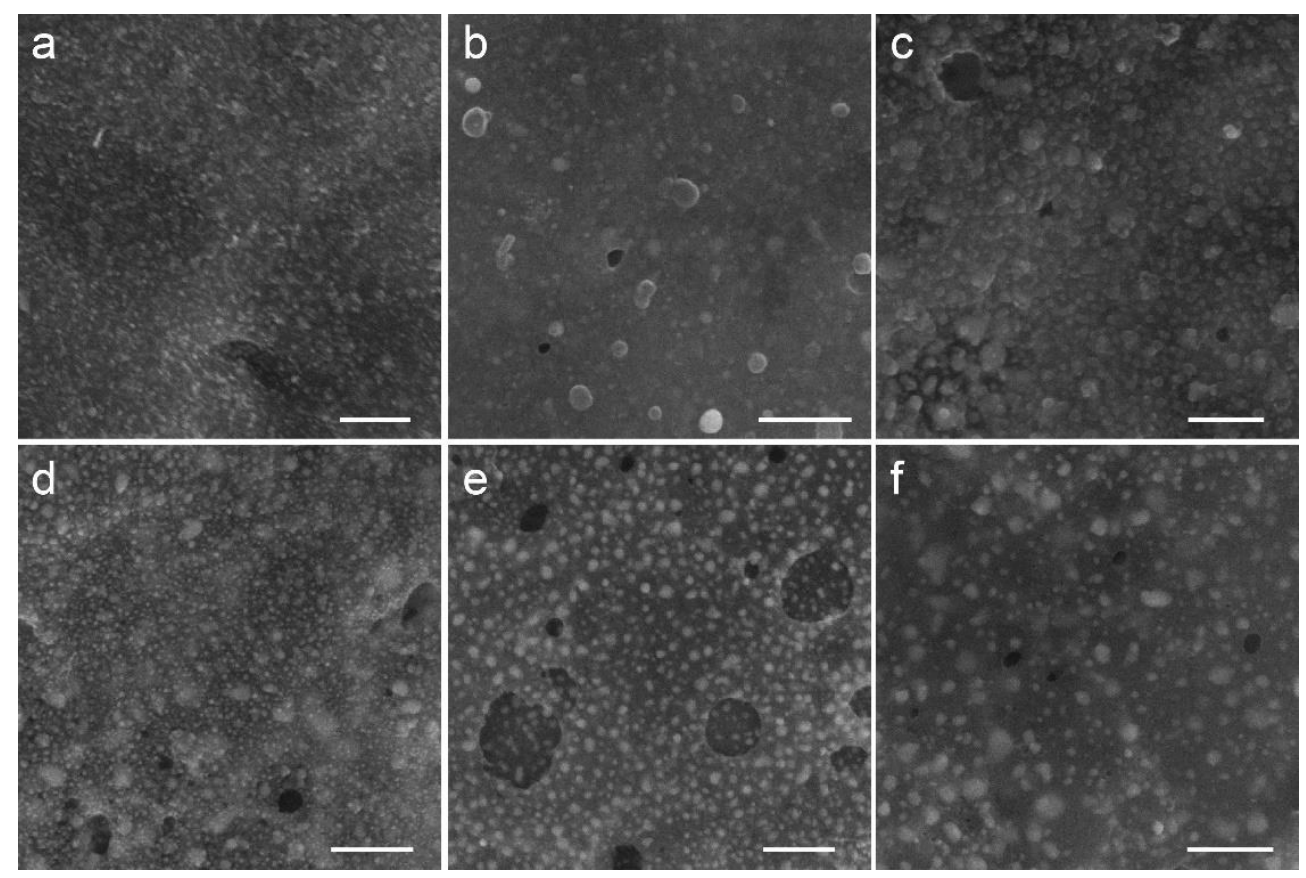

Figure S65. High-magnification SEM images of $\mathrm{FeC}_{\mathrm{x}}$ samples from (a) MIL-101 at laser power of $7 \mathrm{~W}$, (b) MIL-101-( $\left.\mathrm{NH}_{2}\right)_{0.5}$ at laser power of $5 \mathrm{~W}$, (c) MIL-101-(NH2) 0.5 at laser power of $7 \mathrm{~W}$, (d) MIL-101-( $\left.\mathrm{NH}_{2}\right)_{1}$ at laser power of $3.5 \mathrm{~W}$, (e) MIL-101-( $\left.\mathrm{NH}_{2}\right)_{1}$ at laser power of $5 \mathrm{~W}$, (f) MIL-101-( $\left.\mathrm{NH}_{2}\right)_{1}$ at laser power of $7 \mathrm{~W}$. Scale bar is $200 \mathrm{~nm}$ in (a-f). 
In Air
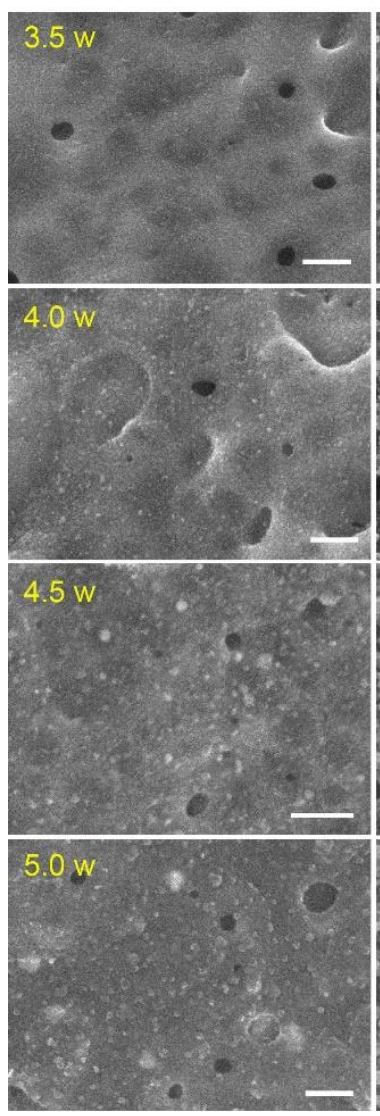
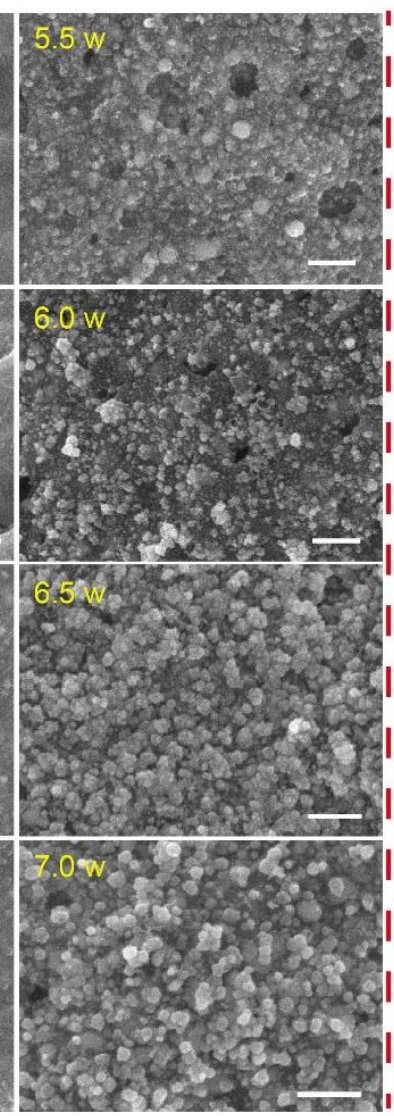

In $\mathrm{Ar}$
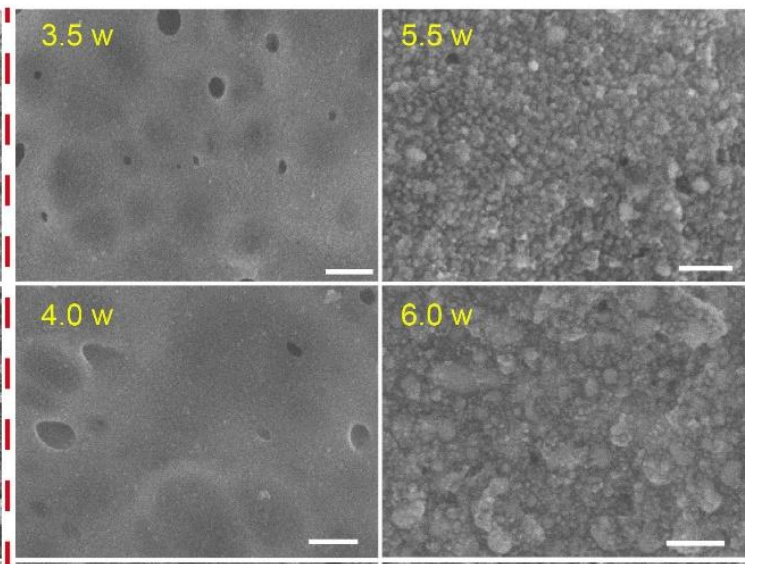

6.0 w

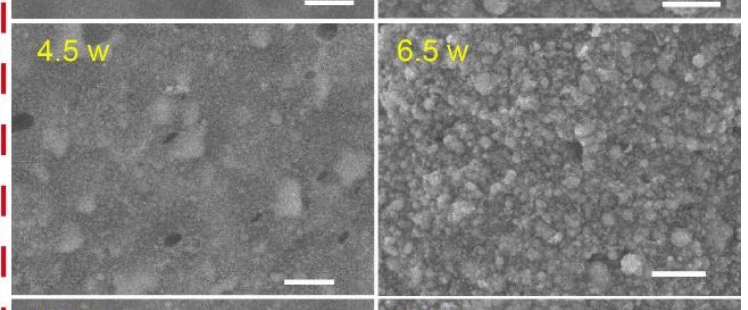

$5.0 \mathrm{w}$

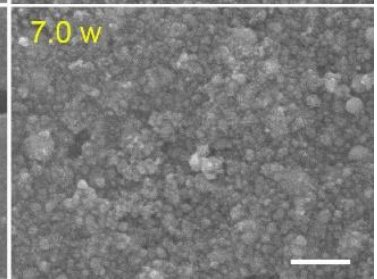

Figure S66. SEM images of iron carbides obtained at different laser power and gas atmosphere. With the laser power increase, the particle size increase. When laser metallurgy was performed in Ar atmosphere, the particle size became smaller compared with that obtained in the air. Scale bar is $200 \mathrm{~nm}$. 

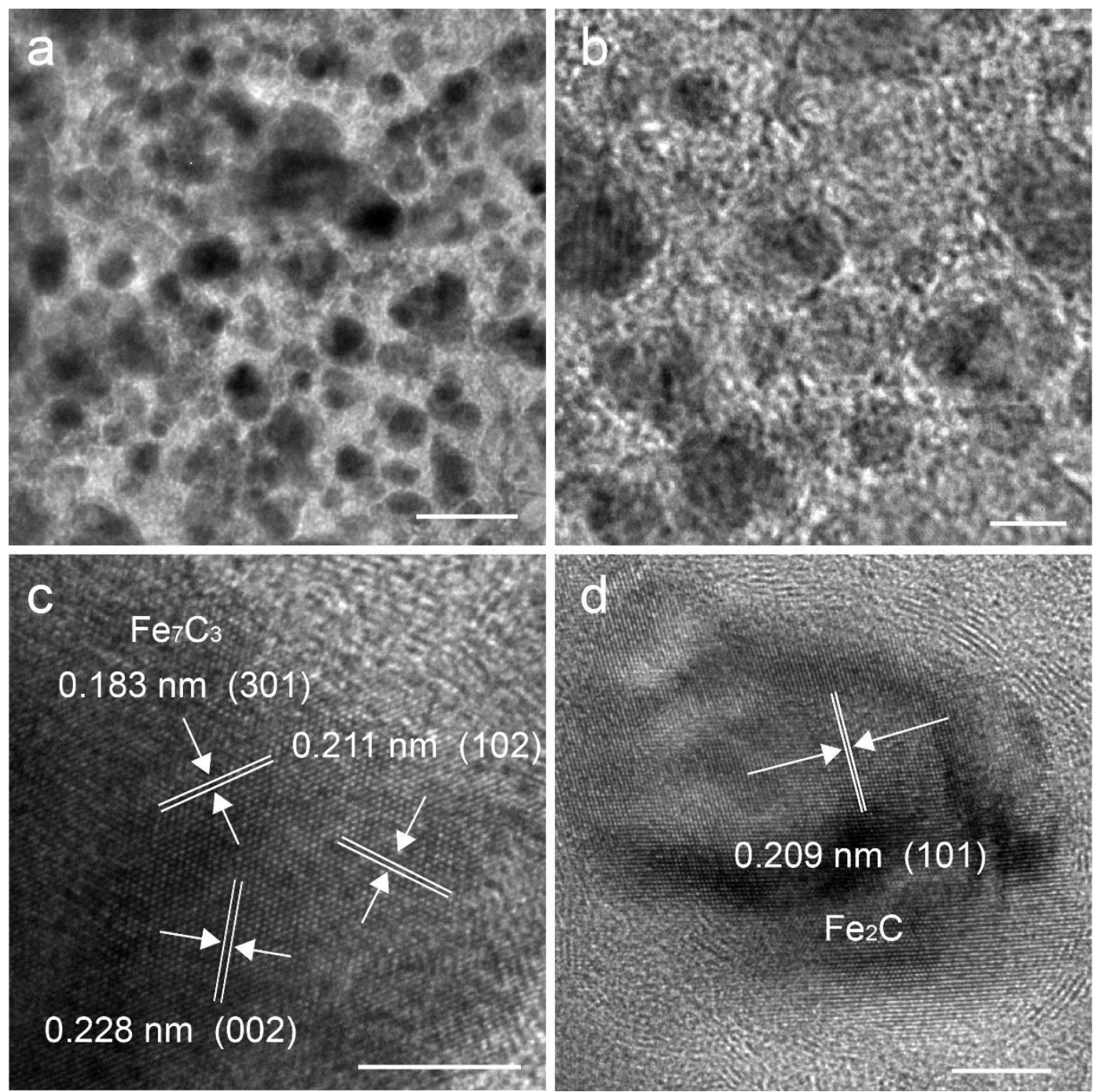

Figure S67. TEM images of iron carbide from MIL-101- $\mathrm{NH}_{2}$ by laser metallurgy at $5 \mathrm{~W}$.

The lattice fringe is in accordance with lattice plane of $\mathrm{Fe}_{7} \mathrm{C}_{3}$ and $\mathrm{Fe}_{2} \mathrm{C}$, respectively. Scale bar is $20 \mathrm{~nm}$ in (a), $10 \mathrm{~nm}$ in (b) and $5 \mathrm{~nm}$ in (c, d). 

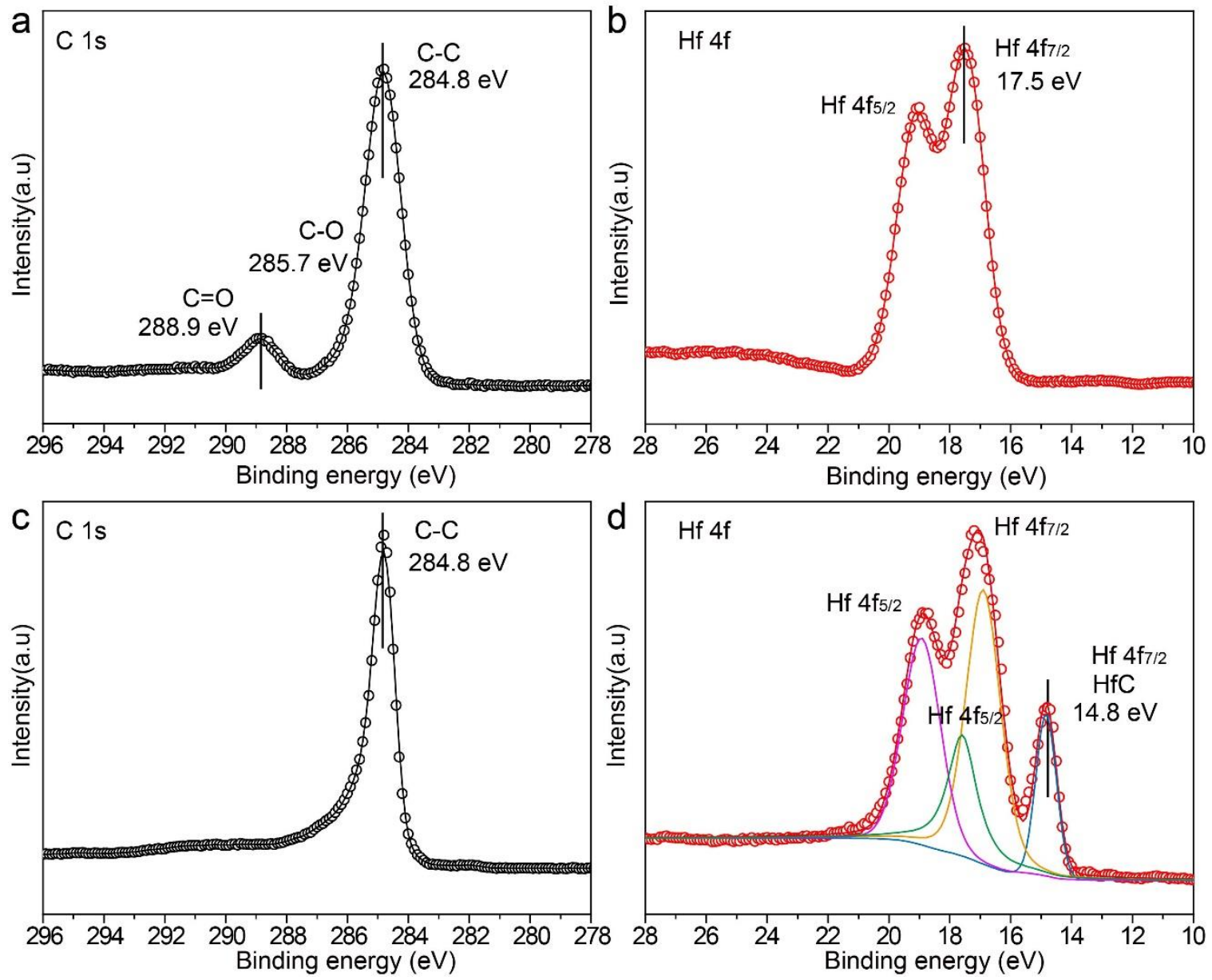

Figure S68. XPS patterns of MOLs and HfC. (a) C 1s, (b) Hf 4f of pristine MOLs, (c) C 1s, (d) Hf $4 \mathrm{f}$ of carbon supported HfC. After laser treatment, the disappearance of O-C=O peak suggest the removal of oxygen specious and formation of carbon species. The peak at $14.8 \mathrm{eV}$ indicates the formation of HfC. 

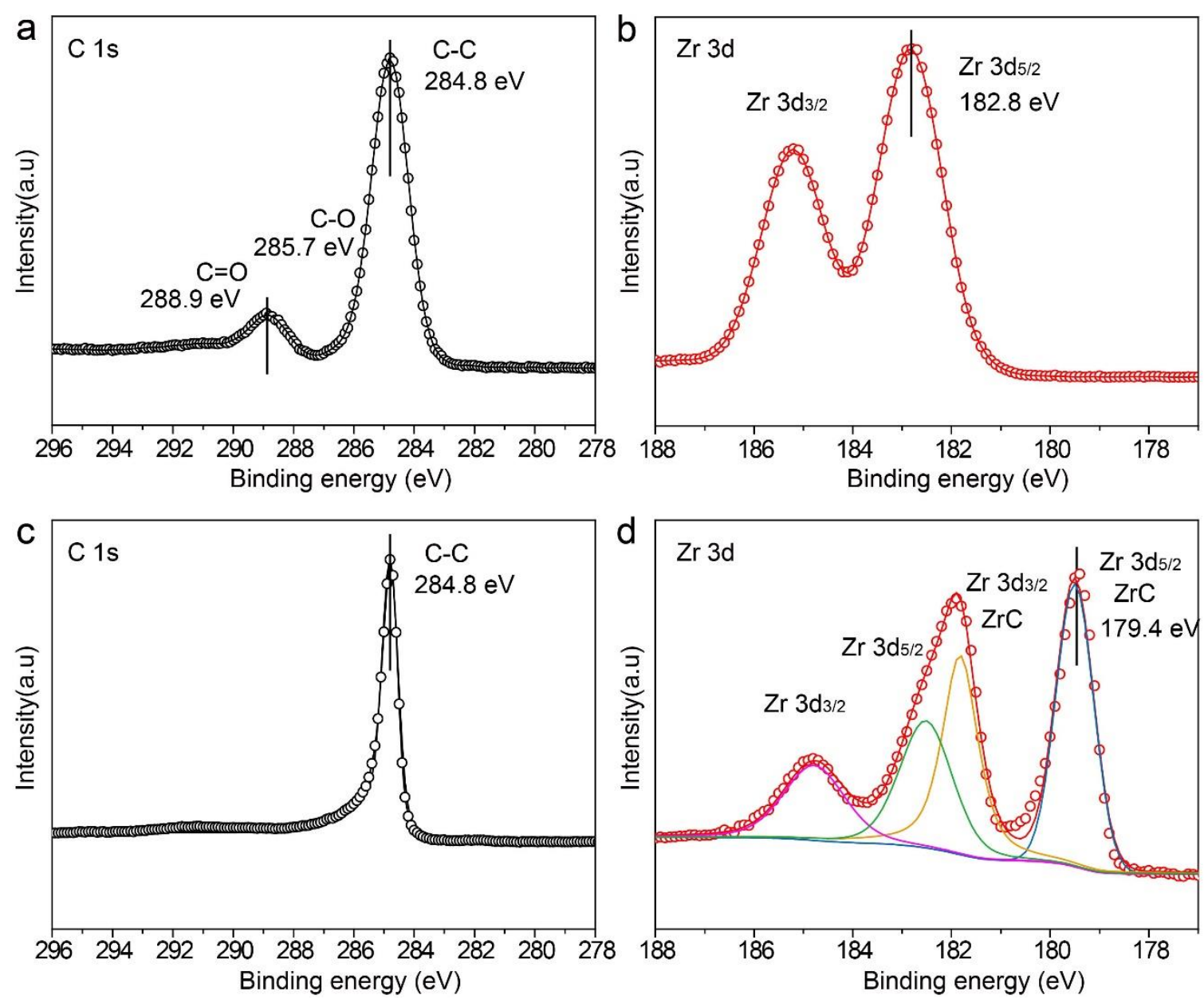

Figure S69. XPS patterns of UMCM-309a and ZrC. (a) C 1s, (b) Zr 3d of pristine UMCM309a, (c) C 1s, (d) Zr 3d of carbon supported ZrC. After laser treatment, the disappearance of $\mathrm{O}-\mathrm{C}=\mathrm{O}$ peak suggest the removal of oxygen species and formation of carbon specious. The peak at $179.4 \mathrm{eV}$ indicates the formation of $\mathrm{ZrC}$. 

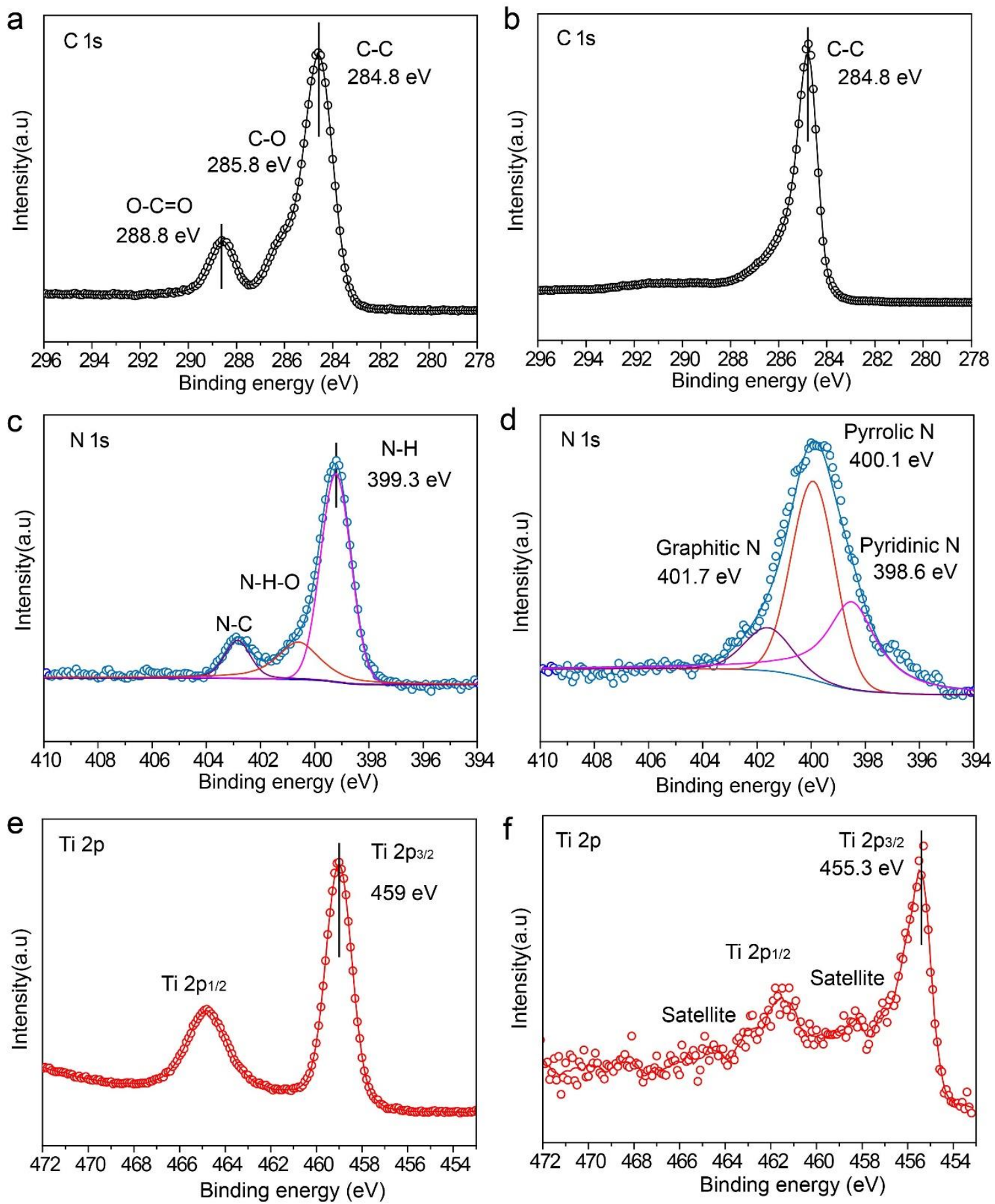

Figure S70. XPS patterns of $\mathrm{NH}_{2}-\mathrm{MIL}-125$ and TiC. (a) C 1s, (c) N 1s, (e) Ti 2p of pristine $\mathrm{NH}_{2}-\mathrm{MIL}-125$, (b) $\mathrm{C} 1 \mathrm{~s}$, (d) N 1s, (f) Ti 2p of carbon supported TiC. After laser treatment, the disappearance of $\mathrm{O}-\mathrm{C}=\mathrm{O}$ peak suggest the removal of oxygen species and formation of carbon specious. The peaks at $461.5 \mathrm{eV}$ and $455.3 \mathrm{eV}$ indicate the formation of TiC. 

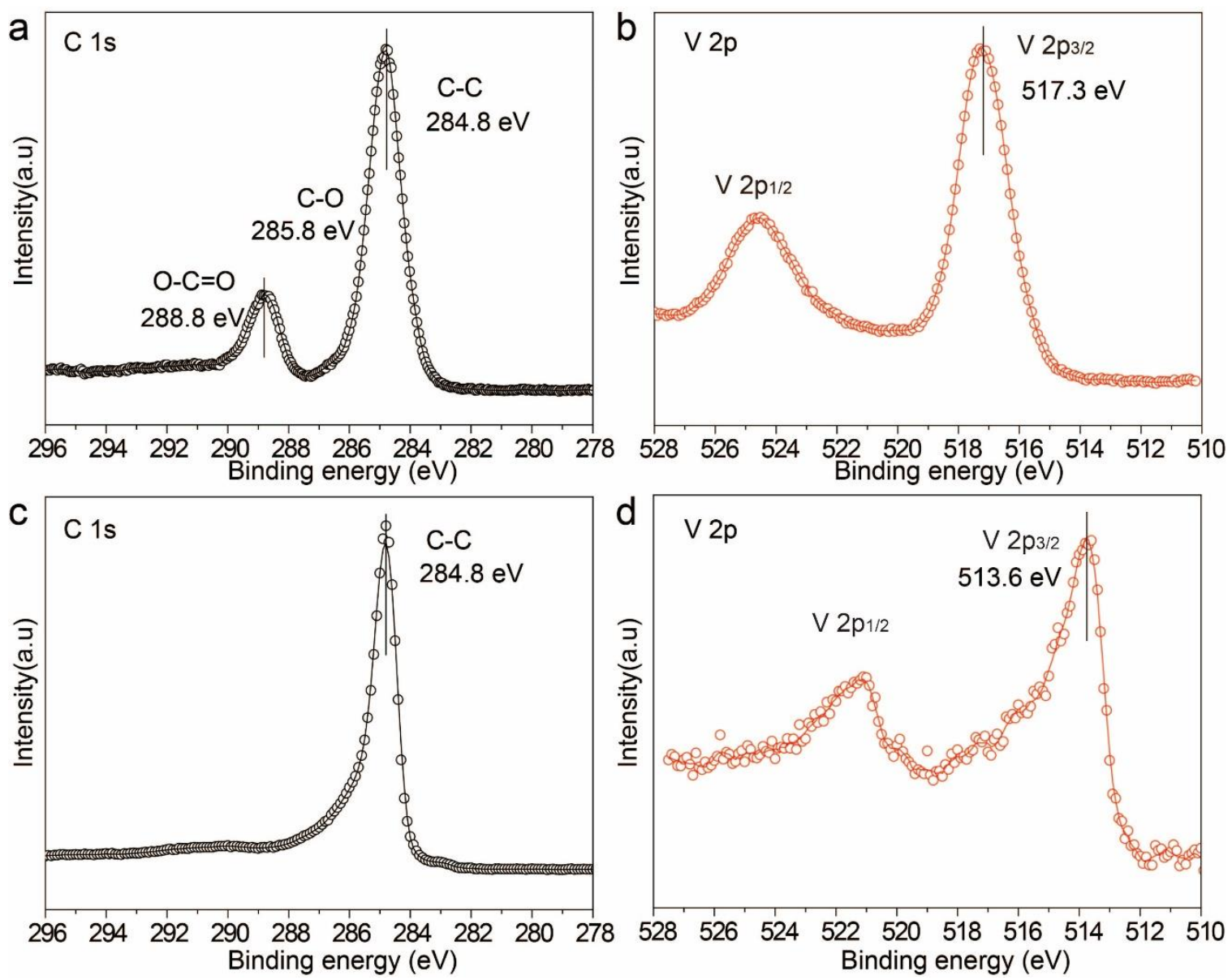

Figure S71. XPS patterns of MIL-47 and $\mathrm{V}_{8} \mathrm{C}_{7}$. (a) $\mathrm{C} 1 \mathrm{~s}$, (b) V $2 \mathrm{p}$ of pristine MIL-47, (c) $\mathrm{C} 1 \mathrm{~s}$, (d) V 2p of carbon supported $\mathrm{V}_{8} \mathrm{C}_{7}$. After laser treatment, the disappearance of O$\mathrm{C}=\mathrm{O}$ peak suggest the removal of oxygen specious and formation of carbon species. The peaks at $521.2 \mathrm{eV}$ and $513.6 \mathrm{eV}$ indicate the formation of $\mathrm{V}_{8} \mathrm{C}_{7}$. 

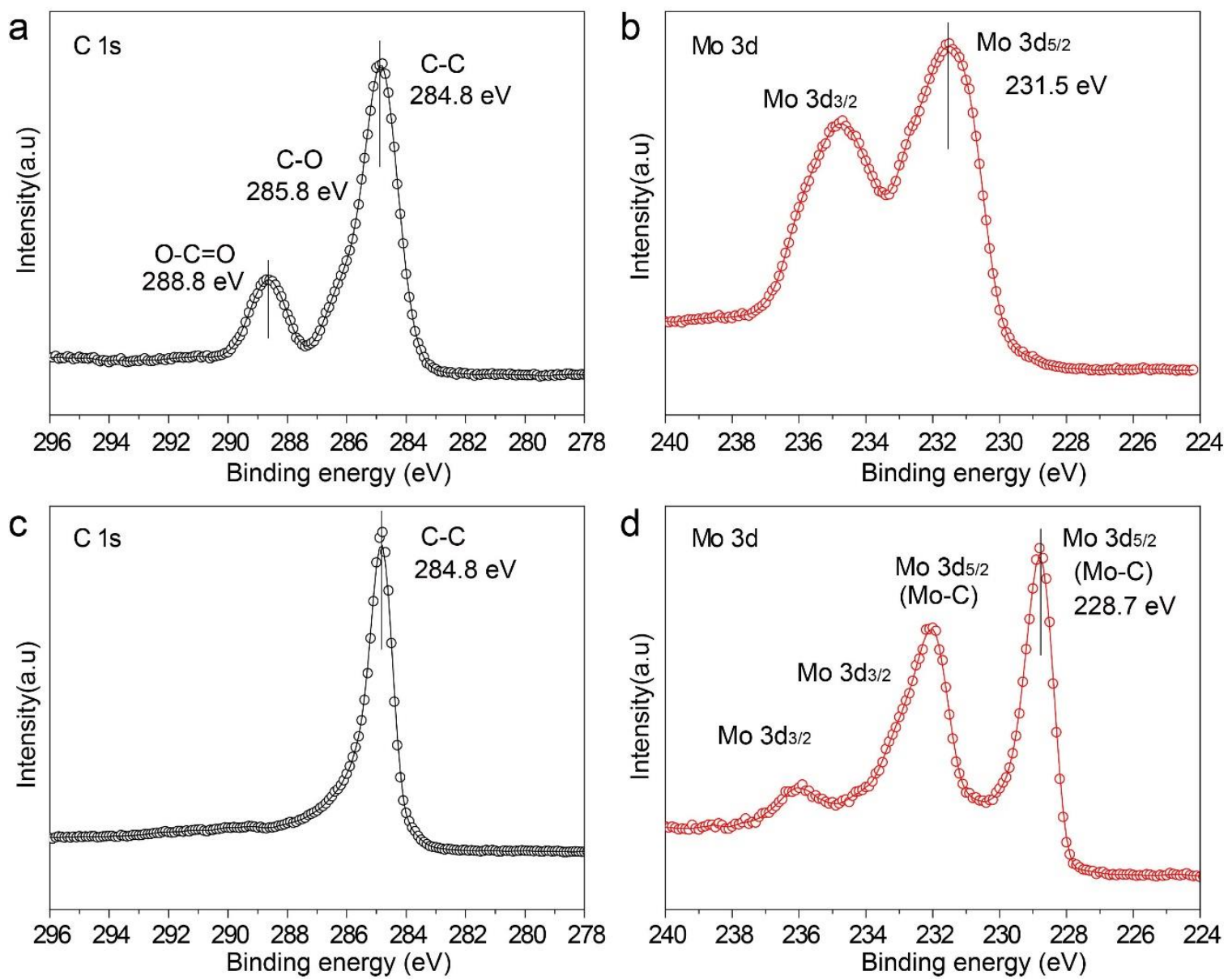

Figure S72. XPS patterns of TUDMOF-1 and $\alpha$-MoC. (a) C $1 \mathrm{~s}$, (b) Mo $3 \mathrm{~d}$ of pristine TUDMOF-1, (c) C 1s, (d) Mo 3d of carbon supported $\alpha$-MoC. After laser treatment, the disappearance of $\mathrm{O}-\mathrm{C}=\mathrm{O}$ peak suggest the removal of oxygen specious and formation of carbon species. The peaks at $232.1 \mathrm{eV}$ and $228.7 \mathrm{eV}$ indicate the formation of $\alpha-\mathrm{MoC}$. 

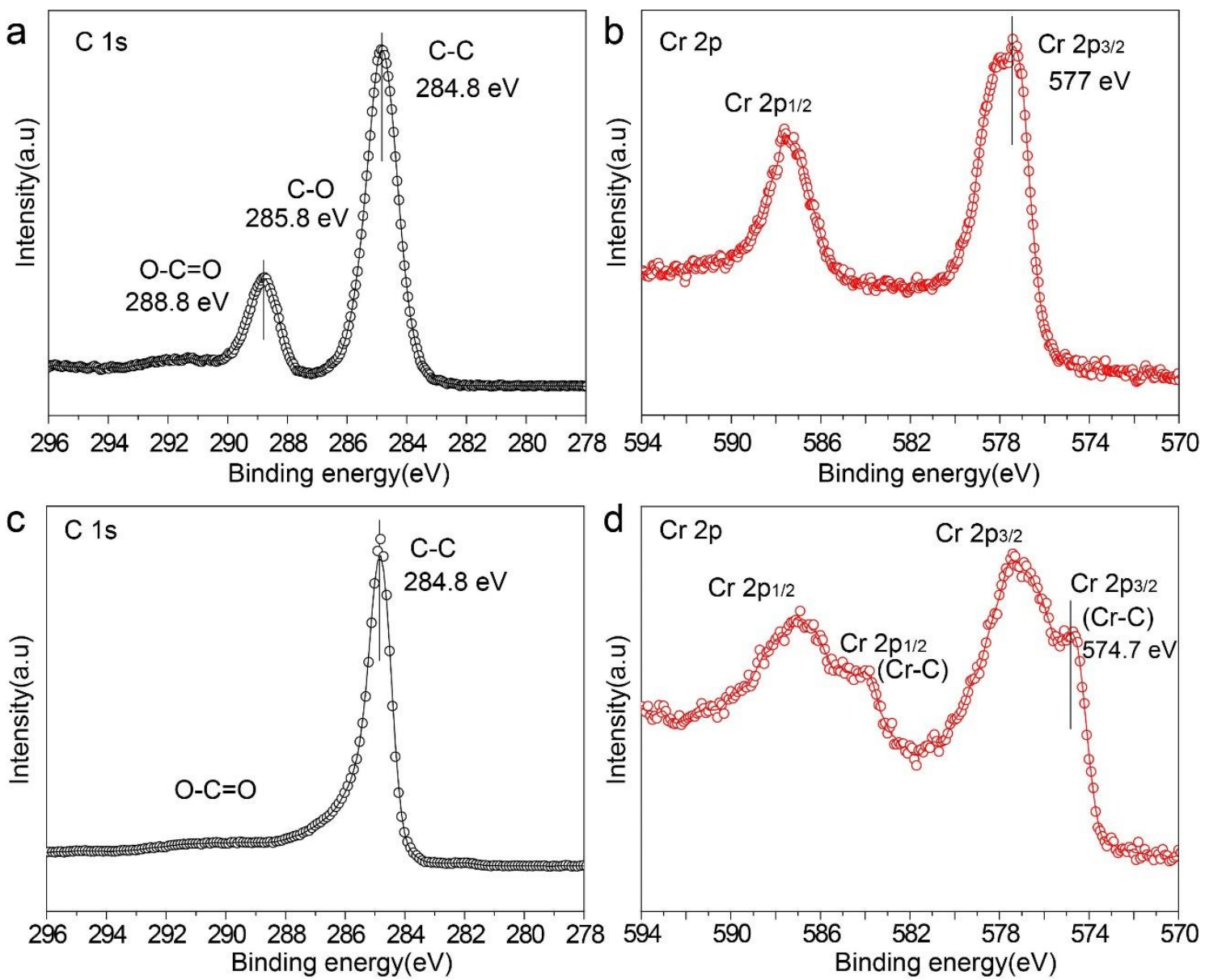

Figure S73. XPS patterns MIL-53 of and $\mathrm{Cr}_{3} \mathrm{C}_{2}$. (a) C 1s, (b) $\mathrm{Cr} 2 \mathrm{p}$ of pristine MIL-53, (c) $\mathrm{C} 1 \mathrm{~s},(\mathrm{~d}) \mathrm{Cr} 2 \mathrm{p}$ of carbon supported $\mathrm{Cr}_{3} \mathrm{C}_{2}$. After laser treatment, the peaks at $583.6 \mathrm{eV}$ and $574.7 \mathrm{eV}$ indicate the formation of $\mathrm{Cr}_{3} \mathrm{C}_{2}$. 

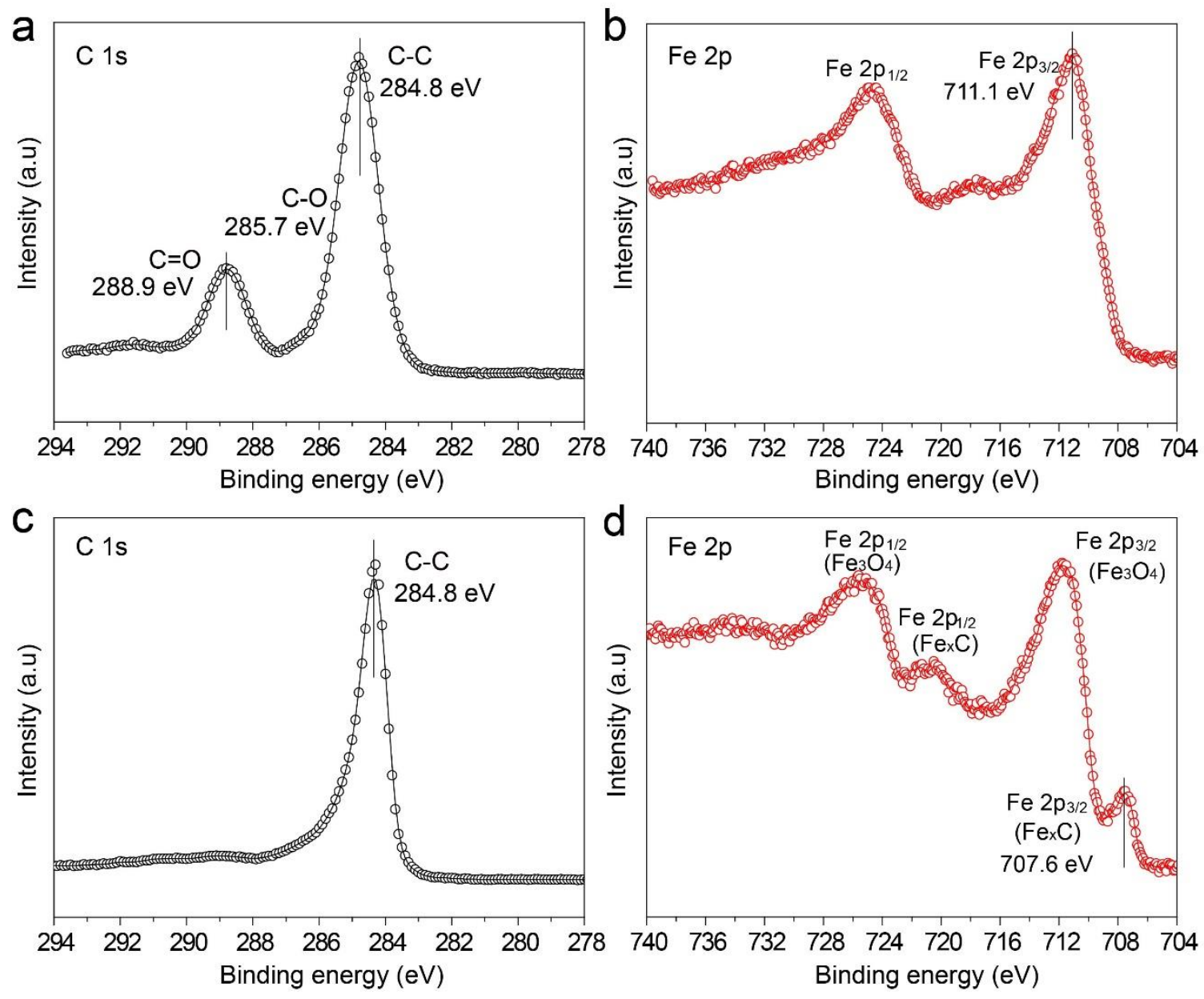

Figure S74. XPS patterns of MIL-101 and $\mathrm{FeC}_{x}$. (a) C 1s, (b) Fe 2p of pristine MIL-101, (c) $\mathrm{C} 1 \mathrm{~s}$, (d) $\mathrm{Fe} 2 \mathrm{p}$ of $\mathrm{FeC}_{x}$ from MIL-101 by laser metallurgy at $7 \mathrm{~W}$. After laser treatment, the disappearance of $\mathrm{O}-\mathrm{C}=\mathrm{O}$ peak suggest the removal of oxygen specious and formation of carbon species. The peaks at $720.7 \mathrm{eV}$ and $707.6 \mathrm{eV}$ indicate the formation of iron carbide. 

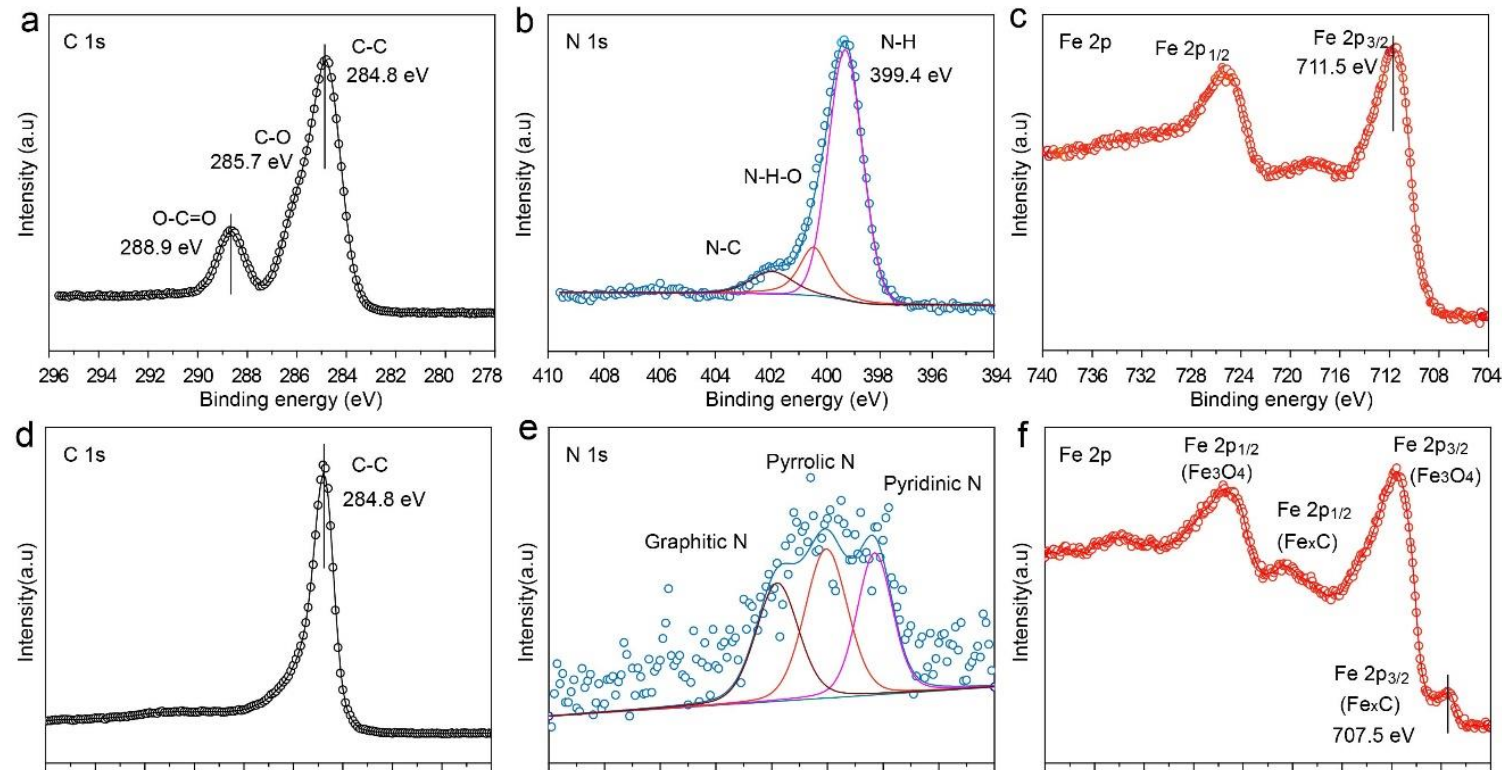

$296294292290 \quad 288286 \quad 284 \quad 282$
Binding energy (eV)
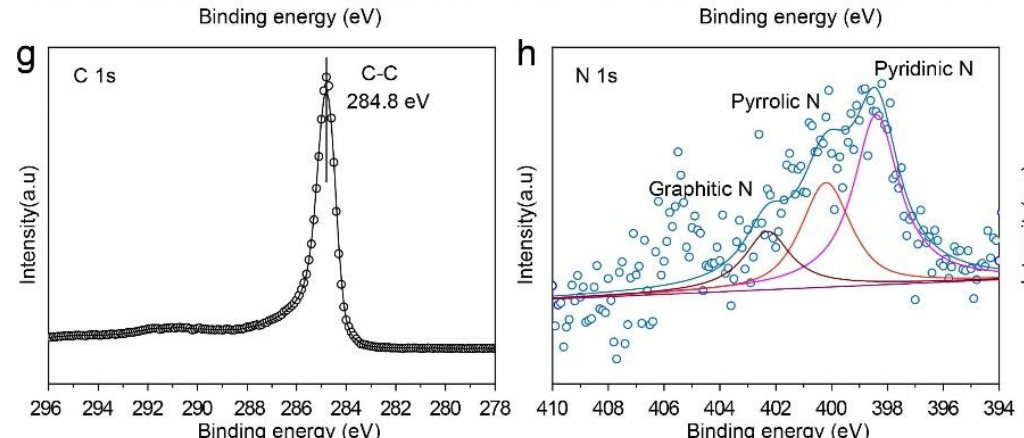

$\begin{array}{llllllllll}740 & 736 & 732 & 728 & 724 & 720 & 716 & 712 & 708 & 704\end{array}$

Binding energy $(\mathrm{eV})$

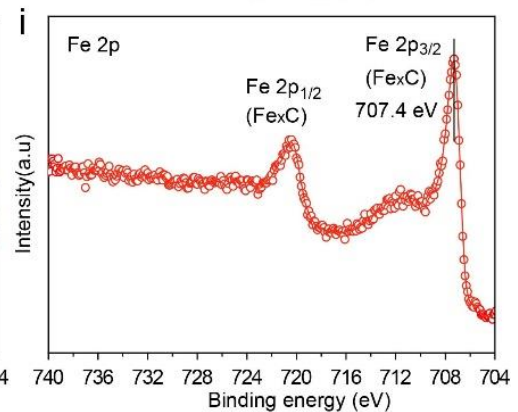

Figure S75. XPS patterns of MIL-101-( $\left.\mathrm{NH}_{2}\right)_{0.5}$ and $\mathrm{FeC}_{x}$. (a) $\mathrm{C} 1 \mathrm{~s}$, (b) N 1s, (c) Fe 2p of pristine MIL-101-( $\left.\mathrm{NH}_{2}\right)_{0.5}$; (d) C 1s, (e) N 1s, (f) Fe 2p from MIL-101-( $\left.\mathrm{NH}_{2}\right)_{0.5}$ by laser metallurgy at $5 \mathrm{~W}$; (g) C 1s, (h) N 1s, (i) Fe 2p from MIL-101-( $\left.\mathrm{NH}_{2}\right)_{0.5}$ by laser metallurgy at $7 \mathrm{~W}$. After laser treatment, the disappearance of $\mathrm{O}-\mathrm{C}=\mathrm{O}$ peak suggest the removal of oxygen species and formation of carbon species. The peak at $720.7 \mathrm{eV}$ and 707.4 707.5 $\mathrm{eV}$ indicate the formation of iron carbide. 

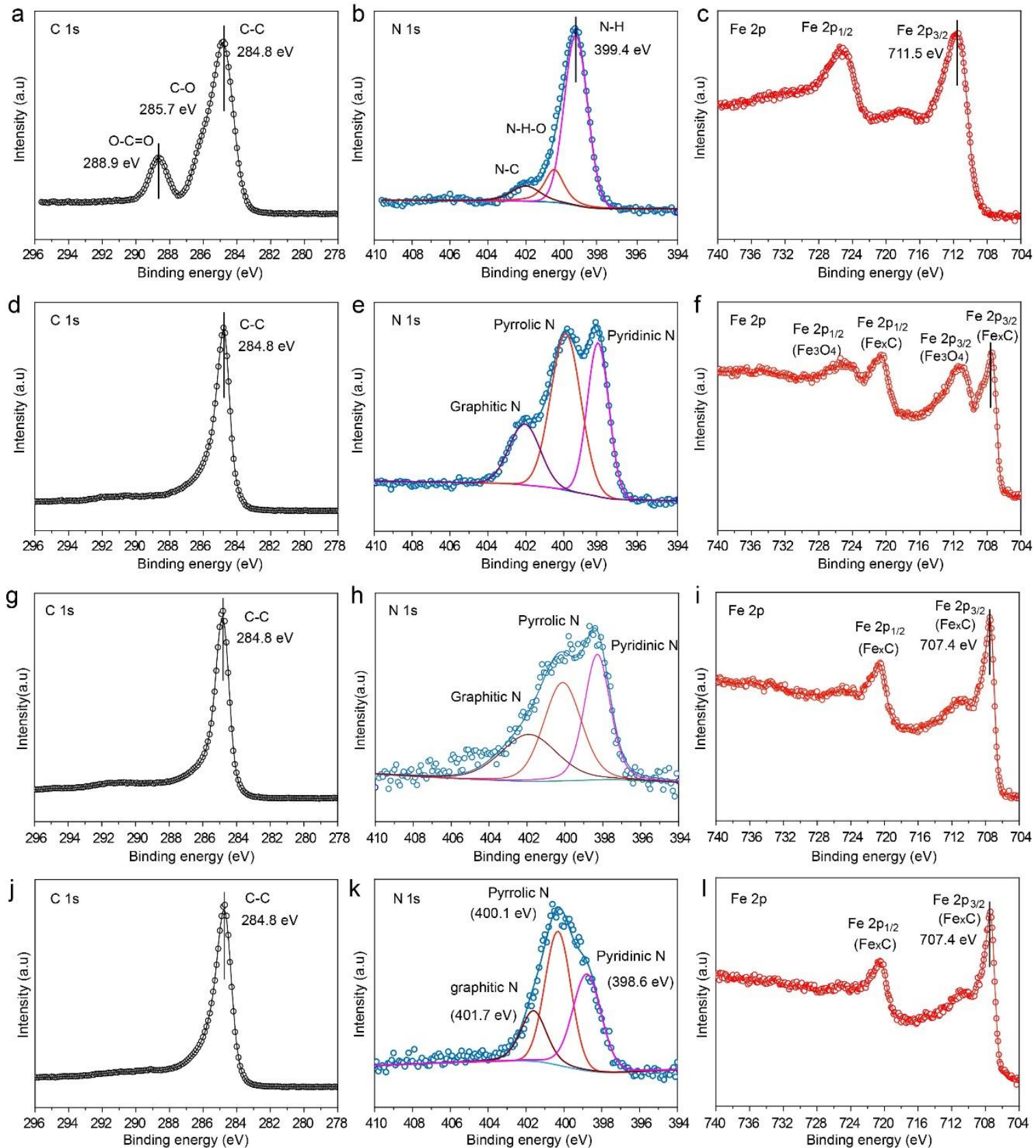

Figure S76. XPS patterns of MIL-101- $\mathrm{NH}_{2}$ and $\mathrm{FeC}_{x}$. (a) $\mathrm{C}$ 1s, (b) $\mathrm{N}$ 1s, (c) $\mathrm{Fe} 2 \mathrm{p}$ of

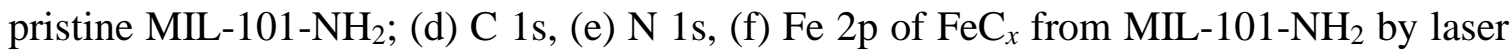
metallurgy at $3.5 \mathrm{~W}$; (g) $\mathrm{C} 1 \mathrm{~s}$, (h) $\mathrm{N} 1 \mathrm{~s}$, (i) Fe 2p from MIL-101- $\mathrm{NH}_{2}$ by laser metallurgy at $5 \mathrm{~W}$; (j) $\mathrm{C}$ 1s, (k) N 1s, (l) Fe 2p from MIL-101- $\mathrm{NH}_{2}$ by laser metallurgy at $7 \mathrm{~W}$. After laser treatment, the disappearance of $\mathrm{O}-\mathrm{C}=\mathrm{O}$ peak suggest the removal of oxygen specious and formation of carbon species. The peaks at $720.7 \mathrm{eV}$ and 707.4 707.6 eV indicate the formation of iron carbide. 

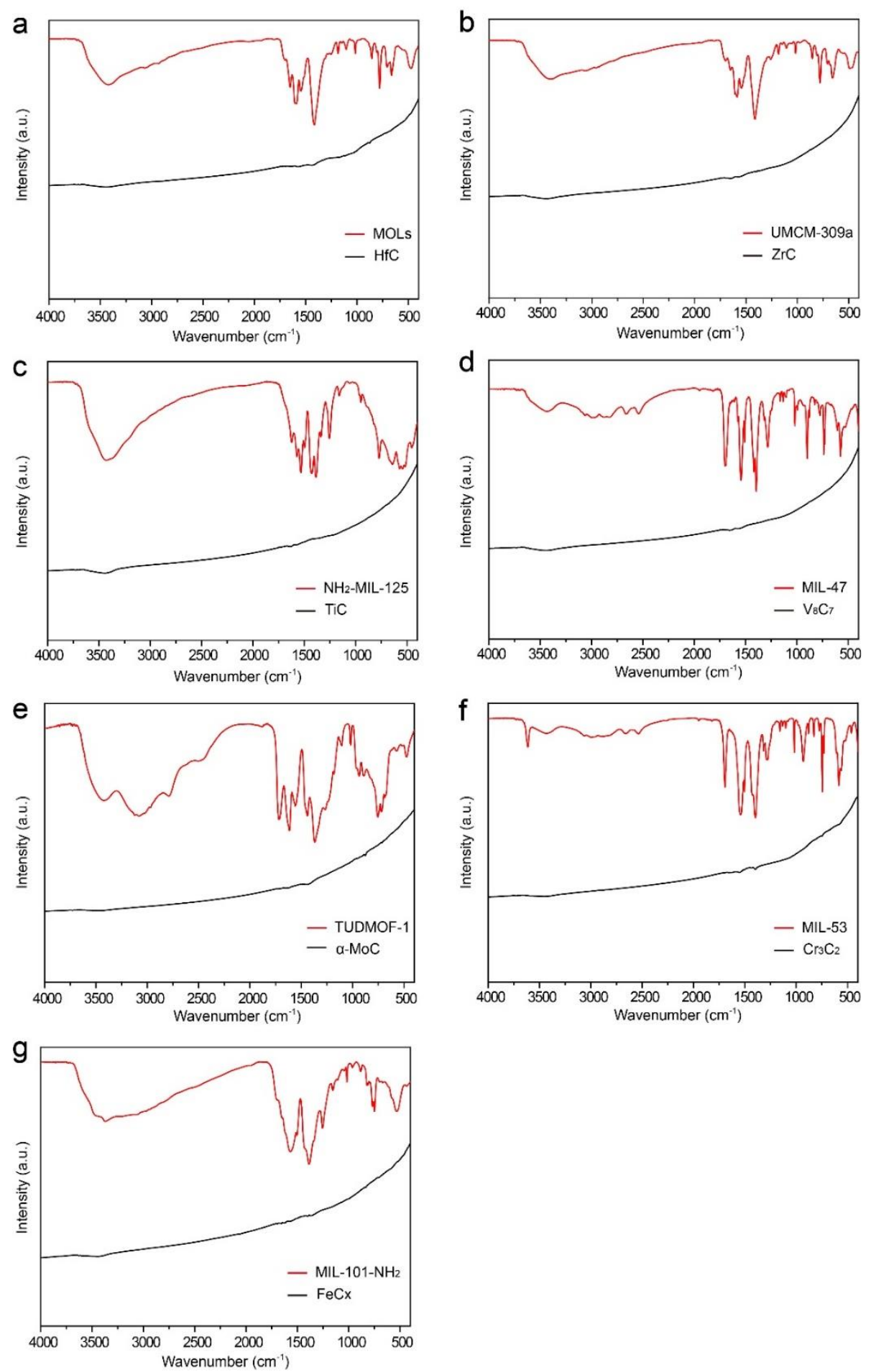

Figure S77. Infrared spectroscopy of TMCs (black line) and their corresponding MOF precursors (red line). (a) MOLs and HfC, (b) UMCM309-a and ZrC, (c) $\mathrm{NH}_{2}-\mathrm{MIL}-125$ and TiC, (d) MIL-47 and $\mathrm{V}_{8} \mathrm{C}_{7}$, (e) TUDMOF-1 and $\alpha-\mathrm{MoC}$, (f) MIL-53 and $\mathrm{Cr}_{3} \mathrm{C}_{2}$, (g) MIL$101-\mathrm{NH}_{2}$ and $\mathrm{FeC}_{\mathrm{x}}$. 

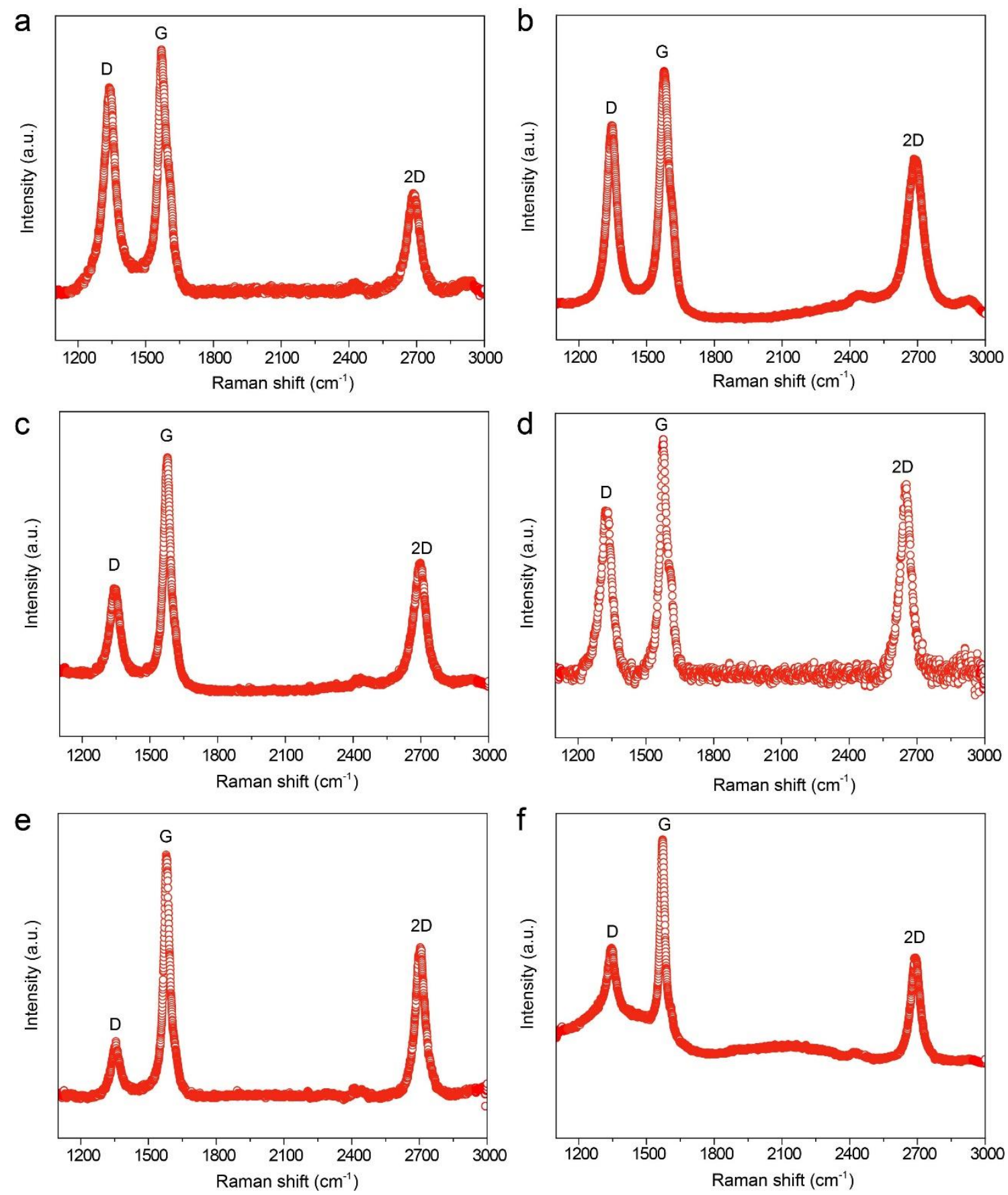

Figure S78. Raman spectrums of (a) $\mathrm{HfC}$, (b) $\mathrm{ZrC}$, (c) $\mathrm{TiC}$, (d) $\mathrm{V}_{8} \mathrm{C}_{7}$, (e) $\alpha$-MoC and (f) $\mathrm{Cr}_{3} \mathrm{C}_{2}$ produced by laser metallurgy. 

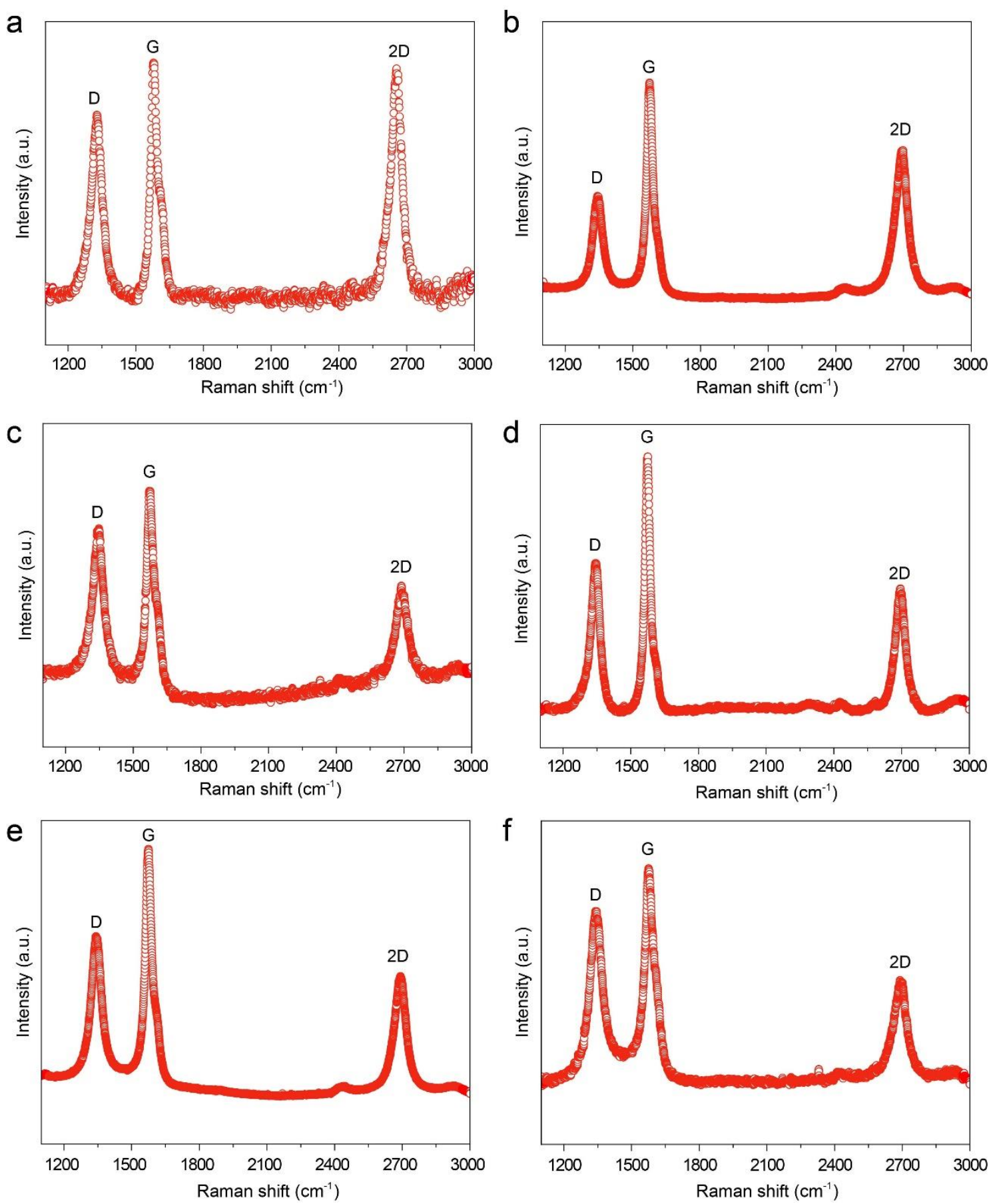

Figure S79. Raman spectrums of $\mathrm{FeC}_{\mathrm{x}}$ from (a) MIL-101 by laser metallurgy at $7 \mathrm{~W}$, (b) MIL-101-( $\left.\mathrm{NH}_{2}\right)_{0.5}$ by laser metallurgy at $5 \mathrm{~W}$, (c) MIL-101-( $\left.\mathrm{NH}_{2}\right)_{0.5}$ by laser metallurgy at $7 \mathrm{~W}$, (d) MIL-101- $\mathrm{NH}_{2}$ by laser metallurgy at $3.5 \mathrm{~W}$, (e) MIL-101- $\mathrm{NH}_{2}$ by laser metallurgy at $5 \mathrm{~W}$ and (f) MIL-101- $\mathrm{NH}_{2}$ by laser metallurgy at $7 \mathrm{~W}$. 

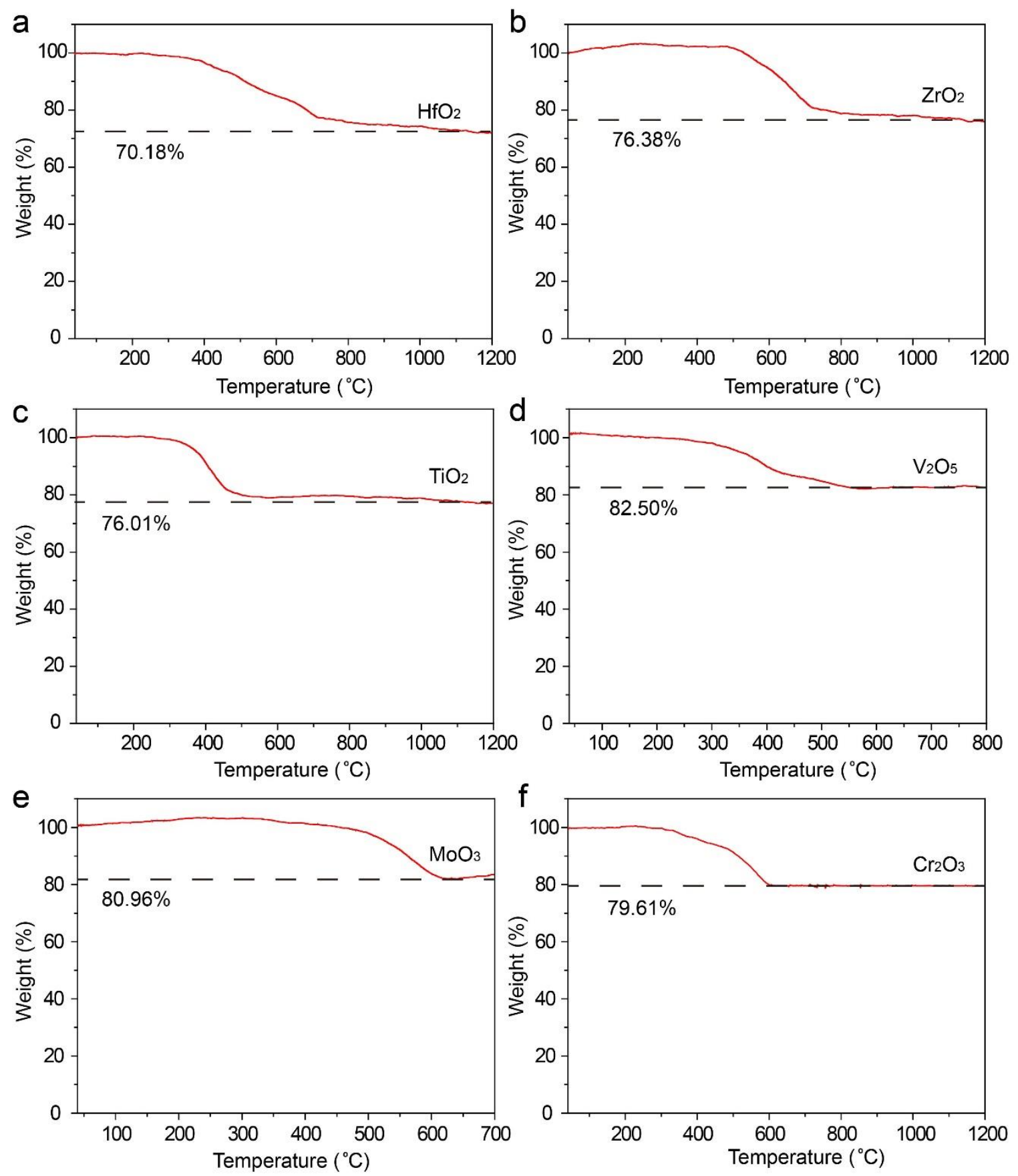

Figure S80. TGA curves of (a) $\mathrm{HfC}$, (b) $\mathrm{ZrC}$, (c) $\mathrm{TiC}$, (d) $\mathrm{V}_{8} \mathrm{C}_{7}$, (e) $\alpha-\mathrm{MoC}$ and (f) $\mathrm{Cr}_{3} \mathrm{C}_{2}$ synthesized by laser metallurgy. 

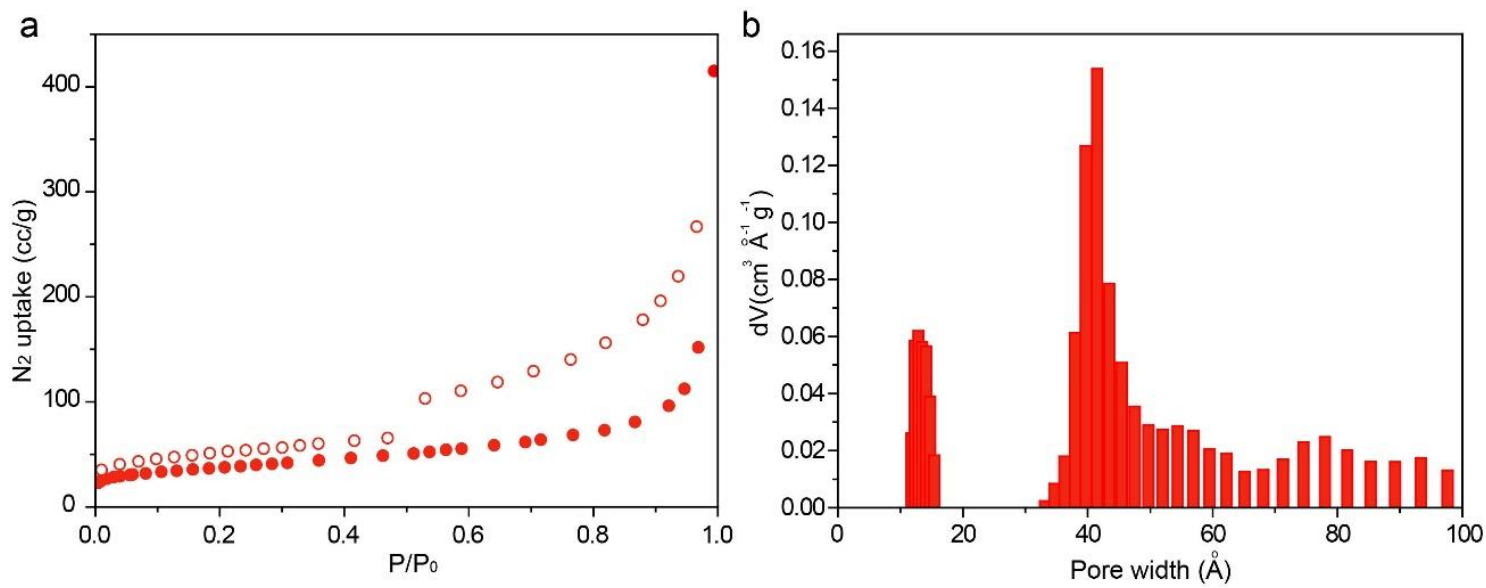

Figure S81. (a) Nitrogen absorption isotherm and (b) pore width distribution of HfC product.
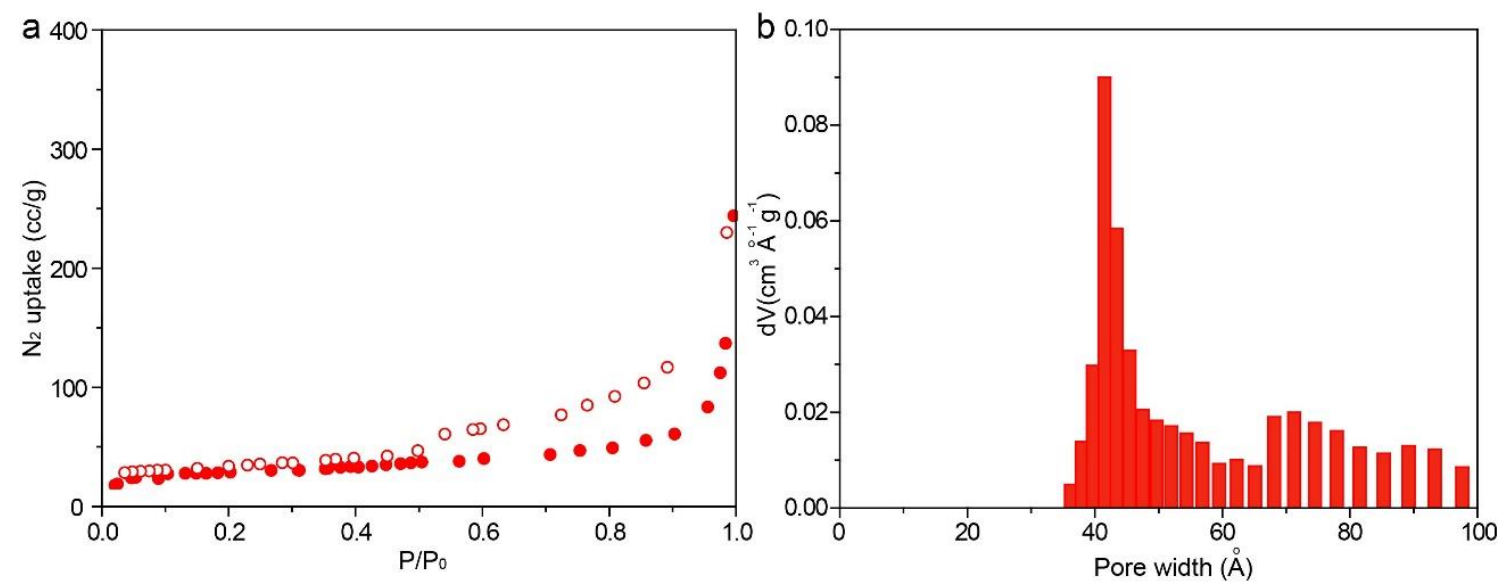

Figure S82. (a) Nitrogen absorption isotherm and (b) pore width distribution of $\mathrm{ZrC}$ product.
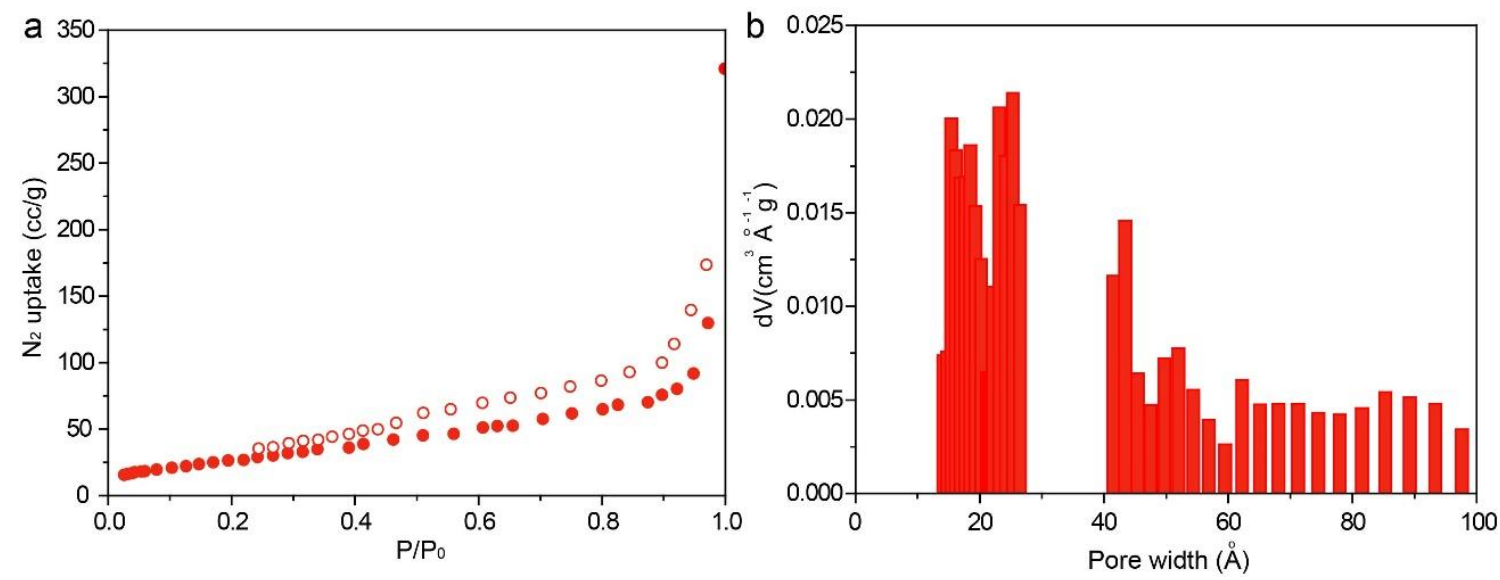

Figure S83. (a) Nitrogen absorption isotherm and (b) pore width distribution of $\mathrm{TiC}$ product. 

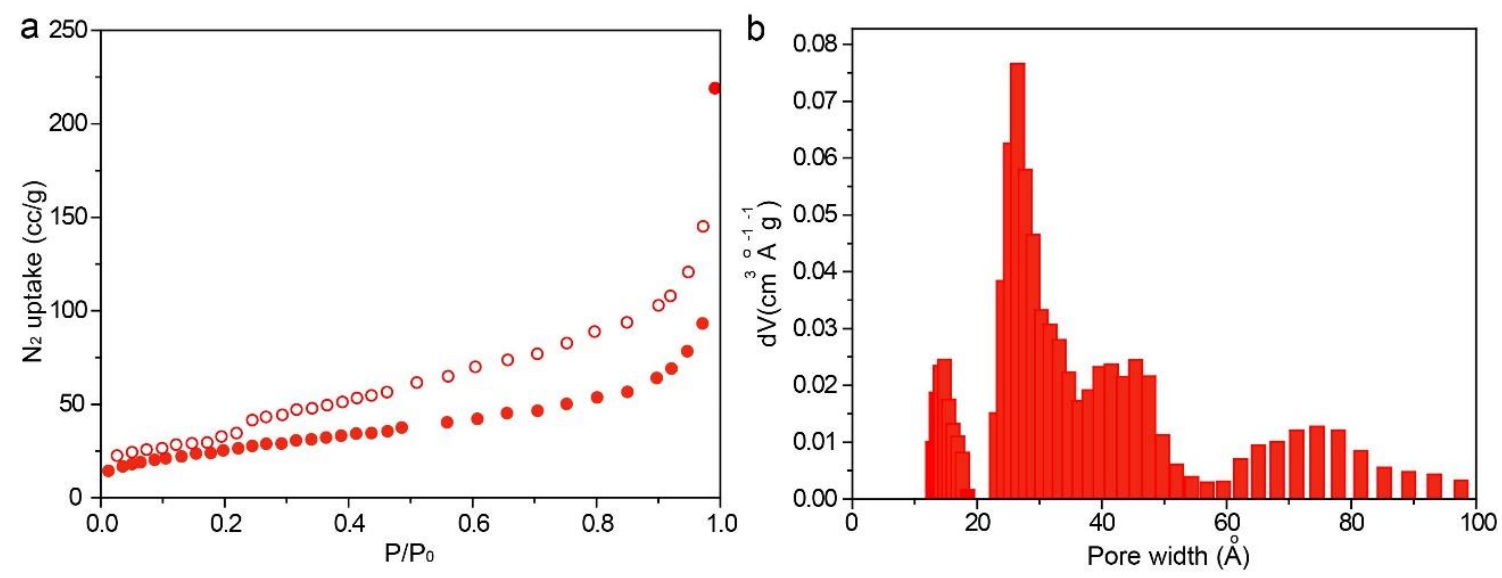

Figure S84. (a) Nitrogen absorption isotherm and (b) pore width distribution of $\mathrm{V}_{8} \mathrm{C}_{7}$ product.
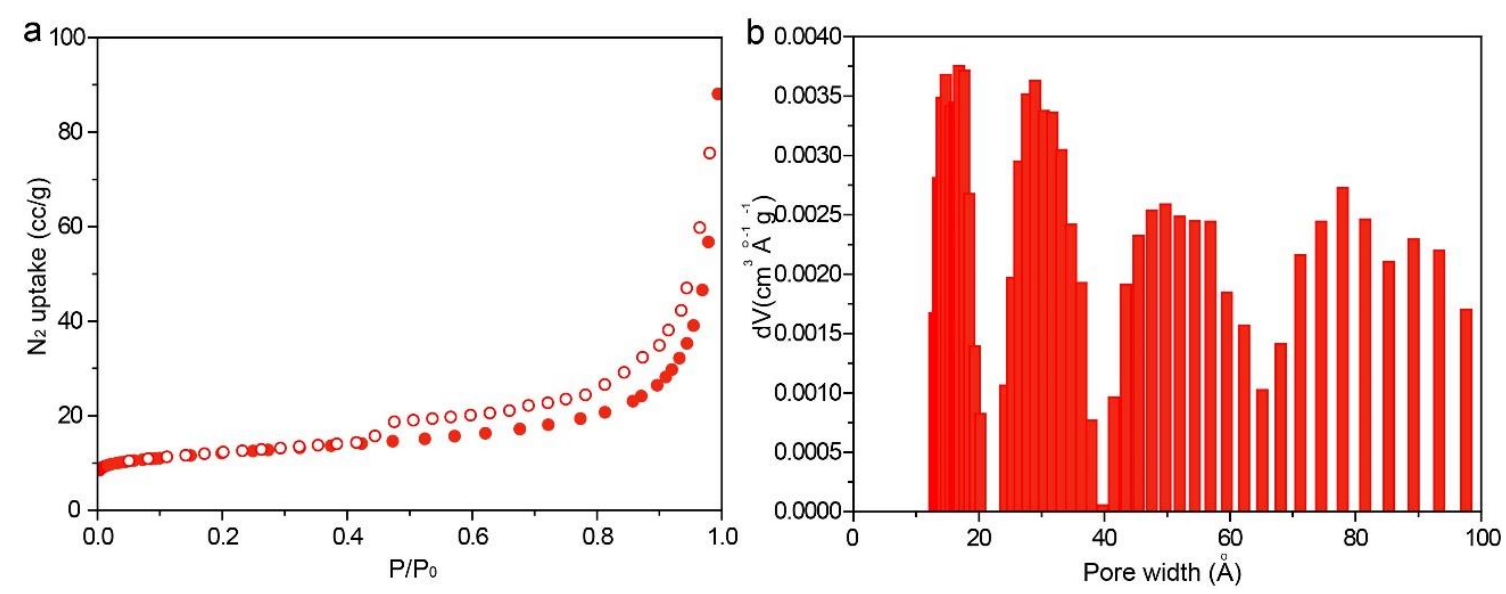

Figure S85. (a) Nitrogen absorption isotherm and (b) pore width distribution of $\alpha$-MoC product.
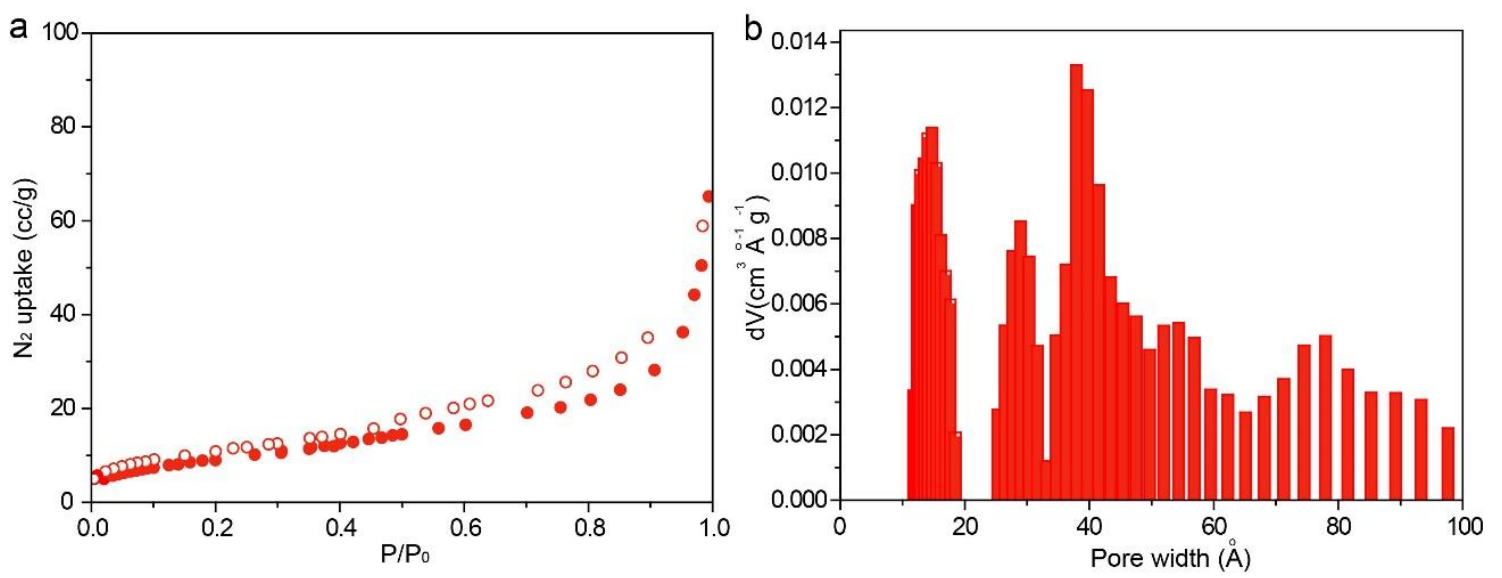

Figure S86. (a) Nitrogen absorption isotherm and (b) pore width distribution of $\mathrm{Cr}_{3} \mathrm{C}_{2}$ product. 


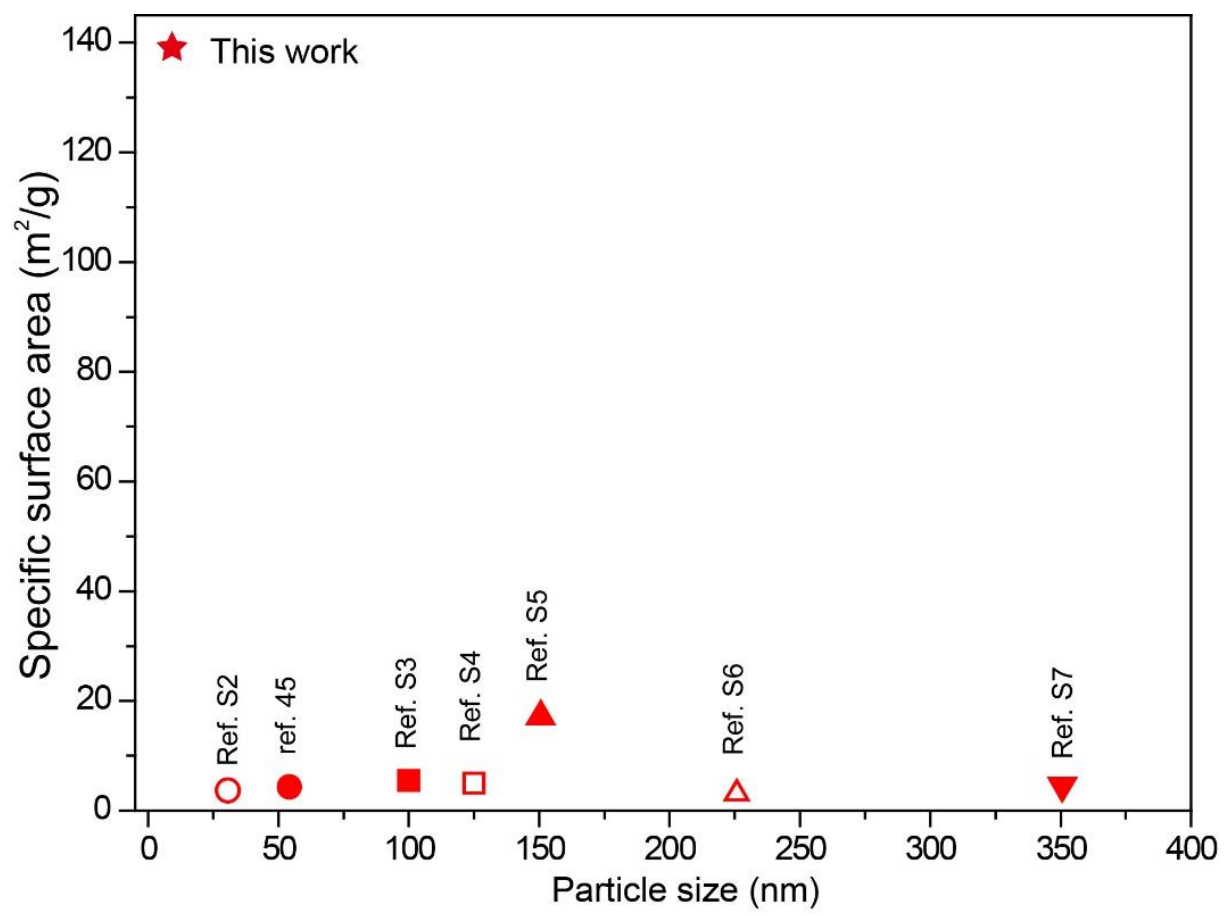

Figure S87. (a) Comparison of particle size and specific surface areas of HfC synthesized by laser metallurgy and other methods. 

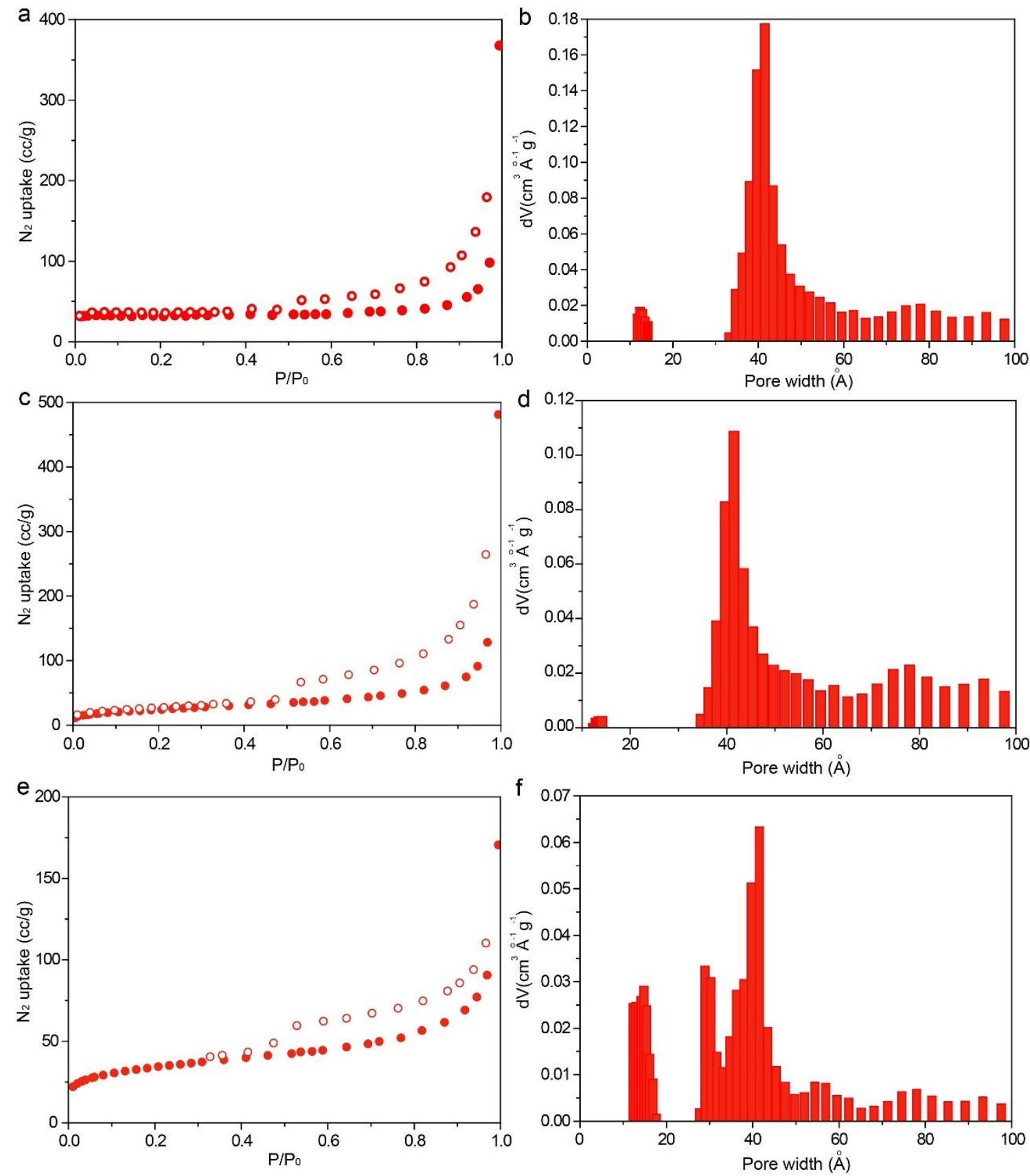

Figure S88. (a) Nitrogen absorption isotherm and (b) pore width distribution of $\mathrm{FeC}_{\mathrm{x}}$ from MIL-101 by laser metallurgy at 7 W. (c) Nitrogen absorption isotherm and (d) pore width distribution of $\mathrm{FeC}_{\mathrm{x}}$ from MIL-101-( $\left.\mathrm{NH}_{2}\right)_{0.5}$ by laser metallurgy at $5 \mathrm{~W}$. (e) Nitrogen absorption isotherm and (f) pore width distribution of $\mathrm{FeC}_{\mathrm{x}}$ from MIL-101- $\left(\mathrm{NH}_{2}\right)_{0.5}$ by laser metallurgy at $7 \mathrm{~W}$. 

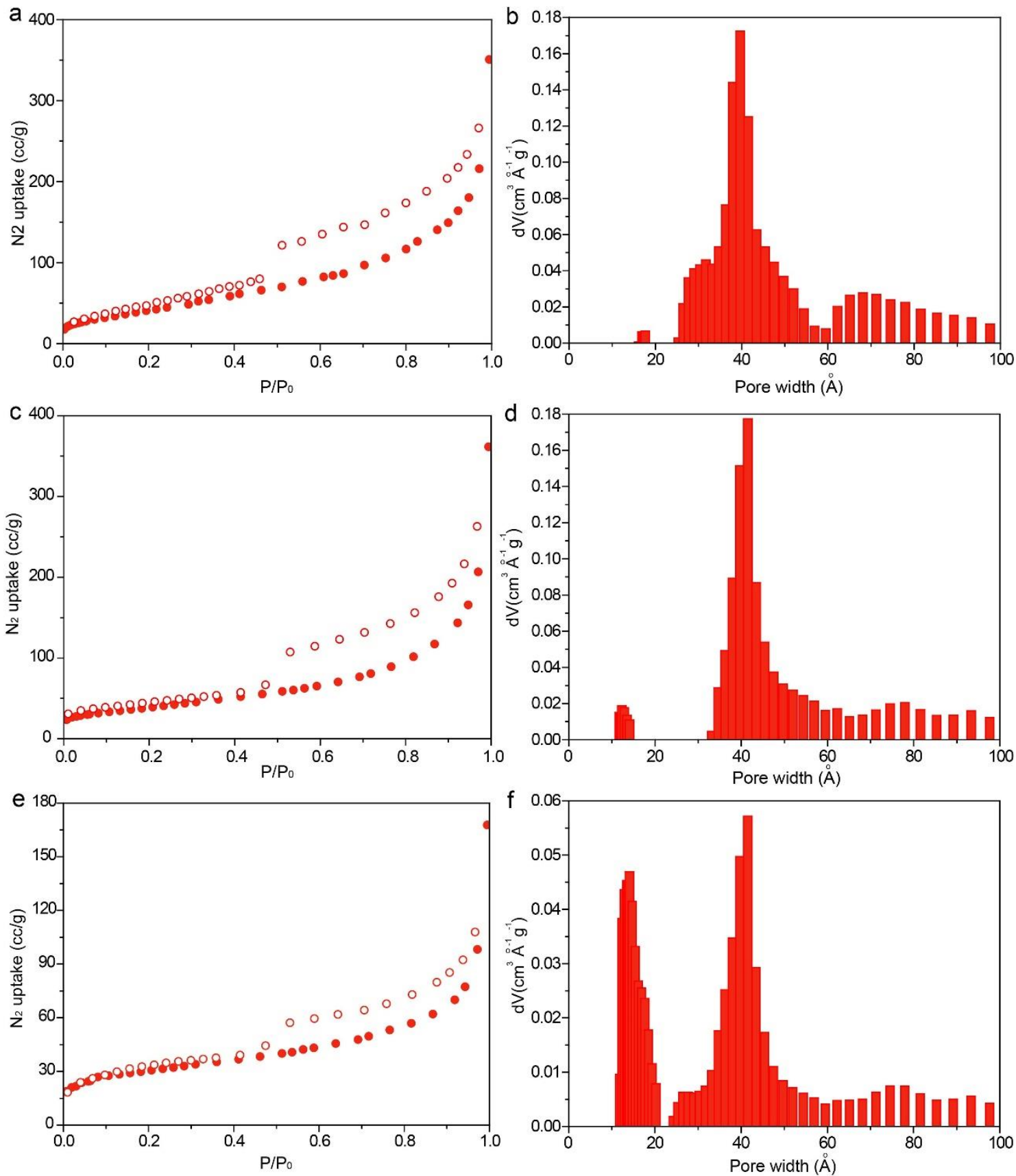

Figure S89. (a) Nitrogen absorption isotherm and (b) Pore width distribution of $\mathrm{FeC}_{\mathrm{x}}$ from MIL-101- $\mathrm{NH}_{2}$ by laser metallurgy at $3.5 \mathrm{~W}$. (c) Nitrogen absorption isotherm and (d) pore width distribution of $\mathrm{f} \mathrm{FeC}_{\mathrm{x}}$ from MIL-101- $\mathrm{NH}_{2}$ by laser metallurgy at $5 \mathrm{~W}$. (e) Nitrogen absorption isotherm and (f) pore width distribution of $\mathrm{f} \mathrm{FeC}_{\mathrm{x}}$ from MIL-101- $\mathrm{NH}_{2}$ by laser metallurgy at $7 \mathrm{~W}$. 


\section{Section S4. Catalysis performance test of TMC nanoparticles in FTS}

Before FTS test, the content of Fe in the products was analyzed by TGA performed in air condition (Fig. S90). No obvious weight loss was found before $250{ }^{\circ} \mathrm{C}$, suggesting the thermal stability of the catalysts. The weight increases in the range of $300 \sim 400{ }^{\circ} \mathrm{C}$ were ascribed to the combination of oxygen in air with the iron atoms. When the temperature was increased to $600{ }^{\circ} \mathrm{C}$, all of the carbon species were burned as gases and the residual was identified as $\mathrm{Fe}_{2} \mathrm{O}_{3}$ as revealed by PXRD. Elemental analyst showed that the nitrogen content in the $\mathrm{FeC}_{\mathrm{x}}$ products was proportional with the mount of amino functional groups in MOF precursors (Table S2), while the iron content was relatively stable at $43 \sim 49 \mathrm{wt} \%$, which was also in accordance with ICP-MS result (Fig. S90).

FTS catalytic tests were carried out in a fixed-bed microreactor and the catalysts were loaded in a quartz tube with inner diameter of $4 \mathrm{~mm}$. For each test, $35 \mathrm{mg}$ of catalyst was mixed with $120 \mathrm{mg} \mathrm{SiC}$ particles. Samples were tested under the pressure of $2 \mathrm{MPa}$

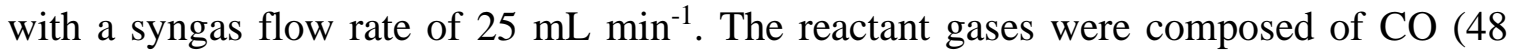
vol. \%), $\mathrm{H}_{2}\left(48\right.$ vol. \%) and $\mathrm{Ar}\left(4\right.$ vol. \%). The reaction temperature was $340{ }^{\circ} \mathrm{C}$ and with $2{ }^{\circ} \mathrm{C}$ min $^{-1}$ heating rate in the beginning.

The FTS products were analyzed by two online GC instruments. One was equipped with a flame ionization detector (FID) and a FFAP capillary column $(30 \mathrm{~m} \times 0.32 \mathrm{~mm} \times$ $1.0 \mu \mathrm{m})$. The other one was equipped with FID detector and a thermal conductivity detector (TCD). A PoraPLOT Q capillary column $(50 \mathrm{~m} \times 0.32 \mathrm{~mm} \times 10 \mu \mathrm{m})$ was connected to the FID detector, while a $13 \mathrm{X}$ packed column $(3 \mathrm{~m} \times 3 \mathrm{~mm}$ O.D. $\times 2 \mathrm{~mm}$ I.D. $)$ with a prelinked Porapak Q packed column ( $2 \mathrm{~m} \times 3 \mathrm{~mm}$ O.D. $\times 2 \mathrm{~mm}$ I.D. $)$ was connected to the TCD detector. $\mathrm{CO}, \mathrm{CO}_{2}$ and $\mathrm{CH}_{4}$ were analyzed by TCD with $\mathrm{Ar}$ as internal standard, while other products were analyzed by the two FID detectors, and $\mathrm{CH}_{4}$ was used to connect the analysis. A six-way valve kept in an oven at $240^{\circ} \mathrm{C}$ was used for products sampling. $\mathrm{CO}$ conversion was calculated on the basis of a carbon atom. The $\mathrm{CO}$ conversion $\left(C_{\mathrm{CO}}\right), \mathrm{CO}_{2}$ selectivity $\left(S_{\mathrm{CO} 2}\right)$ and hydrocarbon selectivity $\left(\mathrm{S}_{\mathrm{CxHy}}\right)$ were calculated according to the equations shown below:

$$
\begin{aligned}
& C_{C O}=\frac{\mathrm{CO}_{\text {in }}-\mathrm{CO}_{\text {out }}}{\mathrm{CO}_{\text {in }}} \times 100 \% ;(3) \\
& S_{\mathrm{CO}_{2}}=\frac{\mathrm{CO}_{2_{\text {out }}}}{\mathrm{CO}_{\text {in }}-\mathrm{CO}_{\text {out }}} \times 100 \% ;(4)
\end{aligned}
$$




$$
S_{C_{x} H_{y}}=\frac{x C_{x} H_{y_{\text {out }}}}{\sum x C_{x} H_{y_{\text {out }}}} \times 100 \% \text {; (5) }
$$

Where $C O_{\text {in }}$ denotes the moles of $\mathrm{CO}$ in feedstock, and $\mathrm{CO}_{\text {out }}, \mathrm{CO}_{2 o u t}$ and $\mathrm{C}_{x} \mathrm{H}_{\text {yout }}$ denote the carbon moles of $\mathrm{CO}, \mathrm{CO}_{2}$ and hydrocarbons at the outlet of the reactor, respectively. The calculated carbon balance is between $95 \% \sim 98 \%$ under different reaction conditions.

The $\mathrm{CO}$ conversion (\%), carbon selectivity (\%) and molar fraction of each product are listed in Table S3. The catalytic activity is expressed as Fe time of yield (FTY), defined as the amount (mol) of $\mathrm{CO}$ converted to hydrocarbons per gram of Fe per second. The $\mathrm{o} / \mathrm{p}$ ratio represents the molar ratio of olefin versus paraffin. We found that the $\mathrm{CO}$ conversion rate increased gradually with the $\mathrm{N}$ content in $\mathrm{FeC}_{\mathrm{x}}$ catalysts. When the nitrogen content increased from 0 to $0.68 \mathrm{wt} \%$ in $\mathrm{FeC}_{\mathrm{x}}$ catalysts, $\mathrm{CO}$ conversion increased from $49.9 \%$ to $73.9 \%$. The catalyst with nitrogen content of $1.55 \mathrm{wt} \%$ showed a high CO conversion of $85.8 \%$, with FTY of $285.9 \mu$ molco $_{\mathrm{Fe}^{-1}} \mathrm{~s}^{-1}$. The selectivity to $\mathrm{C}_{5+}$ products of these catalysts was as high as $43.8 \%$, while the selectivity for $\mathrm{C}_{2}-\mathrm{C}_{4}$ olefins was restricted under $15.4 \%$. In order to further improve the selectivity for the formation of $\mathrm{C}_{5+}$ products, $\mathrm{K}^{+}$ ions were introduced into the $\mathrm{FeC}_{\mathrm{x}}$ catalysts by wet-impregnation of $\mathrm{K}_{2} \mathrm{CO}_{3}$ aqueous solution. After impregnation with $\mathrm{K}^{+}$ions, the $\mathrm{CO}$ conversion, o/p ratio and selectivity for long chain hydrocarbons were increased obviously. This was attributed to the existence of $\mathrm{K}$ on the surface of iron carbide catalyst alters the electronic structure which made the catalyst more active for $\mathrm{CO}$ activation [S8-S10]. The chain growth probabilities $(\alpha)$ increased from 0.64 (for the catalyst without $\mathrm{K}$ ) to 0.73 (catalyst with $0.6 \mathrm{wt} \% \mathrm{of} \mathrm{K}$ ), and the o/p ratio for $\mathrm{C}_{2}-\mathrm{C}_{4}$ increased from 0.82 (without K) to 3.9 (with K) (Fig. S95). By comparison with catalysts with different amount of $\mathrm{K}$, we found that $0.6 \mathrm{wt} \% \mathrm{~K}$ is an optimal amount (Fig. S93b). This catalyst showed $51 \%$ selectivity towards $\mathrm{C}_{5+}$ hydrocarbons, excellent stability of time on stream, and a restricted methane selectivity of $15 \%$.

The spent catalysts were characterized by SEM images and PXRD. After FTS reaction, graphite fibers were observed in all samples (Fig. S96 and S97). PXRD patterns showed that the main iron-containing phases in the catalysts were $\mathrm{Fe}_{5} \mathrm{C}_{2}$ and $\mathrm{Fe}_{3} \mathrm{O}_{4}$ after FTS reaction (Fig. S99). New peaks assigning to N-Heneicosane carbon species were detected 
in higher $\mathrm{K}^{+}$content $(0.8 \mathrm{wt} \%$ and $1.0 \mathrm{wt} \%)$, while these peaks were absent in catalyst with lower $\mathrm{K}^{+}$dopant $(0.6 \mathrm{wt} \%)$ (Fig. S100). The catalysts with higher content of $\mathrm{K}^{+}$displayed faster performance decay in FTS test, because of the well-known carbon deposition phenomenon on the surface of catalyst which covered the active sites of catalysts. 

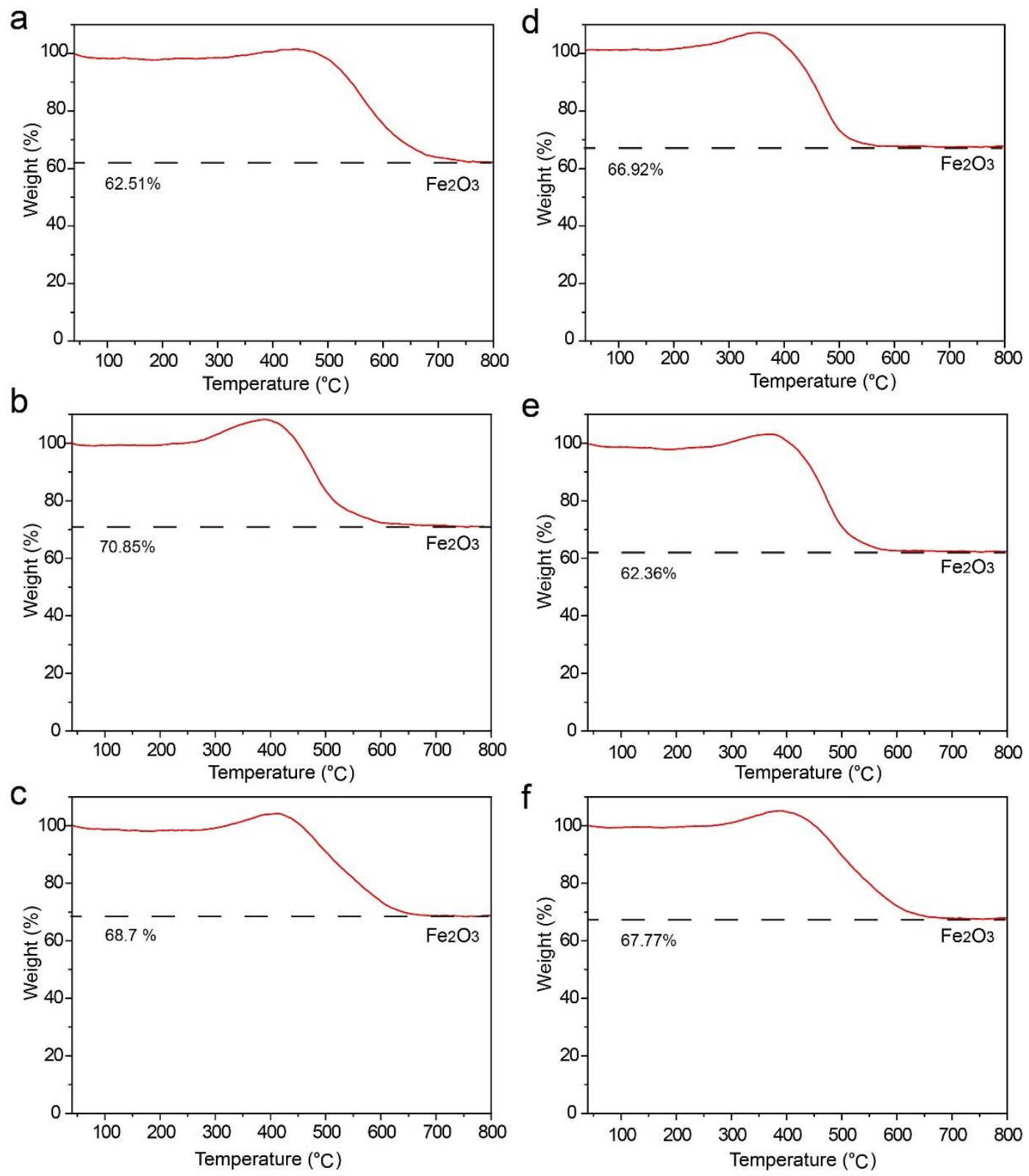

Figure S90. TG curves of $\mathrm{FeC}_{x}$ products obtained from (a) MIL-101 by laser metallurgy at $7 \mathrm{~W}$; MIL-101-( $\left.\mathrm{NH}_{2}\right)_{0.5}$ by laser metallurgy at (b) $5 \mathrm{~W}$, (c) $7 \mathrm{~W}$; and MIL-101- $\mathrm{NH}_{2}$ by laser metallurgy at (d) $3.5 \mathrm{~W}$, (e) $5 \mathrm{~W}$ and (f) $7 \mathrm{~W}$. The residual was identified as $\mathrm{Fe}_{2} \mathrm{O}_{3}$ by PXRD. 
Table S2. Element contents of catalyst

\begin{tabular}{|c|c|c|c|c|}
\hline Catalyst & $\mathrm{Fe}(\mathrm{wt} \%)^{[\mathrm{b}]}$ & $\mathrm{C}(\mathrm{wt} \%)$ & $\mathrm{N}(\mathrm{wt} \%)$ & $\mathrm{H}(\mathrm{wt} \%)$ \\
\hline MIL-101-7 W $\mathrm{W}^{[\mathrm{a}]}$ & 43.72 & 45.87 & -- & 0.452 \\
\hline MIL-101-( $\left.\mathrm{NH}_{2}\right)_{0.5}-5 \mathrm{~W}$ & 49.55 & 42.69 & 0.69 & 0.401 \\
\hline MIL-101-( $\left.\mathrm{NH}_{2}\right)_{0.5-7} \mathrm{~W}$ & 48.05 & 40.01 & 0.23 & 0.393 \\
\hline MIL-101-NH $-3.5 \mathrm{~W}$ & 46.80 & 47.04 & 2.08 & 0.476 \\
\hline MIL-101-NH ${ }_{2}-5 \mathrm{~W}$ & 43.61 & 45.90 & 1.55 & 0.373 \\
\hline MIL-101)-NH2-7 W & 47.40 & 46.63 & 0.68 & 0.295 \\
\hline
\end{tabular}

${ }^{[a]}$ MIL-101-7 W represents $\mathrm{FeC}_{x}$ obtained from MIL-101 by laser metallurgy at $7 \mathrm{~W} .{ }^{[b]}$ The iron content is obtained from ICP-MS analysis, which is accordance with TG result.

Table S3. Catalytic performance of iron carbide catalyst in Fischer-Tropsch synthesis ${ }^{[a]}$

\begin{tabular}{|c|c|c|c|c|c|c|c|}
\hline \multirow{3}{*}{ Catalyst } & \multirow{3}{*}{$\begin{array}{c}\mathrm{CO} \\
\text { Conv. } \\
1 \%\end{array}$} & \multirow{3}{*}{$\begin{array}{c}\mathrm{CO}_{2} \\
\text { Select. } \\
1 \%\end{array}$} & \multicolumn{4}{|c|}{ Hydrocarbon selectivity $\left(\mathrm{CO}_{2}\right.$ free $) / \%$} & \multirow{3}{*}{$\begin{array}{l}\text { FTY (umol } \mathrm{gFe}^{-1} \\
\left.\mathrm{~s}^{-1}\right)^{[\mathrm{b}]}\end{array}$} \\
\hline & & & \multirow[t]{2}{*}{$\mathrm{CH}_{4}$} & \multirow[t]{2}{*}{$\mathrm{C}_{2}-\mathrm{C}_{4},=$} & \multirow[t]{2}{*}{$\mathrm{C}_{2}-\mathrm{C}_{4}{ }^{0}$} & \multirow[t]{2}{*}{$\mathrm{C}_{5+}$} & \\
\hline & & & & & & & \\
\hline MIL-101-7 W & 49.86 & 35.27 & 33.84 & 14.72 & 16.44 & 35.00 & 185.7 \\
\hline MIL-101-NH $2-3.5 \mathrm{~W}$ & 82.58 & 44.47 & 36.18 & 14.98 & 16.99 & 31.85 & 246.4 \\
\hline MIL-101-NH2-5 W & 85.84 & 42.26 & 29.85 & 14.12 & 17.19 & 38.84 & 285.9 \\
\hline MIL-101-NH $-7 \mathrm{~W}$ & 73.88 & 42.03 & 30.86 & 15.09 & 16.93 & 37.12 & 227.3 \\
\hline MIL-101-( $\left.\mathrm{NH}_{2}\right)_{0.5}-5 \mathrm{~W}$ & 71.17 & 40.51 & 26.71 & 15.07 & 14.45 & 43.77 & 214.9 \\
\hline MIL-101-( $\left.\mathrm{NH}_{2}\right)_{0.5-7} \mathrm{~W}$ & 62.11 & 40.30 & 30.29 & 15.41 & 15.73 & 38.75 & 194.1 \\
\hline MIL-101-7 W-K & 58.96 & 45.91 & 15.87 & 25.58 & 6.99 & 51.56 & 183.5 \\
\hline MIL-101-( $\left.\mathrm{NH}_{2}\right)_{0.5-5} \mathrm{~W}-\mathrm{K}^{[\mathrm{c}]}$ & 60.26 & 44.59 & 17.61 & 29.27 & 7.27 & 45.85 & 175.8 \\
\hline MIL-101-NH -5 W-K & 93.76 & 48.07 & 17.32 & 24.19 & 6.99 & 51.50 & 292.3 \\
\hline MIL-101- $\mathrm{NH}_{2}-5 \mathrm{~W}^{[\mathrm{d}]}$ & 62.77 & 48.45 & 29.11 & 19.59 & 14.99 & 36.31 & 414.6 \\
\hline MIL-101-NH ${ }_{2}-5$ W-K ${ }^{[d]}$ & 80.29 & 47.50 & 16.80 & 26.23 & 8.35 & 48.62 & 550.6 \\
\hline
\end{tabular}




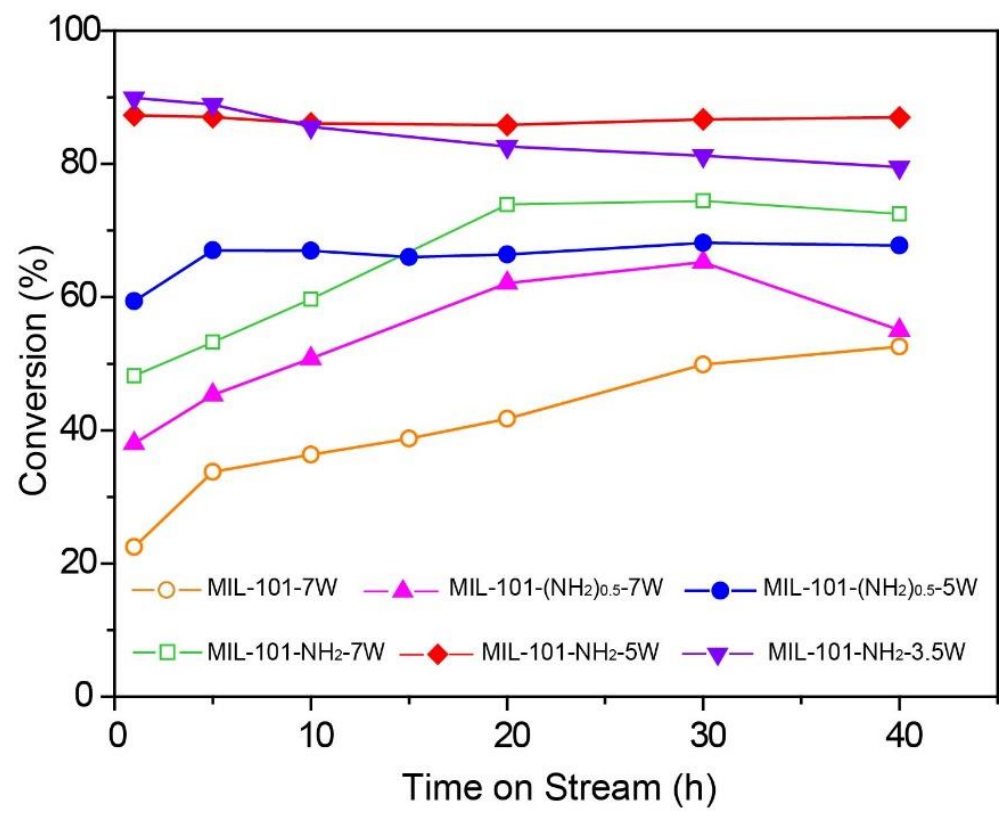

Figure S91. Time on stream evolution of $\mathrm{CO}$ conversion for the catalysts without $\mathrm{K}$. Reaction conditions: $35 \mathrm{mg}$ catalyst, syngas ( $\mathrm{CO}: \mathrm{H}_{2}: \mathrm{Ar}=48: 48: 4 ; 25 \mathrm{~mL} \mathrm{~min}^{-1}$ ), 2.0 $\mathrm{MPa}, 340{ }^{\circ} \mathrm{C}, \mathrm{GHSV}=13300 \mathrm{~h}^{-1}$.
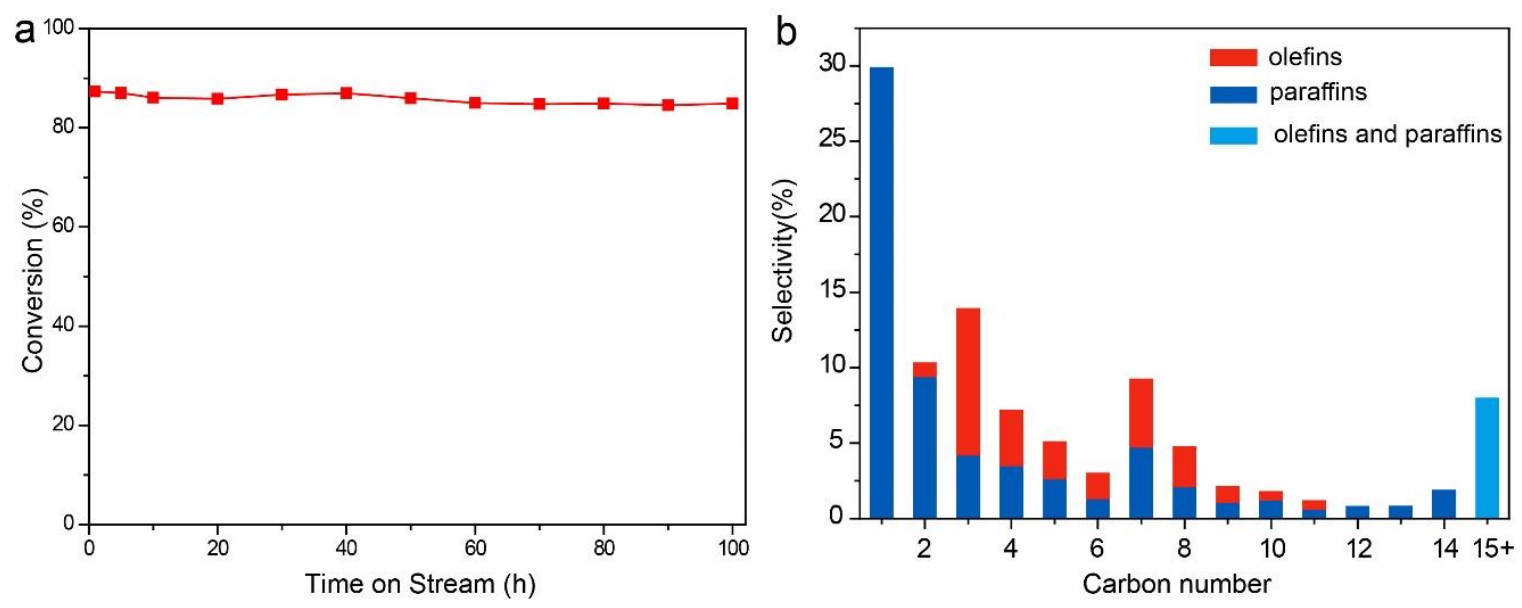

Figure S92. (a) Time on stream of $100 \mathrm{~h}$ evolution of CO conversion and (b) hydrocarbon selectivity for the catalysts $\mathrm{FeC}_{x}$ from MIL-101- $\mathrm{NH}_{2}$ by laser metallurgy at $5 \mathrm{~W}$. Reaction conditions: $35 \mathrm{mg}$ catalyst, syngas ( $\left.\mathrm{CO}: \mathrm{H}_{2}: \mathrm{Ar}=48: 48: 4 ; 25 \mathrm{~mL} \mathrm{~min}^{-1}\right), 2.0 \mathrm{MPa}, 340{ }^{\circ} \mathrm{C}$, $\mathrm{GHSV}=13300 \mathrm{~h}^{-1} \cdot \mathrm{C}_{15+}$ hydrocarbons including olefins and paraffins. 

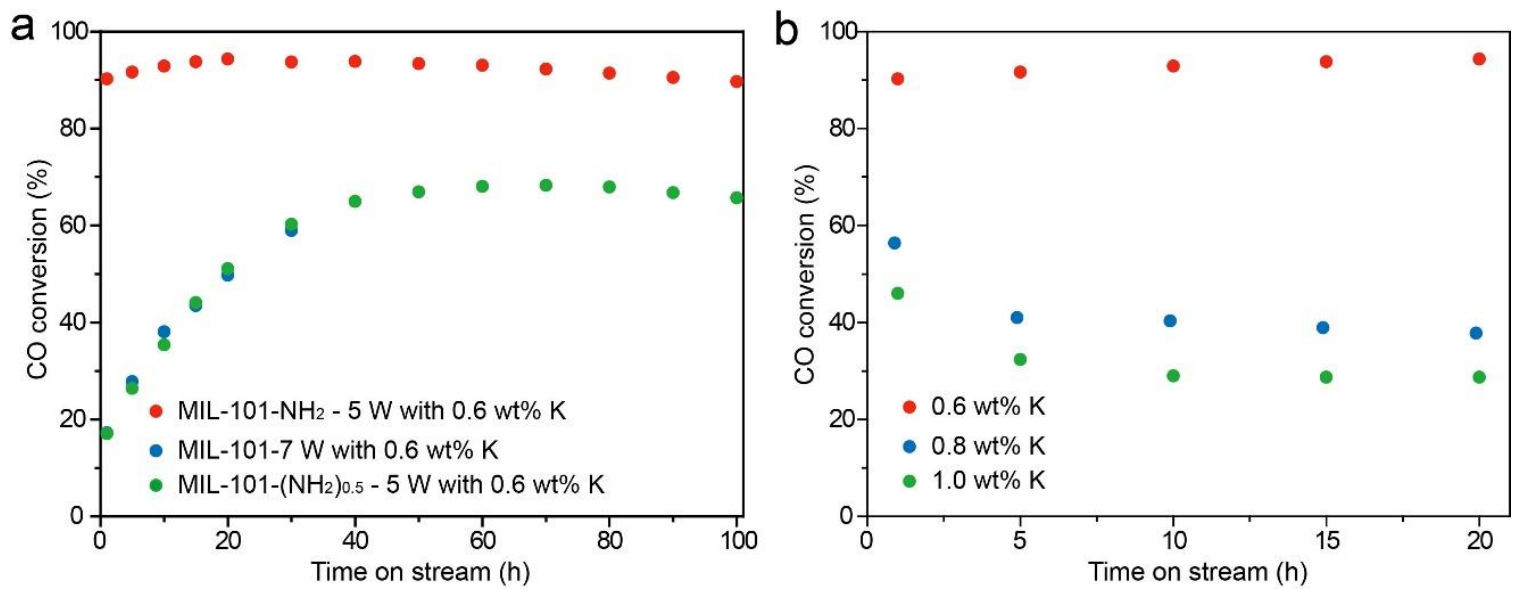

Figure S93. (a) Time on stream evolution of CO conversion for the catalysts with K. (b) Time on stream evolution of $\mathrm{CO}$ conversion for the $\mathrm{FeC}_{x}$ catalysts from MIL-101- $\mathrm{NH}_{2}$ by laser metallurgy at $5 \mathrm{~W}$ with different amount of $\mathrm{K}$ dopant. Reaction conditions: $35 \mathrm{mg}$ catalyst, syngas $\left(\mathrm{CO}: \mathrm{H}_{2}: \mathrm{Ar}=48: 48: 4 ; 25 \mathrm{~mL} \mathrm{~min}^{-1}\right), 2.0 \mathrm{MPa}, 340{ }^{\circ} \mathrm{C}, \mathrm{GHSV}=13300$ $\mathrm{h}^{-1}$.

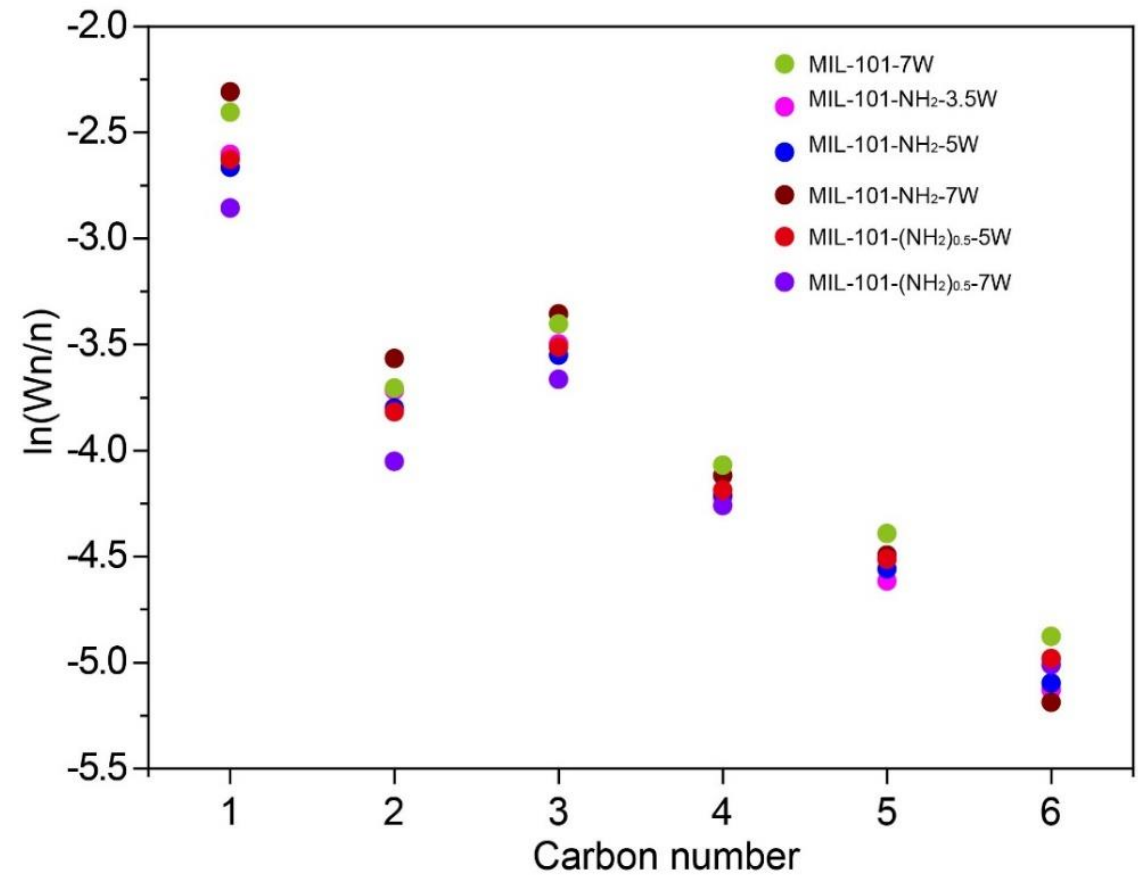

Figure S94. Anderson-Schulz-Flory (ASF) distribution plot (logarithm of the weight fraction $(\mathrm{Wn})$ of the carbon number $(\mathrm{Cn})$ in the product versus $\mathrm{n})$ for the catalyst without $\mathrm{K}^{+}$dopant after $30 \mathrm{~h}$ TOS. 

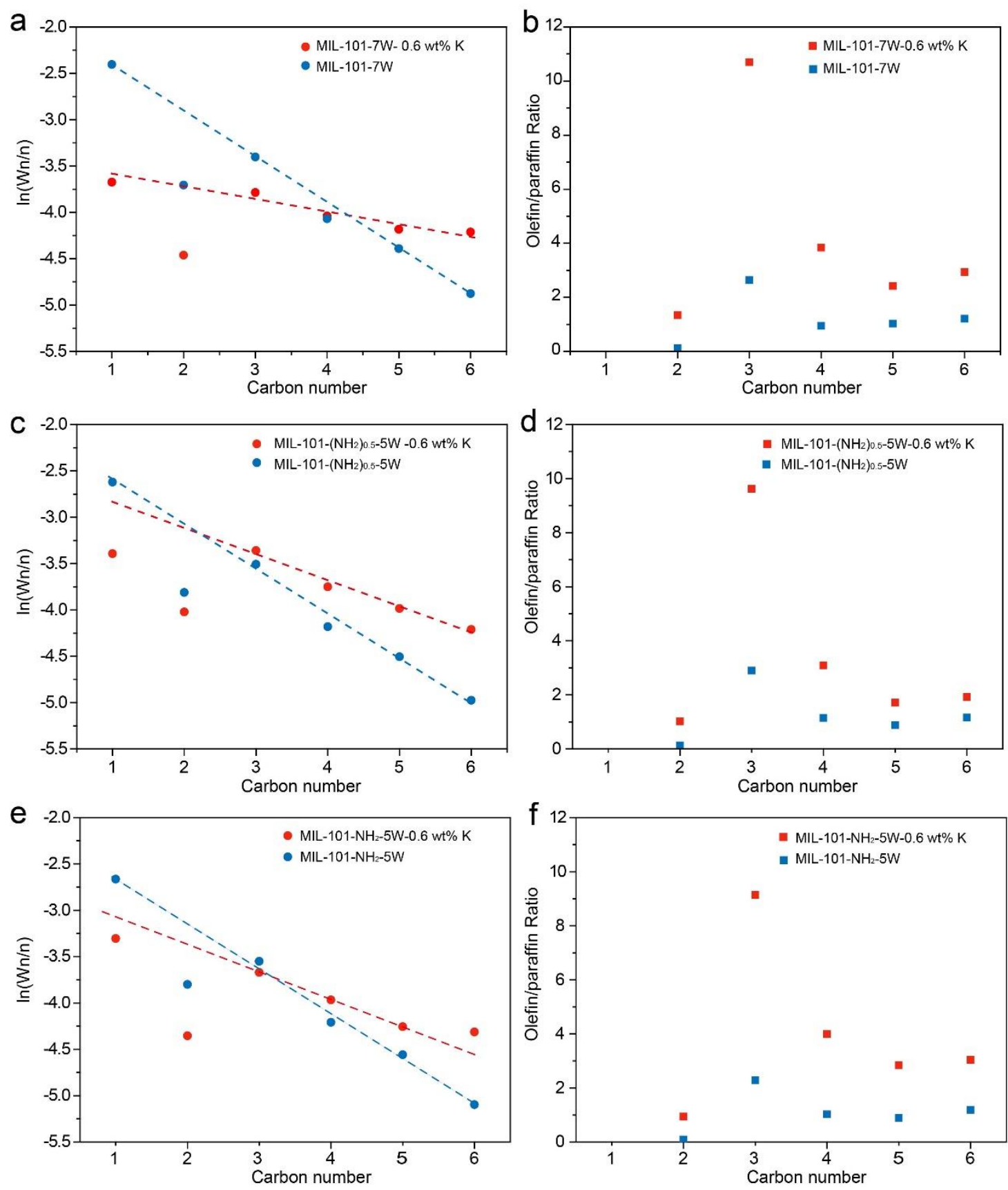

Figure S95. (a, c, e) Anderson-Schulz-Flory (ASF) distribution plot (logarithm of the weight fraction (Wn) of the carbon number $(\mathrm{Cn})$ in the product versus $\mathrm{n}$ ) for the catalyst without $\mathrm{K}$ (blue) and with $\mathrm{K}$ (red) after $30 \mathrm{~h}$ TOS. (b, d, f) Comparison of o/p (olefins/paraffins) molar ration for the catalyst without $\mathrm{K}$ and with $\mathrm{K}$. 

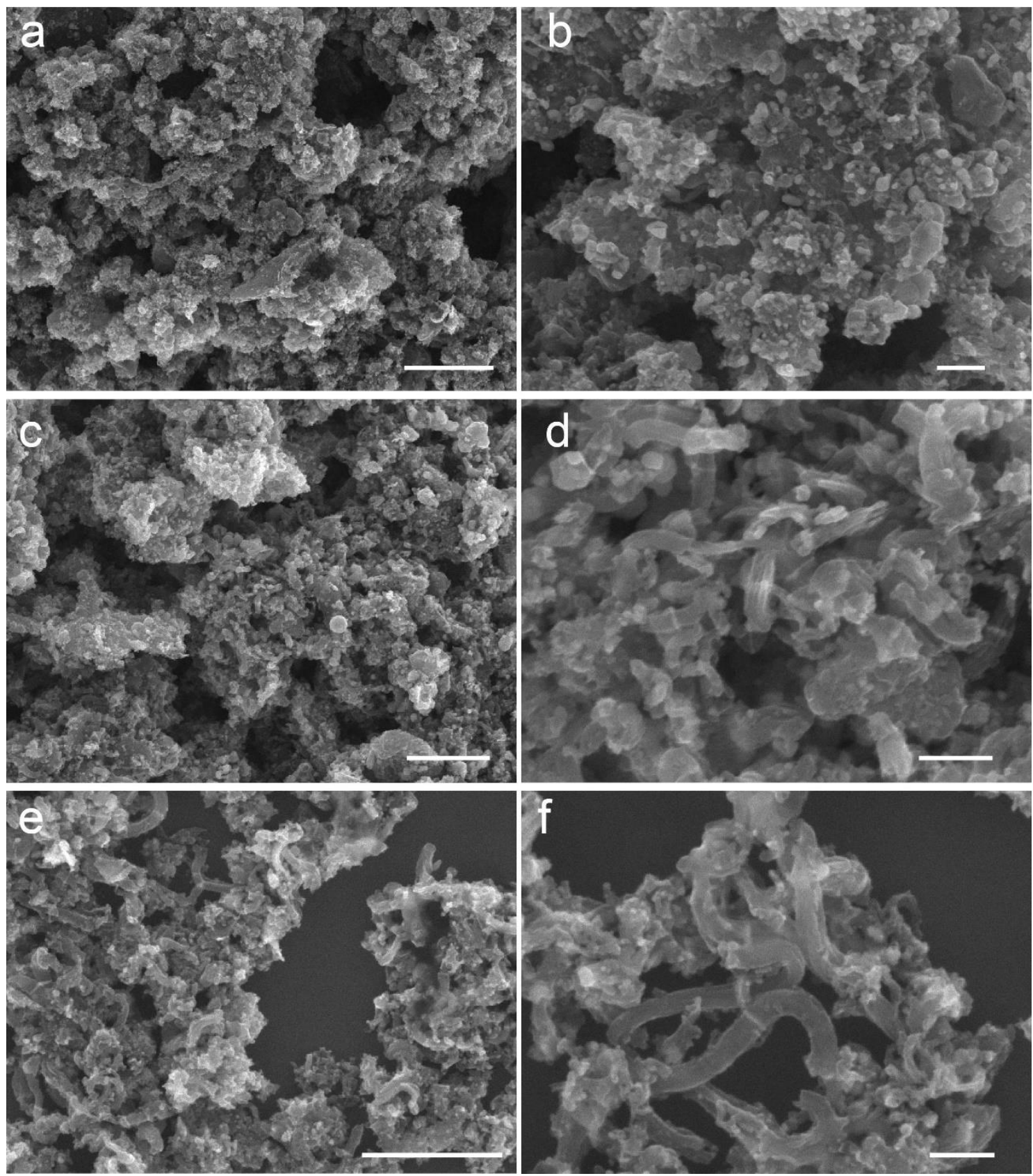

Figure S96. SEM images of spent iron carbide catalysts obtained from (a, b) MIL-101 by laser metallurgy at laser power of $7 \mathrm{~W},(\mathrm{c}, \mathrm{d}) \mathrm{MIL}-101-\left(\mathrm{NH}_{2}\right)_{0.5}$ at laser power of $5 \mathrm{~W}$ and $(\mathrm{e}, \mathrm{f}) \mathrm{MIL}-101-\left(\mathrm{NH}_{2}\right)_{0.5}$ at laser power of $7 \mathrm{~W}$ after FTS reaction. Scale bar is $1 \mu \mathrm{m}$ in (a, c, e) and $200 \mathrm{~nm}$ in (b, d, f). 

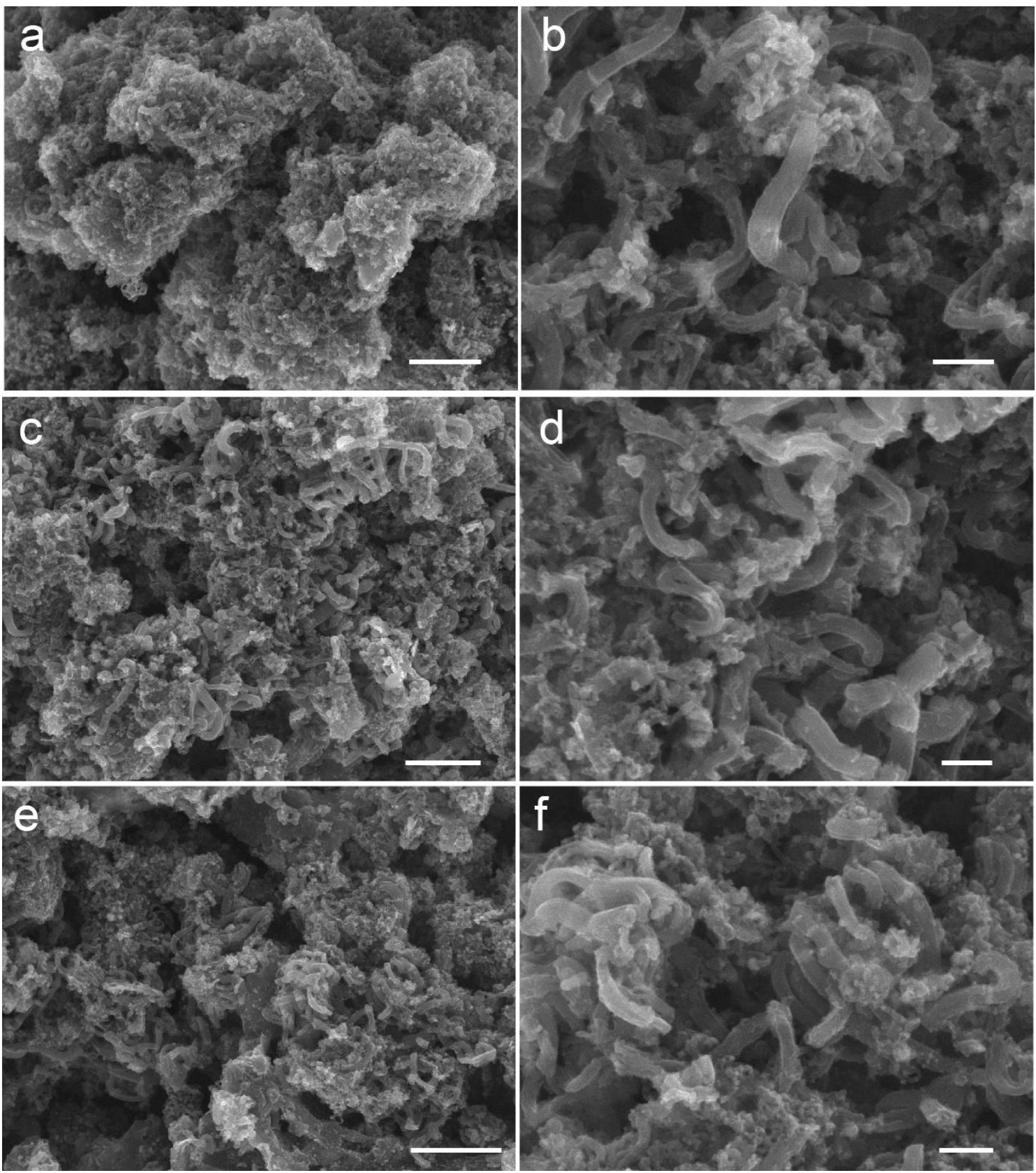

Figure S97. SEM images of spent iron carbide catalysts after FTS reaction. MIL-101-NH 2 obtained by laser metallurgy at different laser power of (a, b) $3.5 \mathrm{~W}$, (c, d) $5 \mathrm{~W}$ and (e, f) $7 \mathrm{~W}$. Scale bar is $1 \mu \mathrm{m}$ in (a, c, e) and $200 \mathrm{~nm}$ in (b, d, f). 

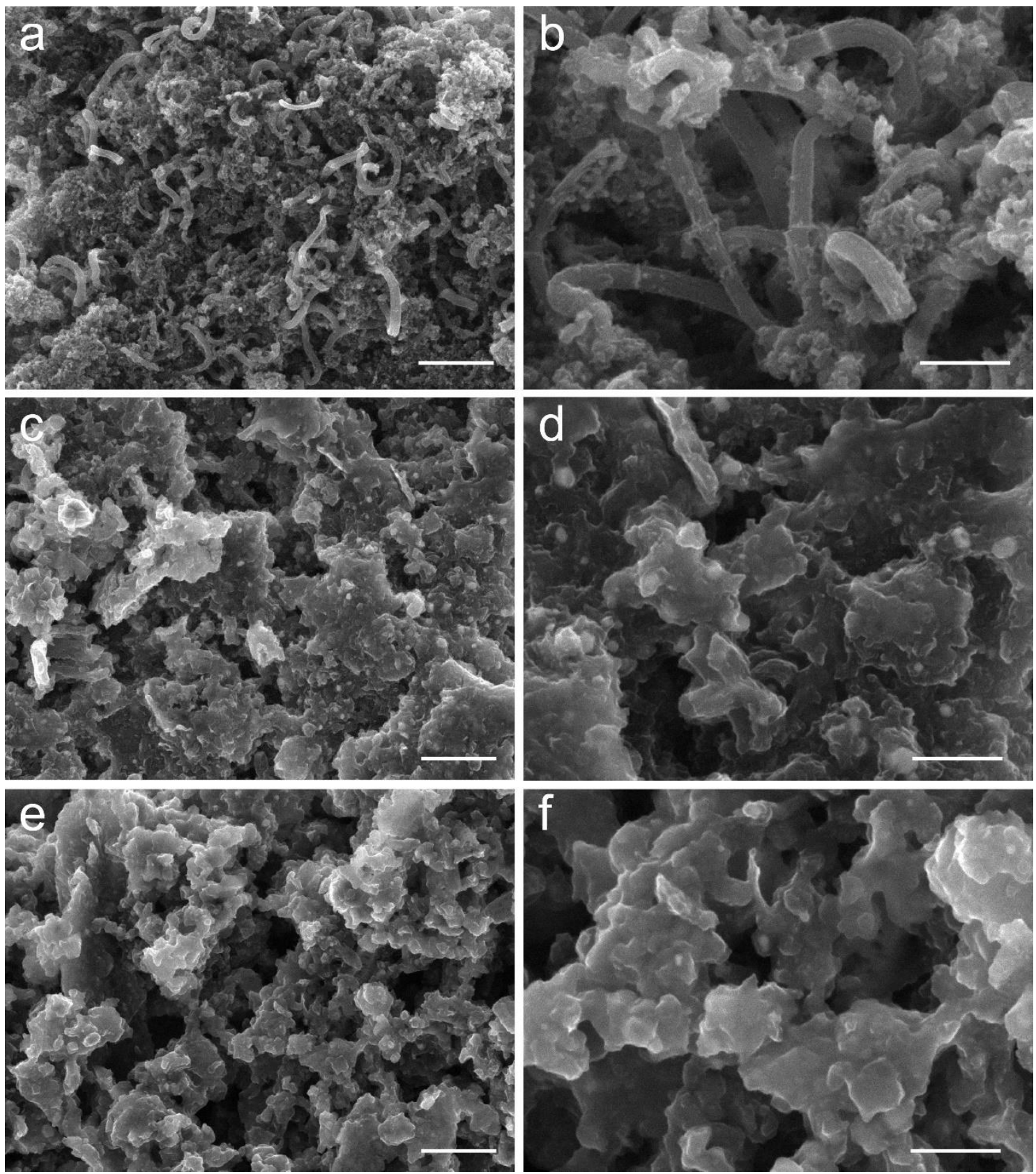

Figure S98. SEM images of $\mathrm{K}$ doped $\mathrm{FeC}_{x}$ catalyst from $\mathrm{MIL}-101-\mathrm{NH}_{2}$ by laser metallurgy at $5 \mathrm{~W}$ after reaction for $100 \mathrm{~h}$ with $\mathrm{K}$ content of (a, b) $0.6 \mathrm{wt} \% \mathrm{~K}$, (c, d) $0.8 \mathrm{wt} \% \mathrm{~K},(\mathrm{e}, \mathrm{f})$ $1.0 \mathrm{wt} \% \mathrm{~K}$. Carbon nanotubes were observed in $0.6 \mathrm{wt} \% \mathrm{~K}$ doped catalyst after FTS. Scale bar is $1 \mu \mathrm{m}$ in (a, c, e) and $200 \mathrm{~nm}$ in $(\mathrm{b}, \mathrm{d}, \mathrm{f})$. 

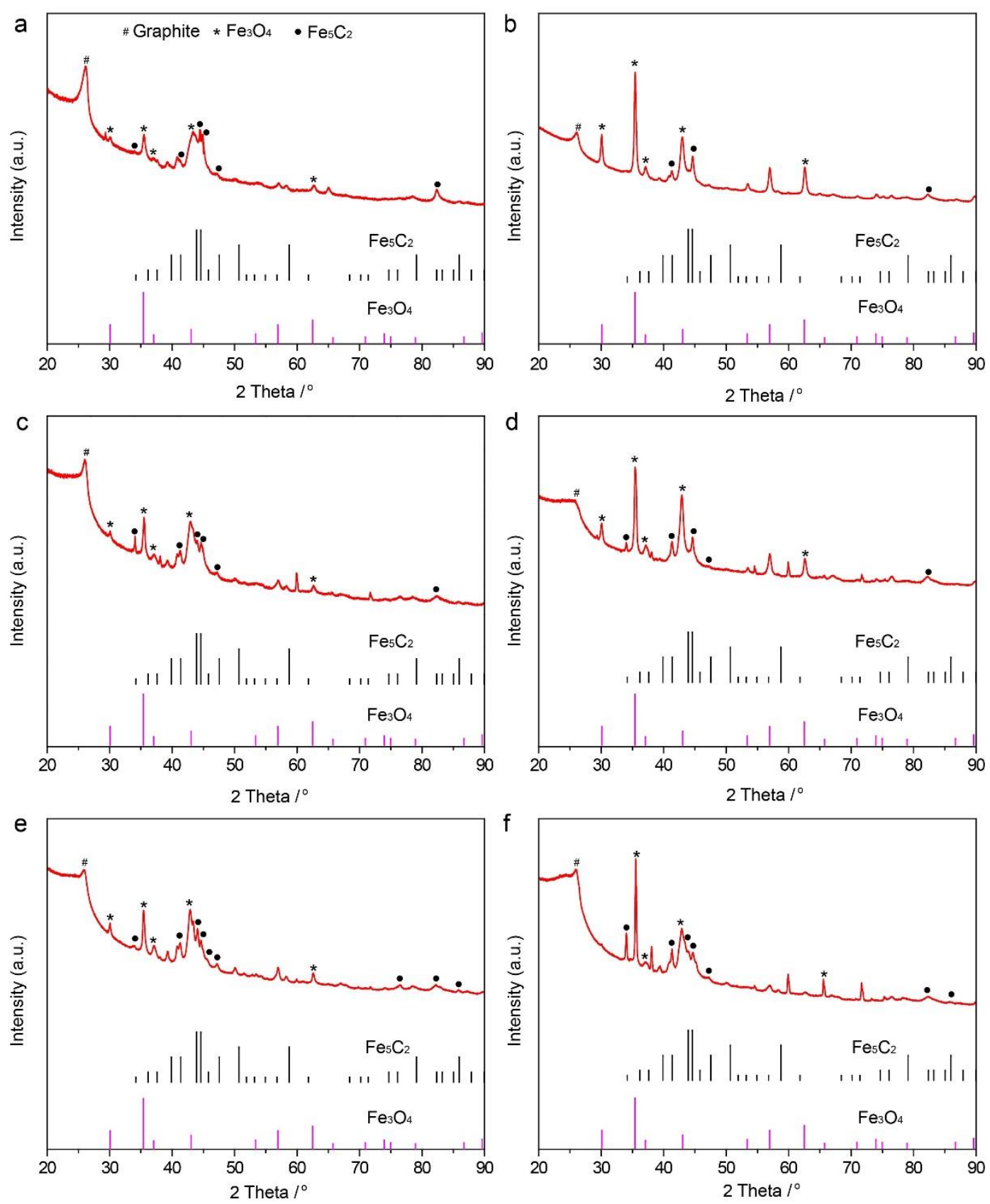

Figure S99. PXRD patterns of iron carbides catalysts after FTS test for $40 \mathrm{~h}$. (a) MIL-101 by laser metallurgy at $7 \mathrm{~W}$, (b) MIL-101- $\left(\mathrm{NH}_{2}\right)_{0.5}$ by laser metallurgy at $5 \mathrm{~W}$, (c) MIL-101$\left(\mathrm{NH}_{2}\right)_{0.5}$ by laser metallurgy at $7 \mathrm{~W}$, (d) MIL-101- $\mathrm{NH}_{2}$ by laser metallurgy at $3.5 \mathrm{~W}$, (e) MIL-101- $\mathrm{NH}_{2}$ by laser metallurgy at $5 \mathrm{~W}$, (f) MIL-101- $\mathrm{NH}_{2}$ by laser metallurgy $7 \mathrm{~W}$. The PXRD patterns show the catalyst are mixture phase of $\mathrm{Fe}_{5} \mathrm{C}_{2}$ and $\mathrm{Fe}_{3} \mathrm{O}_{4}$ after FTS catalysis. The corresponding JCPDS card number of $\mathrm{Fe}_{5} \mathrm{C}_{2}$ is 20-0508, and JCPDS card number of $\mathrm{Fe}_{3} \mathrm{O}_{4}$ is $19-0629$. 


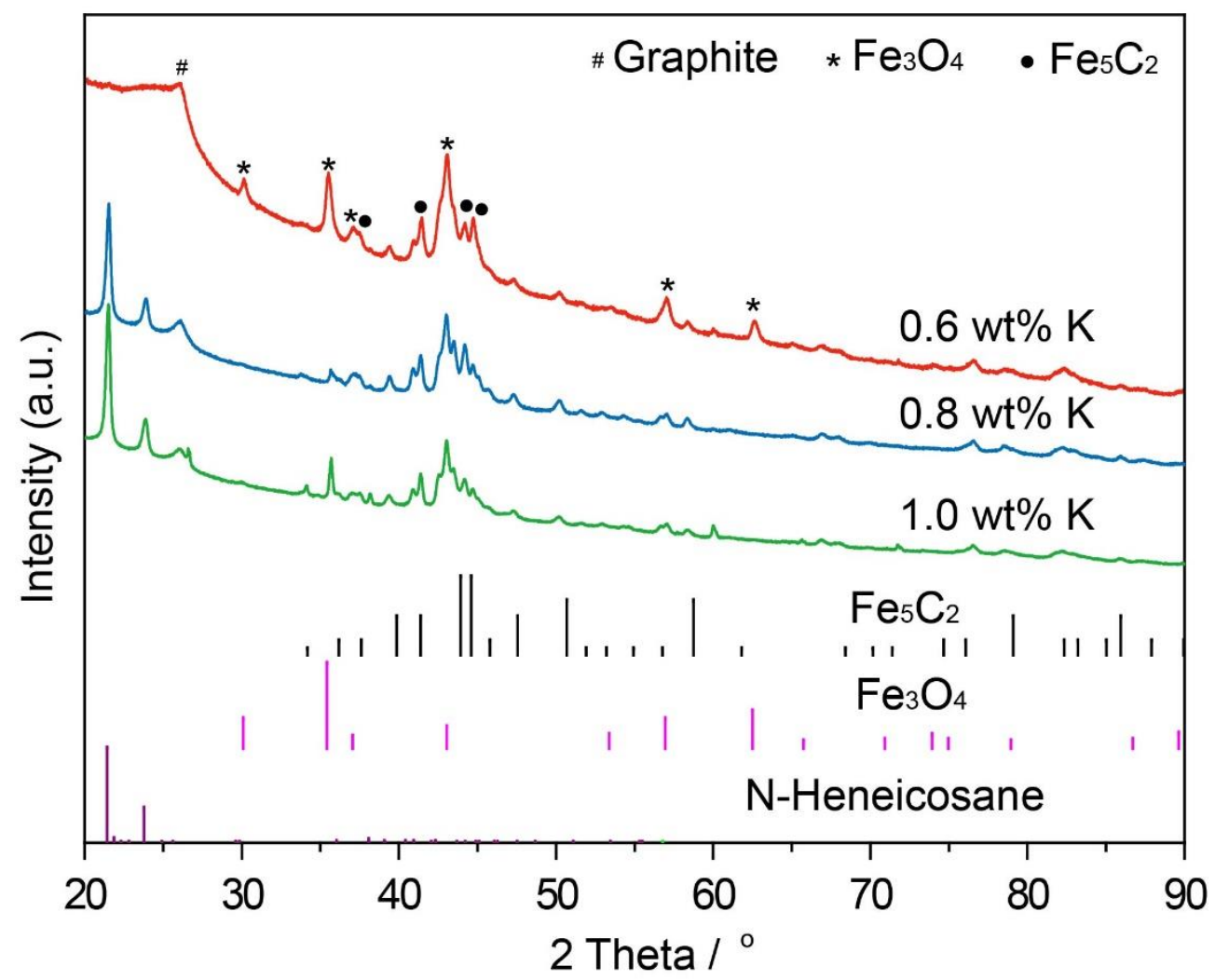

Figure S100. The PXRD patterns of $\mathrm{FeC}_{x}$ catalyst from MIL-101- $\mathrm{NH}_{2}$ by laser metallurgy at $5 \mathrm{~W}$ and doped with different amount of $\mathrm{K}$ after catalytic reaction for $100 \mathrm{~h}$. 


\section{Section S5. Performance comparison with other FTS catalysts}

The uniform iron carbide nanoparticles obtained by laser metallurgy using MOF as precursor show high catalytic performance towards FTS (Table S4). We listed the catalytic performance of these catalysts and compared with the performance delivered by other ironbased catalysts. In practical application, the cost-optimal feeding molar ratio between $\mathrm{H}_{2}$ and $\mathrm{CO}$ is $1: 1$, because these gases are generated by reaction of $\mathrm{H}_{2} \mathrm{O}$ and $\mathrm{C}$ to give a molar ratio of 1:1 between $\mathrm{H}_{2}$ and $\mathrm{CO}$. When this feeding ratio is 2, additional $\mathrm{H}_{2}$ is needed thus raises the cost. In this study, the reaction condition, $340^{\circ} \mathrm{C}, 2 \mathrm{MPa}, \mathrm{H}_{2} / \mathrm{CO}=1: 1$, is a traditional reaction condition applied in practical FTS application. The $\mathrm{FeC}_{\mathrm{x}}$ catalysts obtained by laser metallurgy of MOFs delivers high CO conversion of $94 \%$ with FTY of $292 \mu \mathrm{mol} \mathrm{gFe}^{-1} \mathrm{~s}^{-1}$ at GHSV of $13300 \mathrm{~h}^{-1}$. When GHSV was increased to $30000 \mathrm{~h}^{-1}$, the catalysts showed high CO conversion of $80.29 \%$ and FTY of $550.6 \mu \mathrm{mol} \mathrm{gFe}^{-1} \mathrm{~s}^{-1}$, standing as one of the best FTS catalysts. In addition, the overall activity for $\mathrm{C}_{5+}$ hydrocarbon products, representing the capability of each $\mathrm{Fe}$ atoms to convert $\mathrm{CO}$ to $\mathrm{C}_{5+}$ products in specific time, is as high as $74.17 \mu \mathrm{mol} \mathrm{gFe}^{-1} \mathrm{~s}^{-1}$, outperforming other iron-based catalysts. The laser induced iron carbide catalysts showed identical catalytic performance without suffering a pretreatment or activation time as commonly observed in other catalysts, another unique feature of catalysts fabricated by laser metallurgy method. 
Table S4. The catalytic performance of iron carbide catalysts obtained by laser metallurgy compared with other iron carbide catalysts.

\begin{tabular}{|c|c|c|c|c|c|c|c|c|c|}
\hline Catalyst & Reaction condition & $\begin{array}{l}\mathrm{CO} \\
\text { conv. } \\
(\%)\end{array}$ & $\begin{array}{l}\text { Selectivity } \\
\text { (hydrocar } \\
\text { bon, \%) }\end{array}$ & $\begin{array}{l}\mathrm{O} / \mathrm{P} \\
\left(\mathrm{C}_{2}-\mathrm{C}_{4}\right)\end{array}$ & $\begin{array}{l}\text { Overall } \\
\text { selectivity to } \\
\mathrm{C}_{5+}(\%)\end{array}$ & $\begin{array}{l}\text { FTY } \\
\left(\mu \mathrm{mol} \mathrm{g}_{\mathrm{Fe}^{-}}\right. \\
\left.{ }^{1} \mathrm{~S}^{-1}\right)\end{array}$ & $\begin{array}{l}\text { Overall } \\
\text { FTY for } \\
\mathrm{C}_{5+} \quad(\mu \mathrm{mol} \\
\mathrm{g}_{\left.\mathrm{Fe}^{-1} \mathrm{~S}^{-1}\right)}\end{array}$ & $\begin{array}{l}\text { Pretreatment } \\
\text { time }(\mathrm{h}) \\
\text { /Activation } \\
\text { time }(\mathrm{h})\end{array}$ & Ref. \\
\hline $\mathrm{FeSi}$ & $260^{\circ} \mathrm{C}, 1.5 \mathrm{Mpa}, \mathrm{H}_{2} / \mathrm{CO}=2$ & 21.01 & 96.5 & 0.44 & 9.86 & n.a & n.a & 20/n.a & $\mathrm{S} 11$ \\
\hline Fe-FTS/MAS & $260^{\circ} \mathrm{C}, 2 \mathrm{Mpa}, \mathrm{H}_{2} / \mathrm{CO}=2$ & 33.2 & 68.9 & n.a & 9.95 & n.a & n.a & $16 / 4$ & $\mathrm{~S} 12$ \\
\hline Fe-in-CNT & $270^{\circ} \mathrm{C}, 5.1 \mathrm{Mpa}, \mathrm{H}_{2} / \mathrm{CO}=2$ & 40 & 82 & n.a & 13 & n.a & n.a & $5 / 10$ & 50 \\
\hline $\mathrm{Fe} / \mathrm{PGO}-600$ & $270^{\circ} \mathrm{C}, 3 \mathrm{Mpa}, \mathrm{H}_{2} / \mathrm{CO}=2$ & 35 & 89.2 & 1.57 & 14.05 & n.a & n.a & $6 / 2$ & $\mathrm{~S} 13$ \\
\hline Fe-Mn-07 & $250^{\circ} \mathrm{C}, 1.5 \mathrm{Mpa}, \mathrm{H}_{2} / \mathrm{CO}=2$ & 45.1 & 80.8 & 3.1 & 16.1 & n.a & n.a & $24 / 0$ & S14 \\
\hline $\mathrm{Fe}_{\mathrm{x}} \mathrm{O}_{\mathrm{y}}$ & $270^{\circ} \mathrm{C}, 2 \mathrm{Mpa}, \mathrm{H}_{2} / \mathrm{CO}=2$ & 79 & 77 & 2.25 & 36.5 & 28 & 10.22 & 16/n.a & $\mathrm{S} 15$ \\
\hline $\mathrm{Fe}-\mathrm{C}-8$ & $270^{\circ} \mathrm{C}, 2 \mathrm{Mpa}, \mathrm{H}_{2} / \mathrm{CO}=2$ & 74.7 & 87 & 1.7 & 44.2 & 33 & 14.59 & 16/n.a & S16 \\
\hline $\mathrm{Fe}_{5} \mathrm{C}_{2}$ & $270^{\circ} \mathrm{C}, 3 \mathrm{Mpa}, \mathrm{H}_{2} / \mathrm{CO}=2$ & 30 & n.a & 2.49 & n.a & n.a & n.a & $0 / 0$ & 51 \\
\hline $\mathrm{Fe} / \mathrm{CNT}-\mathrm{h}$ & $275^{\circ} \mathrm{C}, 0.8 \mathrm{Mpa}, \mathrm{H}_{2} / \mathrm{CO}=2$ & 44 & n.a & 0.024 & n.a & 35.8 & n.a & $20 / 10$ & $\mathrm{~S} 17$ \\
\hline $\mathrm{Fe} / \mathrm{AC}$ & $300^{\circ} \mathrm{C}, 0.1 \mathrm{Mpa}, \mathrm{H}_{2} / \mathrm{CO}=1$ & 4.8 & 90.1 & 4.5 & 1.92 & 9.9 & 0.19 & $12 / 10$ & $\mathrm{~S} 18$ \\
\hline $\mathrm{Fe}$ & $250^{\circ} \mathrm{C}, 1.48 \mathrm{Mpa}, \mathrm{H}_{2} / \mathrm{CO}=1$ & 21 & 71 & n.a & 5.5 & 7 & 0.38 & 16/n.a & S19 \\
\hline $\mathrm{Fe} / \mathrm{SiO}_{2}$ & $350^{\circ} \mathrm{C}, 0.1 \mathrm{Mpa}, \mathrm{H}_{2} / \mathrm{CO}=1$ & 32 & 57 & 1 & 7.3 & 30 & 2.19 & $10 / 0$ & $\mathrm{~S} 20$ \\
\hline $\mathrm{Fe}_{3} \mathrm{O}_{4}$ & $320^{\circ} \mathrm{C}, 1 \mathrm{Mpa}, \mathrm{H}_{2} / \mathrm{CO}=1$ & 47 & 57.3 & 2.5 & 8.4 & n.a & n.a & $10 / 5$ & $\mathrm{~S} 21$ \\
\hline 38-Fe@C & $340^{\circ} \mathrm{C}, 2 \mathrm{Mpa}, \mathrm{H}_{2} / \mathrm{CO}=1$ & 77 & 53.2 & 1.8 & $\sim 8.6$ & 380 & 32.68 & $0 / 10$ & 28 \\
\hline $\mathrm{Fe} / \mathrm{CNTs}$ & $270^{\circ} \mathrm{C}, 2 \mathrm{Mpa}, \mathrm{H}_{2} / \mathrm{CO}=1$ & 23.4 & 83.9 & 0.09 & 11.6 & n.a & n.a & $8 / 5$ & $\mathrm{~S} 22$ \\
\hline $\mathrm{Fe} / \mathrm{G}$ & $260^{\circ} \mathrm{C}, 2 \mathrm{Mpa}, \mathrm{H}_{2} / \mathrm{CO}=1$ & 44.9 & 54.7 & n.a & 13.6 & n.a & n.a & 4/n.a & $\mathrm{S} 23$ \\
\hline $\mathrm{Fe} / \mathrm{NCNTs}$ & $270^{\circ} \mathrm{C}, 2 \mathrm{Mpa}, \mathrm{H}_{2} / \mathrm{CO}=1$ & 27 & 81.3 & 0.15 & 13.7 & n.a & n.a & $8 / 4$ & S24 \\
\hline FNP & $280^{\circ} \mathrm{C}, 3 \mathrm{Mpa}, \mathrm{H}_{2} / \mathrm{CO}=1$ & 42.28 & 67.94 & 3.53 & 15.50 & 5 & 0.78 & $12 / 5$ & $\mathrm{~S} 25$ \\
\hline Fe-MIL-88B-NH ${ }_{2} / \mathrm{C}^{[\mathrm{a}]}$ & $300^{\circ} \mathrm{C}, 2 \mathrm{Mpa}, \mathrm{H}_{2} / \mathrm{CO}=1$ & 81.8 & 57.1 & 1.67 & 23.68 & 320 & 63.94 & $4 / 60$ & 29 \\
\hline $\mathrm{FeSi}$ & $280^{\circ} \mathrm{C}, 2 \mathrm{Mpa}, \mathrm{H}_{2} / \mathrm{CO}=1$ & 98 & n.a & n.a & n.a & 27.7 & n.a & $12 /$ n.a & S26 \\
\hline $\mathrm{FeMnK} / \mathrm{SiO}_{2}$ & $270^{\circ} \mathrm{C}, 1.5 \mathrm{Mpa}, \mathrm{H}_{2} / \mathrm{CO}=0.67$ & 74.6 & n.a & 1.27 & n.a & 19 & n.a & $80 / 5$ & $\mathrm{~S} 27$ \\
\hline $\mathrm{FeC}_{\mathrm{x}}$ nanoparticles $^{[\mathrm{b}]}$ & $340^{\circ} \mathrm{C}, 2 \mathrm{Mpa}, \mathrm{H}_{2} / \mathrm{CO}=1$ & 86 & 58 & 0.82 & 19.5 & 286 & 55.63 & $0 / 0$ & This work \\
\hline $\mathrm{FeC}_{\mathrm{x}}$ nanoparticles ${ }^{[\mathrm{c}]}$ & $340^{\circ} \mathrm{C}, 2 \mathrm{Mpa}, \mathrm{H}_{2} / \mathrm{CO}=1$ & 62.77 & 51.6 & 1.31 & 18.7 & 414.6 & 77.6 & $0 / 0$ & This work \\
\hline $\mathrm{FeC}_{\mathrm{x}}$ nanoparticles- $\mathrm{K}^{[\mathrm{b}]}$ & $340^{\circ} \mathrm{C}, 2 \mathrm{Mpa}, \mathrm{H}_{2} / \mathrm{CO}=1$ & 93.69 & 51.7 & 3.81 & 25.4 & 292.3 & 74.1 & $0 / 0$ & This work \\
\hline $\mathrm{FeC}_{\mathrm{x}}$ nanoparticles- $\mathrm{K}^{[\mathrm{c}]}$ & $340^{\circ} \mathrm{C}, 2 \mathrm{Mpa}, \mathrm{H}_{2} / \mathrm{CO}=1$ & 80.29 & 52.5 & 3.32 & 20.78 & 550.6 & 114.4 & $0 / 0$ & This work \\
\hline
\end{tabular}

n.a. (not applicable).

${ }^{[a]}$ Data acquired at $30 \mathrm{~h}$ TOS with with GHSV of $36000 \mathrm{~h}^{-1}$.

${ }^{[b]}$ Data acquired at $30 \mathrm{~h}$ TOS with GHSV of $13300 \mathrm{~h}^{-1}$.

${ }^{[c]}$ Data acquired at $30 \mathrm{~h}$ TOS with GHSV of $30000 \mathrm{~h}^{-1}$. 


\section{References}

[S1] Yao, Y.; Huang, Z.; Xie, P.; Lacey, S. D.; Jacob, R. J.; Xie, H.; Chen, F.; Nie, A.; Pu, T.; Rehwoldt, M. et al. Carbothermal Shock Synthesis of High-Entropy-Alloy Nanoparticles. Science 2018, 359, 1489-1494.

[S2] Zhang, H.; Liu, J.; Tian, Z.; Ye, Y.; Cai, Y.; Liang, C.; Terabe, K. A General Strategy toward Transition Metal Carbide/Carbon Core/Shell Nanospheres and Their Application for Supercapacitor Electrode. Carbon 2016, 100, 590-599.

[S3] Barraud, E.; Bégin-Colin, S.; Le Caër G.; Barres, O., Villieras, F. Mechanically Activated Solid-State Synthesis of Hafnium Carbide and Hafnium Nitride Nanoparticles. J. Alloys Compd. 2008, 456, 224-233.

[S4] Coulibaly, M.; Arrachart, G.; Mesbah, A.; Deschanels, X. From Colloidal Precursors to Metal Carbides Nanocomposites $\mathrm{MC}(\mathrm{M}=\mathrm{Ti}, \mathrm{Zr}, \mathrm{Hf}$ and $\mathrm{Si})$ : Synthesis, Characterization and Optical Spectral Selectivity Studies. Solar Energy Mater Solar Cells 2015, 143, 473-479.

[S5] Matovic, B.; Babic, B.; Bucevac, D.; Cebela, M.; Maksimovic, V.; Pantic, J.; Miljkovic, M. Synthesis and Characterization of Hafnium Carbide Fine Powders. Ceram. Inter. 2013, 41, 719-723.

[S6] Liu, J.; Kan, Y.; Zhang, G. Synthesis of Ultra-Fine Hafnium Carbide Powder and Its Pressureless Sintering. J. Am. Ceram. Soc. 2010, 93, 980-986.

[S7] Patra, N.; Nasiri, N. A. Hafnium Carbide Using Pectin. Ceram. Inter. 2016, 42, 19591963.

[S8] Yang, Y.; Xiang, H.-W.; Xu, Y.-Y.; Bai, L.; Li, Y.-W. Effect of Potassium Promoter on Precipitated Iron-Manganese Catalyst for Fischer-Tropsch Synthesis. Appl. Catal. A 2004, 266, 181-194.

[S9] Luo, M.; O’Brien, R. J.; Bao, S.; Davis, B. H. Fischer-Tropsch Synthesis: Induction and Steady-State Activity of High-Alpha Potassium Promoted Iron Catalysts. Appl. Catal. A 2003, 239, 111-120.

[S10] Graf, B.; Schulte, H.; Muhler, M. The Formation of Methane over Iron Catalysts Applied in Fischer-Tropsch Synthesis: A Transient and Steady State Kinetic Study. $J$. Catal. 2010, 276, 66-75.

[S11] Li, J.; Zhang, C.; Cheng, X.; Qing, M.; Xu, J.; Wu, B.; Yong, Y.; Li, Y. W. Microfibrous Entrapped Hybrid Iron-Based Catalysts for Fischer-Tropsch Synthesis. Appl. Catal. A 2013, 464-465, 10-19.

[S12] Cheng. X.; Yang, H.; Tatarchuk, B. J. Microfibrous Entrapped Hybrid Iron-Based Catalysts for Fischer-Tropsch Synthesis. Catal.Today 2016, 273, 62-71.

[S13] Zhao, H.; Zhu, Q.; Gao, Y.; Zhai, P.; Ma, D. Iron Oxide Nanoparticles Supported on Pyrolytic Graphene Oxide as Model Catalysts for Fischer Tropsch Synthesis. Appl. Catal. A 2013, 456, 233-239.

[S14] Li, T.; Wang, H.; Yang Y.; Xiang, H.; Li, Y. Effect of Manganese on the Catalytic Performance of An Iron-Manganese Bimetallic Catalyst for Light Olefin Synthesis. $J$. 
Energy. Chem. 2013, 22, 624-632.

[S15] Yu, G.; Sun, B.; Pei, Y.; Xie, S.; Yan, S.; Qiao, M.; Fan, K.; Zhang, X.; Zong, B. $\mathrm{Fe}_{\mathrm{x}} \mathrm{O}_{\mathrm{y}} @ \mathrm{C}$ Spheres as An Excellent Catalyst for Fischer-Tropsch Synthesis. J. Am. Chem. Soc. 2009, 132, 935-937.

[S16] Sun, Z.; Sun, B.; Qiao, M.; Wei, J.; Yue, Q.; Wang, C.; Wang, C.; Deng, Y.; Kaliaguine, S.; Zhao, D. A General Chelate-Assisted Co-Assembly to Metallic Nanoparticles Incorporated Ordered Mesoporous Carbon Catalysts for FischerTropsch Synthesis. J. Am. Chem. Soc. 2012, 134, 17653-17660.

[S17] Xiong, H.; Motchelaho, M. A.; Moyo, M.; Jewell, L. L.; Coville, N. J. FischerTropsch Synthesis: Iron-Based Catalysts Supported on Nitrogen-Doped Carbon Nanotubes Synthesized by Post-Doping. Appl. Catal. A 2014, 482, 377-386.

[S18] Lu, J.; Yang, L.; Xu, B.; Wu, Q.; Zhang, D.; Yuan, S.; Zhai, Y.; Wang, X.; Fan, Y.; $\mathrm{Hu}, \mathrm{Z}$. Promotion Effects of Nitrogen Doping into Carbon Nanotubes on Supported Iron Fischer-Tropsch Catalysts for Lower Olefins. ACS Catal. 2014, 4, 613-621.

[S19] Bukur, D. B.; Mukesh, D.; Patel, S. A. Promoter Effects on Precipitated Iron Catalysts for Fischer-Tropsch Synthesis. Ind. Eng. Chem. Res. 1990, 29, 194-204.

[S20] Ordomsky, V. V.; Luo, Y.; Gu, B.; Carvalho, A.; Chernavskii, P. A.; Cheng. K.; Khodakov, A. Y. Soldering of Iron Catalysts for Direct Synthesis of Light Olefins from Syngas Under Mild Reaction Conditions. ACS Catal. 2017, 7, 6445-6452.

[S21] Liu, Y.; Chen, J.F.; Bao, J.; Zhang, Y. Manganese-Modified $\mathrm{Fe}_{3} \mathrm{O}_{4}$ Microsphere Catalyst with Effective Active Phase of Forming Light Olefins from Syngas. ACS Catal. 2015, 5, 3905-3909.

[S22] Liu, R.; Xu, Y.; Li, Z.; Ma, X. A Facile and Efficient Modification of CNTs for Improved Fischer-Tropsch Performance on Iron Catalyst: Alkali Modification. ChemCatChem 2016, 8, 1454-1458.

[S23] Li, C.; Sayaka, I.; Chisato, F.; Fujimoto, K. Development of High Performance Graphite-Supported Iron Catalyst for Fischer-Tropsch Synthesis. Appl. Catal. A 2016, 509, 123-129.

[S24] Li, Z.; Liu, R.; Xu, Y.; Ma, X. Enhanced Fischer-Tropsch Synthesis Performance of Iron-Based Catalysts Supported on Nitric Acid Treated N-Doped CNTs. Appl. Surf. Sci. 2015. 347, 643-650.

[S25] Tu, J.; Ding, M.; Zhang, Y.; Li. Y.; Wang. T.; Ma. L.; Wang. C.; Li, X. Synthesis of $\mathrm{Fe}_{3} \mathrm{O}_{4}$-Nanocatalysts with Different Morphologies and Its Promotion on Shifting $\mathrm{C}_{5+}$ Hydrocarbons for Fischer-Tropsch Synthesis. Catal. Commun. 2015, 59, 211-215.

[S26] Zhang, Y.; Wang, T.; Ma, L.; Shi, N.; Zhou, D.; Li, X. Promotional Effects of Mn on $\mathrm{SiO}_{2}$-Encapsulated Iron-Based Spindles for Catalytic Production of Liquid Hydrocarbons. J. Catal. 2017. 350, 41-47.

[S27] Zhang, C. -Z.; Yang, Y.; Teng, B. -T.; Li, T. -Z.; Zheng, H. -Y.; Xiang, H. -W.; Li, Y. -W. Mechanically Activated Solid-State Synthesis of Hafnium Carbide and Hafnium Nitride Nanoparticles. J. Catal. 2006, 237, 405-415. 